\title{
$5=20-1 \mathrm{NW}$
}

A

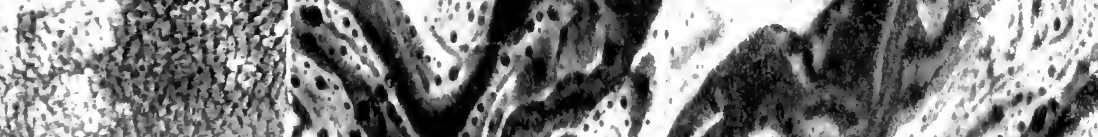
7. 1010.92

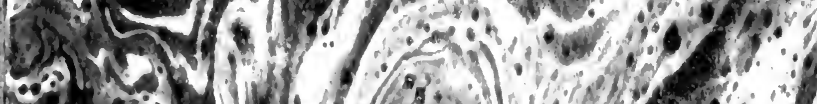
(4) (4)

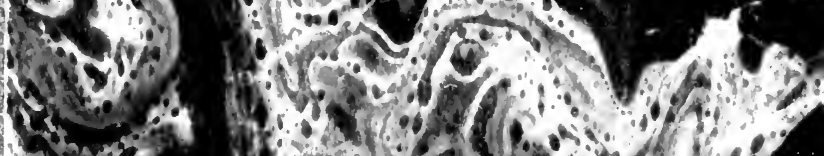

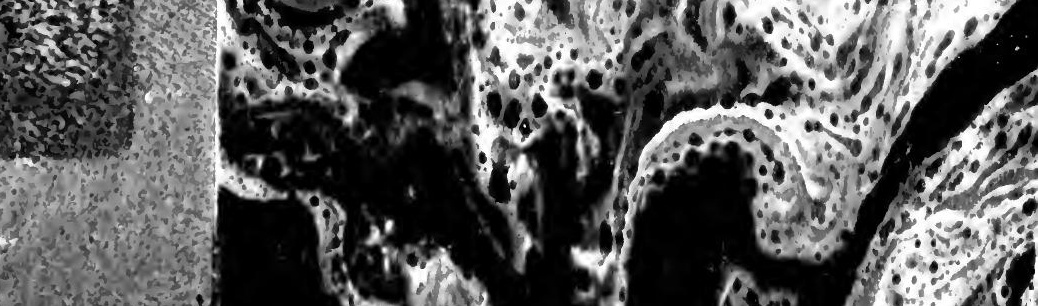
(2)

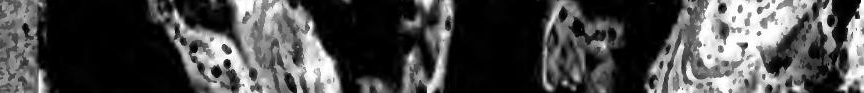

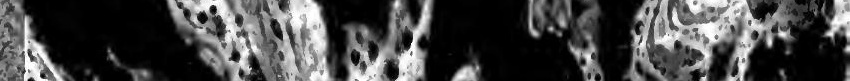

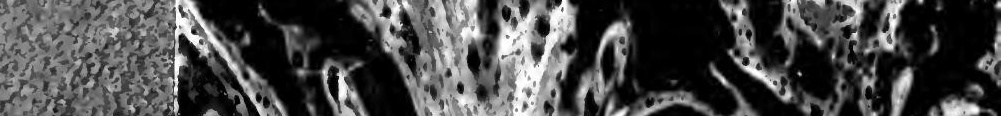

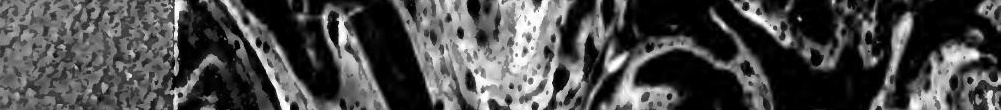

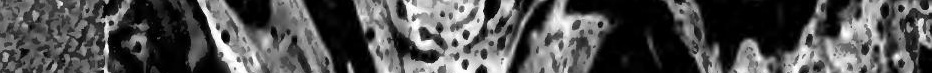

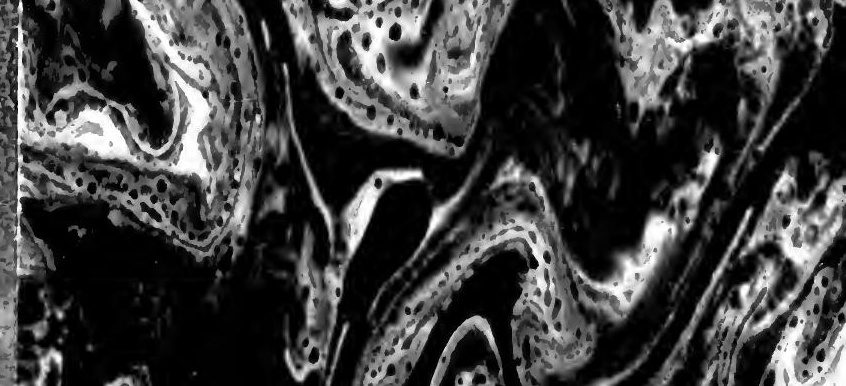


filturity at

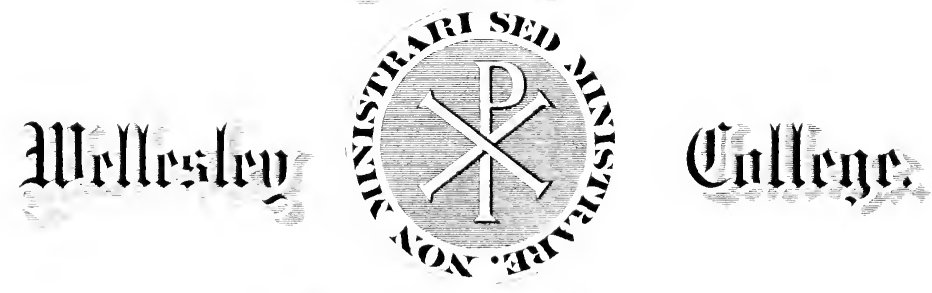

\section{Hurdiased from}

vo 165878

Dean Fund 
Date Due

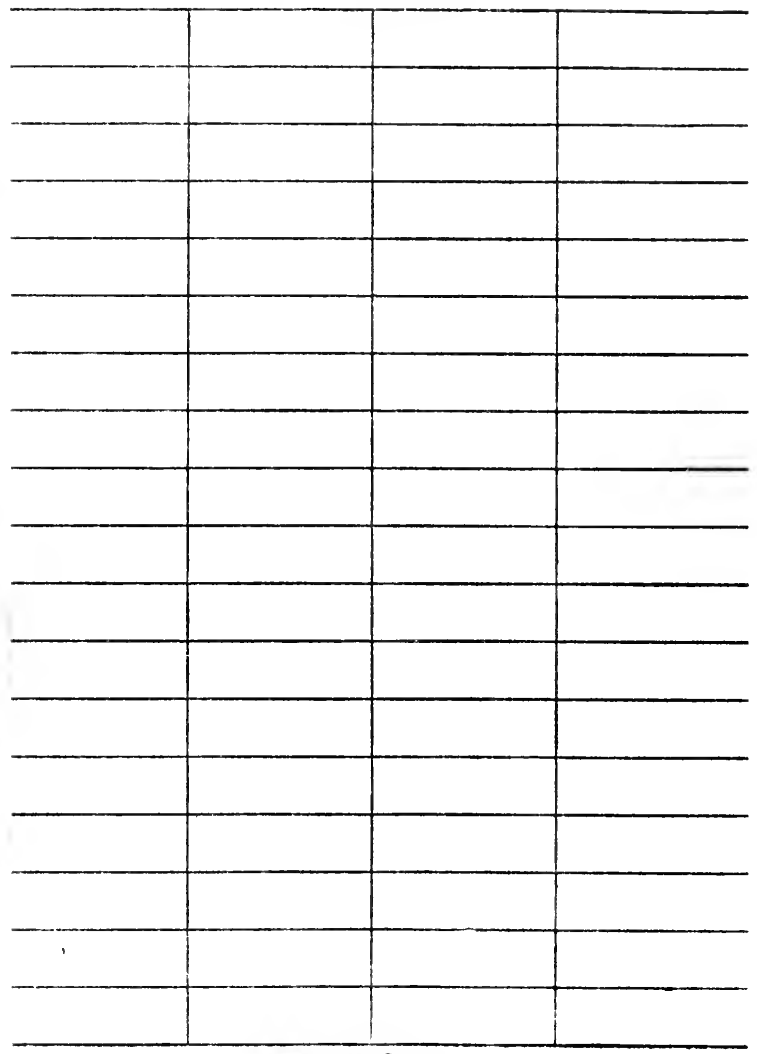

Lobreey Bureasu Cat. no. 1137 





\section{BIBLIOTHÈQUE D'HISTOIRE}

\section{ROMAIN ROLLAND}

\section{VOYAGE MUSICAL}

AU PAYS DU PASSÉ

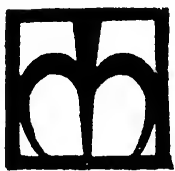

CINQUIEME EDITION 



VOYAGE MUSICAL AU PAYS DU PASSÉ 


\section{CEUVRES DE M. ROMAIN ROLLAND}

\section{LIBRAIRIE HACHETTE}

Musiciens d'autrefois. Un vol., br.

Musiciens d'aujourd'hui. Un vol., br.

Voyage musical au pays du Passé. Un vol,, br.

IIE DES HOMMES ILLUSTRES

I. Vie de Beethoven.

II. Vie de Michel-Ange.

III. Vie de Tolstoï.

Trois vol. br.

\section{LIBRAIRIE ALBIN MICHEL}

JEAN-CHRISTOPHE. Io vol. in-I6 :

1. L'Aubc. - II. Le Matin. - III. L'Adolescent. - IV. La Résolte. - V. La Foire sur la Place. - VI. Antoinette. VII. Dans la Maison. - VIII. Les Amies. - IX. Le Buisson ardent. - X. La Nouvelle Journee.

JEAN-CHRISTOPHE, en 4 vol. in- 8 .

Edition définitive sur papier alfa et hollande.

ÉDITION DE LUXE, en 5 vol. in $-4^{\circ}$ sur vélin, hollande et japon, impression noir et rouge avec des bois de FRANS MASEREEL.

L'AME ENCHANTÉE, 2 vol. in- 16 :

I. Annette et Sylvie. - II. L'Été.

COLAS BREUGNON. I vol. in-I6.

ÉDITION DE LUXE. I vol. in $-4^{\circ}$ sur vélin, hollande et japon, avec des bois en noir et en couleurs de GABRIEL BELOT.

CLERAMBaUlis. I vol. in-16.

PIERRE ET LUCE. I vol. in-16.

théatre de la RÉvolution (Le r 4 Juillet. - Danton. - Les Loups). 1 vol. in-r6.

LeS TRAGÉdies de la FOI (Saint Louis. - Aërt. - Le Triomphe de la Raison). I vol. in-I6.

Le Jen de l'timour et de la Mort. I vol. in-16.

Le Theâtre du Peuple. Essai d'esthétique d'un théâtre nouveau. I vol. in 16.

Le Temps ricindra, 3 actes. I vol. in-16.

Liluli. I vol. in-I6.

Ali-dessus de la Vielèe. I vol. in-16.

Les Precurseurs. I vol. in-16.

\section{AUTRES ÉDITEURS}

stock : Mabatmâ Ganabi. I vol. - AlCAN : Hzndel. I vol. in-18. $\mathrm{DE}$ BOCCARD : Histoire de l'Opéra en Europe avant Lully et Scarlatit. I vol. 


\section{BIBLIOTHÈQUE D'HISTOIRE}

\section{ROMAIN ROLLAND}

\section{VOYAGE MUSICAL}

\section{AU PAYS DU PASSÉ}

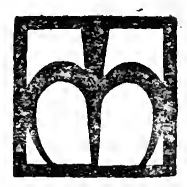

CINQUIEME EDITION

LIBRA IRIE HA CHETTE 79, BOUI,EVARD SAINT-GERMAIN, PARIS 


$$
165878
$$

Tous droits de traduetion, de reproduction et d'adaptation réservés pour twu, pays.

Copyright by Librairie Hachette, 1920. 


\section{AVANT-PROPOS}

Le recueil que voici ${ }^{1}$ fait suite à ma première sériz de Musiciens d'autrefois. La plupart des articles sont consacrés à un âge de transition, où s'élaborent la sensibilité, l'esthétique, les formes de notre musique moderne. Par un phénomène assez commun dans l'histoire, ce ne sont pas les plus grandes personnalités artistiques qui se font, à l'ordinaire, les pionniers de l'avenir. Les J.-S. Bach dominent de trop haut leur temps, pour exercer sur lui d'influence directe; ils sont en dehors du siècle; leur rayonnement ne se fait sentir qu'à distance. Ce sont les Telemann, les Hasse, les symphonistes de Mannheim, qui lancent les courants nouveaux. J'ai tâché de faire revivre ici Telemann. Je dirai plus tard l'admiration et l'amour que j'ai pour Hasse.

1. La plupart de ces études ont paru dans la Revue de Paris (1 ${ }^{\circ r}$ juil. let 1900,15 aoút 1905,15 février 1906, 15 avril 1910). L'article sur le Journal de P'epys a fait partie d'un volume de Mélanges Hugo Riemann, en 1909. Le. Telemann - est inédit. 
On a été extrêmement injuste envers ces maîtres. De leur vivant, leur gloire fut peut-être excessive. Mais l'oubli où ils sont tombés, depuis, l'est sûrement beaucoup plus. Les éveilleurs d'idées, comme Telemann et les "Mannheimer ", ont rarement le temps d'être profonds. Ils sèment à tous les vents. Sachons-leur gré des fruits que nous cueillons aujourd'hui. Ne leur demandons pas la plénitude parfaite de l'automne, quand ils étaient le printemps capricieux et fécond. A chacun son lot! Celui des musiciens novateurs de la première moitié du Xviri siècle a été assez beau, puisqu'ils ont frayé le chemin aux Mozart et aux Beethoven.

R. R.

Juin 1918. 


\section{VOYAGE MUSIGAL}

\section{AU PAYS DU PASSÉ}

\section{I \\ LE ROMAN COMIQUE \\ D'UN MUSICIEN AU XVII SIËCLE}

Il y a deux siècles, les Allemands remplissaient déjà Naples, Rome et Venise, de leurs princes, do leurs marchands, de leurs pèlerins, de leurs artistes et de leurs touristes. Mais l'Italie n'était point alors passive, comme elle le devint, depuis. Elle exportait au centuple ce qu'on importait chez elle; et elle ne manquait pas de rendre à l'Allemagne les visites qu'elle en avait reçues. Elle profita de l'épuisement causé par la guerre de Trente Ans, pour submerger de ses œuvres et de ses artistes la Bavière, la Hesse, la Saxe, la Thuringe et l'Autriche. La musique surtout et le théâtre lui étaient livrés. Cavalli, Bernabei, Steffani, Torri, régnaient à Munich; Bontempi, Pallavicino, à Dresde; Cesti, Draghi, Ziani, Bononcini, Caldara, et G. Porta, à Vienne; Vivaldi était maitre de chapelle en HesseDarmstadt, et Torelli, en Brandebour Inench. Des 
nuées de librettistes, de décorateurs, de cantatrices et de castrats, de violonistes et de clavecinistes, de luthistes, de flùtistes, de " chitarristes " et d'instrumentistes de toute espèce, suivaient ces chefs de file. Leur grande machine de guerre était l'Opéra, suprême création de la Renaissance à son déclin; et leur centre de propagande était Dresde, dont le théâtre italien. fondé en 1662, eut une gloire européenne pendant un siècle entier, jusqu'au départ de Hasse. Leipzig, la vieille ville saxonne, n'échappa point au fléau. En 1693, l'Opéra vint s'implanter chez elle, en plein cœur de l'art allemand : ses fondateurs ne cachaient pas qu'ils voulaient en faire une succursale de Dresde; et, en quelques années ils eurent cause gagnée. La musique d'opéra ne se contenta même plus du théâtre; elle pénétra dans l'église, dernier refuge de la pensée allemande. Son pathétique brillant eut vite raison du sérieux des vieux maîtres : la foule se pressait à ces auditions théâtrales; les chanteurs et les élèves de la Thomaskirche, désertant leur poste, passèrent dans l'autre camp; le vide se fit autour des derniers défenseurs de la tradition nationale.

Il y avait alors à la Thomaskirche un Cantor (maître de chapelle), nommé Jean Kuhnau. Cet homme, un des types les plus attrayants de génie largement développé, comme en offraient ces temps héroöques de l'art, était, dit Mattheson, « très instruit en théologie, droit, éloquence, poésie, mathématiques, langues étrangères, et musinue ". Il avait soutenu des thèses de droit, dont l'une en grec; il était avocat; il cultivait la philosophio 
grecque et hébraïque, traduisait des ouvrages français et italiens, et écrivait lui-même des œuvres de science et d'imagination. Jacob Adlung dit « qu il ne sait pas si Kuhnau fait plus d'honneur à la musique ou à la science ». Comme musicien, il est, sans aucun doute, une des colonnes de l'ancien art allemand. Scheibe le regardait, avec Keiser, Telemann et Hændel, pour un des quatre plus grands compositeurs allemands du siècle. De fait, il possédait une profondeur de sentiment, et en même temps une beauté de forme, une grâce faite de force et de clarté, qui encore aujourd'hui rendrait son nom populaire, - si le monde était. capable de s'intéresser sincèrement à la musique, quand la mode ne l'y pousse point. Kuhnau fut un des créateurs de la sonate moderne; il écrivit des Suites pour clavier, qui sont des modèles d'élégance et de verve, parfois teintée de rêverie. Il composa des poèmes descriptifs à programmes, sous le nom de Sonates bibliques, des Cantates spirituelles et profanes, et une Passion, qui font de lui, pour tout dire, non seulement le prédécesseur direct à la Thomaskirche de Leipzig, mais, en beaucoup d'endroits, le modèle indéniable de Jean-Sébastien Bach.

Voici en quels termes il présente au public un de ses principaux ouvrages de musique. On aura quelque idée de sa bonne grâce tranquille et de son abondanto nature. Il s'excuse de la fantaisie avec laquelle sont écrites ses charmantes sonates, Clavier-Frïchte aus 7 Sonaten (Fruits du clavier); il dit qu’ “il a usé de la même liberté que la nature, lorsqu'en suspendant les fruits aux arbres, elle en donne à une branche plus ou moins qu'à une autre... Je n'ai pas été longtemps à les produiro : il en a été comme en certains pays, où, grâce 
à la chaleur subite, tout pousse avec une telle rapidité qu'on peut faire la récolte un mois après avoir semé. En écrivant ces sept sonates, j'éprouvais une ardeur telle que, sans négliger mes autres occupations, j'en ai fait une chaque jour, et qu'ainsi cet ouvrage, que j'ai commencé un lundi, était terminé le lundi de la semaine suivante. Je ne mentionne ceite circonstance qu'afin que l'on ne s'attende pas à trouver ici des qualités rares et exceptionnelles. Il est vrai qu'on ne désire pas toujours des choses extraordinaires; nous mangeons souvent les plus simples fruits de nos champs avec autant de plaisir que les fruits étrangers les plus exquis et les plus rares, bien que ceux-ci coûtent fort cher et viennent de fort loin. Je sais qu'il y a des gourmets parmi les amateurs de musique qui n'admettent que ce qui vient de France ou d'Italie, surtout quand le hasard leur a permis de respirer l'air de ces pays. Mes fruits sont à la disposition de tous; ceux qui ne les trouveront pas de leur goût n'ont qu'à chercher ailleurs. Quant aux critiques, elles ne leur seront pas épargnées; mais le poison des ignorants ne peut leur faire plus de mal qu'une rosée froide aux fruits mûrs. 》)

La même année (1700), Kuhnau faisait paraître ses belles et expressives Billische Historien, et un roman sur lequel nous nous arrêterons plus longuement. Il avait trente-trois ans. Il se trouvait seul au milieu d'Italiens et d'italianisants. Ses amis, ses élèves l'avaient abandonné. Il voyait s'écrouler la vieille musique allemande, et il faisait des efforts inutiles pour en arrêter la chute. En vain il s'adressait au Conseil de la ville pour protéger l'éducation publique compromise non seulement par la fascination de l'art étranger, mais par 
l'attrait des plaisirs et des gains faciles, qui faisaient cortège à l'Opéra et débauchaient la jeunesse des écoles de Leipzig. Le Conseil donnait tort à Kuhnau et raison au succès. A la mort de Kuhnau, en 1722.2, I'Opéra italien régnait sur l'Allemagne. Il semblerait qu'une telle injustice du sort aurait dù remplir d'amertume le cœur du vieux maître. Mais les artistes de ce temps ne cultivaient point leur mélancolie; et Kuhnau semble n'avoir jamais perdu sa bonhomie goguenarde à l'égard des hommes et des choses ennemies. Il connaissait le monde, et n'était point surpris que les charlatans eussent le pas sur les honnêtes gens. "Il en est des artistes nouveaux venus dans une ville, dit-il, comme des harengs frais; chacun veut en manger, et y dépense bien plus d'argent qu'à des nourritures plus recherchées et meilleures, qu'il est habitué à roir sur sa table. " Mais comme il était homme de foi, non seulement en religion, mais en art, il n'était pas inquiet sur le triomphe final de sa cause; et, en attendant, il se vengeait allégrement de la sottise et de l'ignorance, en les mettant en scène dans un roman satirique, intitulé : Der Musicalische Quack Salber (le Charlatan musical) ${ }^{1}$.

Ce curieux livre, édité en 1700 à Dresde et très connu au xvin ${ }^{e}$ siècle, ne nous était plus conservé que par deux exemplaires, l'un à la Königliche Bibliothek de Berlin, l'autre à la Stadtbibliothek de Leipzig, quand M. Kurt Benndorf eut l'idée de le rééditer, dans la collection des Deutsche Literaturdenkmaeler de A. Sauer ${ }^{2}$.

1. Der Musicalische Quack-Salber, nicht alleine denen verstændigen Liebhabern der Music, sondern auch allen andern welche in dieser Kunst keine sonderbahre Wissenschaft haben, in einen kurtzweiligen und angenehmen Historie zur Lust und Ergetzligkeit beschriehen, von Johann Kuhnau. - Dresden. Anno 1700.

2. Berlin, Behr, 1900. 
Écrit de façon hâtive dans une langue alerte, claire, sous l'influence française, aux phrases courtes et vives, entremêlées de mots italiens et français, ce petit ouvrage se lit encore avec plaisir. Il est plein de bonne humeur et pétille d'intelligence. A peine quelques touches de pédantisme, la maladie de l'époque, viennent un peu gâter parfois cette aimable figure. Il y a beaucoup à apprendre dans ces tableaux variés de la vie saxonne au xvir ${ }^{\mathrm{e}}$ siècle. Ils nous éclairent sur une des plus intéressantes époques allemandes, la rapide convalescence du pays après la guerre de Trente Ans, et la formation du grand siècle classique de la musique.

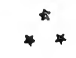

Le héros du roman est un aventurier souabe, des environs d'Uim, qui, profitant de l'engouement de l'Allemagne pour l'Italie, se fait passer pour Italien dans son propre pays. Il n'était guère resté qu'un an en Italie, et en posture fort humble, comme copiste ou famulus de quelques musiciens célèbres: mais il ne lui en avait pas fallu davantage pour se persuader que le génie de ses maîtres était descendu en lui. Il se garda bien toutefois d'en faire l'épreuve en Italie, sachant qu'il lui serait malaisé de faire accepter sa prétention à Rome ou à Venise; mais il passa les Alpes, comptant sur la naïveté de ses compatriotes et sur leur servilo respect pour tout ce qui était étranger.

Il va droit à Dresde, le centre de l'italianisme, la ville de l'Opéra. Il commence par travestir son nom; d'un sobriquet injurieux adressé à son père (Theuer 
$\left.A / f e^{1}\right)$, il a fait un nom d'excellente famille napolitaine: Caralfa. Un des travers du temps était d'habiller les noms germaniques à la mode française ou latine. Kuhnau fustige ce ridicule, avec le vigoureux bon sens de Hulière. a Passe encore, dit-il, pour ceux sur le dos desquels ces appellations étrangères ont été plantées par des parents ridicules; ils sont excusables de s'y tenir. Mais pour ceux qui de leur initiative falsifient leurs noms et se font une race nouvelle, ils mériteraient qu'il leur arrivât ce qui advint à celui qui se nommait Riebener, et se faisait appeler II. Rapparius : quand il voulut hériter de son frère, le juge rejeta sa demande, disant que, dans la requête qu'il lui avait adressée, il s'était reconnu lui-même " incontinent " (Rapparius), et ne pouvait donc prétendre à l'héritage. D'autres fous, en grand nombre, s'affublent de noms français. J'en ai connu un, qui s'appelait Hans Jelme. Et comme sa toilette, ses façons, tout était à la mode française, il voulut aussi y accommoder son nom. A la vérité, toute sa science en français se bornait à ces mots : « Monsieur, je suis votre très humble serviteur ». Mais il fallut absolument que son nom devint français. Et de plus, comme il avait grand désir d'être un gentilhomme, il pensa que, tandis qu'il était en train de changer son nom, il n'était pas plus difficile de lui faire un peu de toilette, en y ajoutant la particule. Il s'intitula donc : Jean de Jelme. Hais il n'avait pas réfléchi que la prononciation allemande en ferait : Schand-Schelm (infåme fripon), et il devint la risée et l'objet de mépris de tous. Je voudrais qu'il en fut ainsi de tous ceux qui rougissent de leurs noms allemands et commettent un

\section{Singe cher,}


faux pour le changer; ils mériteraient que l'Allemagne rougit d'eux en retour, et les jetât hors de ses frontières, arec les autres faussaires ${ }^{1}$. "

Kuhnau criait dans le désert. Il suffit à un Theuer Affe de se baptiser Carafia et d'écorcher quelques mots d'italien, pour que le monde inusical de Dresde s'empresse de l'accueillir. «Ils étaient tous de cette absurde espèce, qui pense qu'un compositeur est un niais s'il n'a pas vu l'Italie, et que l'air welche donne aux artistes toutes les perfections, à la façon du vent de Lusitanie, qui, selon Pline, féconde les juments ${ }^{2}$. " Carafia a d'ailleurs des expédients ingénieux pour réveiller et stimuler la curiosité publique. Il se fait envoyer de divers points de l'Europe des lettres aux suscriptions ronflantes : All' Illustrissimo Signore, il Signor Pietro Caraffa, maestro incomparalile di musica, ou bien, en allemand:Dem Wohl-Edlen, Besien, und Sinnreichen Herrn Pietro Caraffa Hochberühmten Italiøenischen Musico, und unvergleichlichen Virtuosen. L'adresse du logement est presque toujours oubliée, comme par mégarde; de sorte que le postier doit courir de maison en maison, demandant si personne ne connait « l'Orphée de ce temps », “ l'incomparable virtuose ». - Ainsi, en quelques jours, nul n'ignore plus son nom, et il est populaire avant d'avoir paru ${ }^{3}$. Le Collegium Musicum de Dresde lui envoie uno députation, l'invite à assister à ses séances, lui adresse des discours de bienvenue emphatiques, comme à l'entrée d'un prince. On donne des concerts en son honneur. On le supplie d'y prendre part. Caraffa se

\section{Der Musicalische Quack-Salber, c. 7.}

2. Der Mus. Q.-S., c. 1.

3. Der Mus. Q.-S., c. 8. 
LE ROMAN COMIQUe D'UN MUSICIEN AU XVIII SIÈCle. 15

fait prier : malgré quelque virtuosité sur le théorbe et la guitare, son talent est des plus médiocres. Aussi se garde-t-il de le prodiguer, et il trouve des prétextes pour retarder le moment de se faire entendre. Il a, dit-il, une voix admirable, mais il ne peut chanter que sur des paroles italiennes; et le Collegium ne possède que des partitions allemandes. Il a un talent de violoniste unique; mais un rival jaloux, en voulant l'assassiner, lui a estropié la main d'un coup de poignard; et il doit attendre quelques mois avant d'en faire usage. Il accepte pourtant d'accompagner un concerto au clavecin, ayant cru remarquer que la partie en était des plus simples. Mais, pour lui faire honneur, on lui donne un morceau difficile. Aussitôt il commence à critiquer le clavecin : c'est à l'art incomparable de la composition qu'il a mis tout son génie. S’il s'amuse parfois à tapoter sur le clavier, c'est qu'il y est obligé pour s'accompagner, quand il chante une de ses inventions. Mais c'est là un de ses moindres passetemps. D'ailleurs, la musique italienne pour clavier est simple, et n'a point ces complications bizarres, où se complaît le goût allemand. Après toutes ces façons, il s'assied au clavecin, prélude par des accords parfaits et plats et, sous prétexte qu'il est enrhumé, place deux tabatières de chaque côté de lui. "Quand il voyait venir à la main droite des passages difficiles, il puisait tranquillement dans la tabatière de droite. Quand les traits rapides étaient à la basse, il puisait dans la tabatière de gauche. Ainsi, les difficultés étaient toujours esquivées ${ }^{1}$. D

Kuhnau a très bien marqué la nature saxonne, son

1. Der Mus. Q.-S., c. 2.

R Bollayd, - Voyago musical. 
mélange de candeur et de finesse, sa bontiomie lourde et narquoise. Ces braves gens qui sont runus a Ciralfa avec un désir de respect et d'admiration rolicules et touchants, sont trop bons musiciens pour ne pas sentir le manque de talent du claveciniste; mais leur indulgence s'évertue à trouver des excuses. Il est difficile d'ébranler leur confiance; mais dés que le soupçon s'est introduit dans leur honuète cervelle, rien ne pent plus l'en arracher. Iis examment le fitux Italien, sans qu'il s'en doute, avec une consciencieuse lenteur; et quand leur conviction est faite, au lieu de s'indigner et de chasser le charlatan, ils s'en amusent silencieusement; ils se donnent la comédie avec lui; ils l'excitent à mentir, à raconter ses hâbleries, à étaler sa niaiserie prétentieuse; et ils rient sous cape en feignant de l'admirer, jusqu'au moment où Caraffa, consterné, s'aperçoit qu'on le bernait depuis des semaines. C'est ainsi qu'ils l'amènent, malgré sa prudence, à trahir sa nullité, en leur montrant quelques-unes de ses œuvres; et, pour éviter qu'il n'ait recours à son procédé habituel de composition, qui est de copier effrontément, ils réussissent à l'enfermer en loge, et l'observent du dehors. "Caralfa travaille de tout son corps. Il fredonne, il tambourine avec les mains, il frappe sur la table, il chante, il marque la mesure, de la tête et des pieds. Il n'est pas d'ouvrier, occupé au plus dur métier, qui peine autant que lui. Après une heure et demie, la sueur lui ruisselle sur le visage et le dos, et il n'a pas trouvé une mélodie. Il essaie de prendre la plume; il la trempe dans l'encre; il écrit, il rature encore, toujours; il noircit du papier, le déchire, recommence. Il essaie d'un autre moyen; il se lève et marche avec furie à travers la chambre, comme s'il 
voulait enfoncer les portes et les murs : cela pendant un bon quart dheure. Enfin il en vient a cette superstition des joueurs malheureux. qui croient que, pour ressaisir la veine, il faut changer de place et prendre un nouveau siège. Il laisse là bancs et table, et s'assied par terre, sur le plancher. Il avait tendu à son travail toutes les forces de son corps, et il ne remarquait pas qu'il était près de mili et que la lampe brùlait toujours.... Enfin, il lui vint les mélodies de quatre liedor connus : Bonsoir jardinier; - Damon vint en profonde pensée; - Une belle dame habite en ce pays; - Elle repose... - Après avoir souffert de sa pauvreté, il souffre de son abondance; il ne sait lequel de ces beaux airs pourrait s'ad ipter le mieux au texte donné, et lequel surtout serait le moins reconnaissable. Il est sur le point de les tirer aux dés; puis il se décide à les fondre ensemble, ou plutôt à les juxtaposer ${ }^{1}$. " On imagine quelles gorges chaudes les musiciens de Dresde se font de cette niaiserie. A Leipzig, où Caraffa va ensuite, les bourgeois et les étudiants se jouent plus cruellement de lui; ils le mettent aux prises avec un autre musicien ridicule, ils excitent leurs fureurs burlesques, et ils finissent par les soumettre tous les deux au jugement d'un tribunal grotesque, d'une mascarade mythologique et bouffonne, dont les deux sots sont dupes, et qui rappelle la Cérémonie du Bourgeois gentilhomme ${ }^{2}$.

Battu, berné, bafoué, Caraffa ne s'en émeut guère. « Tout antre à sa place aurait mille raisons d'être malheureux, en songeant à sa situation précaire et à sa honte. Caraffa, forcé de se sauver précipitamment de

1. Der Mus. Q.-S., c. 17. '- 2. Der Mus. Q.-S., c. 4 J̃-48. 
Dresde, s'en affecte aussi peu qu'un charlatan, qui est démasqué dans un pays et qui pense : «Bah! il y a " d'autres pays au monde : un de perdu, dix de retrou« vés! On n'a qu'à aller plus loin, et il se passe du “ temps, avant que les autres villes s'aperçoivent de « votre ignorance. Ainsi, on est sûr de ne se coucher " jamais sans souper et d'avoir toujours un habit à " se mettre sur le corps ${ }^{1}$." Partout, sur son chemin, il use sans façon de la table, de la cave, et du lit des cantores, organistes, musiciens des petits pays, qu'il éblouit par sa jactance. Il exploite largement les amateurs ridicules, les marchands ignares qui veulent passer pour connaisseurs, en régalant des artistes. Il s'installe dans les châteaux de campagne, auprès des hobereaux ennuyés qui ne sont point difficiles sur la qualité de sa musique et de ses plaisanteries; il remplit sa bourse et sa panse, jusqu'au moment où il sent qu'il commence à lasser; alors, il décampe prestement, sans demander ses gages, mais non sans emporter parfois quelques couverts d'argent. Il dépouille de leurs économies les pauvres maîtres d'école de villages, avec la promesse de les mettre en état de devenir en un an kapellmeister à des cours princières; et il rit au nez des dupes, quand ils viennent ensuite lui réclamer leur argent, en pleurant et jurant. Si l'un d'entre eux prend mal la plaisanterie et dépose une plainte, c'est son affaire: Caraffa sait les lenteurs des tribunaux allemands.

Enfin, le fripon a un appui qui ne lui manque jamais et qui le console de ses déboires : les femmes. Elles ne sont pas toujours séduisantes, mais elles sont toujours séduites. Bien avant la Sonate à Kreutzer,

1. Der Mus. Q.-S., c. 25. 
LE ROMAN COMIQUe D'UN MUSIGIEN AU XVIII ${ }^{e}$ SIĖCle. 19 Kuhnau avait noté les ravages de la musique, et surtout du virtuose, dans les cœurs féminins; il en donne quelques traits amusants. L'épisode le plus gai et le plus développé est celui de la châtelaine de Riemelin (Hörnitz), que j'aimerais à conter, si ce fabliau, plus gaulois qu'allemand, n'était de touche un peu vive : le héros en est, d'ailleurs, un autre gratteur de luth, et Caraffa n'y joue qu'un rôle secondaire '. Mais Caraffa lui-même est un don Juan. Il a conquis les cœurs des dames romaines, avec une sonate de son invention. "C'était un délire, une pluie d'œillades et de baisers. Jamais mon museau ne se trouva à pareille fête ${ }^{2}$. "A peine arrivé à Leipzig, il tourne la tête de la plus jolie fille de la ville, - belle, sage, riche, bonne musicienne : - elle perd tout sens et toute retenue, dès que Caraffa commence à taper sur le clavier et à chanter de sa voix rauque. Quand le père, un gros marchand, nommé Pluto, est au courant de l'intrigue, il est près de crever de colère; il injurie sa fille. et chasse le drôle. Les rendez-vous n'en continuent pas moins, la nuit, dans son jardin; Caraffa y chante des scènes d'Orphée, en s'assimilant à son héros; la petite serait disposée à jouer Eurydice et à se sauver de chez Pluto, si au dernier moment ne survenait fort à propos une grande diablesse de fille de geôlier, à qui Caraffa a fait un enfant, pendant certain séjour dans une prison de Zittau, où il était retenu pour escroqueries. Elle prend le séducteur à la gorge et réclame à grands cris le mariage. Au milieu du vacarme, Aa jeune « Plutonin » se sauve, et ne revient plus ${ }^{3}$.

1. Der Mus. Q.-S., c. 28. - 2. Der Mus. Q.-S,, c. 11.

3. Der Mus. Q.-S., c. 35, 49-50. 
Ces extravagances se déroulent dans un cadre réel, exactement observé : scènes de tribunal, de foire, charlatans sur la place publique, paysans au cabaret, hobereaux dans leurs châteaux, bourgeois à leur table ou à leurs affaires; et toujours le langage et les façons de chaque classe sont notés avec humour. Au premier plan, le monde des musiciens et des étudiants. Dans chacune de ces villes saxonnes est établi un Collegium musicum. C'est une association de tous les musiciens de la ville, qui se réunit régulièrement une ou deux fois par semaine, dans une salle spéciale. Chacun y vient avec son instrument; et deux des membres, à tour de rôle, sont chargés de fournir le Collegium de morceaux de musique : concertos, sonates, madrigaux, arie. On y discute longuement sur l'art; on compose sur des textes donnés; on cause amicalement. Parfois le Collegium a des banquets, à la fin desquels on exécute divers morceaux, sérieux ou bouffons. Il est rare que ces musiciens ne sachent pas à la fois jouer d'un instrument et chanter. Ils ne sont point d'ailleurs des virtuoses de profession, mais des bourgeois, qui ont d'autres occupations. Celui d'entre eux chez qui ils se réunissent à Dresde, est receveur des contributions ${ }^{1}$.

La musique a aussi sa place aux Universités et dans les Collegia oratoria. A celui de Leipzig, nous assistons à un Actus oratorius sur la musique, que clòt un concert instrumental. Deux étudiants prononcent des

1. Der Mus. Q.-S., c. 19. 
discours, l'un pour célébrer, l'autre pour condamner la musique '. Et il n'est pas étonnant d'entendre louer dignement la musique par un grand musicien. Mais il est plus remarquable de voir porter contre elle des accusations qui vont profondément, et témoignent d'une vue pénétrante de son temps. - " La musique, dit-il, détourne des études sérieuses; elle prive le pays de bien des têtes qui auraient pu s'employer à son service. Ce n'est pas sans motif que les politiques la favorisent : ils le font par raison d'Etat. Elle est une diversion aux pensées du peuple; ello l'empêche de regarder dans les cartes des gouvernants. L'italie en est un exemple: ses princes et ses ministres l'ont laissée infecter par les charlatans et les musiciens, afin de n'être point troublés dans leurs affaires ${ }^{2}$. $)$-. Et certes, l'exemple de l'Italie est bien choisi : car, s'il est vrai que par la musique, elle ait prolongé sa gloire et étendu son influence sur l'Europe, par la musique aussi et dans la musique, elle a achevé de dissoudre ses facultés morales et politiques. De l'Italie du XviII siècle, on pourrait dire, en changeant un peu les termes, ce qu'Ammien Marcellin disait déjà de l'Italie, au temps des grandes invasions : « C'est un lieu de plaisir. On n'y entend que des musiques, et, dans tous les coins, des tintements de cordes. Au lieu de penseurs, on n'y rencontre que des chanteurs; et la vertu a cédé la place aux virtuoses. " - Ce qu'est un virtuose italien vers 1700 , et le vide de son cerveau, Caraffa nous en est un exemple frappant, encore qu'un peu chargé. Rien ne l’intéresse, en dehors de la musique: et en musique rien ne l'intéresse, que la

1. Der Mus. Q.-S., c. 43-44. - 2. Der Mus. Q.-S., c. 43. 
virtuosité. Il ne connaît pas les célèbres compositeurs de son temps; il prend Rosenmüller pour un Italien. Il est ignare en harmonie; il ne sait point ce que c'est qu'un contrapunto semplice o doppio ${ }^{1}$. Il ne sait que parler de son luth, ou de son violon, ou de sa chitarra, et surtout de lui, de lui, de lui. Quel que soit le sujet de conversation, que l'on cause de la guerre, du commerce, d'un beau sermon, ou d'un rhume de cerveau, il trouve toujours moyen de ramener à soi l'entretien, et toujours en parlant de soi à la troisième personne : “Que fit mon Caraffa? " Le pauvre Caraffa "... 2 . En dehors de ses concerts, le reste du monde est néant. « Il savait à peine si Londres et Stockholm étaient en Hollande ou en France, ou si les trônes du Nord étaient les Turcs, et les Portes Ottomanes les Espagnols. Sa cervelle était comme une armoire, dont un rayon a quelques objets, et les autres rien ${ }^{3}$. „ La musique a produit là un monstre. Ils abondaient dans l'Italie du XviII ${ }^{\mathrm{e}}$ siècle. Ils ne manquent pas aujourd'hui encore; aucun pays n'en est privé.

Dans l'Allemagne d'autrefois, la musique n'avait pas tout à fait les mêmes dangers. Elle trouvait un contrepoids dans les études philosophiques ou littéraires, auxquelles on l'adjoignait souvent. On ne la pratiquait point comme une volupté vide. Les plus grands compositeurs allemands du xvir siècle, Schütz, Kuhnau, Hændel, reçurent une éducation sérieuse, ils firent de solides études de droit, et il est remarquable qu'ils hésitèrent quelque temps, semble-t-il, à être musiciens de profession. Un virtuose italien du xvir ${ }^{\bullet}$ siècle 'est qu'un grelot sonore. Chez un Allemand musicien,

1. Der Mue. Q.-S., c. 19. - 2. Der Mus. Q.-S., c. 26.

3. Der Mus. Q.-S., c. 42. 
LE ROMAN COMIQUE DUN MUSICIEN AU XVIHe SHICLE. 23

la raison conserve ses droits, même sur la musique. Mais cette virile intelligence commençait à se laisser entamer par les séductions de l'Italie. A Dresde, à Leipzig, comme à Florence et à Rome, Kuhnau voyait les princes se faire les patrons de l'art sensuel et dissolvant, qui était l'allié naturel du despotisme. Son roman nous est une preuve de l'attraction irrésistible qu'exerçait le virtunse italien sur toutes les classes de la société. Quand Caraffa s'arrète dans une auberge de campagne, il est sûr d'y trouver la même faveur que chez les riches marchands des villes ${ }^{1}$. Le goût public était malade.

Mais Kuhnaia sontait trop sa force, pour être sérieusement inquiet. Il voit le mal, mais s'en amuse, certain que cela n'aura qu'un temps. Son optimisme sans rancune va jusqu'à prévoir la conversion des pécheurs. Caraffa, à la tin du roman, est touché par les remontrances d'un brave prêtre, et s'amende; et si ce repentir n'est pas très vraisemblable en un tel caractère, nous lui devons du moins de nobles pages de l'auteur sur le véritable virtuose et le bienheureux musicien : « Der wahre Virtuose und glückselige Musicus ${ }^{2}$ ". - Il exige beaucoup de lui. Sous le rapport musical, il veut que le compositeur soit familiarisé avec tous les instruments et que le chanteur ou l'instrumentiste (surtout le claveciniste) soit rompu à la composition. Mais cette instruction professionnelle ne suffit point. Kuhnau désire que le compositeur ait des connaissances scientifiques générales, en particulier des mathématiques et de la physique, qui sont le fondement de la musique, "welche gleichwohl der Music fundament ist ${ }^{3} \rrbracket$; qu'il ait réfléchi

1. Der Mus. Q.-S., c. 38. - 2. Der Mus. Q.-S., c. 53, 64 préceptes.

3. Der Mus. Q.-S., c. 42. 
sur son art et connaisse les théoriciens musicaux, non senlenent de son temps, mais du passé et surtout de lantiquité; il ne lui plait point d'ailleurs gu’à l'exemple de Caralla, il se désintéresse de l'histoire, de la pulitique, et de la vie de son temps.

Ces qualités inillectuelles ne seraient rien encore sans les qualités morales. Un vittuose ne méritera pleinement ce beau nom de Virtú, que si à la vertu do son art, s'ajoute celle de sa vie. Comme dit sinint Augustin : "Cantet vox, cantet vita, cantrnt facta". Que son cuvre soit consacrée, non au succis, mais à li gloire de Dieu. II n’a pas à s'occuper du public, de son goût et de ses applaudissements. "Si tu chantes do tello façon que tu plaises au peuple plus quà bieu, ou que tu cherches la louange d'un autre plus que celle de Dieu, tu vends ta roix, et tu la fais, non ylus tienne, mais sienne ${ }^{1}$. \- Que l'artiste soit donc modeste aux yeux de Dieu; mais qu'il soit, en mème temps, conscient de sa valeur. Un musicien qui est lort, et qui le sait, ne doit pas ètre trop humble et vivre de façon elfacée. Il ne lui est pas permis de chercher l'obscurité et la retraite, s’il a quelque chose à dire au monde. Un homme qui a des dons, et qui les tient cachés, fait preuve d'un caractère médiocre, qui ne se fie pas aux grandes ailes que Dieu lui a données pour s'envoler dans les hauteurs. C'est le fait d'un lâche, qui a peur de la peino; et peut-être y a-t-il là aussi un mauvais sentiment de jalousie inavouée, qui ne veut point faire part aux autres de ses richesses, “ comme les ceris mourants, à ce que rapporte Pline. cachent et enfoussient leurs bois, atin quils ne puissent pas servir de méue-

1. - Si sic cantas, ut placeas Populo, magis quam Deo, vel ut ab alio laudem quaras, vocem tuan vendis, et facis eam non luam, sed suam s. 
LE ROMAN COMIQUE D'UN MUSICIEN AU XVIIO SIECLE. 2\% cine aux hommes n. La gent musicale est, trop souvent, ainsi : quand certains possèdent un beau morceau do musique, ils se laisseraient dépouiller de tous leurs vètements, plutót que d'en communiquer une note. Que l'ariste n'aiś point celte économie sordide de ses biens, de ses pensées, de ses forces! Qu'il les répande généreusement autour de lui, sans en tirer vanité, en ramenant toute la gloire à la source divine. Qüil fasse tout le bien dont il est capable. Et si on ne lui en sait aucun gré (c'est l'ordinaire en ce monde), sa bonne conscience sera sa récompense; elle lui donnera l'avant-goùt du céleste plaisir qui l'attend après cette vie, quand il sera appelé dans la chapelle du chateau (Schlosscapelle) de notre puissant Seigneur, « où les anges et les séraphins exécutent des musiques d'une suavité parfaite ${ }^{1}$. »

Il y a dans ces pensées, comme dans tout le livre, un équilibre de raison, une sùreté de soi, une force cachée, qui expliquent le calme avec lequel les vieux maîtres allemands du xvir siècle, les Schütz, les JeanChristophe Bach, les Jean-Michaël Bach, les Pachelbel, les Buxtehude, regardaient l'arenir. Ils avaient mesuré le reste du nionde, et eux-mêmes. Ils attendaient leur heure. - Cette heure est venue pour l'Allemagne. Ello est déjà passée. Quel constraste entre l'inquiétude fébrile de ses artistes de la fin du Xix ${ }^{\mathrm{e}}$ siècle et la tranquille plénitude des âges écoulés! Les victoires trop complètes brûlent l'âme des vainqueurs; leur première ivresse

1. Der Mus. Q.-S., c. 53. 
tombée, elles brisent le ressort de la volonté, elles lui enlèvent sa raison d'agir. Le génie triomphant d'un Wagner a ravagé l'avenir de la musique allemande. Dans la paix puissante d'un Kuhnau, il entrait la pensée des destinées futures de l'art allemand, et comme le pressentiment de son grand successeur : Jean-Sébastien Pach. 


\section{1}

\section{LA VIE MUSICALE D'UN AMATEUR ANGLAIS}

AU TEMPS DE CHARLES II

D'après le JOURnal de Samuel pepys

Rien ne donne une idée plus riante de la vie musicale, dans la société anglaise de la Restauration, que le journal de Pepys. On y voit la place que la musique tenait au foyer d'un bourgeois intelligent de Londres.

Samuel Pepys est bien connu. Je me bornerai à rappeler les faits principaux de sa vie. Fils d'un tailleur, il naquit à Londres en 1662, et s'attacha d'abord à la fortune de Lord Montagu, comte de Sandwich. Après avoir été libéral et en relations avec les républicains, après la mort de Cromwell i! devint, sous la Restauration, commis à l'Echiquier et clerc des actés de l'Amirauté. Il conserva ce poste jusqu'en 1673, et y rendit de grands services à la marine anglaise; avec une probité énergique, il y rétablit l'ordre, l'économie, la discipline, pendant l'époque critique de la peste, de l'incendie de Londres, et pendant la guerre de Hollande. Il était fort estimé du grand amiral, duc d'York, plus tard Jacques II. Cependant, il fut calomnié, au temps de la conspiration papiste, accusé de catho- 
licisu.e, et envoyé à la Tour. Il réussit à se justifier et fut replacé au Conseil de la Harine. Il resta secrétaire de l'Amimuté, jusqu'en 1688. très en farem auprès de Jacques Il. Après l'expulsion des Stuarts, il se retira du gouveruement; mais son activité ne se ralentit pas, jusqu'à sa mort, en 1703. Il n'avait cessé de s'intéresser aux lettres, aux arts et aux sciences. En 1684, il fut nommé président de la Société lioyale. Il collabora à divers ourrages savants. A Mlagdalen College de Cambridge, se trouve la collection de ses manuscrits : Mémoires, gravures, documents sur la marine, cinq volumes de vieilles ballades anglaises recueillies par lui : - enfin, son Journal, où il a noté, dans une sténographie de son invention, tout ce qu'il a fait, jour par jour, de janvier 1639 (1660), jusqu'en mai 1669. Ce journal est, avec celui de son ami Evelyn, le recueil le plus vivant de renseignements contemporains sur l'Angleterre de ce temps. J'en relèverai ici les notes concernant la musique.

\section{$* *$}

Ce ministre de la marine, cet homme d'État consciencieux, était mélomane passionné; il consacrait à la musique une partie de ses journées. Il jouait, du luth, de la viole, du théorbe, du flageolet, du recorder ${ }^{1}$, et un peu d'épinette. C'était la coutume, parmi les bourgeois distingués, d'avoir chez eux une collection d'instruments de musique, notamment une caisse de six violes, pour donner des concerts. Pepys possédait son petit musée d'instruments; il se flattait qu'ils

1. Flûte à bec, à huit trous, dont un recouvert d'une fine membrane - de tous les sons du monde, celui qui m'est le plus agréable "(8 avriI 1668.) 
LA VIE MUSICALE D'UN MHTER AXgLAS.

fussent les moilleurs d'Ingletere; et il touchail de presque tous. Son plus grand phisia était de chanter et de jouer du flareolet. II emprortait partout ce flugeviet avec lui, en promenade, au restaurant:

"Swan et moi alldmes à une taverne, oì. pendant qu'il écrivait, je jouai de mon flageolet, jusqu'à ce que le p'at d'cenfs pochés fiut prét ${ }^{1}$. "

"Je revins par eau, jouant de mon flageolet ${ }^{2}$."

"Le soir, dans le jardin, resté longtemps à jouer du flageolet, au clair de lune. ${ }^{3}$,

Il se risquait même à la composition :

"Composé quelques airs, Dieu me pardonne"!)

Et ses compositions - grâce à la haute situation du compositeur - araient grand succès dans le monde : ce dont Pepys " n'élait pas peu fier ${ }^{5}$ ».

Il finit par se persuader que ses œuvres étaient excellentes :

"Downing, qui aime et comprend la musique, a voulu à toutes forces avoir mon air de : "Beauté 》, et il le vante au-dessus de tout ce qu'il a jamais entendu; et sans me flalter, je sais qu'il est bon ${ }^{6}$.

Il faisait gravement répéter ses chants à des actrices :

a Après diner, j'enseignai à Knipp mon nouveau récitatif, dont elle apprit une bonne partie; il me plait,

1. 9 février 1660 . - 2. 30 janvier 1669 .

3. 3 avril 1661. Voir aussi 17 février 1639,20 juillet 1664 .

4. 9 février 1662 . - วั. 22 aoùt 1666.

6. 9 novembre 1666 . Cf. 5 déc. 1666 : Et, sans me flatter, je pense qa'il est fort bon s. 
et je crois que je serai satisfait, quand elle le saura tout enticr, et?'on le trouvera agréable ${ }^{1}$. "

Au reste, en grand seigneur, il ne se donnait pas la peine d'écrire ses basses lui-même : il les faisait écrire.

"Rencontré Mr. Hingston, l'organiste à la cour. L'ai conduit à la Taverne du Chien, et lui ai fait écrire pour moi une basse, qui, je crois, ira bien. ) - Et il ajoute naïvement : - "Il dit beaucoup de bien de la romance, sans en connaitre les paroles, et assure que l'air est bon; il croit que les mots sont clairement exprimes ${ }^{2}$. "

“ Dr. Childe venu au rendez-vous, et resté avec moi toute la matinée à me faire des basses pour plusieurs airs que je lui ai demandés ${ }^{3}$. »

\section{Il s’intéressait aussi à la théorie musicale :}

" Dans ma chambre avec un bon feu; passé une heure sur l'Introduction à la Musique de Morley, un très bon livre, mais sans méthode ${ }^{4}$. )

"Allé à pied à Woolwich, en lisant tout le long du chemin l'Introduction à la Musique de Playford, oì il y a quelques jolies choses ${ }^{\mathrm{s}}$. )

“A Duck Lane pour chercher Marsanne ${ }^{6}$ en francais; c'est un homme qui a fort bien écrit sur la musique: nais on ne peut se le procurer, ici; alors jai commande yu'on le fasse venir, et jai acheté le Traité sur la Musique de Descartes ${ }^{7}$. 》

« Le page m'a lu le livre de la musique de Descartes,

1. 14 novembre $1666 .-2.19$ décembre 1666 .

3. 15 avril 1667 . -4.10 mars 1667.

5. 22 mars 1667 . - 6. Le père Hersenue. -7.3 avril 1668. 
que je ne comprends pas; et je ne crois pas que celui qui l'a écrit le comprit bien non plus, quoiqu'il fût un homme fort savant ${ }^{1}$. ")

Il se mit en tête d'écrire lui-même ses idées sur la musique. Ce devait être, à l'en croire, quelque chose d'extraordinaire; il n'était pas loin de penser qu'il tenait la clef du mystère des sons.

« $J$ 'ai eu avec M. Bannister une très agréable conversation sur la musique, qui confirme quelques-unes de mes nouvelles idées : en sorte que cela me donne la résolution d'écrire le plan d'une théorie de la musique, comme jamais on n'en a fait une pareille, au monde ${ }^{2}$."

" Fait écrire d̀ Tom quelques petits concerts et quelques idées à moi sur la musique : cela m'encourage beaucoup à m'y adonner davantage; car j'imagine, et jai de bonnes raisons pour le croire, que je suis en bon chemin pour découvrir le mystère ${ }^{3}$."

Ne le prenez point pour un snob. Ce qui est charmant en lui, c'est la sincérité et l'ardeur juvénile de son amour pour la musique. Il l'aime trop. Il en a peur :

" Joué de la viole, ce que je n'avais pas fait depuis longtemps, ni joué d'aucun instrument; et à la fin, j'ai cessé, et jai été un peu à mon bureau, ayant peur de me laisser prendre trop par la musique, et de revenir $\dot{a}$ mon ancienne folie, qui me faisait négliger mes affaires ${ }^{4}$. "

Mais il a beau faire : ỉa musique est la plus forte.

1. 25 décembre 1668. - 2. Mars 1668.

3. 11 janvier 1669 . - 4. 17 février 1668 .

R. Roliano. - Voyago musical. 
"Dieu me pardonne! Je m'apercois toujours que je ne peux vaincre ma nature, qui estime le plaisir par-dessus tout, bien qu'au milieu de ce plaisir, je me rappelle à regret mes affaires que je néglige... Mais quand il s'agit de la musique, - et des fermmes, - je ne puis faire autrement que d'y céder, quelles que soient mes affaires ${ }^{1}$. "

Il sent si violemment la musique que parfois il en est malade :

a Été au théâtre du Roi, pour voir la Vierge Martyre ${ }^{2} . .$. . Ce qui me plait plus que tout au monde, c'est la musique des instruments à vent, lorsque l'ange descend; elle est si exquise qu'elle m'a ravi en extase; et vraiment, elle m'a transporté si bren qu'elle m'a rendu malade, tout de bon, absolument comme autrefois, quand j'étais amoureux de ma femme. Toute la soirée, à la maison, je n'ai pu penser à autre chose; et je suis resté, toute la nuit, transporté à un tel point que je ne puis croire que la musique puisse avoir sur l'âme d'un autre homme autant de puissance que sur la mienne ${ }^{3}$. 》

La musique est sa consolation, quand il est triste :

"La nuit, chez moi, joué du flageolet. J'avais le cœur gros. Mais j'ai eu plaisir à penser que, s'il plaît à Dieu de me prêter vie, je passerai mon temps à la campagne, simplement et agréablement, bien que sans grande gloire". "

"Bien que j'eusse encore le caur gros, en pensant à mon pauvre frère (mort la veille), pourtant je cédai $\dot{a}$ mon envie d'entendre jouer du clavecin ${ }^{5}$.

1. 9 mars 1666. - 2. De Massinger. - 3. 27 février 1668.

4. 15 juin $1607 .-5.16$ mars 1664 . 
Il faut convenir que Pepys n'avait pas très souvent occasion de recourir à cette consolation : car il n'était pas souvent triste; et la musique se présente bien plutôt à lui, comme une joie sans.mélange, la plus parfaite de l'existence :

"Je réfléchis que la musique est tout le plaisir que jai en ce minde, et le p'us grand que je puisse jumais espérer, et lo meilleur de ma vie ${ }^{1 .}$.

Autour de lui, il faut que tout le monde partage sa manie musicale. Et d'abord, sa femme.

Il l'avast épousée, vers 16\%弓̆. quand elle n'avait que quinze ans; il en avait vingt-trois. Il se mit en tête de lui appren:Ire le chant; et tant qu'il fut amoureux d'elle, il la trouva "d'une aptitude inimaginable " ${ }^{2}$. Les premières leçons allaient très bien; le maître et l'élève étaient pleins d'ardeur.

"Veillé tard, donnant à ma femme sa leçon de musi$\left.q u e^{3} . "\right)$

"Revenu à la maison, pour moccuper de ma musique. Mla femme et moi, nous restâmes à chanter dans ma chambre, longtemps ensemble ${ }^{4}$. D

-Il ne s'agissait que d'airs sans prétention. Mais Mme Pepys, voyant son mari prendre un maître de chant, pour la musique italienne, se piqua d'amourpropre, et voulut en faire autant :

1. 12 février 1667. - 2. 28 août 1959.

3. 4 septembre 1659 . - 4.17 mai 1661 . 
"C'e matin, ma femme et moi, sommes restés longtemps au lit; et, entre autres choses, la conversation tomba sur la musique; et elle me demanda de la laisser apprendre à chanter : ce que je pris en considération; et je le lui prornis. Et justement, comme j'étais encore au lit, on vint m'avertir que mon maître à chanter, M. Goodgroom, était arrivé pour ma leçon. Alors ma femme se leva, et commenca à apprendre, ce matin-là ${ }^{1}$. 》)

La voilà donc qui apprend de grands airs italiens et français! Quelle imprudence!... Pepys a beau tâcher de se faire illusion : il lui faut reconnaître que sa femme n'a guère de dispositions :

“ Chanté avec ma femme, qui a récemment ${ }^{2}$ com-

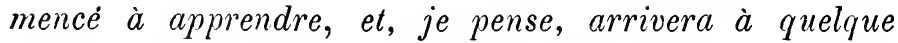
chose; mais elle n'a pas l'oreille juste; et moi, je l'avoue, je n'ai pas assez de patience pour lui apprendre, ou pour l'entendre chanter de emps en temps une note fausse. Je suis à blamer de ne pouvoir supporter chez elle ce qu'il est naturel que je supporte, puisqu'elle n'est qu'une écolière, et que je désire beaucoup qu'elle sache chanter. Je devrais donc l'encourager. Je suis peiné; car je vois que je la décourage et que je lui fais peur de chanter devant moi ${ }^{3}$. 》

Pepys avait d'autant plus de raisons de trouver que sa femme chantait faux, qu'il pouvait faire, dans sa maison, des comparaisons qui n'étaient pas à l'avantage de Mme Pepys. C'était l'habitude d'avoir des domestiques, qui eussent des talents d'agrément; dans

1. $1^{\text {er }}$ octobre 1661 .

2. Le bon Pepys était indulgent: il y avait cinq ans que sa femme apprenait!

3. 30 octobre 1666 . 
La Vie MUSiliale d'Un amateur aíglais.

les familles en re'ations avec Pepys, on voit des domestiques musiciens, qui étaient de vrais artistes. Le sommelier de Milady Wright, M. Evans, jouait parfaitement du ruth et en donnait des leçons à Pepys ${ }^{1}$. La femme du valet d'un de ses amis, Dutton, chantait admirablement ${ }^{2}$. Pepys mettait son amour-propre à ce que ses domestiques fussent aussi des virtuoses; et, en bon mari, - pas tout à fait désintéressé, - il tenait à ce que sa femme eût des suivantes aussi agréables à voir qu'à entendre.

Ce fut d'abord une gentille femme de chambre, Ashwell, qui jouait du clavecin. Pepys lui achète des cahiers de musique, lui enseigne les principes de son art :

“ Monté chez moi, pour enseigner à Ashwell les principes de la mesure, et autres choses. Et lui ai fait répéter un psaume, très bien : car elle a l'oreille juste ${ }^{3}$; et elle a des doigts *. ")

\section{Il fait danser la petite suivante :}

"A près dîner, toute l’après-midi, à jouer demon violon, tandis qu'Ashwell dansait dans ma belle chambre du haut, qui est une salle rare pour la musique ${ }^{5}$. "

Mais Ashwell ne suffit pas à Pepys. Il écrit naïvement :

" Je suis en train de chercher une suivante pour ma femme, qui soit à mon goût, - et surtout une qui comprenne la musique, particulièrement le chant ${ }^{6}$. D

1. 25 janvier 1659 . -2.15 octobre 1665 .

3. Voir plus haut ce que Pepys dit de Mme Pepys.

4. 3 mai 1663 . - 5. 24 avril 1663.

6.28 janvier 1664 . 
Il trouve enfin Loiseau rare. Elle se nommait Nercer. En mème temps, il avait pris un petit page musicien, que lui arait envoyé son ami, le capitaine Cooke, maître de la chapelle royale, sous la direction duquel le page était depuis quatre ans ${ }^{1}$. Voilà Pepys au comble de la joie!

"Chez moi, avec ma femme, Mercer, et le page, veille jusqu'à unze heures, chanlunt et jouant du violon. Ce m'est une grande joie de me voir maitre de tant de plaisir dans ma maison, en sorte que ce sera toujours jour moi, jespire, un bonheur d'être au logis. La jeune fille joue assez bien du clavecin, mais seulement des airs faciles; elle a de bons doigts; elle chante un peu; elle a la voix et l'oreille justes. Mon page, ungentil garçon, chante très bien; et c'est le yarcon le plus agréable du monde, jusqu'à présent ${ }^{2}$. »

Il a bientôt fait de se lasser du page ${ }^{3}$. Mais Mercer devient de jour en jour plus charmante.

"Trouve Mercer jouant de la viole; alors, je me suis mis à ma viole, et à chanter, jusqu'à une heure avancée ${ }^{4}$. "

"Vers onze heures du soir, comme il faisait un beau clair de lune, nous sommes allés dans le jardin, ina ferme, Hercer, et mo:; el nous avons chanté jusque vers minuit. C'était un bien grand plaisir pour nous, et pour nos voisins, qui avaient ouvert leurs fenétres ${ }^{5}$. "

"Après souper, je me mets à chanter avec Mercer;

1. 27 aon̂t 166i4. - 2. 9 septembre 1664 .

3. 22 a vril 1665 . -4 . 18 septembre 1664 .

5. 5 mai 1666. 
et je suis resté à veiller avec elle, trouvant plaisir à l'entendre chanter un air de Lawes, jusqu'après minuit ${ }^{1}$. "

La paure Mme Pepys a le cœur gros.

"En rentrant, trouvé ma femme visiblement mécontente de moi, parce que je passe tant de temps avec Mercer, $\dot{a}$ lui apprendre $\dot{a}$ chanter, et que je n'ai jamais pu en prendre la peine avec ma femme: ce que je reconnais. Mais c'est parce que cette fille a des dispositions étonnantes pour la musique; et la musique est la chose que jaime le plus... ${ }^{2}$. "

Il semble qu'on éloigne Mercer, pour quelque temps. Mme Pepys n'y gagne pas grand'chose. Pepys est mélancolique ${ }^{3}$. Il trouve que sa femme chante décidément bien mal. Mercer revient; et les parties de chant recommencent; et aussi, la jalousie de Mme Pepys :

« Comme il faisait un peu de clair de lune, allé dans le jardin avec Mercer, et chanté, jusqu'à ce que ma femme me rappelle que c'est aujourd'hui jour de jeûne ${ }^{4}$; et j'en ai été fâché, et me suis arrêtét ${ }^{5}$. 》

Mme Pepys s'acharne à apprendre la musique; elle arrive - presque - à faire des trilles. Son mari rend loyalement hommage à sa bonne volonté :

"Après diner, ma femme et Barker ${ }^{6}$ se sont mises $\dot{a}$ chanter. Ma femme se donnait beaucoup de mal; et elle était très fière de pouvoir arriver bientôt à faire des trilles. Et en vérité, je crois qu'elle y arrivera ${ }^{7}$. ఎ

1. 12 juillet 1666 . Voir aussi, 19 juin 1666 .

2. 30 juillet 1666 . -3.23 septembre 1666 .

4. Pour l'anniversaire de la mort du roi. - 5. 30 janvier 1667.

6. Barker était une troisième suivante, musicienne.

7. 7 février 1607. 
Mais décidément, la vertu n'est pas récompensée, en ce monde; et " la paurre petite », comme dit Pepys, ne parvient pas à chanter juste :

"Avant diner, fait chanter ma femme. Pauvre petite! Elle a l'oreille si peu juste qu'elle m'a mis en colère: sı bien que la pauvre petite en a pleuré. Je me dis que je ne dois pas la décourager tant, une autre fois : car elle a un grand désir d'apprendre, pour me faire plaisir; je suis donc très injuste de la décourager ${ }^{1}$. "

Pendant quelque temps, Pepys s'oblige à la patience :

« Je pense qu'elle arrivera à faire des trilles, avec le temps ${ }^{2}$."

a Je l'ai fait chanter : Cela commence à aller mieux que je n'espérais ${ }^{3}$. "

"Elle est cerlainement arrivée à se faire l'oreille plus juste que je ne le croyais possible : ce qui me réjouit jusqu'au fond du cœur ${ }^{4}$. "

Mais ces appréciations prouvent plus en faveur de la bonté de Pepys que du talent de sa femme. Une fois qu'il entend une mauvaise chanteuse, " une idiote pour le chant, incapable de chanter une note juste $\gg$, il lui échappe cet aveu :

" Elle est encore pis que ma femme, et máconculie un peu avec elle ${ }^{5}$. D

La désolée et vaillante petite Mme Pepys, en désespoir de cause, se rabat sur le flageolet. Pepys

1. 1" mars 1667. - 2. 12 mars 1667 .

3. 19 mars et 6 mai $1667 .-4.7$ mai 1667 .

5. 22 janvier 1668 . 
l'y encourage. Peut-être arrivera-t-elle ainsi à faire moins de fausses notes. Il traite avec un professeur, Greeting; et, pour l'encourager, il apprend luimême ${ }^{1}$.

"Etudie le flageolet avec ma femme. Je vois avec plarsir qu'elle sait aisément trouver ses notes ${ }^{2}$."

"Marché une heure dans le jardin, en causant avec ma femme, dont le développement musical commence à me faire grand plaisir ${ }^{3}$. 》

" A souper. Ma femme s'est mise à son flageolet; et elle a joué si gentiment un air de sa façon, que j'ai été infiniment charmé, au delà de tout ce que jattendais d'elle $e^{4}$.

" Passé une partie de la nuit, ma femme et moi, à notre flageolet. Elle joue maintenant n'importe quoi, presque à première vue, et en mesure.... Je me suis couche fort satisfait de ce que ma femme joue si bien du flageolel; jai l'intention de lui faire apprendre un autre instrument : car, quoiqu'elle n'ait pas l'oreille juste, je vois pourtant qu'elle peut arriver à tout ce quine demande que des doigts ${ }^{5}$. 》

Dès lors, le ménage Pepys est heureux. Le soir, Pepys fait jouer du flageolet à sa femme, “ jusqu'à ce qu'il s'endorme avec grand plaisir dans son lit $\left.^{6}{ }^{\prime}\right)$.

Ne croyez point cependant qu'il en oublie sa chère Mercer! Il continue de faire avec elle des parties de chant, - surtout quand sa femme n'est pas là.

1. 8 mai $1667 .-2.17$ mai 1667 .

3. 18 mai 1667 . - 4. 23 mai 1667 .

5. 11 septembre 1667 - -6.13 août 1668 . 
" Ters neuf heirres du soir, entendu la voix de Viercer t't de mon page Tum, chantant dans le jardin... Je mourais d'envie de voir celte fille, ne l'ayant pas rencontrée depuis le départ de ma femme. Je suis allé la trouver au jardin; nous avons chanté ensemble; puis nous sommes rentrés pour souper. Charmé de sa compagnie, aussi bien pour la conversation que pour le chant ${ }^{1}$."

"Mené Hercer au théatre du duc d'York, pour voir la Tempête.... Après le spectacle, conduit Mercer par eau à Spring Gardens. Là, promené avec beaucoup de plaisir, mangé, bu, chanté. Les gens venaient autour de nous, pour nous entendre ${ }^{2}$."

“ Allé par eau à Foxhall.... Il commencait à faire nuit. Nous nous sommes mis dans un coin, et nous avons chanté de telle sorte que tout le monde est venu autour de nous pour nous entendre ${ }^{3}$."

"Cherché Mercer. Elle et moi dans le jardin, à chanter, jusqu'à dix heures du soir ". "

" Joyeuse société. Mercer en est. Après diner, chanté des psaumes ${ }^{5} . .$. ) etc.

Et je ne parle pas de l'autre suivante, Barker, « qui vaut bien mieux encore comme facon de chanter ${ }^{6}$ ).

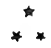

Autour de cette maison musicale, tout le monde est musicien : - les parents, le frère et la belle-sœur, qui

1. 29 avril 1668 . Voir aussi 10 mai 1668.

2. 11 mai 1668. - 3. 14 mai 1668.

4. 15 mai $1668 .-5.17$ mai 1668 . -6.12 avril 1667 . 
jouent excellemment de la basse de viole ${ }^{1}$; - les anis, qui tous font de la musique, bonne ou manaise. Les dames jouent du luth, de la viole, du clavecin; parfois elles y mettent tant d'acharnement quelles finissent par lasser la société :

« La fille de M. Turner joue du clavecin, à vous rendre malade ${ }^{2}$."

"Je suis parti sans prendre congé, ne laissant pas une ame auprès d'elle, pour l'entendre ${ }^{3}$."

Les grands seigneurs savent tous jouer et chanter". Le protecteur de Pepys, Lord Sandwich, fait sa parlie avec lui, dans de petits concerts de musique de chambre ${ }^{5}$, et compose des antiennes à trois parties ${ }^{6}$. On ne peut aller nulle part, sans entendre de la musique:

Au restaurant :

«Emmené ma femme à dîner au Hall des Drapiers.... Très bon repas, beau hall, bonne société, très bonne musique. J'eus plaisir à reconnaitre, à sa voix, un homme que je n'avais janais vu, et qui chantait derrière le rideau, autrefois, dans l'opéra de sir Davenant ${ }^{7}$. "

En promenade :

“ Promené dans Spring Gardens.... Beaucoup de monde. Temps et jardin agréables. C'est fort divertissant

1. 18 décembre 1662 , et 2 lévrier 1667 .

2. $1^{\text {er }}$ mai $1663 .-3.10$ novembre 1656.

4. On ne voit guère qu'une exception : Lord Landerdale, mais il passe pour excentrique; et peut-être veut-il passer pour tel (28 juillet 1666).

5. 23 avril $1660 .-6.14$ décembre 1663.

7. 28 juin 1660 . 
d'entendre ici le rossignol et les autres oiseaux, lia des violons, une harpe ${ }^{1}$....

\section{Dans la campagne :}

( $A$ une certaine distance, il $y$ avait sous un arbre, sur l'herbe, une compagnie qui chantait. Je dirigeai mon cheval ver's eux, et je vis que c'étaient quelques bourgeois qui s'étaient rencontrés par hasard et chantaient à quatre ou cinq parties excellemment. Vu les circonstances, je n'ai jamais été plus ravi par la musique, de toute ma vie ${ }^{2}$.)

Aux bains de Bath : (il semble que la musique fasse partie du traitement) :

" Après ètre resté plus de deux heures dans l'eau, rentré me coucher et sué pendant une heure. - Arrivent des musiciens, pour me jouer de la musique extrêmement bonne, aussi bonne que toutes celles que j'aie jamais entendues, à Londres ou ailleurs ${ }^{3}$. »

Sur mer, - pendant le voyage qu'il fait pour chercher Charles II :

Un matelot, - un ivrogne et un rustre, en apparence, - joue de la harpe, "comme je crois ne pouvoir jamais en entendre jouer, de ma vie ${ }^{4}$ ".

Chez le coiffeur :

"Pour nous servir, un barbier qui joue très bien du violon ${ }^{5}$. )

Dans le peuple de Londres :

Chez Pepys, vient « un ouvrier orfèvre, un pauvre

1. 29 mai 1667. -2.27 juillet 1663 .

3. 13 juin 1068. - 4. 30 avril 1660 . - 5. 20 aout 1662 . 
hère, un très petit bonhomme qui ne porte pas de gants $\mathbf{}$. Il tient parfaitement sa partie dans un quatuor vocal, avec Pepys et des amis ${ }^{1}$.

Le théâtre occupe naturellement une grande place dans la vie de ce mélomane. A la vérité. Pepys s'impose, pendant un ceriain temps, de n'y aller qu'une fois par mois, pour ne pas trop se distraire de ses affaires, et par économie ${ }^{2}$. Mais il n'attend pas le second jour du mois :

“ $1^{\mathrm{er}}$ fóvrier 1664. - Aujourd'hui étant un nouveau mois, je puis aller au théatre. »

Et, quand on parcourt les notes, on voit que la règle a bientôt fait de fléchir.

En tout cas, s'il a fait vœu de ne pas aller au théâtre plus d'une fois par mois, il ne s'est pas interdit de faire venir le théâtre chez lui, - je veux dire, les gens de théâtre, surtout quand ce sont de jeunes et jolies chanteuses, comme Mrs Knipp, chanteuse au King'sTheatre, - " cette petite friponne ${ }^{3}$, - Knipp, qui est gentille certes, et la créature la plus folle, et qui chante le plus noblement du monde, comme je n'ai jamais entendu de ma vie" ". - Il passe la nuit à lui faire chanter ses airs, qui lui semblent admirables ${ }^{5}$. Elle lui répète ses rôles. Elle vient le trouver, au parterre du théâtre, " après son air dans les nuages ${ }^{6}$ ". Il l'emmène en promenade, à Kensington. Elle chante.

1. 15 septembre 1667.

2. Aussi, par un reste de puritanisme. Mais la lecture du Journal montre avec quelle rapidité s'effrite ce sentiment chez l'ancien républicain, devenu le courtisan des Siuarts.

3. 23 février 1666 . - 4. 6 décembre 1605 .

5. 23 fevrier 1666. - 6. 17 avril 1668 . 
"De belles dames nous écoutaient... Prodigieusement gais. Chanté tout le long de la route, jusqu'à la ville ${ }^{1}$. ")

Ah! les bonnes soirées que Pepys se donne, chez lui, avec ces charmantes musiciennes: sa femme, les suivantes de sa femme, les amies de sa femme, et les jolies comédiennes! Knipp y vient parfois, dans son costume de théâtre, "en paysanne, avec un chapeau de paille $^{2} \mathrm{D}$.

- «....Et maintenant, ma maison est pleine.... Quatre violons qui jouent bien... Nous avons chanlé, puis dansé, puis chanté beaucoup de choses à trois voix. Harris, du Duke Theatre, a chanté son air irlandais, le plus étrange et le pius joli que je lui aie jamais entendu.... Continué $\dot{a}$ danser et chanter. Notre Mercer s'est mise à chanter un air italien qui m'a transporté ${ }^{3}$.... Knipp et Polt chantent de bons vieux airs anglais. J'ai eu un plaisir inoü̈, à les entendre chanter ${ }^{4} . .$. J'ai passé la nuit dans le ravissement... La meilleure société musicale oi je me sois jamais trouvé, de ma vie; je voudrais pouvoir y vivre et $y$ mourir, aussi bien à cause de la musique qu'à cause du visage de ma femme et de Knipp ${ }^{5}$.... 》

Pepys savoure son bonheur. La nuit, sur l'oreiller, il se remémore ces délicieuses soirées :

a Je me dis que cette jouissance est une des plus agréables que je puisse espérer dans ce, monde ${ }^{6}$."

1. 17 avril 1668. - 2. 24 février 1667.

3. 24 janvier 1667 . - 4. 17 avril 1668.

5. 6 décembre $1603 .-6.24$ jenvier 1697. 
Un seul nuage à sa félicité : la musique coûte cher. Terminant la description d'une de ces soirées enchanteresses, il écrit :

"Seulement, les musiciens m'ont ennuye; ils n'ont pas été satisfaits, à moins de 30 shillings ${ }^{1}$. "

Pepys n'aime pas à payer : c'est un trait de ressemblance avec bien des riches amateurs de son temps et du nôtre. Rien ne l'ennuie autant que de donner de l'argent à un artiste : il l'avoue naïvement :

" M. Berkenshaw m'a terminé mon air en deux parties, qui me plait fort. Je lui donnai cinq livres sterling pour ce mois-ci, c'est-à-dire pour cinq semaines de lecons : ce qui est beaucoup d'argent, et me contraria it donner ${ }^{2}$. 》

Aussi s'arrange-t-il de façon à se brouiller avec son maître (en faisant de telle sorte que la brouille semble venir de l'autre), aussitôt qu'il croit en avoir extrait tout ce dont il avait besoin ${ }^{3}$. Et quand M. Berkenshaw a donné dans le panneau et rompu avec Pepys, Pepys se délecte à jouer les airs qu'il a extorqués doucement à 11. Berkenshaw, pendant ses leçons :

" Je les trouve tout à fait incomparables, et je n'en suis pas peu fier : car je suis sûr que personne au monde ne les a, en dehors de moi, - pas même lui qui les a ecrits ${ }^{4}$. 》

Quand il s'agit de défendre sa bourse contre les artistes, il est d'une prudence de serpent. - Un

1. 24 janvier 1667 . -2.24 février 1662.

3. 27 février $\mathbf{i} 662$. - 4. 14 mars 1662. 
joueur de viole vient chez lui, et lui joue « quelques très belles choses de sa composition ». Pepys se garde bien de le trop complimenter :

"J'eus peur d'aller trop loin dans mes éloges, et qu'il ne m'offrit de copier ces pièces de musique pour moi : car j'aurais été forcé alors de lui donner, ou de lu prêter quelque chose ${ }^{1}$. »

Rien d'étonnant à ce que, dans ces conditions, la musique semble, à Pepys, le moins dispendieux des plaisirs ${ }^{2}$. Rien d'étonnant non plus à ce que les musiciens meurent de faim dans cette Angleterre, où chacun se dit passionné de musique. Tels ces forains, qui font la parade devant des paysans. Les paysans regardent, rient, - et s'en vont, quand on fait la quête.

“ $M$. Hingston, organiste à la cour, m'a dit qu'un grand nombre de musiciens sont près de mourir de faim, n'étant pas payés de cinq années de leurs gages; et même qu'Evans, le fameux harpiste, qui n'avait pas son égal au monde, est mort de besoin, l'autre jour, et qu'il a fallu l'enterrer aux frais de la paroisse; on l'aurait porté en terre, à la nuit, sans un seul flambeau, si $\boldsymbol{H}$. Hingston n'avait rencontré par hasırd le cortège, et s'il n'avait donné 12 pence pour acheter deux ou trois flambeaux ${ }^{3}$. .

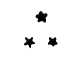

Voilà qui nous renseigne déjà sur le peu de fond de la « musicalité » anglaise! Nous en serons encore mieux instruits, quand nous aurons essayé de voir

1. 23 janvier $1664 .-2.8$ janvier 1663.

3. 10 docembre 1666 . 
LA VIE MUSicale D'UN AMATEUR ANGLais.

clair dans les jugements musicaux de Pepys et de déterminer les limites de son goùt. Combien il est étroit!

Pepys n'aime pas le chant à l'ancienne mode '. Il n'aime pas le chant à plusieurs voix :

" Je suis de plus en plus convaincu que le chant à plusieurs voix n'est pas du chant, mais une sorte de musique instrumentale, parce que le sens des mots, qu'on n'entend pas, se perd, et surtout parce qu'on les met en fugues. Le vrai chant, selon moi, ne devrait être qu'à une voix, deux au plus ${ }^{2}$. "

Il n'aime pas les maîtres italiens :

"Ils ont passé toute la soirée à chanter le meilleur morceau de musique du monde, de l'avis de tous, un m⿻rceau fait par Signor Carissimi, le fameux maître Romain: c'était beau, certainement, trop beau pour que j'en puisse juger ${ }^{3}$. )

"Pas du tout transporté pas cette musique, que je m'attendais à trouver extraordinaire.... Je dois reconnaître que c'est de très bonne musique, je veux dire que la composition est extrêmement bonne; mais pourtant, elle ne me plaît pas ${ }^{4}$."

Il n'aime pas les chanteurs italiens; surtout, il déteste la voix des castrats. Il rend seulement hommage d̀ l'excellente mesure et à l'expérience consommée de ces artistes; mais ils lui restent étrangers, de goût, et il ne cherche pas à les comprendre ${ }^{5}$.

1. 16 janvier 1660 .

2. 15 septembre 1667 . Voir encore 29 juin 1668.

3. 22 juillet 1664 .

4. 16 février 1567 .

5. Il les jugera plus favarablement, un peu plus tard, en les entendant, à la chapelie de la Reine (21 mars 1668). Voir plus loin.

R. Rolland. - Voyagso musical. 
Il ince neore mons l'ecole anglase contrmporaino, l'école de Cooke, d'où sortiront l'elham Ilumphrey, Wise, Blow et Purcell :

"Vraiment, comme exécution el comme composition, c'était bien inférieur à ce que j'avais enterdu, la veille ${ }^{1}$ : ce que je n'aurais pu penser ${ }^{2}$. »

Il n'aime pas davantage la musique française :

" Sans esprit de parti, je ne trouve rien dans leurs airs qui passe les nôtres. je l'ai remarqué pour plusieurs airs pour violon de Baptiste (Lully), le grand compositeur actuel, comparés avec ceux de Banister ${ }^{3}$. "

Il déteste la musique du maître français de Charles II, Grebus (Grabu) :

"Que Dieu me pardonne! Je n'ai jamais été si peu satisfait d'un concert, de ma vie!" "

D’une fą̧on générale, toute musique instrumentale l'ennuie :

" Je dois l'avouer : soit parce que je n'en entends que rarement, soit parce que la voix vaut mieux, je n'y trouve pas le moindre plaisir: m'est avis que deux voix valent bien vingt instruments ${ }^{5}$. "

Que de choses éliminées! Que lui reste-t-il donc? Il vient de le dire : une voix, deux voix au plus, accompagnées ou non du luth, du théorbe, ou de la viole. Et que devront chanter ces voix? - Des airs simples, intelligemment déclamés, comme ceux de Lawes, le

1. Il s'agit de chants italiens de Draghi.

2. 13 février 1667. - 3. 18 juin 1666.

4. $1^{\circ \mathrm{r}}$ octobre $1667 .-5.10$ aout 1664 . 
grand musicien à la mode, celui dont le nom revient le plus souvent dans ce Journal 1. - Au théàtre, Pepys semble aimer surtout la musique de Lock, avec qui il était en relations personnelles ${ }^{2}$, et celle de l'auteur de la partition de scène écrite pour la Vierge et Martyre de Massinger, en 1668, - cette musique qui le rendait malade de plaisir. -- A l'église, c'est encore Lock qu'il admire ${ }^{3}$, et les Psaumes à quatre voix de Ravenscroft, quoiqu'ils lui semblent bien monotones ${ }^{4}$.

Mais, au fond, ce qu'il préfére, de beaucoup, ce sont les bons vieux airs anglais.

" Mrs Manuel chante étonnamment bien, tout à fait dans le style italien. Malgré tout, elle ne sne plait pas autant que Knipp, chantant un lon vieil air anglais "."

" Mrs Manuel chante bien. Pourtant j'avoue que je n'en suis pas assez charmé pour l'admirer... J'ai plus de plaisir à entendre Knipp chanter deux ou trois petits airs anglais, que je comprends, - quoique la composition et l'exécution de l'autre soient belles ${ }^{6}$. "

Encore faut-il que ces airs soient anglais strictement, purs anglais. Pepys n'admet pas même les airs écossais :

« Un domestique de Lord Landerdale joue sur le violon quelques airs écossais, - des meilleurs du pays, $\dot{a}$ en juger par la façon dont ces gens paraissent les apprécier par leurs éloges et leur admiration; mais, Seigneur!

1. Pepys en chante constamment. (Mars, avril, mai, juin, novembre 1660,14 déc. 1662,19 nov. 1665 , etc.)

2. 11 et 21 février 1660. Pepy's connaissait aussi Purcell le père.

3. 21 février 1660.

4. Nov.-déc. 1664. Ici, les Italiens vont plus tard le conquérir.

3. 17 aot 1667. - 6. 30 décembre 1667 
... les airs les plus étranges que jaie jamais entendus, de ina vie! Tous du même style! ${ }^{1}$ 》

On voit que la musique se réduit à peu de choses, pour Pepys. Chose curieuse qu'une telle passion musicale, unie à cette paurreté de goût! Ce goût n'a qu'une grande qualité : sa franchise. Pepys ne cherche pas à s'en faire accroire; il dit sincèrement ce qu'il sent; il a le bon sens britannique, qui se méfie des engouements irraisonnés. On remarquera particulièrement la défiance instinctive qu'il manifeste à l'égard de la musique italienne, qui commençait à envahir l'Angleterre. Quand il l'entend chez Lord Bruncker, un des patrons des Italiens à Londres, il note, au milieu de l'enthousiasme général :

"Ils ont bien chanté; mais dans un chant il faut considérer les paroles, et comment la musique s'y adapte; l'accent du pays doit être connu et compris de l'auditeur: sinon, l'on ne sera jamais bon juge de la musique vocale d'un autre pays. Aussi, ne comprenant pas les paroles, et n'étant pas habitué à l'italien, je n'ai pas du tout été pris par celle musique; leurs mouvements, leur façon d'élever et d'abaisser la voix peuvent plaire à un Italien; mais à moi, ils ne m'ont pas plu; et je crois, du fond du ccur, que je pourrais mettre en musique des paroles anglaises, d'une facon plus agréable pour les oreilles anglaises les plus exercées, que toute celle musique italienne... ${ }^{2}$. 》

“ Je suis de plus en plus convaincu que chaque nation ayant un accent et une intonation propres à sa

1. 28 juillet 1666 . Voir aussi son mépris pour les airs de cornemuse (24 mars 1668).

2. 16 février 1667. Voir aussi 11 février 1609. 
langue, - intonation et accent qui ne correspondent pas à ceux des autres pays et qui ne leur plaisent point, le chant doit aussi être différent. Mieux la musique est adaptée aux paroles, plus elle a l'intonation habituelle $\dot{a}$ la langue; de sorte qu'un air bien composé par un Anglais paraìtra toujours meilleur à un Anglais qu'un air écrit sur des paroles étrangères par un étranger ${ }^{1}$.... )

Ceci est plein de bon sens et fait penser à ce qu'écrira Addison, quelque cinquante ans plus tard. Cette saine méfiance aurait dû mettre en garde les dilettantes et les musiciens anglais contre l'imitation étrangère, surtout contre l'imitation italienne, qui allait être mortelle pour l'art anglais. Mais l'art italien était bien fort; et l'on vient de voir dans quelles étroites limites se resserrait le goût anglais. Il abandonnait la plus grande partie du terrain à l'art étranger, pour se renfermer dans sa petite maison : grosse imprudence. La musique étrangère, une fois implantée en Angleterre, chercha à tout conquérir. Quelques notes de Pepys montrent que déjà lui-même commence à fléchir :

" A la chapelle de la reine. Entendu les Italiens ihanter. Vraiment leur musique m'a paru tout à fait admirable, supérieure à tout ce que nous faisons ${ }^{2}$. D

C'est l'avou de la défaite prochaine, où l'art anglais va abdiquer, aux mains des Italiens.

\section{7 avril 1667 .}

2. 21 mars 1668. Voir aussi les jugements de Pepys sur Draghi, qu'il rencontre chez Lord Bruncker, avec Killigrew, qui travaille à implonter la musique italienne à Londres, et fait venir d'ltalie des chanteurs, des instrumentistes, des décorateurs (12 février 1667). 


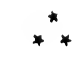

J'ai insisté un peu longuement sur ce journal d'un amateur anglais, à la cour de Charles II. Cn: n'est pas pour le simple amusement de faire revivre quelques types aimables, qui n'ont pas trop varié depuis deux siècles: - l'Anglais distingué, homme d'État et artiste, bien sain, bien équilibré, avec l'activité calme, la sérénité d'âme, la bonne humeur, l'optimisme un peu enfantin, qu'on rencontre souvent chez les hommes d'outre-Manche; agréablement doué, comme musicien, mais superficiel, et cherchant dans la musique plutôt un plaisir hygiénique, suivant le conseil de Milton ', qu'une passion dont on n'est plus le maître. Et autour de lui, d'autres types connus : Mme Pepys, l'Anglaise qui veut être musicienne, qui travaille son clavier avec persévérance, qui ne se décourage jamais, « et qui a de bons doigts ». - D'autres encore....

Mais ce n'est pas pour cela que je me suis appliqué à dépouiller ce journal. Il a cet intérêt pour l'histoire, qu'il est un thermomètre de la musicalité anglaise, vers 1660 , c'est-à-dire au début de l'àge d'or de la musique anglaise. Il fait comprendre que cet âge d'or n'ait pas duré. - Si brillante et même géniale, par instants, que fût la musique de l'ère de Purcell, elle n'avait point de racines, point de terre surtout où

1. On sait que Milton, dans son célèbre Tractate on Education, conseille, après les exercices athlétiques, * pendunt qu'on se sèche el qu'on se repose avant le repas, de récréer et de calmer les esprils fatigués, par les solennelles et divines harmonies de la musique ". Il ajoute que la musique serait encore plus à propos après le repas, "pour assister el aider la nature dans la première digestion, et pour renvoyer l'esprit satisfuit au travail : 
enfoncer ses racines. Le public d'Angleterre le plus intelligent, le plus instruit, le plus épris de l'art, ne s'intéressait avec sincérité qu'à un genre de musique excessivement restreint, qui s'étayait sur la poésie, et qui en était un dérivé : une musique vocale de chambro à une ou deux voix, des dialogues, des ballades, des danses, des chansons poétiques. Là était l'essence et la saveur intime de l'âme musicale anglaise ${ }^{1}$. Toute la musique britannique qui voulait ètre nationale devait s'en inspirer; et ce qu'elle a produit de mieux est peutêtre en effet ce qui, comme certaines pages du charmant Purcell, en a le mirux gardé le parfum do poésio affectueuse et d'élégance rustique. Mais c'était une base un peu mince, un terrain bien exigu pour l'art; la forme d'une telle musique ne se prêtait pas à un grand développement; et la culture musicale, assez généraloment répandue dans le pays, mais toujours à fleur de peau, ne l'eùt pas permis.

Et en face de cette petite prorince des chansons et des ballades anglaises, qui s'est conservée d̀ peu près intacte jusqu'à nos jours, - on voit poindre, dans le Journal de Pepys, l'invasion italienne qui va tout submerger.

1. Je ne parle point ici de la musique religieuse et chorale anglaise, qui a produit des cuvres de larpe envercure, sous la Restauration des Stuaris, et qui garia toijours une noble tenue, - sans avoir un caractère proprement national. 


\section{III}

\section{PORTRAIT DE HENDEL}

On l'appelait le grand ours. Il était gigantesque, large, corpulent; de grandes mains, de grands pieds, les bras et les cuisses énormes. Ses mains étaient si grasses que les os disparaissaient dans la chair et formaient des fossettes ${ }^{1}$. Il allait, les jambes arquées, d'une marche lourde et balancée, très droit, la tête en arrière, sous sa vaste perruque blanche, dont les boucles ruisselaient pesamment sur ses épaules. Il avait une longue figure chevaline, devenue bovine avec l'âge, et noyée dans la graisse, doubles joues, triple menton, le nez gros, grand, droit, l'oreille rouge et longue. Il regardait bien en face, une lumière railleuse dans l'œil hardi, un pli moqueur au coin de la grande bouche fine ${ }^{2}$. Son air était imposant et jovial. «Quand

1. Quand il jouaî̀ du clavecin, dit Burney, ses doigts étaient si recourbés et collés ensemble qu'on ne pouvait remarquer aucun mouvement, et tout au plus les doigts.

2. Voir le portrait gravé de IV. Bromley, d'après la peinture de Hudson. Il est assis, les jambes écartées, le poing sur la cuisse; il tient un feuillet de musique; la tête haute, l'œil ardent, les sourcils très noirs sous la perruque blanche, sanglé à éclater dans son pourpoint ferıné, il déborde de santé, de fierté, d'énergie.

Non moins interessant, et hen!coup moins connu est le beail portiait 
il souriait, - dit Burney, - sa figure lourde et sévère rayonnait d'un éclair d'intelligence et d'esprit : tel, le soleil sortant d'un nuage. ")

Il était plein d'humour. Il avait \& une fausse simplicité malicieuse ", qui faisait rire les personnes les plus graves, sans que lui-même il rît. Jamais homme ne conta mieux une histoire. "L'heureuse manière qu'il avait de dire les choses les plus simples autrement que tout le monde leur donnait une couleur amusante. S'il avait possédé l'anglais aussi bien que Swift, ses bons mots eussent été aussi abondants et de même nature. » Mais, « pour bien jouir de ce qu'il disait, il fallait presque savoir quatre langues : l'anglais, le français, l'italien et l'allemand, qu'il mêlait tout ensemble ${ }^{1}$ ».

Ce salmigondis de langues ne tenait pas moins à la façon dont s'était formée sa jeunesse vagabonde, à travers les pays d'Occident, qu'à son impétuosité naturelle qui empoignait, pour répondre, tous les mots qu'il avait à sa disposition. Il était comme Berlioz : l'écriture musicale était trop lente pour lui; il aurait eu besoin d'une sténographie pour suivre sa pensée : il écrivait, au début de ses grands morceaux choraux, les motifs en entier pour toutes les parties; en route, il laissait tomber une partie, puis l'autre; il finissait

gravé par J. Houbraken d'Amsterdam, d'après la peinture de F. Kyte, en 1742. On y voit Hændel sous un aspect exceptionnel, après la grave maladie qui faill it l'emporter, et dont les traces sont marquées sur son visage. Il est épaissi, fatigué, l'œil lourd, la figure massive; sa force semble assoupie : on dirait un gros chat, qui dort les yeux ouverts; mais la meme lueur railleuse flotte toujours dans le regard endormi.

1. Ce portrait est tracé d'après les peintures de Thornhill, Hudson, Denner, Kyte, d'après le monument de Roubilliac à Westminster, et les descriptions de contemporains, tels que Mattheson, Burney, Hawkins et Coxe.

Voir aussi les biographies de Hændel par Schœlcher et Ohrysande 
par ne plus garder qu'une seule voix, ou même il terminait arec la basse seule; il courait toul d'un trait jusqu'au bout de l'ourrage commencé, remettant à plus tard pour compléter l'ensemble, et, le lendemain du jour où il avait terminé une œuvre, en commençait une autre, parfois en menait deux de front, sinon trois ${ }^{1}$.

Jamais il n'aurait eu la paiience de Gluck, qui commençait, avant d'écrire, par "faire le tour de chacun do ses actes, puis celui de la pièce entière, - «ce qui lui coùtait ordinairement, disait-il à Corancez, une année, et le plus souvent une maladie grave ». - Hændel avait composé un acte, avant de connaître la suite de

1. Je donnerai comme exemple de cette fièvre de création les deux, annécs 1736-9, où Hæendel était malade, où il faillit mourir. En voici le résumé :

En janvier 1736, il écrit la Fête d'Alexandre. En février-mars, il dirige une saison doratorios. En avril, il écrit Atulanta et le Wedding Anthem. En avril-mai, il dirige une saison d’opéras. Du 14 août au 7 septembre, il écrit Giustizo, du 15 sejtembre au 14 aetubre. Arminio. En novembre, il dirige une saison doperas. Du 18 novenobre au 18 janvier 1737, il écrit Berenice. En février-nars, il dirige une double saison d'opéras et d'oratorios.

En avril, il est frappé de paralysie; il semble perdu, pendant tout l'été. Les bains d'Aix-la-Chapelle le guérissent. Il revient à Londres au commencement de novembre 1737.

Le 15 novenibre, il commence Faramondo; le 7 décrmbre, il commence le Funeral Anthem, qu'il fait exéctiter à Westminster, le 17 décembre; le 24 décembre il a terminé Faramondo; le 23 décembre. il commence Serse, qu’il a terminé le 14 fézrier 1738. Le 23 février, il donne la première représentation d'un pasticcio nouveau : Alessandro Severo. - lit, quelques mois plus tard, nous le voyons écrire Saül, du 23 juillet au 27 septembre 1738, commencer Israël en Egypte, le $1^{\text {er }}$ octobre, et le lerminer, le 28 octobre. Dans ce même mois d'octobre, il fait paraitre son premier recueil des Cenctrtos d'orgue, et livre ì l'éditeur le recueil des 7 Trios ou Sonates à deux parties avec basse, op. 5 .

Je répète que cet exemple est celui des deux années oì llandel a élé le pius grivenientinalide, presifue à la mort; et je déíte quou puisse trouver la moindre trace de maladie dans ces ouvres. 
la pièce, et parfois avant que le librettiste eût le temps de l'écrire ${ }^{1}$.

Le besoin de créer était si tyrannique qu'il firit par l'isoler du reste du monde. "Il ne se laissait, dit Hawkins, interrompre par aucune visite futile; et l'impatience d'être délivré des idées qui affluaient constamment à son cerveau le retenait presque toujours enfermé. 》 - Sa tête ne cessait de travailler; et, tout à ce qüil faisait, il ne s'apercerait plus de ce qui l'entourait. Il avait l'habitude de se parler si haut que chacun savait ce qu'il pensait. Et quelle exaltation, quels pleurs, en écrivant! Il sanglotait, en composant lair du Christ : He was despised. - "J'ai entendu raconter, dit Shield, que quand son domestique lui apportait son chocolat, le matin, il restait souvent surpris à le voir pleurer et mouiller de ses larmes le papier sur lequel il écrivait. " - A propos de l'Halleluyah du Messie, il citait lui même les paroles de saint Paul : "Si j'étais dans mon corps, ou hors de mon corps, en l'écrivant, je ne sais pas. Dieu le sait. "

Cette énorme masse de chair était secouée par des accès de fureur. Il jurait presque à chaque phrase. A l'orchestre, « quand on voyait vibrer la grosse perruque blanche, les musiciens tremblaient ". Lorsque ses chœurs étaient distraits, il avait une façon de leur crier : Chorus! d'une voix formidable, qui faisait sursauter le public. Mème aux répétitions de ses oratorios

1. Le poète Rossi dit dans sa préface de Rinal to que Hiendel lui avait donné à peine le temps d'écrire le poème, et que l'ouvrage entier, poème et musique, fut compose en quatorze jours (1711). - Belsazar a été composé, au fur et à misure que Ch. Jennens envoyait à Hændel les actes du poème, trop lentement au gré cu musicien, qui ne cessait de le talonner el qui, en dén de ance, pon occuper le temps, écrivit dans le mème été (17) j sun subline llérahiès. 
chez le prince de Galles, à Carlston House, si le prince et la princesse n'arrivaient pas exactement, il ne prenait aucune peine pour cacher sa colère; et si des dames de la cour avaient le malheur de causer pendant l'exécution, il ne se contentait pas de jurer et de sacrer, mais il les interpellait violemment par leurs noms. - «Chut! chut! - faisait alors la princesse, avec sa bénignité ordinaire, - Handel est méchant. »

Méchant, il ne l'était point. «Ill était rude et péremptoire, dit Burney, mais entièrement dépourvu de malveillance. Il y avait dans ses plus vifs mouvements de colère un tour original qui, joint à son mauvais anglais, les rendait tout à fait plaisants. "Il avait le don du commandement, comme iully et comme Gluck : ainsi qu'eux, il mêlait à une force colérique qui matait les résistances une spirituelle bonhomie qui savait panser les blessures d'amour-propre qu'il avait causées; il se faisait du rire l'arme la plus puissante. « Il était, pendant ses répétitions, un homme autoritaire; mais il avait dans ses remarques, et même dans ses réprimandes, un humour extrêmement comique. ๖ A l'époque où l'Opéra de Londres était un champ de bataille entre les partisans de la Faustina et de la Cuzzoni et où les deux prime donne se prenaieni aux cheveux, en pleine représentation, au milieu des hurlements de la salle, présidée par la princesse de Galles, - une farce de Colley Ciber, qui mettait en scène ce pugilat historique, représentait Hændel, seul conservant son flegme parmi le charivari : « Je suis d'avis, disaitil, qu'or les laisse s'escrimer en paix. Si vous voulez en finir, jetez de l'huile sur le feu. Quand elles seront fatiguées, leur fureur tombera d'elle-même. " Et, pour que la bataille fût plus vite terminée, il l'activait à 
grands coupis de timbale'. - Même lorsqu'il s'emporte, on sent qu'il rit, au fond. Ainsi, quand il empoigne par la taille l'irascible Cuzzoni, qui refusait de chanter un de ses airs, et que, la portant à la fenêtre, il menace de la jeter dans la rue, en disant d'un air goguenard : “ Oh! madame, je sçais bien que vous êtes une véritable Diablesse; mais je vous ferai sçavoir, moi, que je suis Beelzebub, le chef des diables ${ }^{2}$ ».

Il resta, toute sa vie, d'une liberté admirable. Il haïssait toutes chaînes, et demeura en dehors des fonctions officielles : car on ne peut compter pour telle son titre de professeur des princesses; les grands emplois musicaux de la cour et les grasses pensions ne lui furent jamais accordés, même après sa naturalisation anglaise; de médiocres com ositeurs en étaient gratifiés, à ses cótés ${ }^{3}$. Il ne prenait pas soin de les ménager; il parlait de ses collègues anglais avec des sarcasmes méprisants. Peu instruit, semble-t-il, en dehors de

1. The Contre-Temps, or the Rival Queans, joué le 27 juillet 1727, au Drury-Lane.

2. En français dans le texte cité par Mainwaring. - Hændel employait volontiers le français, qu'il savait fort bien, et dont il faisait usage presque exclusivement dans sa correspondance, même avec sa famille.

3. Il était professeur de musique des princesses royales, avec un traitement de 200 livres, - traitement inférieur, comme le montre Chrysander, à celui du maitre de danse, Anthony l'Abbé, qui recevai 240 livres, et qui était toujours nommé le premier sur la liste. Morice Green, organiste de Westminster et docteur en musique, au proft de qui on réunit, en 173 , les deux grandes charges musicales, - la direction de la musique de la cour et la direction de la chapelle royale, jusque-là exercées par John Ecrles et par lo $D^{r}$ Croft, - touchait 100 livres. 
la nusique ${ }^{1}$, il avait le dédain des Académies et des musiciens acadéniques. Il ne fut pas docteur d'Oxford, quoiqu'on lui eût offert ce titre. On lui prète ce mot:

a Comment, diable, il aurait fallu que je dépensasse mon argent, pour être comme ces idiots ${ }^{2}$ ? Jamais de la vie!"

Et, plus tard, a Dublin, quand on I'intitulait sur une affiche : " $D^{\mathrm{r}}$ Handel », il se fâchait, et faisait bien vite rétablir sur les programmes : « $M$. Handel ».

Quoiqu'il fùt loin de faire fi de la gloire, - s'occupant, dans son testament, de son enterrement à Westminster, et fixant avec soin le prix qu'il voulait mettre à son propre monument, - il ne tenait aucun compto de l'opinion des critiques. Jamais Mattheson ne parvint à obtenir de lui les renseignements dont il avait besoin pour écrire sa biographie. Ses façons à la J.-J. Rousseau indignaient les hommes de cour. Les gens du monde, qui ont toujours eu l'habitude d'ennuyer les artistes, sans que ceux-ci protestent, éprouvaient du dépit de la sauvagerie hautaine avec laquelle il les tenait à distance. Dès 1719, le feld-maréchal comte Flemming écrivait à Mlle de Schulenburg, élève de IIændel :

Mademoiselle!... J'ay souhaitté de parler à M. Hændel, et lui ay voulu faire quelques honettetés à votre égard, mais il n'y a pas eu moyen; je me suis servi de votre nom pour le faire venir chez moy, mais tantot il n'estoit pas au logis, tantot il estoit malade; il est un peu fol à ce qu'il me semble, ce que cependant il ne devroit pas être à mon égard, vu que

1. D'après Hawkins, il avait pourtant fait de bonnes études. Son père le destinait à la jurisprudence, et en 1703 flændel était encore inscrit à la faculté de droit de Halle, où il avait pour maitre le célèbre Thomasius. Ce ne fut qu'à dix-huit ans passes qu'il se consacra délnitivement à la musique.

2. Ses confrères, Pepusch et Greene. 
je suis musicien... et que je fais gloire dêtre un des lag fidèles servileurs de vous, Mademoiselle, qui êtes la plus aimable de ses écolières; j'ay voulu vous dire tout ceci, pour quà votre tour vous puissiez donner des leçons à votre maître ${ }^{1}$....

En 1741, une lettre anonyme au London Daily Post ${ }^{2}$ mentionne « le mécontentement déclaré de tant de messieurs de rang et d'influence » contre l'attitude do Hændel à leur égard.

Sauf pour le seul opéra Radamisto, qu'il dédia au roi Georges I er, - et il le fit arec dignité, - il se refusa à l'humiliante et profitable habitude de mettre ses œuvres sous le patronage de quelque personne riche; et il ne se résolut qu'à la dernière extrémité, quand la misère et la maladie l'accablaient, à donner un concert à son bénéfice, - « cette façon, disait-il, de demander l'aumône 》.

Depuis 1720 jusqu'à sa mort en 1759, il se trouva engagé dans une lutte de tous les instants avec le public. Comme Lully, il était à la tête d'un théâtre, il dirigeait une Académie de musique, il tâchait de réformer - ou de former - le goût musical d'une nation. Mais il n'eut jamais les moyens de gouvernement de Lully, qui fut un monarque absolu de la musique française; et, s'il s'appuyait comme lui, sur la faveur du roi, il s'en fallait de beaucoup que cet appui eùt pour lui la même importance que pour Lully. Il était dans un pays qui n'obéissait pas au mot d'ordre venu d'en haut, - un pays qui n'était pas asservi à l'Etat, mais libre, d'humeur frondeuse, et, à part une élite, fort peu hospitalier, ennemi de l'étranger. - Et

1. 6 octobre 1719 , Dresde. - En français dans le texte.

2. 4 avril 1741: - Voir Chrysander. 
l'étranger, c'était lui, aussi bien que son roi hanovrien, dont le patronage le compromettait plus qu'il ne le servait.

Il était entouré d'une presso de boule-dogues aux redoutables crocs, d'hommes de lettres antimusiciens qui eux aussi savaient mordre, de confrères jaloux, de virtuoses orgueilleux, de troupes de comédiens qui se mangeaient les uns les autres, de coteries mondaines, de cabales féminines, de ligues nationalistes. Il était en proie à des embarras financiers, de jour en jour plus inextricables; et sans cesse il lui fallait écrire des pièces nouvelles pour satisfaire la curiosité d'un public que rien ne satisfaisait, qui ne s'intéressait à rien, pour lutter contre la concurrence des arlequinades et des combats d'ours, - écrire, écrire, non pas un opéra par an, comme faisait tranquillement Lully, mais souvent deux ou trois par hiver, sans compter les pièces d'autres compositeurs qu'il lui fallait faire répéter et diriger. - Quel autre génie a jamais fait un pareil métier, vingt ans?

Dans ce combat perpétuel, jamais il n'usa de concessions, de compromis, de ménagements, pas plus avec ses actrices qu'avec leurs protecteurs, les grands seigneurs, les pamphlétaires, et toute la clique qui fait la fortune des théâtres et la gloire ou la ruine des artistes. Il tint tête à l'aristocratie londonienne. La guerre fut âpre, impitoyable, ignoble de la part de ses ennemis. Il ne fut pas de petits moyens dont on n'usât pour l'acculer à la banqueroute.

En 1733, à la suite d'une campagne de presse et do salons, on fit le vide aux concerts où Hændel donnait ses premiers oratorios, et on réussit à les tuer; on se répétait dójà, on exultant, que l'Allemand découragé 
allait repartir pour son pays. - En 1741, la cabale des geas da monde en vint au point de soudoyer de petits voyous, pour aller déchirer dans les rues les affiches des concerts de IIændel; et « elle usait de mille moyens aussi misérables. pour lui causer du dommage ${ }^{1}$ ». Hændel eût très probablement quitté la Grande-Bretagne, sans la sympathie inattendue qu'il trouva en Irlande, où il alla passer un an. - En 1745, après tous ses chefs-d'œuvre, après le Messie, Samson, Delsazar, Héralilès, la cabale se reforma encore, plus violente que jamais. Bolingbroke et Smollet mentionnent l'acharnement de certaines dames à donner des thés, desfêtes, des représentations, - qui n'étaient pas d'usage en carême, - les jours où devaient avoir lieu les concerts de Hændel, afin de lui enlever ses auditeurs. Horace Walpole trouve plaisante la mode qui était d'aller à l'opéra italien, quand Hændel donnait ses séances d'oratorios ${ }^{2}$.

Bref, Hændel fut ruiné; et si plus tard il finit par vaincre, ce fut pour des raisons étrangères à l'art. Il se passa pour lui, en 1746, ce qui se passa pour Beethoven en 1813, après qu'il eut écrit la Bataille de Vittoria et ses chants patriotiques pour l'Allemagne soulevée contre Napoléon : Hændel devint subitement, après la bataille de Culloden et les deux oratorios patriotiques, l'Occasional Oratorio et Judas Macchabée. un barde national. A partir de ce moment, sa cause fut gagnée, et la cabale dut se taire : il était une partie du patrimoine de l'Angleterre; le lion britannique se tenait à ses còtés. Mais si l'Angleterre ne lui a plus marchandé sa gloire depuis lors, elle la lui avait fait chèrement

1. Lelte du 4 avril $17 \$ 1$ au London Daily Post. - 2. Voir Schœlcher.

R. Rolland. .. Voyage mucical. 
acheter ; el con'est jas la faute du public londonien, si Hendel n'est pas nort, au milieu de sa route, de chagrin et de misère. Deux fois il fit haillite ${ }^{1}$; et une fois il fut frappé d'apoplexie, foudroyé sur les iuines de son entreprise ${ }^{2}$. Nais toujours il se releva, et jamais il ne céda. - "Il n'aurait eu besoin pour rélablir sa fortune que de faire des concessions; mais sa nature s'y opposait ${ }^{3} . .$. II répugnait à ce qui pouvait restreindre sa liberté, il était intraitable sur ce qui touchait à l'honneur de son art. Il ne voulait devoir sa fortune qu'à soi-même ${ }^{4}$. »- Un caricaluriste anglais le représente sous le nom de "la Brute enchanteresse », foulant aux pieds une banderolle où est écrit: Pension, Bénfices, Noulesse, Amitié. - Et, devant le désastre, il riait de son rire de Pantagruel cornélien. Se trourant, un soir de concert, en présenco d'une salle vide, il disait: a Ma musique en sonneramieux ».

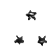

Cette puissante nature, ces riolences, ces emportements de colère et de génie étuient ciominés par une maîtrise souveraine. En lui régrnait cette paix que reflètent en leurs fils certaines unions robustes et tardives ${ }^{5}$. Il garda, toute sa vie, dans son art, cette sérénité profonde. Aux jours où mourut sa mère, qu'il adorait, il écrivait Poro, ce bel opéra insouciant et heureux ${ }^{6}$. La terrible année 1737 , ou il était mourant,

1. En 1730 et en $1743 .-2$. En 1737.

3. Gentleman's Magazine, 1760. - 4. Cove.

5. Le père de hicudel avait suixante-trois ans quand naquit GeorgesFréd’́ric.

o. Vuci les disies lo la nuri et de l'enterrement de sa mère : 
ai fond d'un abime de misire, est encaldé entre toux oratorio:s débordants de joie et le force matérielle, la Féle d'Alexandre (1730) et Saül (1738), de même qu'entre des opéras lumineux Giustino (1736), d'une louceur pastorale, et Serse (1738), où se montre une veine comique.

\section{... La calma del cor, del sen, dell' alma...,}

dit un chant, à la fin du calme Cúustino... C'était lo moment où le cerveau de Mrendel craquait sous les soucis! - Il y a de quoi triompher pour les antipsychologues, qui prétendent que la connaissance de la vio d'un artiste est sans intérêt pour l'intelligence de son œuvre. Mais qu'ils ne se hâtent point : car ceci même est capital pour la compréhension de l'art de Hændel, que cet art ait pu être indépendant de sa vie. Qu'un Beethoven se soulage de ses souffrances et de ses passions dans des cuvres de souffrance et de passion, on le comprend sans peine. Mais que Hændel, malade, assailli d'inquiétudes, se distraye par des œurres d'allégresse ou de sérénité, cela suppose un équilibre d'esprit presque surhumain. Comme il est naturel que Beethoven, aspirant a écrire la Symphonie de la joie, ait été fasciné par Hændel'! Il devait considérer avec des yeux d'envie cet homme qui avait atteint l'état de maitrise

27 décembre 1730 et 2 janvier 1731 . J'en rapproche les dates suivantes, inserit.s par Hændel sur le manuserit de Poro:

- Fini d'écrire le premier acte de Poro : 23 décembre 1730.

Fini d'écrire le second acte : 30 décembre 1730.

Fini d'écrire le troisième acte : 16 janvier 1731 n.

1. Beethoven écrivait, en 1824: "Hændel est le plus grand compositeur qui ait jamais vécu. Je voudrais magenouiller sur sa tombe. " 11 disait de sa musique : "Das ist das Wahre ". (Voici la vérité!) On sait 'quapres la Neuvième Symphonie, il projetait d'écrire de grands oratorius, à la facion de Haudel. 
sur les choses et sur soi, auquel lui-même il aspirait, et où il devait arriver, par un effort d'héroïsme passionné. C'est cet effort que nous admirons : il est sublime, en eflet. Wais la tranquillité arec laquelle Hændel se maintient sur ces sommeis ne l'est-elle pas aussi? On s'est trop habitué à regarder sa sérénité comme l’indifférence flegmatique d'un athlète anglais :

Gorgé jusques aux dents de rouges aloyaux, Hændel éclate en chants robustes et loyaux ${ }^{1}$.

On ne s'est pas douté de la tension de nerfs et de volonté surhumaine qu'il lui a fallu pour défendre ce calme. A certains moments, la machine se détraque. Cette magnifique santé de corps et d'esprit est ébranlée jusque dans ses racines. En l'année 1737, les amis de Hændel crurent que sa raison était perdue pour jamais. Cette crise ne fut pas exceptionnelle dans sa vie. En 17490, lorsque l'hostilité de la société de Londres, s'acharnant contre ses chefs-d'œuvre Belsazar et Héralilès, le ruina pour la seconde fois, de nouveau sa raison fut près de sombrer. Le hasard d'une correspondance récemment publiée vient de nous l'apprendre ${ }^{2}$. La comtesse de Shaftesbury écrit, le 13 mars 1745 :

1. Maurice Bouchor. - La perpétuelle dépense d'énergie, le travail sans relàche, expliquent la voracité maladive de Hændel. Les contemporains ont raillé, de la façon la plus injurieuse, cet ogre qui se commandait des diners pour trois, et qui, lorsqu'on lui demandait où était la compngnie, répondait : "Je suis la compagnie ". Mais il fallait bien que ce monstrueux travailleur réparât ses forces épuisées; et, après tout, il ne semble pas qu'il se soit trouvé mal de ce régime : cétait donc que ce récime lui était nécessaire. Comme le dit Nattheson, " il serait aussi peu à propos de mesurer le manger et le boire de Hxndel sur ceux des hommes ordinaires que si l'on voulait que la table d'un marchand de Londres fùt la mème que celle d'un paysan suisse" .

2. William Barclay-Squire : Handel in 1745 (publié dans le H. RiemannFestschrift, 1909, Leipzig). 
J'allai à la Fête d'Alexandre, avec un plaisir mélancolique. J'eus des larmes de chagrin, à la vue du grand et malheureux Hændel, abattu, hâve, sombre, assis à côté du clavecin dont il ne pouvait pas jouer; j'étais triste, en pensant que sa lumière s'était brûlée au service de la musique.

Le 29 aoùt de la même année, le révérend William Harris écrit à sa femme :

Rencontré Hændel dans la rue. L'ai arrêté, lui ai rappelé qui j'étais. Sur quoi, je suis sûr que cela vous aurait divertie de voir ses gestes bizarres. Il a parlé beaucoup de son état précaire de santé.

Cet état dura sept ou huit mois Le 24 octobre, Shaftesbury écrit à Harris :

Le pauvre Hændel a l'air un peu mieux. J'espère qu'il se rétablira complètement, bien qu'il ait eu la tête tout à fait dérangée.

Il se rétablit complètement, puisqu'en novembre il écrivait son Occasional Oratorio, et bientôt après, son Judas Macchabée. Mais on voit sur quel abìme il était perpétuellement suspendu. C'est par la force des poignets qu'il se tenait, lui, le plus sain des génies, audessus, à deux doigts de la folie. Et, je le répète, ces fissures d'un moment dans l'organisme ne nous ont été révélées que par les hasards d'une correspondance. Il a dû en exister bien d'autres que nous ignorons. Pensons-y, et n'oublions pas que le calme de Hændel recouvre une dépense de passion prodigieuse. Hændel indifférent, flegmatique, c'est la façade. Qui le comprend ainsi ne l'a jamais compris, n’a jamais pénétré cette âme que soulevaient des transports d'enthousiasme, d'orgueil, de fureur et de joie, cette àme, par mononts, oui, presque hallucinée. Hais ha musig̨te 
élait nour lui une région sereine, où il ne voulait point que les troubles de sa vie eussent accès; quand il s'y livre tout entier, c'est malgré lui, emporté par son délire de visionnaire, - ainsi, quand lui apparaît le Dieu de Moïse et des Prophètes dans ses Psaumes et ses oratorios, - ou trahi par son cœur, à des moments de pitié, de compassion, mais sans aucune sensiblerie ${ }^{1}$.

Il était, dans son art, un homme qui regarde sa vie de très loin, de très haut, à la façon de Gœethe. Noire sentimentalité moderne, qui s'étale avec une complaisance indiscrète, est déroutée par cette réserve hautaine. Dans ce royaume de l'art, inaccessible aux hasards capricieux de la vie, il nous semble que règne parfois une lumière trop égale. Ce sont les ChampsElyséens : on s'y repose de la vie; on l'y regrette souvent. Mais n'y a-t-il pas quelque chose d'énouvant dans le spectacle de ce maitre serein au milieu des tristesses, qui reste le front sans rides et le cœur sans soucis?

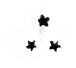

Un tel homme, qui vivait uniquement pour son art, etait mal fait pour plaire aux femmes; et il ne s'en inquièta guère. Elles farent pourtant ses plus cha!lds partisans et ses adrersaires les plus venimeux. Les pamphlets anglais se sont ćgayés d'une de ses adoratrices, qui, sous le pseudonyme d'Ophelia, lui envoya, au temps de son Jules César, une couronne de laurier. avec un poème enthousiaste où elle le représentait

1. Dans le Funeral Anthem, dans le Foundling Anthem, et dans certaines pages des dernières cuvres, de Theodora, de. Jephté. 
comme le plus grand non senlement des musiciens, mais des poètes anglais de son temps. It je faisais allusion tout à l'heure à ces dames da monde qui mettaient un acharnement haineux à le ruiner. Handel passait, indifférent aux unes commo aux autres.

En Italie, quand il avait vingt ans, il eut quelques liaisons passacères, dont la trace survit en plusieurs de ses Cantates italiennes ${ }^{1}$. On parle d'un amour qu'il aurait eu, à Hambourg, alors qu'il était second violon a l'orchestre de l'Opéra. Il s'était épris d'une de ses élèves, une jome fille de bonne famille, et il roulait l'épouser; mais la mère déclara qu'elle ne consentirait jamais àce quesa fille épousât un racleur de violon. Plus tard, la mèro morta, et Hrndel devenu célébre, on lui fit saroir que les obstacles étaient levés; alors, il répondit que le temp̣s était passé; et, raconte soi ami Schmidt, qui se plaît, en Allemand romanesque, à embellir l'histoire, - a la jeune dame tomba dans une langueur qui mit fin à ses jours ». - A Londres, un peu plus tarl, nourean projet de mariage avec une dame de la société élégante : c'était encore une de ses élèves; mais cette aristocratique personne eût voulu qu'il renonçà à sa profession. Hendel, indigné, “brisa des relations qui eussent entravé son génie ${ }^{2}$ ". Hawkins dit : “ Ses sentiments sociables n'étaient pas très forts; et de là vient sans doute qu'il passa toute sa vie dans le célibat: on assure qu'il n'eut aucun commerce arec les femmes ». - Schmidt, qui le connut beaucoup mieux que Hawkins, proteste que Ilændel n'était pas insociable, mais que son furieux

1. Par exemple, dans la cantate, intitulée : Départ de Rome (Part i: a di G. F. Handel, 1708).

2. Voir Chrysauder et, Coxe : Anecdotes of Hændel and Schmint. 
besoin d'indépendance « lui faisait craindre de s'amoindrir, et qu'il avait peur des liens indissolubles ».

A défaut de l'amour, il connut et pratiqua fidèlement l'amitié. Il inspira des affections touchantes, comme celle de ce Schmidt qui abandonna sa patrie et les siens pour le suivre, en 1726, et qui ne se sépara plus de lui, jusqu'à sa mort. Certains de ses amis étaient des esprits lés plus nobles du temps : tel, l'intelligent $\mathrm{D}^{\mathrm{r}}$ Arbuthnot, dont l'épicurisme apparent recouvrait un mépris stoïque des hommes et qui écrivait, dans sa dernière lettre à Swift, ce mot admirable : a Laisser, pour le monde, la voie de la vertu et de l'honneur, le monde n'en vaut pas la peine ». Hændel avait aussi un sentiment profond et pieux de la famille, qui jamais ne s'effaça ${ }^{1}$, et qu'il traduisit en quelques figures émouvantes, comme la bonne mère dans Salomon, et comme Joseph.

Mais le plus beau sentiment, le plus pur qui fùt en lui, a été son ardente charité. Dans un pays qui vit, au xviII ${ }^{\mathrm{e}}$ siècle, un magnifique mouvement de solidarité humaine ${ }^{2}$, il fut un des plus dévoués à la cause des malheureux. Sa générosité ne s'exerça pas seulement à l'égard de tel ou tel, qu'il avait pernomnellement connu, comme il fit pour la veuve de son ancien maitre, Zachow : elle se répandit constamment, abondamment, au profit de toutes les œurres charitables, surtout de deux d'entre elles qui lui tenaient au cœur : l'OEuvre

1. Il eut surtout un grand amour pour une sceur, qui mourut en 1718, et pour sa mère, qui mourut en 1730. Plus tird, sen affection se reporta sur la fille de sa sœur, Johanna-Friderica, née Michaelsen, à qui il légua tous ses biens.

2. Fondations d'hôpitaux et de sociétés de bienfaisance. - Ce mouvemen!, admirable dans toute l'angleterre vers le milieu du xvin ${ }^{e}$ siècle, se fil sentir en irlande avec une ardeur : péciale. 
des Paumres Musiciens, et celle des Enfants assistés. The Society of Husicians avait été fondée en 1738 par un groupe des principaux artistes de Londres, de tous les partis, pour venir en aide aux musiciens sans ressources et à leurs familles. Un musicien âgé recevait par semaine 10 shillings; une veuve de musicien, 7 shillings. On veillait aussi à leur donner une sépulture convenable. Hiendel, si gèné qu'il fùt, se montra plus libéral que les autres. Le 20 mars 1739, il dirigea au bénéfice de la société, tous frais payés, la Fète d'Alexandre, avec un nouveau concerto d'orgue, spécialement écrit pour l'occasion. Le 28 mars 1740 , dans ses plus mauvais jours, il dirigea Acis et Galatée et la petite Ode à sainte Cécile. Le 18 mars 1741, il donna un spectacle de gala, très onéreux pour lui, le Parnasso in Festa, avec décors et costumes, plus cinq concerti soli exécutés par les plus célèbres instrumentistes. Il fit à la société le legs le plus important qu'elle reçùt : 1,000 livres.

Quant au Foundling Hospital, fondé en 1739 par un vieux marin, Thomas Coram, " pour l'assistance et l'éducation des enfants abandonnés », “ on peut dire, écrit Mainwaring, qu'il dut à Hændel son établissement et sa prospérité ${ }^{1}$ ». Hændel écrivit pour lui en 1749 son bel Anthem for the Foundling Hospital. En 1750, il fut élu governor (administrateur) de cel hôpital, après le don qu'il lui avait fait d'un orgue. On sait que son Messie fut exécuté d'abord, et presque uniquement réservé, dans la suite, au bénéfice d'œuvres de charité. La première audition à Dublin, le 12 avril 1742, en fut

1. On trouvera dans le Musical Times du $1^{\text {er }}$ mai 1902 beaucoup de rensrignements et de documents relatifs au Foundling Hospital et à la part que iliendel prit à 'sa direction. 
donnée au profit des paures. Le produit du concert fut intégralement partacé entre la socité des rrisonniers pour dettes, l'Infirmerie des panves ${ }^{1}$, et l'llopital Mercer. Quand le succès du Messie se fut contirmé ia Londres, - non sans peine, - en 1730, Hande! décida d'en donner des auditions annuelles, au bénéfice de l'IIospice des Enfants assistés. Mème devenu aveugle, il continua de diriger ces exécutions. De 1750 à 17399 , date de la mort de Handel, le Uessie rapporta à l'Hospice 6,933 livres sterling. Hendel avait fait défense à son éditeur Walsh de rien publier de l'œuvre, dont la première édition ne parut qu'en 1763 ; et il légua à l'Hospice une copie de la partition, avec toutes les parties. Il en avait donné une autre à la Société des Prisonniers pour dettes de Dublin, " avec permission d'en user, autant qu'elle le voudrait, pour leur service ».

Cet amour pour les pauvres inspira à IIændel certains de ses accents les plus intimes, comme telles pages du Foundling Anthem, pleines d'une bonté touchante, ou comme l'érocation pathétique des orphelins et des enfants délaissés, dont les voix grêles et pures s'élèvent toutes seules, toutes nues, au milieu d'un chœur triomphal du Funeral Anthem, pour attester la bienfaisance de la reine morte.

Un an, presque jour pour jour, avant la mort de IIændel, on relève sur les registres de l'Ilôpital des Enfants assistés le nom d'une petite Maria-Augusta Ilændel, née le 15 avril 1758 . C'était une enfant trouvée, à qui il avait donné son nom.

1. Inflrmerie gratuite, fondée en 1726 par six chirurgiens. 


\section{$* *$}

La charité fut pour lui la vraie foi. Il aimait Dieu dans les paurres.

Pour le reste, il était peu religieux, au sens strict du mot, - sauf à la fin de sa vie, après que la perte de la vue l'eut retranché de la société des hommes et presque totalement isolé. Hawkins le vit alors, dans ses trois dernières années, assidu au service de sa paroisse, - St. George, Hannover Square, - a à genoux, et manifestant par ses gestes et ses attitudes la plus fervente dévotion ". Pendant sa dernière maladie, il disait : ¿ Je voudrais pouvoir expirer le Vendredi Saint, dans l'espoir de joindre mon bon Dieu, mon doux Seigneur et Sauveur, le jour de sa Résurrection ${ }^{1}$ ".

Mais, dans le cours de sa vie et la plénitude de sa force, il ne pratiquait guère. Luthérien de naissance, et répondant ironiquement à Rome, quand on voulait le convertir, qu’ “ il était décidé à mourir dans la communion où il avait été élevé, qu'elle fùt vraie ou fausse ${ }^{2}$, , il n’éprouvait pourtant aucune gêne à se conformer au culte anglais, et il passait pour assez incroyant.

Quelle que fût sa foi, il avait l'âme religieuse, et une haute idée des devoirs moraux de l'art. Après la première exécution du Messie à Londres, il disait à un grand seignneur : « Je serais fâché, milord, si jo faisais plaisir aux hommes; mon but est de les rendre meilleurs ${ }^{3}$ n.

1. Il mourut, le matin du Samedi Saint. - 2. hiainwiring.

3. Cité par Schoelcher. 
Dès son vivant, « son caractère moral était reconnu publiquement $n$, comme Beethoven l'écrivait fièrement de lui-même ${ }^{1}$. Hême à l'époque où il était le plus discuté, de clairvoyants admirateurs avaient senti la valeur morale et sociale de son art. Des vers, publiés en 1743 dans les journaux anglais, vantaient le pouvoir miraculeux qu'avait la musique de Saül d'adoucir la douleur, en glorifiant la douleur. Une lettre du 18 avril 1739 au London Daily Post disait qu' « un peuple qui sentirait la musique d'Israël en Egypte, n'aurait rien à craindre, en quelque temps que ce fût, si toute la puissance d'une invasion se levait contre lui ${ }^{2}$ ").

Aucune musique au monde ne rayonne une telle force de foi. C'est la foi qui soulève les montagnes, et, comme la verge de Moüse, fait jaillir du rocher des âmes endurcies le flot de l'éternité. Telle page d'oratorio, tel cri de résurrection, est un miracle vivant, Lazare qui sort du tombeau. Ainsi, à la fin du second acte de Theodora ${ }^{3}$, l'ordre foudroyant de Dieu qui éclate, au milieu du sommeil lugubre de la mort :

"Lève toi! ") cria Sa voix. - Et le jeune homme se leva.

Ou encore, dans le Funeral Anthem, le cri enivré, presque douloureux de joie, de l'âme immortelle, qui

1. Lettre à la municipalité de Vienne, $1^{\text {er }}$ février 1819.

2. Le texte dit exactement : * Si toute la puissance du papisme se levait contre nous ".

Il semble que Hændel lui-même ait été frappé par ces lignes. Sept ans plus tard, alors que l'Angleterre était envahie par les troupes papistes et que l'armée du prétendant Charles-Edouard s'avançait jusqu'aux portes de Londres, Hændel, écrivant l'Occasional Oralorio, ce grand hymne épique à la patrie menacée et à Dieu qui la défend, reprit pour la troisième partie de l'œuvre les plus belles pages d'Israël.

3. Chwur: all vit le ieune homme gui dormait •. 
se délivre de la dépouille du corps et tend les bras vers Dieu ${ }^{1}$.

Mais rien, pour la grandeur morale, n'approche du chœur qui termine le second acte de Jephié. Rien, mieux que l'histoire de cette œuvre, ne fait pénétrer dans la foi héroïque de Hændel.

Quand il commença de l'écrire, le 21 janvier 1751, il était en pleine santé, malgré ses soixante-six ans. II composa le premier acte, d'un trait, en douze jours. Nulle trace de soucis. Jamais son esprit n'avait été plus libre, et presque indifférent au sujet qu'il traitait ${ }^{2}$. Au cours du second acte, sa vue tout à coup s'obscurcit. L'écriture, si nette au début, se brouille et tremble ${ }^{3}$. La musique prend aussi un caractère douloureux ${ }^{4}$. Il

1. Chœurs : "Mais sa gloire est éternelle ", alternant avec les chœurs funèbres: a Son corps est allé se reposer dans le tombeau •. Le motif en a été emprunté par Hændel à un motet d'un vieux maitre allemand du $\mathrm{xvl}^{\mathrm{e}}$ siècle, son homonyme Handl (Jakobus-Gallus): Ecce quomodo moritur justus. Mais un simple changement rythmique suffit à donner des ailes au vieux choral, en fait un élan d'extase, qui se brise soudain, haletant d'émotion, ne pouvant plus parler. Huit fois, ce cri s'élève au cours du morceau.

2. Plusieurs airs d'Iphis sont bàtis sur des rỵthmes de danse : au premier acte, The smiling dawn, sur un rythme de bourrée; au second acte, Welcome as the cheerful Light, sur un rythme de gavotte.

3 . On peut suivre exactement les progrès du mal sur le manuscrit autographe, dont le fac-simile a été publié par Chrysander dans la grande collection Breitkopf, en 1883 .

4. Le changement de ton commence, dans le second acte, au cri d'horreur que pousse Jephté, en apercevant sa fille venue à sa rencontre. C'est d'abord une suite d'airs douloureux de Jephté, de la mère et du flancé d'Iphis, puis un quatuor, où les parents d'Iphis mêlent leurs gémissements. A ces pleurs répond la voix pure d'Iphis qui les console, en un récitatif qui semble ouvrir le ciel, puis un air très simple, d'une résignation courageuse qui cache la peine, la peur, au fond. L'émotion grandit. Jephté chante un air récitatif, qui fait penser à ceux d'Agamemnon dans Iphigénie en Aulide; à la fin, le récit s'entrecoupe, se ralentit, défaille de douleur et d'horreur; certaines phrases semblent écrites par Beethoven. Enfln s'élève lo chœ'ar, au milieu duque! la maladie foudroya Hændel. 
vebait de commencer le chour final de l'acte 11 : Combien sombres, ô Seigneur, sont tes desseins! A peine avait-il écrit le mouvement initial, un largo aux modulations pathétiques, qu'il dut s'arrêter. Il marque, au bas de la page :

Suis arrivé jusqu'ici, le mercredi 13 février. Empêché de continuer, à cause de mon oil gauche.

Il s'interrompt, dix jours. Le onzième, il marque sur son manuscrit :

Le 23 février, vais un peu mieux. Repris le travail.

Et il met en musique ces paroles, qui contenaient une allusion tragique à son propre malheur :

Notre joie sen va en doulcur... comme le jour disparait dans la nuit.

Péniblement, en cinq jours, - lui à qui cinq jours, nagcuère, suffisaient à écrire un acte entier, - il se traîne jusqu'à la fin de ce sombre chceur, qu'illumine, dans la nuit qui l'enveloppe, une des plus superbes affirmations de la foi sur la douleur. Au sortir de pages mornes et tourmentées, quelques voix (ténor et basse), à l'unisson, murmurent tout bas :

Tout ce qui est...

Elles hésitent un moment, semblent reprendre haleine, puis, toutes les voix ensemble affirment, avec une conviction inébranlable :

... est bien.

L'héroïsme de Hrendel et de sa musique intrépide, qui souffle la vaillance et la foi, se résume en ce cri d'Herculo mourant. 


\section{IV}

LES OFIGINES DU "STYLE CLASSIQUE " DANS LA RUSIQUE DU XVIIO SIECLE

Tout musicien perçoit immédiatement les différences profondes qui séparent du grand style préclassique de J.-S. Bach et de hændel le style dit classique de la fin du xviri ${ }^{\circ}$ siècle. - l’un, avec son ample rhétorique, rigoureusement déduite, sa savante écriture polyphonique, son esprit objectif et général, - l'autre, clair, spontané, mélodique, refiétant les nuances changeantes d'âmes individuelles qui se mettent tout entières dans leurs œuvres, et bientôt en arrivent aux Confessions à la Jean-Jacques de Beethoven et des romantiques. Il semble qu'entre ces deux styles il se soit écoulé plus d'un âg'e d'homme.

Or, qu'on remarque les dates: J.-S. Bach meurt en 17ว̈0, Hærdel en 1739. En 17399, meurt C. H. Graun. En 1739, Haydn donne sa première symphonie. L'Orfeo de Gluck est de 1762; les premières sonates de Phil.-Em. Bach, de 1742. Le génial protagoniste de la Symphonie nouvelle, Johann Stamitz, est mort avant Hændel, en 17ว̆7. Ainsi, les chefs des deux grands courants artistiques ont vécu, côte à côte. Le style de Keiser, 
de Telemann, de Hasse, des symphonistes de Hannheim, qui est la source des grands classiques Viennois, est contemporain des œuvres de J.-S. Bach et de landel. - Bien plus, il avait, de leur virant, la primansí sur eux. Dès 1737 (l'année qui suit la F'ête d'Alexandre do Hændel, et qui précède Saül et la série entière des magnifiques oratorios), Frédéric II de Prusse, alors Kronprinz, écrivait au prince d'Orange :

" Les beaux jours de Hendel sont passés, sa tête est épuisée, et son goût hors de mode. 》

Pt Frédéric II opposait à cet art « démodé 》 celui do «son compositeu" », comme il nomme C.-H. Graun.

En 1722-3, quand J.-S. Bach se présentait pour la succession de Kuhnau au Kantorat de Saint-Thomas à Leipzig, on lui préférait de beaucoup Telemann; et ce ne fut que parce que Telemann ne voulut pas de la place, qu'elle fut donnée à J.-S. Bach. Le même Telemann, dès le début de sa carrière, en 1704, encore à peine connu, tenait en échec le glorieux Kuhnau : tant était déjà fort le courant de la mode nouvelle. Ce courant ne fit que s'affirmer, par la suite. Un poème de Zachariä, qui reflète assez exactement l'opinion des cercles les plus cultivés de l'Allemagne, le T'emple de l'Éternité, écrit en 175\%, met sur la même ligne Hændel, Hasse et Graun, célèbre Telemann dans les termes qu'on emploierait aujourd'hui pour parler de J.-S. Bach ${ }^{\text {, }}$ et, quand il arrive à J.-S. Bach et à « ses fils mélodieux»,

1. a... Mais qui est ce vicillard, qui de sa plume légère, plein d'ane ardìtr sacrée, enciante le Temrile Eternel? Ecoutez! Comme bruissent les vagues de la mer! Comme les montagnes poussent des cris d'allégresse et des hymnes an Seigneur! Comme un harmonieux Amen remplit d'un saint effroi l'âme pieuse! Comme tremblent les temples du fracas religieux de l'Alleluyal Telemann, c'est toi, toi, le pere de la sainte musique.... • 
il ne trouve plus à glorifier en eux que les rirtuoses, rois de l'orgue et du clavier. Ce jugement est encore celui de l'historien Burney, en 1772. - Et certes, il est fait pour nous surprendre. Mais nous derons nous garder des indignations faciles. Il y a peu de mérile, du haut des deux siècles qui nous séparent, à laisser tomber un mépris écrasant sur les contemporains de J.-\$. Bach et de Hændel, qui les ont mal jugés. Il est plus instructif de tâcher de les comprendre.

Et d'abord, observons l'attitude de J.-S. Bach et do IIændel, à l'égard de leur temps. Ni l'un ni l'autre n'affecte la pose fatale d'un gé.. incompris, commo tant de nos grands ou petits granu: nommes d'aujourd'hui. Ils ne s'indignent point. Et même, ils sont en fort bons termes avec leurs rivaux plus heureux. J.-S. Bach et Hasse étaient excellents amis, pleins d'estime l'un pour l'autre. Telemann avait noué, dés l'enfance, une amitié cordiale avec Hændel; il entretenait de bonnes relations avec J.-S. Bach, qui le choisit pour parrain de son fils Philipp Emanuel. J.-S. Bach confia l'éducation musicale d'un autre de ses fils, son préféré, Wilhelm Friedemann, à J. Gottlieb Graun. Rien d'un esprit de parti. Des deux côtés, des hommes supérieurs qui s'estiment et qui s'aiment.

Essayons d'apporter à leur étude le mème généreux esprit d'équité et de sympathie. J.-\$. Bach et Hiendel n'y perdront rien de leur grandeur colossale. Mais nous aurons la surprise de trourer autour d'eux une quantité de belles ceurres, d'artistes pleins d'intelligence et de génie; et il ne nous sera pas impossible de comprendre les raisons des préférences des contemporains. Sans parler de la valeur individuelle de ces artistes qui est souvent très grande, c'est lenr esprit

R. Rolland. - Voyagre musical 
qui more aux chefollenve clansiques de la fin du xrme ricele.J.-s. Batch et illandel sont lenx montagnes, qui dominent, mais qui ferment une proque. Telemann, Passe, Jommelli, et les symphonistes de Mannheim sont les rivières qui so sont frayé un chemin vers l'arenir. Comme ces rivières se sont jetés dans re plus grants fleuves, - Mozirt, beethoren, - qui les ont absorbées, nous les avons oubliées, tandis que nous voyous toujours an loin les gankes cimes. Mais il nous faut être reconnaissants envers les novateuis. La vie était arec eux; et ils nous l'ont transmise.

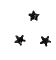

On connait la fameuse Querelle des Anciens et des Modernes, inauguréo en France, vers la fin du xvir ${ }^{e}$ siècle, par Charles Perrault et Fontenelle, qui opposaient à l'imitation de l'antiquité l'idée cartésienne du progrès, - et reprise. une vingtaine d'années plus tard, par Houdar de la Motte, au nom de la raison et du goût modernes.

Cette querelle dépassait la personnalité de ceux qui la lancèrent. Eile répondait à un mouvement unicersel dans la pensée européenne; et l'on trouve dans tous les grands pays de l'Occident, dans tous les arts, des symptômes analogues. Ils sont frappants dans la musique allemande. La génération des Keiser, des Telemann, des Mattheson, dès l'enfance, éprouve une aversion instinctive pour ceux qui représentent l'antiquité en musique, pour les contrapontistes, les canonistes. A l'origine du mourement est Keiser, dont l'influence arlistique fut profonde et décisive sur Hasse, Graun, 
Mattheson ${ }^{1}$ (aussi bien que, d'ailleurs, sur Iæxndel). Mais le premier qui manifesta ces sentiments d'une façon nette. insistante et répétée, fut Telemann.

Dès 1704, en face du vieux musicologue Printz, il prend l'attitude de Démocrite, opposé à lléraclite :

"Il pleurait amèrement sur les extravagances des mélodistes d'aujourdhui. Et moi, je riais des ouvrages non mélodiques des vieu.x. »

En 1718, il cite pour son compte ces vers français :

"Ne les élève pas (les anciens) dans un ouvrage saint A u rang où dans ce temps les auteurs ont atteint. ))

C'est une franche déclaration pour les modernes, contre les anciens. Et qu'est-ce donc que les modernes, pour lui? Les modernes, ce sont les mélodistes.

" Singen ist das Fundament zur. Music in allen Dingen. Wer die Composition ergreifft, muss in seinen Sätzen singen. ")

( Le chant est le fondement de la musique tout entière. Qui compose doit chanter dans tout ce qu'il écrit. ")

Telemann ajoute qu'un jeune artiste doit se mettre à l'école des mélodistes italiens et jeunes-allemands, non à celle « des vieux, qui contrepointent à tire larigo, mais qui sont dénués d'invention, et qui écrivent à quinze et vingt voix obligées, ou Diogène lui-même avec sa lanterne ne trouverait pas une goutte de mélodie ».

Le plus grand théoricien musical de l'époque, Mattheson, ne parlait pas autrement. Dans sa Critica. Musica

1. Graun se nourrit, à Dresde, des partitions de Keiser. Hasse professait encore, en 1772, son admiration sans bornes pour ce musicien, - un des pius grands, disait-il, que le monde ait jamais possédés n. Quant à Naltheson, il fut, en beaucoup de choses, le porte-parile de keiser. 
de 1722 , il se vantait « d'avoir été sans vanité ${ }^{1}$ le premier à insister énergiquement et expressément sur l'importance de la mélodie »....A Arant lui, dit-il, il n'y arait pas un auteur musical, " qui ne sautât par-dessus celte première, plus excellente, et plus belle partie de la musique, comme un coq jar-dessus des charbons ardents

S’il ne fut pas le premier, comme il le prétendait, il fit du moins le plus de bruit. En 1713, il engagea une lutte violente en l'honneur de la mélodie contre les Nontrapunlitisten, que représentait un organiste de Wolfenbüttel, Bokemeyer, savant et combatif comme lui. Nattheson ne voyait dans le canon et le contrepoint qu'un exercice intellectuel, sans prise sur le cœur. Pour amener son adversaire à résipiscence, il prit pour arbitres Keiser, Heinichen, et Telemann, qui se prononcèrent pour lui. Bokemeyer se déclara battu, et remercia Mattheson de l'avoir converti à la mélodie, " comme à l'unique et vraie source de la musique pure", (als der einzigen und wahren Quelle echt musilialiscter Kunst ${ }^{2}$ ).

\section{Telemann disait :}

"Wer auf Instrumenten spielt muss des Singens liündig seyn. (Qui joue des instruments, doit ètre instruit du chant). "

\section{Et Mattheson :}

"Quelque morceau qu'on écrive, rocal ou insirumental, tout doit etre cantabile. »

1. Il en avait beaucoup, au contraire : car on a vu par les cilations ci-dessus de Telemann et par l'exemple de Ketiser, qu'il ne mainuait pas de devanciers.

2. Pokemeyer fut si convainen qu'il écrivit un petit traité de la

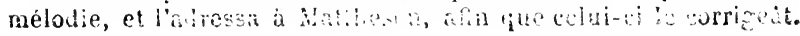


Cette importance prédominante donnée à la mélodie cantabile, au chant, faisait tomber les barrières entre les divers genres de musique, en leur donnant à tous pour modẻle le genre où s'épanouissait dans sa perfection la mélodie rocale et l'art du chant : l'opéra italien. Les oratorios de Telemann, de Hasse et de Graun, les messes de l'époque, sont en style d'opéra ${ }^{1}$. Dans son Musikalische Patriot de 1728, Nattheson rompt des lances contre le style contrapontique à l'église; là comme ailleurs, il veut établir "le style théctral ", parce que ce style permet, selon lui, d'atteindre mieux que tout autre le but de la musique religieuse, qui est “ d'exciter les passions vertueuses ». Tout est, ou doit être, dit-il, théatral, au sens le plus vaste du mot theatralisch, qui signifie: imitation artistique de la nature. " Tout ce qui agit sur les hommes est théatral... La musique est théatrale.... Le monde entier est un théatre géant. » - Ce style théâtral pénétrera la musique entière,

1. Hændel et J.-S. Bach eux-mêmes ne sont pas restés indemnes de a contagion, Non seulement Hændel a écrit 40 opéras, mais ses oratorios, ses Psaumes, ses Te Deum ahondent en éléments dramatiques. Quant à J.-S. Bach, il est caractéristique qu'il ait pris poùr librettiste de ses premières cantates Erdmann Neumeister, qui écrivait qu'une cantate "n'est autre chose qu'un morceall d'opéra n, et qui introduisit en Allemagne la cantate religieuse en style d'opéra. En prenant parti pour ce genre de cantates dramatiques, avec récitatifs et airs, Bach choquait bien des gens. Les piétistes de Mühlhausen, où il était maitre de chapelle en 1708 , le forcèrent à démissionner, indignés par ses cantates trop frivoles, par son style de concert ou d'opéra à l'église. On retrouve des réminiscences des opéras de Keiser dans ses plus cilèbres cantates. Est-il besoin de rappeler aussi ses cantates profanes, les unes mythologiques, les autres réalistes et bouffes, et le réemploi qu'il fit de fragments considérables de ces compositions dans ses ourres religieuses? Il ne voyait donc pas toujours de limite tranchée entre le style profane et le style religieux. - Mais J.-S. Bach et flændel étaient protégés contre l'excès du style d'opéra par leur génie choral et contrapontique, qui saccordait mal avec l'opéra d'alors. 
même dans ses provinces qui semblent le plus à l'a!ıri, le lied, la musique instrumentale.

Mais ce changement de style ne marquerait pas un progrès vivant, si l'opéra lui-même, qui était le modèle commun, n’avait été transformé, à la même époque, par l'introduction d'un élément nouveau qui allait se développer avec une rapidité inattendue : l'élément symphonique. Ce qui est perdu, du côté de la polyphonie vocale, se retrouve du còté de la symphonie instrumentale. La grande conquête de Telemann, de Hasse, de Graun, de Jommelli, dans l'opéra, c'est le recitativo accompagnato, les scènes récitatives avec orchestre dramatique ${ }^{1}$. C'est par là qu'ils seront des révolutionnaires, au théâtre de musique. Une fois l'orchestre introduit dans le drame, il sera maître de la place. En vain criera-t-on qu'ils ruinent le beau chant. Eux, qui le soutenaient contre l'ancien art contrapontique, ne craignent pas de le sacrifier, au besoin, à l'orchestre. Jommelli, si respectueux de Métastase pour tout le reste, lui tiendra tête sur ce senl point, avec une obstination inébranlable ${ }^{2}$. - Il faut lire les doléances des vieux musiciens :

1. Je ne veux point dire qu'ils en furent les inventelrs. L'Accompagnato remonte aux premiers temps de l'opéra vénitien, et est pratiqué par Lully, dans ses dernières œurres. Mais, à partir de Leonardo Vinci et de llasse (aux environs de 1725-30), ces grands monologues dramatiques, récités avec orchestre, se développèrent d'une façon magnifique.

2. Non pas que llétastase fût ennemi du recitativo stromentale. Il était un trop parfait poète-musicien pour ne pas en sentir l'effet dramatique. II reconnalt clairement, dans certains de ses écrits, le pouvoir qu'it Vorchestre de traduire la tragédie intérieure. Mais ce pouvoir même lui 
“ On n'entend plus la roix, l'orchestre est assourdissant.

Dés 170, aux représentations doperas, on no pourait plus comprendre les paroles des chanteurs, si l'on ne suivait sur le librelto: l'accompagnement étouffait les voix. ${ }^{1}$ Et l'orchestre dramatique ne cessa de se développer, au cours du siècle. "L'immotération de l'accompagrement instrumental, dira Gerber, est deverue une mode générale. "

L’orchestre déborde si bien le théàtre que, de très bonne heure, il s'âlranchit et prétend être lui-même thêâtre et drame. Dès 1738. Scheibe, le plus intelligent des musicologues allemands arec Mattheson, écrivait des symphonies-ourertures, qui exprimaient « le contenu des pièces", ¿t la foçon des ouverlures de Beethoven pour Coriolan, ou pour Léonore ${ }^{2}$. Je ne parle pas des descriptions en musigue, qui foisonnaient en Allemagne, vers 1720, comme on le voit par les railleries de Hattheson dans sa Critica Musica. Le mouvement venait d'Italie, où Vivildi et Locatclli, sous l'intuence de l'opéra, écrivaient des concertos à programme, qui so répandirent dans l'Europe entière ${ }^{3}$. Puis, ce fut la

semblait inquiétant. La tragédie intérieure menaçait de déhorder sur laction; la poésie éliat en danzer d’ùre novée par la musirque; et Mètastase, qui avait un sens si fin de légnilibre de lous les éléments théatraux, devait tenir la main à ce que fùt strictement limitée dans chaque acte la part de recirativo con stromenti.

1. Yoir Lotenz Hizler : Huical bibl. 1740, Leipzig. t. II, p. 13, citć par W. Kleefeld : Das Orchester der detitschen Oper, 18:8. Voir aussi Maltheson : Die neueste Untersuchuny der Singspiele, 1744, Hambourg.

2. Les ouvertures de Scheibe pour Polyeuctes ein inartyrer et pour Mithridates. Christ. Heinr. Sihmid, dans sa Chronologie des deutschen Theaters, 175̈, Leipzig, nomme cet essai "une grande chose mémorritle de l'année ". Voir Carl Menvitke : Hasse und die Brüder Gruun als Symphoniker, 1906, Leipzig.

3. Tels les quatre concertos de Vivaldi, cunsacrés aux quatre saisons, ou les concertos la Tumicsla, la Nolle, etc. Chacun des concertos des 
musique française, "saltile imitatrice de la naiure" ". dont linfluence fut própondírante sur le développement de la Tonmalerei (peinture en musique) dans l'art allemand ${ }^{2}$. - Hais ce que je tions à noter, c'est que même los adversaires de la musique à programme, ceux qui comme Watheson raillaient l'extravagance des descriptions de batailles, de tempêtes, des calendriers musicaux ${ }^{3}$, des symbolismes pućrils qui représentaient en contrepoint le premier chapitre de saint Mathieu, l'arbre généalogique du Sauveur, ou qui, pour exprimer les douze apôtres du Christ, écrivaient douze parties, ceux-là même attribuaient à la musique instrumentale le pouvoir de traduiro la vie de l'âme.

" On peut très bien représenter avec de simples instruments, dit Hattheson, la grandeur d'âme, l'amour, la jalousie, etc. On peut rendre toules les inclinations áu cour par de simples accords et leur enchainement sans

Saisons illustre un promramme que lui trace un sonnet. Je renvoie à lanalyse du charmant concerto d'Aatomne, par II. Arnold Schering (Geschichte des Instrumentalkonzerts, 190:3, Breitkopf). 11. Schering a montré l'influence de ces œuvres sur Graupner à Darmstadt, et sur Jos. Gregorius Werner, prédécesseur de llaydn à la direction de la chapelle du prince Esterhazy.

1. Le mot est de Telemann, en 1742 .

Sur les theoriciens français de "l'imitation "en musique, voir la thèse de J. Ecorcheville : De Lulli à Rameau, l'Esthétique musicale de $1, j 00$ à 1730 .

2. Aucun des critiques allemands, qui relèvent, soit pour la louer, soit pour la blâmer, la passion de Telemann pour les peintures musicales, ne manque d'en altribuer la cause à l'influence française. Et Telemann revendiquait l'honneur de s'être fait en ceci le disciple de la France.

3. Exemple : un Instrumental-Kalender en douze mois, par Jos.-Gregorius Werner. Tout est traduit en musique, jusqu’a la longueur des jours et des nuits, qui, étant en février de dix et de quatorze heures, s'exprime par des reprises de Nenuets en dix et quatorze mesures. - A. Schering se demande si Haydn ne s'est pas sonvenu de son prédécesseur dans ses symphonies de jeunesse : Le soi, Le matin, ete. 
paroles, en sorte que l'auditeur saisisse et compremne lo marche, le sens, la pensée du discours musical, comme si c'était un véritable discours parlé.'."

Un peu plus tard, vers 1767, dans une lettre à Philipp-Emmanuel Bach, le poète Gerstenberg de Copenhague exprimait, avec une netteté parfaite, l'idée que la vraie musique instrumentale, et en particulier la musique pour clarier, devait exprimer des sentiments et des sujets précis; et il espérait que Philipp Emmanuel, qu'il nommait "un Raphaèl en musique », (ein Rafiael durch Töne), réaliserait cet art ${ }^{2}$.

On était donc arrivé à ! n ennscience claire du pouvoir expressif et descriptif de la musique pure; et l'on peut dire que certains compositeurs allemands de cetle époque en furent enivrés, comme Telemann, chez qui la Tonmalerei, la peinture en musique, prend la première place.

Mais ce qu'il faut bien voir, c'est qu'il ne s'agissait pas seulement d'un mouvement littéraire, qui voulait introduire dans la musique des éléments extramusicaux, en faire une peinture ou une poésie. C'était une révolution profonde qui s'accomplissait au cœur de la musique. L'âme individuelle s'émancipe de l'impersonnalité de la forme. L'élément subjectif, la personnalité de l'artiste, $y$ fait irruption avec une audace toute nouvelle. - Certes, nous reconnaissons la personnalité de J.-S. Bach et de Hændel dans leurs puissantes nuvres. Mais nous savons avec quelle rigueur ces œuvres se développent, suivant des lois très strictes.

1. Die Neueste Untersuchung der Singspiele, 1744. - Mattheson suit ici les traditions de Keiser.

2. O. Fischer : Zum musikulischen Standpunkte des Nordischen Dichterkreis'z, (Saninelb̈ude der I. M. G. janvier-mars 1004). 
qui non seulement ne sont pas celles de l'emolion, mais qui manifestement l'évitent ou la contredisent de parti pris, - que ce soit une fugue, ou une Aria da capo, qui font inévitablement revenir les motifs à dus moments et à des places prévues d'arance, alors que l'émotion commanderait de poursuivre, et non de revenir sur ses pas, - qui, d'autre part, ont peur des fluctuations de sentiments, et n'y consentent qu'à condition qu'elles se présentent sous des aspects symétriques, des oppositions un peu raides et mécaniques entre le $f$. et le $p$. entre le tutti et le concertino, des Échos, comme on disait alors. Il semblait qu'il ne fut pas artistique de livrer d'une façon immédiate son sentiment individuel, et qu'il fallut interposer entre soi et le public le voile de belles formes impersonnelles. Sans doute, les œuvres de cette époque y gagnaient leur superbe apparence de sérénité hautaine, qui recouvre les petites joies et les petites douleurs. Mais combien elles y perlent d'humanité! Cette humanité fait entendre son cri d'émancipation ea musique, avec les artistes de la nourelle époque. Éridemment, nous ne pouvons nous attendre à ce que, du premier coup, elle atteigne à la liberté frémissante d'un Beethoven. Et pourtant. les racines de l'art d'un Beetho-

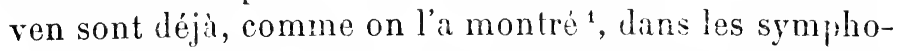
nies de Mannheim, dans l'œuvre de cet étonnant Johana Stamitz, tont les trios d'orchestre, écrits aux environs de 1750 , marquent un âge nouveau. Par lui, la musique instrumentale se faic le souple vêtement do l'âme vivante, toujours en mouvement, perpétuelic-

1. Voir surtout les travaux du grand musicolozue, à qui revient l'honneur d'avoir remis en lumière Stanitz et son école. flugo Riemain. dans ses éditions des Sinfonien der Pfalzbayerischen Sichute, et daus vis articles : Deithoven und die Mannheiner (Die Husik, i207 8). 
ment chan reante, avec ses fluctuations et ses contrastej inaitendus.

Je ne roudrais pas exagérer. Cen'est jamais l'émotion toute puru qu'on peut exprimer en art, ce n'en est qu'une image plus ou moins approchante; et le progrès d'une langue, comme la musique, est seulement d'en approcher de plus en plus, sans y atteindre jamais. Je ne prétends donc point - (ce qui serait absurde) - que les noureaux symphonistes aient brisé les calres et délivré la pensée de l'esclavage des formes; ils ont au contraire établi des formes nouvelles; et c'est à cette époque que se sont décidément imposés les types classiques de la Sonate et de la Symphonie, tels qu'on les explique aujourd'hui dans les écoles de musique. Mais si ces types ont pu devenir pour nous surannés, si le sentiment d'aujourd'hui s'y trouve à la gêne et passablement étriqué, s’ils ont pris à la longue un air de convention scolastique, - il faut penser combien ils apparaissaient alors libres et vivants, par comparaison avec les formes et le style usilés. Et d'ailleurs, on peut dire que pour les inventeurs de ces formes nouvelles, ou pour ceux qui, les premiers, en firent emploi, elles semblaient beaucoup plus libres que pour ceux qui suivirent. Elles n'étaient pas encore devenues des formes générales, elles étaient la forme personnelle de leurs créateurs, modelée suivant les lois de leur propre pensée, sur le rythme de leur respiration. Je ne crains pas de dire que la Symphonie d'un J. Stamitz, moins belle, moins riche, moins abondante, est beaucoup plus spontanée que celle d'un Haydn, ou d'un Mozart. Elle est faite à sa mesure. Il crée ses formes, il ne les subit pas.

Quels êtres prime-sautiers, ces premiers symphonistes de Mannheim! Is osent, à l'indignation des vieux 
Inusicins et sutout des pontifes de l'Allemagne du rord, briser l'unité esthétique, mélanger les styles, fire entrer dans leur ouvere, comme dit un critique, " le loiteux, le non-mélodique. le bas, le burlesque, le dimembré, tous les accès fiévreux de l'allernalive contimuclle du piano et du forte ${ }^{1}$ ». Ils profitent de toutes les conquêtes récentes, des proģrès de l'orchestre, des recherches hamoniques audacieuses d'un Telemann répondant aux vieux maîtres effarouchés qui lui disent: "Il ne faut pas aller trop loin. - Jusqu'au fin fond (den untersten Grund), si l'on veut mériter le nom de maitre ${ }^{2}$ ') Ils profitent aussi des genres nouveaux, du Singspiel qui vient de naitre. Ils font entrer hardiment le style bouffe dans la symphonie, côte à côte avec le style sérieux, au risque de scandaliser Philipp-Emmanuel Bach, qui voit dans l'irruption du style comique (Styl so beliebte liomische) un principe de décadence de la musique ${ }^{3}$, — décadence qui devait conduire à Mozart! - Bref, leur loi, c'est le naturel et la vie, - cette même loi qui va pénétrer la musique tout entière, qui renouvelle le lied, qui fait naître le Singspiel, qui conduira à ces essais de liberté extrême du théâtre musical, qui se nomment le mélodrame, la musique libre unie à la parole libre.

Ce grand souffle de libération de l'âme individuelle, nous le reconnaissons : il a remué la pensée de touto l'Europe du second tiers du $x I_{I}{ }^{e}$ siècle, arant de s'exprimer, en fait par la Révolution française, en art par le Romantisme. Si la musique allemande d'alors

1. Allg. deutsche Bibliothek, 1791 (cité par M. Mennicke, Hasse und die Brüder Graun).

2. Lettre de Telemann, à G.-H. Graun, 15 déc. 1751.

3. Autobiographie, citée par Nohl : Musiker Briefe, 1867, et pas c. Mennicke. 
reste fort loin encore de l'esprit romantique - (hirn qu'on en trouve déjà des signes avant-coureurs), - - rant qu'elle fut garantie des excès de l'indivilualisme artistique par deux sentiments profonds : la conscience ciu devoir social de l'art, et un patriotisme passionné.

On sait combien le sentiment germanirue était décku dans la musique allemande, à la tin du xvit siècle. U: avait d'elle, à l'étranger, l’idée la plus dédainnenses. Qui ne connaît le mot de Lecerf de la Yiéville, en 170.3, mentionnant les Allemands, "dont la réputation n's: pas grande en musique », - ou celui de l'abbé de Châteauneuf, admirant d'autant plus un virtuose allemand qu'il venait, disait-il, « d'un pays peu sujet à produire des hommes de feu et de génie »? - Les Alle. mands souscrivaient à cet arrêt; et tandis que leui's princes et leurs riches bourgeois passaient le temps à voyager en Italie ou en France, à singer les manières de Paris ou de Venise, l'Allemagne était pleine de musiciens français ou italiens qui y faisaient la loi, y imposaient leur style, et avaient toutes les faveurs. J'ai résumé plus haut un roman de J. Kuhnau : le Charlatan musical, paru en 1700, dont le héros comique est un aventurier Allemand qui se fait passer pour Italien, afin d'exploiter le snobisme de ses compatriotes. C'est le type des Alemands d'alors, qui reniaient leur nationalité, pour participer à la gloire des Velches.

Dans les vingt premières années du xvirle siècle, se fait déjà sentir un changement dans les esprits. La génération musicale qui entoure Hændel, à Ilambourg, - Keiser, Telemban, Mabiosm, - no ra pas cin 
Italie; elle y met son orgueil, elle commence à se rendre compte de sa force. Hæñdel lui-même se refusait d'abord à faire le pèlerinage italien; au temps où il écrivait son Aimira, à Hambourg, il affectait un grand dédain pour la musique d'Ilalie. La ruine de l'opéra de Hambourg l'obligea cependant à faire le voyage classique; et une fois qu'il fut là-bas, il subit le charme de la Circé latine, comme tous ceux qui l'ont une fois connue. Toutefois, il lui prit le meilleur de son génie, sans altérer son génie propre; et sa victoire en Italie, le triomphe de son Agrippina à Venise, en 1708, eut un effet considérable pour le relèvement de l'orgueil national; l'écho en fut immédiat en Allemagne. Encore plus, le succès de son Rinaldo à Londres, en 1711. Qu'on y songe : voilà un Allemand du Nord, qui, de l'aveu de l'Europe, avait vaincu les Italiens sur leur propre terrain! Les Italiens eux-mêmes l'avouaient. Se: partitions italiennes de Londres étaient jouées aussitôt en Italie. Le poète Barthold Feind, en 1715, apprend à ses compatriotes de Hambourg que Hændel était appelé par les Italiens " l'Orfeo del nostro secolo ».... " Rare honneur, ajoute-t-il, car aucun Allemandn'estainsitraití par un Italien ou un Francais, ces messieurs ayant l'habitude de se moquer de nous."

Aussi, avec quelle rapidité et quelle violence le sentiment national va-t-il se réveiller en musique, dans les années suivantes! - En 1728, le Musikalische Patriot de Mattheson crie : "Fuori Barlari!"

"Qu'on interdise le métier aux Velches qui nous enveloppent, de l'est à l'ouesl, et qu'on les renvoie, pardessus leurs Alpes sauvages, se purifier dans le fourncau ae l'E'na! D 
En 1729, Martin-lleinrich Fuhrmann lance de furieux pamphlets contre l'Opern-Quarli italien.

Surtout, Joh.-Adolf Scheibe relève inlassablement la fierté nationale. En 1737-40, dans son Critische. Husicus. En 174\%, il dit que Bach. Imndel, Telemann, llasse et Graun, " poutr la gloire de nolre patrie font lionte (beschämen) à tous les auties crmpositeurs étrangers, qucls qu'ils soient... Nous ne snmmes ylus d's imitateurs des Italiens, ajoute-t-il; bien plulút pouvons-nous nous vanter que les Italiens sont enfin dovenus les imitalenrs des Allemands.... Oui, hous arons enfin trouvé le bon goît en musique, dont l'italie ne nous a "ait jamais encore offert le modele parfait... Le bon gatit en musinue (d'un liasse, d'un Gram est le propre de l'esprit allemand (deutschen Witzos); aucune autre nation ne peut s'enorgueillir de ceite supériorite. D'ailleurs, les Allemands sont depuis longtomys de grands maitres dans la musique instrumentale; et ils ont conservé cette maitrise."

De mème parlent Wizler et Warpury. Et les Italiens s'inclinent derant ces arrêts. Antonio Lotti écrit à Mizler, en 1738:

" Miei compatrioti sono genii e non compositori, ma la vera composizione si trova in Germania'."

On voit le changement de front qui s'est produit en musique. D’abord, la période des grands Italiens trionphants en Allemagne; - puis celle des grands Allemands italianisés : Hændel, Hasse. - Et maintenant, voici le temps des Italiens germanisés : Jommelli.

lième en France, où l'on restait beaucoup plus cantonné chez soi, sans s'occuper de ce qui se passait en

1. Carl Mennicke inscrit cetle phrase de Lotti en tête de son ouvrage

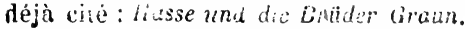


Allemagne, on se rend compte de la rérolution qui s’opère. Dès 1734, Séré de Rieux a enregistréla victoire de Hændel sur l'Italie :

Flavius, Tamerlan, Othon, Renaud, César, Admete, Siroé, lodelinde, et Richard, Eternels monumens dressés à sa mémoire, Des Opéra Romains surpassèrent la gloire. Venise lui peut-elle opposer un rival? ${ }^{1}$

Grimm, qui était un snob et se fùt bien gardé d'afficher une parenté qui lui aurait nui dans l'opinion, se fait gloire, dans une lettre de 1752 à l'abbé Raynal, d'être le compatriote de Hasse et de Hindel. Telemann est fêté à Paris, en 1737. Hasse n'est pas moins bien reçu, en 1750 , et le Dauphin le charge d'écrire le T'e Deum pour l'accouchement de la Dauphine. J. Stamiz fait triompher à Paris ses premières symphonies, vers 1754-5. Et bientôt, les journaux français écraseront Rameau sous la comparaison des symphonistes allemands. Ou plutôt, comme ils disent: « Nous n'aurons pas l'injustice de comparer les ouvertures de Rameau avec les symphonies que l'Allemagne nous a données depuis douze ou quinze ans ${ }^{2}$...

La musique allemande a done reconquis sa place, a la tête de l'art européen; et les Allemands le savent. Dans ce sentiment national, tous les autres différends s'effacent, tous les artistes allemands, à quelque groupe qu'ils appartiennent, se donnent la main; l'Allemagne les unit, sans distinction d'écoles. La poésie de Zachariä, que je citais tout à l'heure, nous montre, vers lo

1. Epitre sur la Musique, trnisione hant.

2. Niercure de Frurice, arril 1772. 
milieu du siecle, les chefs de la nowvelle école et les chefs de l'ancienne groupés, pour la gloire de l'Allemagne, dans ce qu'il appelle le Temple de l'Éternité.

«... Avec un joyeux ravissement, la Muse de l'Aliemagne voit des cohortes d'artistes, et elle benit leurs noms, trop nombreux pour pouvoir tenir tous dans les bornes de cet étroit poème, mais que la renommée grave en lettres immortelles sur les piliers du Temple de l'Eternité.... O Muse de l'Allemagne, revendinue l'honneur davoir ceint tes tempes du laurier musical! Tu nossèdes une multitude de maitres, plus nombreux el plus grands que la France et le Welschland.... .

Le classement de ces maîtres par Zachariä est bien différent de celui que nous faisons aujourdhui. Mas ils sont presque tous la; et de l'ensemble de leurs gloires se dégage une fierté enivrée de la puissance musicale de l'Allemagne.

Ce n'est pas seulement l'orgueil des artistes qui est exalté, c'est leur patriotisme. On écrit des opéras patriotiques ${ }^{1}$. Nême dans les cours où règne l'italianisme musical, comme celle de Frédéric II à Berlin, on voit C.-H. Graun chanter les batailles de Frédéric : Hochkirchen, Rossbach, Zorndorf, soit en sonates, snit en scènes dramatiques ${ }^{2}$. Gluck écrit son Vaterlandslied

1. Le plus célèbre est le Günther von Schwarzburg de Ignaz Holzbaucr, un des plus mélodieux opéras d'Allemagne avant Mozart, qui s'en inspira (1770, Mannheim). - Déjà Steffani avait éerit en 1689 un Henriro Leone, qui fut joué pour l'inauguration de l'Opéra de Hanovre, et po.ir le cinquième centenaire du siège de Bardewick par Henri le Lion. -Dans le même genre, il faudrait citer nombre d'œuvres de Schürmanı, de Scheibe, ete.

2. On prétend que Graun mourut de chagrin, en apprenant la défaitc de Frédéric II à Züllichau (17509).

R. Rolund. - Voyage nusi.al. 
(1766) et son Hermannschlacht sur des paroles de Klopstock. Bientòt le jeune Mozart, dans ses lettres frémissantæs, écrites de Paris (1778), s'emporte jusqu'à l'outrage contre les Italiens et les Français :

"Mes mains et mes pieds tremblent de l'ardent désir d'apprendre aux Français à connaitre, $\dot{a}$ estimer et $a$ craindre toujours davantage les Allemands ${ }^{1}$. 》

Ce patriotisme surexcité, qui est déplaisant chez de grands artistes comme Mozart, en les rendant grossièrement injustes pour le génie d'autres races, a du moins eu ce résultat qu'il les a fait sortir de l'individualisme orgueilleux ou du dilettantisme énervé. Dans l'art allemand, dont l'atmosphère était raréfiée, et qui eût péri d'asphyxie, s'il n'avait eu depuis deux siècles, pour respirer, la foi religieuse, il fait rentrer le grand air. Ces musiciens nouveaux n'écrivent pas pour eux seuls, ils écrivent pour tous leurs compatriotes, ils écrivent pour tous les hommes.

Et ici, le patriotisme allemand se retrouve d'accord avec les théories des a philosophes 》du temps : L'art ne doit plus être l'apanage d'une élite, il est le bien de tous. Tel est le Credo de la nouvelle époque; et on l'entend répéter sur tous les tons :

1. A son père, 31 juillet 1778. Cf. Schubart : préface des Musicalische Rhapsodien, 1786, Stuttgart :

- L'oreille allemande a beau (mag noch so sehr) etre habituée aux roucoulements (girren) du chant velche : elle ne peut pas s'empêcher de trouver beau un chant populaire sorti du cœur. Et toi, chant de la patrie! comme tu élèves l'àme, quand poète et musicien sont patriotes, et que leurs sentiments se baisent comme des gouttes de rosée dans le calice d'une fleur! Moi-même, depuis vingt aus, j'ai opéré des miracles avec les Kriegsliedern de Gleim, mis en musique par Bach Des centaines de gens peuvent en témoigner, devant qui j'ai exécuté ces chants. 
a Qui pout être utile a beaucnup, dit Telomann, fait minu que qui ćcrit seulement pour un petit nombre "

".... Wer vieien nütsen kan,

Thut besser als wer nur für wenige was schreibet...."

Or, pour être utile, poursuit Telemann, il faut êtro aisém nt compris de tous. Par suite, la première loi est d'ètre simple, facile, clair.

" Je me suis toujours altaché à la facilité, dit-il. La musique ne doit ras être une peine, une science occulle, une espèce de magie noire.... D

Mattheson, écrivant son Vollinmmene Kapellmeister, (1739), qui est le code du style nouveau. l'Art Musical de la nourelle école, demande qu'on mette le grand art de côté, ou du moins qu'on le cache : il s'agit d'cerire difhcilement de la musique facile. Il dit mème que le musicien doit chercher, s'il vent faire une bonne mélodie, à ce que le thème "ait un je ne sais quoi que tout le monde connaisse déjà $n$. - Naturellement, il ne s'agit pas d'expressions déja employées, mais qui semblent si naturelles que chacun croie les connatre). - Comme modèles de cette Leichtigkeir mélodique, il recommande l'étude des Français.

Les mêmes idées sont exprimées par les hommes qui sont à la tête de l'école berlinoise du lied, dont le Boileau fut le poète Ramler. Dans sa préface à șes Oden mit Melodien de 1733-3, Ramler donne, lui aussi, à ses compatriotes l'exemple de la France, où tout le monde chantait alors, dit-il, ảans toutes les classes de la société :

« Nous autres Allemands, continue-t-il, nous étudions la musigue partnut; mais nos airs ne sont pas de ces 
chills qui passent sans peine de bouche en bouche... Il faut érire pour tous. Nous vivons en société. Iraitsnous des liefler, qui ne soient ni si poitiques que les belles chanteuses ne puissent les comprendre, ni si vides et si plats que les gens d'esprit ne puissent los lite. )

Les principes qu'il expose ensuite sont excessifs ${ }^{1}$. I! n'en amenerent pas moins une floraison du style popitlaire, im Voliston; et le maître parfait da genre, lo Mozart du lied populaire, Joh.-Abr.-Peter Schulz dira. dans la préface d'un de ses charmants recueils im Volliston (1784) :

" Je me suis ampliqué à être le plus simple possible et lo nlus intelligille. Oui, même j"ai cherché à donner $\dot{a}$ tonles mes inventions l'apparence de choses connues dejà, - a condition, bien entendu, que cette apparence ne soit pas une réalici. )

Ce sont exactement les idées de Mattheson. A côté de ces mélodies en style populaire, surgit une floraison incroyable de musique de société, Lieder geselliger Freude, Deutsche Gesänge pour tous les âges, pour les deux sexes, "pour les Hommes allemands " (für Deutsche Männer), “ pour les Enfants ) (für Kinder), "pour le beau sexe " (für's schöne Geschlecht ${ }^{\tilde{2}} .$. ), etc. La musique est devenue éminemment sociable.

Aussi bien, les chefs de la nouvelle école ont-il;

1. Que les mélodies soient accessibles à tous et noffrent pas de difficuliés à apprendre; qu'on en élaque tous les ornements vocaux, foritures, et autres colificliets encombrants, héritage du slyle d'opéra; que les mélodies aient tout leur sens el tout leur charme, même saus acco:nịannement, même sans aucune basse..., etc.

2. Vuir les iielor de Peichardt. 
admirablement travaillé à en répandre partout la connaissance et l'amour. Voici les grands concerts qui se fondent. Vers 1715, Telemann commençail à donner des auditions ourertes, au Collegium. Husicum quil avait institıé à Francfort. Ce fut surtout à partir de 1722, à Hambourg, qu'il organisa des concerts réguliers, publics et payants. Ils avaient lieu, deux fois par semaine, les lundi et jeudi, a quatre licures. On payait 1 fl. 8 gr. d'entrée. Telemann y dirigeait des curres de toute sorte, morceaux instrumentaux, cantates, oratorios. Ces concerts, fréquentés par les gens les plus distingués de la ville, suivis de près par la critique, dirigés avec soin et ponctualité, derinrent si florissants qu'en 1761 on inaugura une belle salle confortable et chaulíée, où la musique était chez soi. C'est plus que Paris n'a eu, jusqu'à ces derniers temps, la générosité d'ofrrir à ses musiciens. - Johann-Adam Hiller, maitre de Neefe qui fut maitre de Beethoven, Hiller, un des champions du style populaire dans le lied et au théâtre, où il fonda l'opéra-comique allemand, contribua puissamment, comme Telemann, à propager la musique dans toute la nation, en dirigeant depuis 1763 les Liebhaberhonzerte (concerts des amateurs) de Leipzig, d'où sortirent plus tard les fameux Gewandhauslionserie.

Nous sommes donc en présence d'un grand mourement musical, qui est à la fois national et démocratique.

Mais il a un autre caractère, qui est très inattendu : ce courant national charrie une multitude d'élénesisis 
étrangers. Le nonveau style, qui se forme au cours du xvin ${ }^{e}$ siècle en Allenngne et qui va s'epanouir dans les classiques Viennois, est en réalité beaucoup moins purement allemand que le style de J.-S. Bach. Et pourtant, ce dernier l'était moins qu'on ne le dit en général : car J.-\$. Bach s'était assimilé une partie de l'art de France et d'Italie; mais chez lui, le fond restait echt deutsch. - Il n'en est pas de mème avec les musiciens noureaux. La rérolution musicale qui s'est réalisée pleinement à partir de 1750 environ, et qui a abouti à la suprématie de la musique allemande, était - si étrange qu'il semble - le produit de courants élrangers. Les historiens de la musique les plus clairvoyants, en Allemagne, conme Lugo Riemann, l'ont bien aperçu, mais sans s'y arrêter. Il faut y insister. Co n'est pas un fait insignifiant que les clicfs de la nouvelle musique instrumentale allemande, les premiers symphonistes de Mannheim, Johann Stamitz, Filtz, Zarth, soient originaires de Bohème, comme le réformateur de l'opéra allemand, Gluck, comme le créateur du mélodrame et du Sings,iel tragique allemand, Georg Benda. Cette fougue, cet élan spontané, ce naturel de la nouvelle symphonie est un apport des Tchèques et des Italiens dans la musique allemande. Et ce n'est pas non plus un fait indifiérent que cette nouvelle musique ait trouvé son point d'appui et son centre de rayonnement à Paris, où parurent les premières éditions des symphonies de Mannheim, où J. Stanitz vint diriger ses ceuvres et eut en Gossec un disciple immédiat, - en France, où d'autres maitres de Mannheim vinrent se fixer, Richter à Strasbourg, Beck à Bordeaux. Ils l'avaient bien senti, ces critiques du Nord de l'Allemagne, hostiles au mouvement, qui qualifiaient 
ces symphonies de "symphonies à la récente mode $W_{t} l s c h e^{1}$ » et leurs auteurs do « musiciens à la mode de Paris $^{2}$ ").

Ces afinités avec les peuples de l'Ouest et du Sud ne se font pas remarquer dans la seule symphonie. L'opéra de Jommelli à Stuttgart, comme le sera plus tard celui de Gluck, est transformé, revivifié par l'influence de l'opéra français, dont son maître le duc Karl Eugen lui impose le modèle. Le Singspiel, l'opéra-comique allemand, a son berceau à Paris, où Weisse avait vu les œuvrettes de Favart, qu'il transplanta chez lui. Le nouveau lied allemand s'est inspiré des exemples de la France, comme le disent expressément Ramler et Schulz, - lequel écrit encore des lieder sur paroles françaises. Telemann avait reçu une éducation plus française qu'allemande. Il avait appris à connaître la musique française, une première fois à Hanovre, lorsqu'il était au gymnase de Hildesheim, vers 1698 ou 9, - une seconde fois en 170 à Sorau, où il se nourrit, dit-il, " des cuvres de Lully, Campra et autres bons maîtres », et « s'appliqua presque entièrement à leur style, si bien qu'en deux ans il fit jusqu'a 200 ouvertures françaises 》, - une troisième fois, à Eisenach, patrio de J.-S. Bach, qui (retenons ce fait) était vers 1708-9 un foyer de musique française : Pantaléon Hebenstreit y avait « installé la chapelle du duc à la manière francaise », et si bien réussi qu'à en croire Telemann, " elle surpassait l'orchestre célèbre de l'Opéra parisien 》. Un voyage en 1737 à Paris acheva de faire de l'Allemand Telemann un musicien français; tandis que ses

1. Allgemeine dealsike Bibliothek, cité par C. Mennicke.

2. Hiller, 17 ico. 
conves restaient au répertoire da Concer: sonituel de Paris, lui, à Kambourg, faisait une propagande passionnée pour la musique française. Et n'est-ce pas un trait caractiristique de l'époque que la tranquilité avec laquelle ce pionnier du style nouveau déclare, dans son Autobiographie de 1729 :

"Quant à mes styles en musique, (il ne dit pas mon style), on les comait. D'abord ce fut le style polonais, puis le style francais, et surtout le style italien où j’ai le plus écrit. »)

Je ne puis, dans ces notes rapides, qui ne sont que l'esquisse d'rn cours, insister sur certaines influences, en particulior sur celle de la musique polonaise, dont on tient trop peu de compte, et dont le style a cependant fourni nombre d'inspirations aux maîtres allemands d'alois ${ }^{1}$. Mais ce que je veux mettre ici en lumière, c'est que les chefs de la nouvelle musique allemande, bien que pénétrés d'un sentiment national très profond, étaient imprégnés des souffles étrangers, qu'ils araient recueillis tout le long des frontières de

1. Telemann, qui connut à Sorau et à Pleise la musique polonaise, - dans tonte sa vraie barbare beauté ", ne nianque pas, avec sa franchise habituelle, qui le rend sympathique, de proclamer ce qu'il lui doit: "On ne saurait croire quelle fantaisie extraordinaire!... Quelqu'un qui prendrait des notes, pourrait, en huit jours, faire provision d'idées pour sa vie entière. Bref, il y a beaucoup de bon dans cette musique, si on sait s'en servir... Elle m'a rendu des services plus tard, même en mainte œuvre sérieuse.... J'ai plus tard écrit dans ce style de grands Concerts et des Trios, que j'ai habillés ensuite d'un habit italien...."

M. Nax Schneider a relevé des traces de cette musique polonaise dans les Sonates méthodiques et la Kleine Kammermusic de Telemann. - Ce fut surtout par l'intermédiaire de la Saxe, dont l'électeur était roi de Pologne, que cette musique se répandit en Allemagne. Mème un italianisant comme Hasse en fut touché; il parle, dans une conversation avec Burney, de "cette musique polonaise, vrainent naturelle, et souvent très tendre et délicate . 
l'Allemagne, - Tchèques, Polonais. Italiens. Français. Ce ne fut pas un hasard : ce fut un besoin. La puissante musique allemande avait - a toujours eu - le sang lourd. La musique d'autres pays, (le nòtre par exemple), a surtout besoin d'aliments, de charbon pour nourrir la machine. Ce n'est pas le charbon qui manque dans la musique allemande, c'est l'air. Elle n'était certes point pauvre, au xvin ${ }^{\mathrm{e}}$ siècle; elle était plutôt trop riche, encombrée de sa richesse; la cheminée était bourrée; le feu risquait de s'éteindre, sans les granús courants d'air que les Telemann, les Hasse, les Stamitz, ont fait entrer par la porte, - par toutes les portes ourertes de France, de Pologne, d'Italie et de Bohême. L'Allemagne du Sud et les pays rhénans, Mannheim, Stuttgart et Vienne, furent le foyer d'élaboration de l'art nouveau : on s'en aperçoit assez à la jalousia de l'Allemagne du Nord, qui en fut longtemps l'ennemie ${ }^{1}$.

Ce n'est pas dans la mesquine pensée de diminuer la grandeur de l'art classique allemand de la fin du xvirr $^{\mathrm{e}}$ siècle que je montre ce qu'il doit à des influences ou à des éléments étrangers. - Il fallait qu'il en fùt ainsi, pour que cet art devint rapidement universel, comme il advint. Un esprit de nationalisme étroit et replié sur soi n’a jamais porté un art à la suprématie. Il le conduirait, à bref délai, tout au contraire, ì périr de consomption. Pour qu'un art soit fort it vivant, il ne faut pas qu'il s'encapuchonne peureus.ment dans une secte; il ne faut pas qu'il s'abrite daris

1. A cette inimitié et au silence obstiné que les critiques du Nord de l'Allemagne gardaient sur les productions de Mannheim, nous avons dù d'ionnorer totalement celles-ci, jusqu'à ces temps derniers, hien qu'Haydn

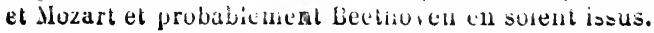


une serre, comme ces malheureux arbres qu'on fait pousser en caisse; il faut qu'il pousse en terre libre, et qu'il y étende librement ses racines, partout où il peut boire la vie. L'esprit doit absorber toute la sub. stance de l'univers. Il n'en gardera pas moins ses caractères de race; mais au lieu que cette race s'étiole et s'épuise, comme elle ferait en ne se nourrissant que de soi, il y transfuse une vie nouvelle, et, par l'apport des éléments étrangers qu'elle a assinilés, il lui donne un rayonnement d'universalité. Urbis. Orbis. Les autres races se reconnaissent en elle; et non seulement elles s'inclinent devant sa victoire. mais elles l'aiment, et elles s'y associent. Cette victoire devient la plus grande à quoi puisse prétendre un art ou une nation : une victoire de l'humanité.

De ces victoires, si rares, un des plus beaux exemples est, en musique, l'art classique allemand de la fin du xviII siècle. Cet art est devenu le bien, le pain de tous, de tous les hommes d'Europe, parce que tous y ont collaboré, tous y ont mis du leur. Si un Gluck, si un Mozart, nous sont si chers, c'est qu'ils sont à nous tous. Tous : Allemagne, France, Italie, ont contribué à les créer de leur esprit et de leur sang.

(Leçon d'ouverture du cours d'histoire de la musique, professé à la Faculté des Leltres de Paris, en 1909-1910. - Revue musicale S.I.M., février 1910.) 


\section{V \\ L'AUTOBIOGRAFHIE DUU ILLUSTRE OUBLIE}

TELEMANN

RIVAL HEUREUX DE J.-S. BACH

L'histoire est la plus partiale des sciences. Quand elle s'éprend d'un hormme, elle l'aime jalousement, elle ne reut plus entendre parler des autres. Du jour où a été reconnue la grandeur de J.-S. Bach, tout ce qui était grand de son temps est devenu moins que rien. C'est à peine si l'on pardonne à Hændel l'impertinence d'avoir eu autant de génie que J.-S. Bach et beaucoup plus de succès. Les autres sont rentrés dans la poussière; et plus que tous, Telemann, à qui la postérité a fait payer l'insolente victoire que, vivant, il remporta sur J.-S. Bach. Cet homme, dont la musique était admirée dans tous les pays d'Europe, depuis la France jusqu’à la Russie, et que Schubart appelait « le maître sans égal », que le sévère Mattheson déclarait le seul musicien qui fût au-dessus de l'éloge ${ }^{1}$, est

1. Ein Lulli wird gerülumt; Corelli læsst sich loben; Nur Telemann allein ist übers Lob erhoben. 
aujourd'hui oublié, dédaiggné. On ne cherche même pas à le connaître. On lo juge sur des ouï-dire, sur des mots qu'on lui a prêtés et dont on ne se donne pas la peine de comprendre le sens. Il a été immolé au zèle pieux des Bachistes, comme Bitter, Wolfrum, ou notre ami A. Schweitzer, qui ne comprend pas que J.-S. Bach ait transcrit de sa main des cantates entières de Telemann. On peut ne pas le comprendre. Mais si l'on admire J.-S. Bach, le seul fait qu'il ait eu cette opinion de Telemann, devrait donner à réfléchir. Seul, Winterfeld a jadis étudié avec scrupule les compositions religieuses de Telemann, et aperçu son importance historique dans le développement de la cantato spirituelle. - Depuis quelques années, on commence à reviser l'arrêt trop léger de l'histoire. En 1907, M. Max Schneider a publié dans les Denkmaeler der Tonkunst in Deutschland deux des dernières œuvres de Telemann : Der Tag des Gerichts (Le jour di: Jugement) et Ino, en les accompagnant d'une excellente notice historique. De son côté, M. Curt Ottzenn a écrit une brève étude, un peu superficielle, intitulée : Telemann als Opernkomponist: ein Beitrag zur Geschichte der Hamburger Oper (1902, Berlin); et il y a joint un album musical de fragments d'opéras et d'opéras-comiques de Telemann ${ }^{1}$.

1. M. Hugo Riemann a publié un trio instrumental de Telemann, dans sa belle collection : Collegium Musicum.

On trouvera dans la préface de M. Max Schneider à son volume des Denkmaeler une petite bibliographie sur le sujet. - J'ai largemeut usó de ses travaux. 
Les rencignements ne manquent pas sur la vie le Telomann. Luimime a pris le soin d'écrire trois relations de sa carrière : en 1718, en 1729 et en 1739.

Ce goùt dos autobiographies est un signe des temps; on le retrouve chez d'autres musiciens allemands d'alors ${ }^{1}$; il concorde avec la publication des premiers lexiques, Dictionnaires et Histoires des Musiciens par Walther et Mattheson. Comparez au plaisir que les artistes de la nouvelie époque ont à se décrire, l'indifférence d'un J.-S. Bach, ou d'un Hændel, qui ne répond même pas au questionnaire biographique que lui envoyait Mattheson. Ce n'était pas que J.-S. Bach et Hændel fussent moins orgueilleux que Telemann, Holzbauer, etc. Ils l'étaient beaucoup plus. Mais ils mettaient leur orgueil à étaler leur art et à cacher leur personnalité. La nouvelle époque ne distingue plus l'une de l'autre. L'art derient le reflet de la personnalité. Telemann, allant au-derant des critiques, s'excuse, à la fin de son récit de 1718 , d'avoir trop parlé de lui. Il ne voudrait pas, dit-il, qu'on crùt qu'il a cherché à se vanter :

" Je puis témoigner devant le monde entzer qu'en dehors de l'amour-propre légitime, que chacun doit avoir, je n'ai aucun fol orgueil. Tous ceux qui me connaissent l'attesteront. Si je parle beaucoup de mon travail, ce n'est

1. Ainsi, chez Holzbauer. 
pas pour me grandir : car c'est une loi pour tous de ne pouvoir rien alteindre sans tratail...

... Nil siue magno

Vita labore dedit mortalibus.

Mais mon dessein a été de montrer à ceux qui veulent Etudier la musique qu'on ne va pas loin dans celte science inépuisable sans un puissant effort....

Il croit donc, comme les gens de son temps, que sa vie peut être aussi intéressante et utile à connaître que son cuvre. Mais sans tant de raisons, il a un plaisir infini à se raconter. Ses naïves confessions sont pleines de bonne humeur, de drôlerie, d'exubérance; il les farcit de citations dans toutes les langues, de vers de son invention, de morales de mirliton; il ne cache rien de lui; après la mort de sa première femme, il écrit en vers l'histoire de son amour, des fiançailles, du mariage, de la maladie, de l'agonie; il ne fait grâce d'aucun détail; il tient à mettre l'univers dans la confidence de ses joies et de ses peines. Que nous sommes loin de Hændel et du silence dont il enveloppait son cœur attristé, alors qu'il écrivait la sereine musique de Poro, dans les jours où il venait de perdre sa mère! La personnalité de l'artiste réclame sa place au soleil; elle s'étale avec une salisfaction indiscrète. Ne nous en plaignons pas : c'est à ce changement d'esprit, à cette disparition de la contrainte morale qui pesait sur l'expression des sentiments individuels que nous devrons la libre et vivante musique de la fin du siècle, et los cris de passion de Beethoven. 


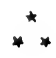

Georg-Philipp Telemann naquit à Magdebourg, lo 1. mars 1681. Il était fils et petit-fils de pasteurs uthériens. Il n'avait pas quatre ans, quand il perdit son père. De bonne heüe, il montra une remarquable facilité en toutes choses : latin, gree et musique. Les voisins s'amusaient à entendre le petit bonhomme qui jouait du violon, de la cithare et de la flùte. Trait exceptionnel chez les musiciens allemands de son temps : il avait un goût très vif pour la poésie allemande. Tout jeune, - un des plus jeunes de l'école, il fut choisi par le cantor comme suppléant, pour les leçons de chant. Il prit quelques leçons de clavier; mais il manquait de patience : son maître était un organiste, au style un peu archaïque. Le petit Telemann n'avait pas le respect du passé. "Dans ma tête trottaient déjà, dit-il, de plus joyeuses musiques. Après un martyre de quinze jours, je me séparai de mon maître. Et depuis, je n'ai plus rien appris, en musique. 》(Entendez: appris avec un maître; car il apprit beaucoup tout seul, avec les livres.)

Il n'avait pas douze ans, quand il commença à composer. Le cantor, qu'il suppléait, écrivait de la musique. L'enfant ne manquait pas de lire ses partitions en cachette; et il pensait combien il est glorieux d'inventer o's belles shoses. Il se mit à en écrire, lui aussi, sans en parler à personne; il faisait parrenir ses compositions au cantor, sous un pseudonyme; et il eut la joie de les entendre louer, - bien plus, chanter à l'église, et jusque dans les rues. Il s'enhardit. Un libretto d'opéra lui tomba sous la main : il le mit en musique. 0 bon- 
heur! L'opéra fut joué sur un théâtre, et le petit auteur $\mathbf{y}$ tint même un des rôles.

"Ah! mais nuel orage je m'attirai sur la tête, avec mon opéra! écrit-il. Les ennemis de la musique vinrent en foule voir ma mère, et lui représentèrent que je deviendrais un charlatan, un danseur de corde, un joueur, un meneur de marmottes, etc... si la musique ne m'était enleveee! Aussitôt dit, aussitôt fait : on me prit mes notes, mes instruments, et avec eux la moitié de ma vie. "

Pour le punir davantage, on l'envoya dans une écolo au loin, sur le Harz, à Zellerfeld. Il y devint très fort en géométrie. Mais le diable ne perdait pas ses droits. Il advint que, pour une fête populaire dans la montagne, le maître qui devait faire une cantate tomba malade. L'enfant profita de l'occasion. Il écrivit l'œuvre, et dirigea l'orchestre. Il avait treize ans, et il était si petit qu'on dut lui faire une banquette pour le surélever, afin que les musiciens de l'orchestre pussent le voir. "Les excellents montagnards, touches, dit Telemann, plus par mon apparence que par mes harmonies, me portèrent en triomphe dans leurs bras. "Le directeur de l'école, flatté de ce succès, autorisa Telemann à cultiver la musique, déclarant qu'après tout cette étude n'était pas contradictoire avec celle de la géométrie, et même qu'il y avait une parenté entre les deux sciences. L'enfant profita de la permission pour négliger la géométrie; il se remit au clavier, et étudia la basse continue, dont il se formula et s'écrivit lui-même les règles : "car, dit-il, je ne savais pas encore qu'il y avait des livres sur ce sujet. »

Vers dix-sept ans, il passa au gymnase de Hildesheim, où il apprit la logique; et bien qu'il ne pût 
souffrir les Barbara Celarent, il s'en tira brillamment. Mais surtout, il arança beaucoup son instruction musicale. Il ne cessait de composer. Pas un jour sine linea. Il écrivait principalement de la musique d'église et do la musique instrumentale. Ses modèles étaient Steffani, Rosenmüller, Corelli, Caldara. Il prenait goùt au style des nouveaux maitres allemands et italiens, « à leur facon pleine d'invention, chantante, et en même tem. s travaillée. "Leurs œurres lui fournissaient la confirmation de ses préférences instinctives pour la mélodie expressive, et de son antipathie pour l'ancien style contrapontiste. Une heureuse chance le farorisa. Il était à peu de distance de Hanovre et de Wolfenbüttel, dont les célèbres chapelles étaient des foyers du style nouveau. Il y allait souvent. A Hanovre, il apprit la manière française. A Wolfenbüttel, le style théâtral de Venise. Les deux cours avaient des orchestres excellents; et Telemann y étudia avec zèle la nature des divers instruments. - " Je serais devenu peut-être un plus fort instrumentiste, dit-il, si un feu trop vif ne m'avait poussé à connaître, en dehors du clavier, du violon et de la flute, le hautbois, la traversière, le chalumeau, la gambe, etc... jusqu'à la contrebasse et à la Quint-Posaune (trombone basse) ». - Trait bien moderine : le compositeur ne cherche pas à être un virtuose sur un instrument spécial, comme J.-S. Bach et IIændel sur l'orgue et le clavier, mais à connaître les ressources de tous les instruments. Et Telemann insiste sur la nécessité de cette étude pour le compositeur.

A Hildesheim, il écrivait des cantates pour l'égylise catholique, bien qu'il fùt luthérien convaincu. Il metait aussi en musique des pièces de théâtro d'un lin ses

R. Rolland. - Vojage musical. 
professeurs, des sortes d'opéras-comiques, dont les récitatifs étaient parlés et les airs chantés.

Cependant, il avait vingt ans; et sa mère - (pas plus que le père de IIendel) - ne consentait à ce qu'il fit do la risusique; et - (pas plus que Hendel), - Tele. mann ne se révoltait contre la volonté familiale. En 1701, il s'en alla à Leipzig, avec la ferme intention d'y étudier le droit. Pourquoi fallut-il qu'il passât par Halle, où il fit la connaissance, tout justement, de IIændel, âgé de seize ans, qui, bien qu'il fùt censó suivre les cours de la Faculté de droit, avait trouré moyen de se faire nommer organiste, et s'était acquis daris la ville une réputation musicale étonnante pour son âre? Les deux jeunes gens se lièreat d'amitié. Il fallut se quilter. Telemann avait le cœur gros en continuant sa route. Cependant, il tint bon, et arriva à Leipzig. Mais le paurre garçon tombait de tentation en tentation. Il avait loué une chambre en commun avce un autre étudiant. La première chose qu'il vit en entrant, ce fut, à tous los murs, dans tous les coins de la chanbre, des instruments de musique. Son compar̨non était mélomane; et tous les jours, il infligeait à Telemann le supplice de lui faire de la musique; et Telemann, hérö̈quement, cachait qu'il était musicien. Le dénouement était fatal. Un jour, Telemann ne put se tenir de montrer une de ses compositions, un Psaume, a son camarade. - (Il proteste, à vrai dire, que ce fut son camarade qui trouva le morceau dans son coffre.) - L’ami n'eut rien de plus pressé que de divulguer lo secret. On joua lo Psaume à l'église Saint-Thomas. Le bourgmestre, enchanté, fit venir 'Telemann, le gratifia d'un présent, et le chargea d'écrire, tous les quinzo jours, un morceau pour l'église. C'en était trop. Tele- 
mann écrivit à sa mere qu'il ne pourait plus y tenir, il ne pouvait plus, il fallait qu'il fit de la musique. La mathan trivoya sa bénédiction. Et Telemann, enlin, eut le droit d'être musicien.

On roit quelle répugnance les familles allemandes àars araient à laissei leurs fils embrasser la carrière musicale; et il est curieux que tant de grands musiciens : Schüt, Ilandel, Kuhnau, Telemann, aient dù cébuter par l'étude du droit ou de la philosophie. Cependant, cette éducation ne semble pas avoir fait tort aux compositeurs: et ceux d'aujourd'hui, dont la culture - (même des plus instruits) — est si médiocre, auraient lieu de réfléchir sur ces exemples, qui prouvent qu'une instruction générale peut s'accorder très bien avec la science musicale, et peut-ètre l'enrichir. Pour sa part, Telemann a certainement dù à sa culture littéraire quelques-unes de ses meilleures qualités musicales, - son sens si moderne de la poésie en musique, - soit traduito en déclamation lyrique, soit transposéo en peintures symphoniques.

Pendant son séjour a Leipzig, Telemann se tiouva en concurrence avec Kuhnau; et, bien qu'il professât, à ce qu'il dit, le plus grand respect pour " les glorieuses qualites » de " cet homme extraordinaire», il lui causa beaucoup d'ennuis. Kuhnau, qui était dans la force de l'âgre, s'indignait qu'on eût chargé un petit étudiant en droit d'écrire, tous les quinze jours, une composition musicale pour l'église Saint-Thomas, dont il était cantor. C'était, en effet, assez désobligeant pour lui; ế ce fait montre à quel point le style nouveau répondait au goût général, puisqu'au vu d'un seul morceau, écrit dans le nouveau style, on donnait la préférence à un ,écolier sans titres sur un maîtro 
illustro.- Ce ne fut las tout. En 170 , Telemann fut choisi comme organicte et maitro de chapelle à In Nene Eirche (depuis, Nathäkirche), avec la mention "qu'il pourrait au besoin diriger anssi le chour it l'alise Sami-Thomas, et que l'on aurait ainsi sous ln

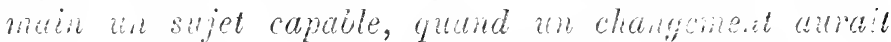
licu ". Entendez : "Quand H. Kuhnau mourat 》: car il cuit dábile et de santé néliocre; on asconsunit sa mort, - qu'il eut d'ailleurs l'esprit do faire attendre jusiu'en 1722. - On comprendra que Kuhnau trourât le procédé de maurais goùt. Pour achever de l'exaspérer, Telemann réussit à se faire donner la direction des opéras, bien qu'elle fut. en rè le générale, inconciliable avee la charge d'organiste. Lit tous les étudiants allèrent à lui, attirés à la fois par sa joune renommée, par l'attrait du thêâtre, et par le gain. Ils désertaient Kuhnau, qui se plaignait amèrement. Dins une lettre du 4 décembre 1704, il romontre que, "par suite de la nomination d'un nouvel organiste, qui fait les opéras d'ici, les étudiants, qui jusque-là se joignaient gratuitement au chour de l'église, et qui avaient été en vartie instruits par moi, maintenant qu'ils pewvent s'assurer quelques profits avec l'opéra, laissent le chour, et aident l' "opérisle". - Mais la réclamation de Kulmau fut vaine, et Telemann l'emporta.

C'est ainsi que, dès le début de sa carrière, Telemann tenait en échec le glorieux Kuhnau, avant de damer le pion à J.-S. Bach. - Tant était fort le courant de la mode musicale nouvelle!

Telemann sarait d'ailleurs profiter et faire protıter les autres de sa fortune. Il n'avait rien d'un intrigant; et l'on ne peut même pas dire que ce soit l'ambition qui l'ait pousiś à frendre loutes les places qüil a 
collectionnées penuant sa longue carrière : c'était une activité extraordinaire et un besoin fóbrile de l'exercer. A Leipzig, il travai!la assidument, prenant Kuhnaa pour modib dans le style fugué, et se pelectionnant dans la mélodic par des travaux en commun arec Hændel ${ }^{2}$. En mème temps, il fondait à Leiprig, avec les étudiants, un Collegium líusicum, qui donnait des concerts : - préludant aini aux grands concerts périodiques et publics, dont il derait plus tard prendre linitiative à Hambourg.

En 1705, il fut appelé à Sorau, entre Francfort-surl'Oder et Breslau, comme capellmeister d'un grand s:oigneur, comte Erdmann ron Promnitz. La petite cour princière était très brillante. Le comte était revenu récemment de Franco et aimait la musique française. Telemann se mit à écrire des ouvertures françaises; il lut, la plume à la main, les ceurres de «Lully, Campra, et autres bons maîtres ". - "Je m'appliquai, dit-il, presque entièrement à ce style, si bien qu'en deux ans, je fis jusqu'à deux cents ouvertures. »

Avec le style français, Telemann apprenait à Sorau le style polonais. La cour se rendait parfois, pour quelques mois, dans une résidence du comte en IlauteSilésie, à Plesse, ou à Cracovie. Telemann y fit connaissance "avec la musique polonaise et hariaie ${ }^{\text {, }}$ dans toule sa vraie et barbare beauté. Elle était jouée, dit-il, en certaines hotelleries, par quatre instruments : un violon très aigu, une muselte polonaise, une Quint-

1. Comme il dit, a la piume de l'excellent Monsieur Kuhnau me servi dans les fugues et contropoints .

2. Ils s'écrivaient, s'envoyaient leurs compositions, les critiquaies mutuellement.

3. Les Haukes ant des Tehèques de Yhavie. 
Posaune (trombone basse), et un Regal (petit orgue). Dans les cercles plus importants, il n'y avait pas de Regal; mais les autres instruments ćtaient renforcés. J'ai entendu jusqu'à trente-six muscttes et huit violons ensemble. On ne saurat croire quelles extraordinaires fantaisies inventent les joueurs de cornemuses ou les violons, quand ils improvisent, pendant que les danseurs se reposent. Quelqu'un qui prendrait des noles pourrait, en luit jours, faire provision d'idies our sa rie tout entière. Bref, il y a beaucoup de bon dans celte musique, si on sait s'en servir.... Cela m'a rendu plus tard des services, même pour maintes com:nsitions sérieuses.... J'ai écrit dans ce style de graids concertos el des trios, que j̈ai rhal,illís ensuite à l'italienne, en faisant alterner Adagio et Allegro '. "

Voilà donc la musique populaire qui commence à pénétrer franchement l'art savant. La musique allemande se retrempe dans les musiques des races qui entourent ses frontières; elle va leur emprunter un peu de leur naturel, de leur fraîchour d'inventions; et ello leur devra une jeunesse nouvelle.

De Sorau, Telemann passa en 1709 à la cour d'Eisenach, où il se trouva encore dans un milieu musical, pénétré d'influences françaises. Le directeur de la chapelle était un virtuose d'une célébrité européenne, Pantaleon Hebenstreit, inventeur d'un instrument, appelé de son nom Pantaleon ou Pantalon, - une espèce de tympanon perfectionné. qui annonçait notre piano actuel. Pantaleon, qui s'était fait applaudir par Louis XIV, avait une habileté non commune dans la composition et le style français; et la chapelle

1. M. Max Schneider note des exemples de cette musique polonaise dans les Sonates mélhodiques et la kleine Cammer Music de Telemann. 
d'Eisenach était " installée le plus possible à la manière fran:aise ». Telemann prétend même "qu'elle surpassait lorchestre de l'upéra de Paris n. Il paracheva ici son éducation françase. - En vérité, il est beaucoup plus question, dans la vie de Telemann, d'éducation musicale françaiso, ou polonaise, ou italienne, - surtout frunçaise, - que d'éubcation allemande. - Telemann écrivit, à Eisonach, uno quantité de concevos en style français et un nombre considérable de sonates (de 2 à 9 parties), de trios, de sérénades, de cantates sur des paroles italiennes ou allemandes, où il donnait une grande importance à l'accompagnement instrumental. Surtout il attachait du prix à sa musique religieuse.

Ce fut à Eisenach, où Joh-Bernhard Bach était organiste, qun Telemann entra en relations avec J.-S. Bach, dont il fut en 1714 le parrain d'un des fils, PhilippEmanuel. Il se lia aussi arec le pasteur-poste Neumeister, protagoniste de la cantate religieuse en style d'opéra, et un des libretlistes préférés de J.-S. Bach. - Enfin, à Eisenach, se produisit un événement qui agit profondément sur son caractère. Il perdit, au commencement de 17!1, sa jeune femme, qu'il arait épousée, à la fin de 1709 , à Sorau. Il a racunté l'histoire de ces événements, dans une longue pièce en vers, intitulée : Pensées poétiques, par lesquelles voulut honorer la cendre de son aimée de tout cour Louise, son mari abandonné, Georg-Philipp) Telemann, 1711'.

1. La prenière femme de Telemonn, Amalie-Luise Juhions, était la tille du cepelmeister de Cassel, Daniel Éberlin, - un homme bien étrance, à en juger par le curriculum vilae que trace de lui son gendre: il arat ete canture des tromes pontificales en Vorée, mis hing? e. caine à Nurembers, puis cugetmeister à Cassel; par la suite, il devint 
Ce petit poème, bien que trop diffus et d'une sentimentalité peu discrète, est plein d'une émotion tendre, comme une belle musique.

- "Ainsi, je t’ai vue morte, ma bien-aimée! commence-t-il. Est-il possible que je respire encore?... 》

Il raconte comment ils s'étaient connus, comment il l'arait aimée.

"... Nous nous rencontrâmes d'abord en pays étranger. Je ne pensais pas à elle. Elle ne savait rien de moi.... Je ne sais pas oì je l'ai vue, pour la première fois. Ce que je sais, c'est qu'aussitôt je l'aimai.... Je me dis : Elle doit étre à moi... - Mais Dieu me dit: Tu dois être d'abord un autre Jacob, - (c'est-ia-dire : tu dois la conquérir par la peine et les larmes). »)

Il soupira, des années. Elle paraissait insensible. Comme il souffrit, une fois qu'elle fut gravement malade!... Et une autre fois, qu'on voulut la marier !... Il pensait "que son cceur allait se briser! ». Elle, semblait toujours aussi indifférente. Ce ne fut qu'au dernier moment, quand il quittait Sorau, fuyant devant l'invasion suédoise, qu'elle laissa lire dans son cceur....

- "... Je lui dis : Bonne nuit! pour la dernière fois. Mais qu'allait m'apprendre cet adieu? Je vis ses yeux qui pleuraient, et j'entendis... (ah! quelle joie!): « Adieu, mon Telemann, ne m'oubliez pas! - Je partis, dans un transport d'allégresse, malgré les périls du voyage....

Viennent les lettres amoureuses. Puis, le retour, la demande en mariage, les fiançailles....

Hoffineister des pages, secrétaire intime, controleur des monnaies, banquier à Hambourg, etc., enfin capilaine de la milice à Casscl. Il ciat savant conlrapontiste, bon violoniste, et publia des trins. 
a... Comment tout cela arriva, je ne le sais pas moimême.... )

Les voilà mariés. C'est un bonheur sans nuages, malgré la vie difficile et la maigre cuisine.

«... Dans nos yeux la table était royale, - la table sur laquelle il y avait rarement plus d'un plat. »

Amour fidèle, nulle dispute. Et voici qu'ils ont un cher petit enfant.

"... Je tremble de tout mon corps. J'arrive, dit Telemann, $\dot{a}$ des heures trop cruelles....

Six jours après ses couches, elle était bien portante. gaie, elle plaisantait comme à l'ordinaire. Mais lui, il avait d'étranges pressentiments. Il lui fallait se cacher pour pleurer.

" Quand vint le soir, elle commenca à se plaindre. " Elle demanda un prêtre. "C'était comme si je rêvais. Je ne pouvais pas le croire, je ne voulais pas aller le chercher. Mais comme elle insistait, j'allai enfin. " Elle disait : "Mon bien-aimé, mon cher Telemann, je t'en prie, du fond de mon âme, pardonne si je t'ai jamais fait souffrir. " Elle protestait de son amour avec une tendresse touchante. " $A u$ lieu de répondre, je pleurais amèrement.... Le prétre vint. Alors, j'appris ce que c'était que prier. Sa chère bouche éiait une porte du ciel. Seul, Jésus était sa consolation. Seul, Jésus était sa vie. Seul. Jésus était sa lumière. Seul. Jésus était son salut. "Elle ne se lassait point de l'invoquer. "Jésus ne quitia sa bouche que lorsque la mort s'assit sur sa langue.... Elle me tenait la main, et me dit: Merci mille fois pour ton fidèle amour. Ton cour est à moi. Je l'emporte au ciel.... On voulait qu'elle dormit. Elle refusait, chantant, 
sa bolle voix : “Je ne loisse pas Jésus, il m'nime et je laime. Ie ne laisse pas Jésus. " Elle chantait, joyeuse, arec les hras tendus et le visage souricnt.... La fatigue l'accabla. Elle tomba dans un sommeil, oü elle resta deux heures. Une partie de ma peine s'était évanouie, j'altendais, consolé, une bonne journée. Son doux repos s'interrompit, elle commenca, d'une voix faible: "Mon Jésus m'a parlé en réve... ". Puis, elle se plaignit que los lumières n'avaient plus leur éclai, comme avant. Elle se pencha, et s'endormit heureuse, en Christ.... )

« ... Et maintenant, que dire? Si je dis : « Le ciel m'écrasait. l'air m'étouffait. mes oreilles bruissaient comine une tempêle, un nuage noir me couvrait les yeux, mes mains et mon caur tremlilaient comme des feuilles, mes pieds ne roulaient pas me soutenir... Quand jaurai raronte tont cela. tout au long. aurai-je seulement effleuré ma peine? - Asses! Pros we ne peut sacuir ce qu'est cetle touleur, que alui quil'a éproméce d

Et il termine par ces mots :

“ Mein Engel, gute Nacht! D (" Mon ange, bonne nuit! в)

Ce touchant récit, que pénètre une foi douloureuse, fait sentir, comme dit 'Tel minno qu' " il étuit devenu, à Eisenach, un autre homme, aussi, en Christ (auch in Christentum) ». Mais si profondémont qu'il eût été frappé. sa nature était trop vive et trop mobile pour s'enfermer dans ses regrets : trois ans plus tard, l'époux inconsolablo so remariait arfo une femme, - qui devait se charger de venger l'anire. 
Il avait quitté Eisenach. Malgré sa belle situation à la cour, son besoin de changement l'avait poussé à accepter, en 1712, les propositions qu'on lui faisait, à Francfort-sur-le-Mein.

"Comment, dit-il lui-même, suis-je venu chez ces Républicains, parmi lesquels, à ce qu'on croit, les sciences sont de peu de prix,

"Où le docte savoir ne leur semble plus rien, Où l'on hasardo tout pour acquérir du bien? ") ${ }^{1}$

Comment ai-je pu laisser une cour aussi choisie que celle d'Eisenach? Il y a un proverlse qui dit : Qui veut viore en toute sécurité, doit virre dans une république. Et bien que je n'eusse ricn à craindie pour le moment, je ne voulais pas faire l'épreure "qu'à la cour,

A u matin l'air pour nous est tranquille et serein, Mais sombre vers le soir et de nuages plein 1.

Il n'eut pas lieu de regretler sa résolution. Il fut nommé capellmeister de plusieurs églises de Francfort. Et il accepta l'emploi bizarre d'intendant d'une noble société francfortoise, qui se réunissait au palais de Frauenstein; il avait à s'occuper de tout autre chose que de musique : il gérait les finances, pourvoyait aux banquets, tenait un Talaliskollegium, etc. C'était dans les mœurs du temps; et Telemann ne dérogeait pas, en acceptant co métier; loin de lì : il faisait ainsi partie du cercle le plus distingué de la ville; et il y fonda, en 1713, un grand follogium Ifusicum, qui se réuni-sait au palais de Frauenstein. tous les jeudis, de la Saint-llichel à Pâuues, pour récréer la compa-

1. Telemann a la manie de citer des vers francais; et, comme beau coup d'etranecers, il les aime mieux maurais que bons. 
gnie et pour contribuer au perfectionnement de la musique. Ces concerts n'étaient pas fermés; on y invitait des étrangers. Telemann se chargeait de les approvisionner de musique : Sonates à violon seul, avec clavecin; Kleine Cammermusic; Trios pour violon, hautbois, flùte ou basson, et basse; cing oratorios sur la vie de David; plusieurs Passions, dont une, sur le fameux poème de Brockes, exécutée en avril 1716 à la IIauptkirche de Francfort, fut un grand événement musical; un nombre incalculable de musique de circonstances; vingt Sérénades de noces, « dont tous les vers sont de moi, dit Telemann; mais je ne les récrirais pas, à cause de leur licence et de leur sel qui n'était jas trop attique ». Ces sérénades de noces avaient des airs en l'honneur de chaque santé que l'on portait. L'ordre des toasts était le suivant :

$1^{\circ}$ A S. M. Romaine Catholique;

$2^{\circ}$ A l'Impératrice Romaine;

$3^{\circ}$ Au prince Eugène;

$4^{\circ}$ A u duc de Marlborough;

$5^{\circ}$ Aux magistrats;

$6^{\circ} A$ une prochaine et bonne paix, et au commerce fiorissant;

$7^{\circ}$ A la jeune mariee;

$8^{\circ}$ A Monsieur le marié;

$9^{\circ}$ A l'heureux couple.

(Je pense que le couple devait être en effet fort heureux, à cette neuvième rasade.)

On était donc au moment des guerres contre Louis XIV, et tout près de la paix. Telemann écrivit une Cantate pour la paix (3 mars 1715). 11 en écrivit aussi pour la victoire de l'empereur à Semlin et à 
Pecerwardein, - pour la paix de Passarowitz (1718), sans parler des anniversaires de naissance princiers.

En 1721, il abandonna Francfort pour Ilambourg, où il fut nommé capellmeister et cantor au Johanneum. Le musicien nomade devait enfin trouver là une altache solide, une situation qu'il conserva, près d'un demi-siècle, jusqu’à sa mort. Ce n'est pas à dire qu'en 1723 il n'ait été sur le point d'émigrer de noureau, pour prendre la succession de Kubnau, - enfin mort, à Leipzig. Il avait été choisi à l'unanimité. Hais Hambourg, plutòt que de le laisser partir, accepta toutes les conditions que Telemann lui imposa. Un peu plus tard encore, en 1729, il eut quelque velléité do s'en aller en Russie, où des propositions lui étaient faites pour fonder une chapelle allemande. - " Mais l'agrément de Hambourg, et le dessein de rester enfin tranquille, dit-il, triomphèrent de ma curiosité. »

« Rester tranquille.... » La tranquillité de Telemann était toute relative. Il était shargé de l'instruction musicale au Gymnasium et au Johanneum : - (chant, histoire de la musique : des cours, presque tous les jours). - Il avait à fournir de musique les cinq églises principales de Hambourg, à part le Dom, où trônait Mattheson ${ }^{1}$. - Il était directeur de la musique à l'Opéra de Hambourg, qui était fort déchu, mais avait été remis à flot, en 1722. La situation n'était pas une sinécure. Les coteries pour les chanteurs étaient presque aussi violentes qu'à l'Opéra de Londres, sous Hændel;

1. Pour les fètes jubilaires de juin 1730, en l'honneur du second centenuire de la Confession d'Augstiourg, il y eut musique de cent personnes aux cinq églises. Toutes les cuvres jouées étaient de Telemann, qui, quoique malade, dirigeait tout. 11 avait écrit dix cantates pour ces seules rêtes. 
a la guerre de plume nétait pas moins grossière. Elle n'éparrna point Felemann, qui vit dévoiler ses infortunes conjugales et le goût de sa femme pour les officiers suédois. Sa verve musicale ne sémble pas en avoir été troublée : car de cette époque datent toute une suite d'opéras et d'opéras-comiques étincelants d'invention et de bonne humeur.

Cela ne lui suffit point : dès son arrivée à Ilambourg, il avait fondé un Collegium Musicum et des concerts publics. En dépit des anciens, qui voulaient interdire au cantor de faire jouer sa musique dans une Wirthaus publique, et d'y donner des opéras, comédies, et autres « jeux pousscint à la volupté », il persévéra et il eut gain de cause. Les concerts qu'il fonda durèrent jusqu'à nos jours. Ils avaient lieu d'abord dans la caserne de la garde bourgeoise, deux fois par semaine, le lundi et le jeudi, à quatre heures. L'entrée était de 1 fl. 8 gr. Telemann $y$ faisait entendre toutes ses œuvres religieuses ou profanes, publiques ou privées, déjà données ailleurs; - sans parler d'œuvres spécialement écrites pour les concerts : Psaumes, Oratorios, Cantates, musique instrumentale. Il ne dirigeait guère d'autre musique que la sienne ${ }^{1}$. Ces concerts, fréquentés par l'élite de la ville, suivis de près par la critique, et dirigés avec soin et régularité, devinrent très florissants. En 1761, on inaugura pour eux une belle salle, confortable et chauffée.

Ce n'était pas tout encore : il fondait en 1728 le premier journal musical publié en Allemagne ${ }^{2}$. Il

1. Il ne fit exception, semble-t-il, que pour Irendel, dont il diriger en 1722 la Passion, en 1755 des Compositions vocules et instrumentales, - et pour Graun, dont il fit entendre en 1736, la Tod Jesl.

2. Le Getresc Music-Meister. Il y publiait des morceaux de inaltres 
conservait son titre de Capellmeister de Saxe; il fournissait à Eisenach la Tafelmusik (musique de table) ordinaire et les compositions pour les fètes de la cour. Il s'était engagé, en quittant Francfort, à envoyer, tous les trois ans, des compositions religieuses, en échange du droit de bourgeoisie qu'on lui avait octroyé. 11 était capellmeister de Bayreuth, depuis 1726; il y envoyait un opéra par an, et de la musique instrumentale. Enfin, la musique ne suffisant pas à apaiser sa faim d'activité, il arait accepté d'ètre le correspondant de la cour d'Eisenach; il lui écrivait tout ce qui se passait de nouveau dans le Nord: quand il était malade, il dictait à son fils.

Qui fera le compte de son œuvre? Rien qu'en vingt ans de sa vie, - (de 1720 ¿ 1740 environ) - il additionne lui-même, sommairement: douze cycles complets de musique religieuse pour tous les dimanches et fètes de l'année ${ }^{1}$, - dix-neuf Passions, dont les poèmes étaient aussi de lui, souvent, - une vingtaine d'opéras et d'opéras-comiques, - une vingtaine d'oratorios, une quarantaine de Sérénades, - six cents ouvertures, trios, concertos, morceaux de clavier, etc. - sept cents airs - etc., etc.

Cette activité fabuleuse ne fut interrompue que par un voyage, qui était le rêve de toute sa vie : à Paris. Plus d'une fois il y avait été invité par les virtuoses parisiens, qui admiraient ses œuvres. Il arriva, à la Saint-Michel de 1737, et resta huit mois. Blavet,

contemporains, entre autres, de Pisendel, de Zelenka, de Goerner, de J.-S. Bach (un catnon à quatre voix). Il y donna lui-même une suite d'airz extraits de ses opéras

1. On en retrouva irente-neuf, à sa mort. 
Guignon, Forcroy fils et ldouard ${ }^{1}$ jouèrent ses quatuors, "d'une facon admiralle», dit-il. "Ces auditions frappèrent la cour el la ville, et me valurent en peu de temps une faveur presque générale, que rehaussait une extrime courtoisie. "Il en profita pour faire graver à Paris ces quatuors et six sonates ${ }^{2}$. Le 25 mars 1738 , le Concert Spirituel donna son $71^{\circ}$ Psazme à cinq voix et orchestre. Il écrivit à Paris une cantate française : Polypheme, et une symphonie boufonne sur une chanson à la mode : Père Barnabas. — - Et je m'en allai, dit-il, pleinement satisfait, acec l'espoir de revenir. ")

Il resta fidèle à Paris, et Paris lui resta fidèle. On continua de graver sa musique en France et de la faire entendre au Concert Spirituel. De son côté, Telemann parlait avec enthousiasme de son voyage, et bataillait en Allemagne pour la musique française. Les Hamburgische Berichte von gelehrten Sachen disent, en 1737 : “ Monsieur Telemann obligera beaucoup les connaisseurs de musinue, si, comme il le promet, il décrit l'état présent de la musique à Paris, ainsi qu'il a appris à la connaitre par sa propre expérience, et par là s'il cherche à faire aimer loujour's davantage chez nous la musique frangaise, qu'il a si fort mise à la mode, en Allemagne. " - Telemann commença d'exécuter ce projet. Dans une préface de 1742 , il annonce qu'il a dójà mis sur le papier "une bonne partie » de ses récits de voyage, et que seul le manque de temps l'a empêché jusqu'ici d'achever. II est d'autant plus désireux de les publier, dit-il, qu'il espère « parer dans

1. Blavet tenait la fiute, Guignon le vioion, Forcroy la gambe, et Edouard le violoncelle.

2. Dès 1736 , on avait fait paraitre a Paris des cuvres de Telemann. (Voir Hichel Brenct.) 
une certaine mesure aux préjugés qu'on élève çà et là contre la musique fran:aise ». - On ne sait malheureusement pas ce que ces notes sont devenues.

Cet aimable homme, dans ses vieux jours, partageait son cour entre deux passions : la musique et les fleurs. On a des lettres de 1742 , où il sollicite des fleurs; il est, dit-il, "insatiable d'hyacinthes et de tulipes, avide de renoncules et surtout d'anémones ». - Il eut à souffrir de l'àge : affaiblissement des jambes, diminution de la vue. Mas jamais son activité musicale, ni sa bonne humeur n'en fut altérée. Sur la partition d'airs de 176:2, il écrivait ces vers :

" Avec une encre trop forle, avec des plumes boueuses, avec de mauvais yeux, par un temps sombre, sous une lampe pâle, jai composé ces pages. Ne me grondez pas pour cela! )

Ses plus fortes compositions musicales datent des dernières années de sa vie, quand il avait plus de quatre-vingts ans ${ }^{1}$. En 1767, l'année de sa mort, il publiait encore une œuvre théorique, et écrivait une Passion. - Il mourut à Hambourg, le 2 ว̆ juin 1767, chargé d'années et de gloire. Il avait plus de quatrevingt-six ans.

Résumons cette longue carrière, et tâchons d'en fixer les lignes principales. Quel que soit le jugement que nous portions sur la qualité de l'œuvre, impossible de

1. Telles sont les deux cantates publiées par M. Schneider : Dor Tog des Gerichts (1761 ou 1762), 'et Ino (17ós).

R. ROLLAND. - Voy?ge musical. 
n'être pas frappé par sa quantité phénoménale' et par li prodiggteuse vilalité d'un tel homme, qui, de l'àge de dix ans à l’âge de quatre-ringt-six ans, écrit de la musique arec une ardeur et une joie in!assable, - sans préjudice de cent autres occupations.

Du commencement à la fin, cette vitalité reste enthousiaste et fraîche. Chose rare, à aucun moment de sa vie, il ne vieillit, il ne devient conservateur, il va toujours de l'avant, avec la jeunesse. Fous l'avons vu, à ses débuts, aitiré par l'art noureau, - l'art mélodique, - et ne cachant pas son antipathie pour les fossiles.

En 1718, il reprend, pour son compte, ces méchants vers français :

"Ne les élève pas (les anciens) dons un ouvrage saint Au rang où dans ce temips les auteurs ont atteint.

Plus féconde aujourd'hui, la musique divine

D'un art laborieux étale la doctrine,

Dont on voit chaque jour s'accroître les progrès. ")

Ces vers le disent pour lui : il est un moderne, dans la grande querelle des anciens et des modernes; et il croit au progrès. « Il ne faut jamais dire à l'art : Tu n’iras pas plus loin. - On va toujours plus loin, et il faat toujours aller plus loin. » - “ S'il n'y a plus rien

1. Meme les admirateurs de Telemann faisaient, de son vivant, des réscrves au sujet de sa productivité anormale, sans mesure et sans repit. Hændel disait, en plaisantant, que Telemann écrivait un morceau d'église, aussi vite qu'on écrit une leitre. - Graun écrit à Telemann, en 17.52 : "Je ne suis pas content de volre mot: "Il n'y a olus rien de nonveau à trouver, en mélodie $n$. Chez la plupart des compositeurs français, je crois bien que la mélodie est epuisée, en efret, mais pas clıez un Telemann, si sculement il voulait ne pas se donner la satiété en écrivant trop!n - Et Ebcling dit, en 177; : "Il eút été plus grand s'il ti'uvait pas eu tant de facilité à ècrire, d'une façon incroyablement démesurèe •. 
de now con à trouver dans la mélodie, écrit-il au timoré Graun, il faut le chercher dans l'harmonie'. 》

Graun, archiconservateur, s'épouvanto :

"Chercher de nouvelles combinaisons dans l'harmonie est, pour moi, comme chercher de nowvelles lettres dans une langue. Nos professeurs d'aujourdhui en abolissent plutiôt quelques-unes ${ }^{2}$."

- "Oui, écrit Telemann, on me dit : Il ne faut pas aller trop loin. Et moi, je réponds : jusqu' au fond des fonds (den untersien Grund), si l'on veut mériter le nom de vrai maître. C'est là ce que j'ai voulu justifier dans mon système des Intervalles, et j"attends pour cela non des blâmes, mais plutôt un gratias, au moins de l'arenir. ")

Cette audace novatrice stupéfiait mème des novateurs, comme Scheibe. Scheibe, dans la préface de son Traité des Intervalles (1739), dit que la connaissance qu'il fit de Telemann à Ílambourg le convainquit encore davantago de la vérité de son système : «car, écrit-il, je trouvai dans les compositions de ce grand homme des intervalles très souvent inhabiuels, quejavais depuis longtemps admis dans ma série des intervalles, muis que moi-même je ne tenais pas encore pour praticables, ne les ayant jamais rencontrés chez d'autres compositeurs.... Tous les intervalles qui se trouvaient dans mon système, étaient employés par Telemann avec la plus belie grêce et d'une façon si expressive, si touchante, si justement appropriée à la force des émotions qu'on ne pouvait rien y blàmer, sans blâmer la nature mème. ఎ

\section{15 décembre 1751. - 2.14 janvier 1752 ,}


Une autre province de la musique où il fut un novateur passionné, c'est la Tommalerei, la peinture musicale. Il s'y acquit une réputation universelle, tout en heurtant les prijugés de ses compatriotes : car on ainait rou en Allemagne ces descriptions musicales, dont le goùt venait de France; mais les plus sévères ne laissaient pas d'être subjugués par la puissance de certainz de ces tableaux. M. Max Schneider a retrouvé dans un ourrage de Lessing ${ }^{1}$ le jugement suivant de Philipp-Emanuel Bach :

“M. Bach, qui a surcédéà Telemann, à Hambourg, fut son ami intime; cependant, je l'ai enterdu en juger très impartialement... "Telemann, disait-il, est un grand peintre; il en a donné des preuves saisissantes surtout dans un de ses Jahryänge (cycles de musique religieuse pour toutes les fètes de l'année), que l'on connait ici sous le nom de Der Zellische (celui de Zelle). Entre autres choses, il m'exécuta un air, oit il acait exprimé l'étonnement et l'effroi causés par l'apparition d'un esprit; mème sans les paroles qui étaient misérables, on comprenait aussitòt ce que la musique voulait dire. Mais Telemann a fréquemment dípassé le but; il est tombé dans le mauvais goùt, en peignant des sujets que la musique ne doit pas peindre. Grain alait, au contraire, un goût beaucoup trop délicat pour tomber dans celte faute; la réserve sur laquelle il se tenait à ce sujet faisait qu'il peignait rarement ou pas diu tout, et qu'il se contentait, le plus souéent, d'une aimable mélodie. »

Et il est sùr que Graun a en effet un sens plus fin de la beauté. Mais Telemann en a un beaucoup plus grand de la vie.

\section{Kolithluncen zur Literatur, publiées à Viesne en 1804.}


L'AUtobIographie D'UN ILLUSTRE OLblíé.

Un critique distingué de ce temps, Christ-Daniel Ebeling, professeur au Johanneum de Hambourg, écrivait, peu après la mort de Telemann ${ }^{1}$ :

"... Son défaut capital, - défaut qui lui vient des Français, - c'est sa passion pourles peintures musicales. Il les employait parfois tout à fait à contresens, restant attaché à l'expression d'un mot, et onbliant le sentiment général;... il voulut aussi peindre des choses qu'aucune musique ne peut rendre... Mais personne ne peint avec des traits plus forts, et ne sait davantage transporter l'imagination, quand ces beautés sont à leur place...."

Il ne faut pas oublier que IIændel prêta, de son temps, aux mêmes critiques, de la part des Allemands. Peter Schulz écrivait, en 17\%2:

" Je n'arrive pas à comprendre comment un homme du talent de Hændel a pu s'alsaisser, lui et son art, au point d'avoir cherché à peindre jar des notes, dins un oratorio des Plaies d'Égypte, les sauterelles qui sauient, le tourbillon des poux, et autres choses aussi dégouttantes. On ne saurait imaginer un mésusage plus absurde de l'art. »

Le brave Peter Schulz est un charmant musicien, et il a peut-être raison, en théorie; mais à quoi servent les théories? Tous les esthéticiens du monde peuvent bien prouver par $\mathbf{A}+\mathbf{B}$ que toute description musicalo est absurde et que Hændel, comme plus tard Berlioz et Richard Strauss, ont péché contre le bon goût et contre la musique même : rien ne fera que le chœur de la grêle, dans Israël en Eyypte, ne soit un chef-d'œurre, et qu'on ne puisse pas plus résister à son tourbillon

1. Hamburge Unterhaltungen, 1770. 
qu'à celui de li Marche de Rakokczy ou de la bataille, dans Ieldenleben. - Mais sans entrer dans une discussion, inutile, - (car la musique se passe de ces discussions, et le public suit la musique, laissant les discuteurs), - ce qu'il faut remarquer ici, c'est que, dans lo cas de Telemann, on relevait, de son temps, des influences françaises.

On l'a vu par sa biographie: les moyens deconnaitre la musique française ne lui avaient pas manqué. En somme, son éducation musicale avait étó plus française qu'allemande. Une première fois, à llanovre, lorsqu'il était au gymnase de Ilildesheim, vers l'âge de dix-sept ans, - une seconde fois, à Sorau, en 1703, - une troisième fois, à Eisenach, en 1709, auprès de Pantaleon Hebenstreit, il s'était trouvé dans un milieu d'art français, et il s'était appliqué à écrire en style français. Son voyage de 1737 à l'aris avait achevé de faire de lui un Français en Allemagne, dévoué à la cause de notro musique, et propagandiste passionné. «Il l'avait mise à la mode en Allemagne'. "

Et s'il pensait à publier ses impressions de voyage à Paris, c'était, de son aveu, pour « combattre les yréjugés courants à l'égard de la musique française n et pour la mettre en lumière " dans sa vraie beanté, comme une subtile imitatrice de la nature ».

Un document très curieux nous montre quelle fine connaissance Telemann avait du style français : c'est une correspondance avec Graun, en 1751-1732, au sujet de Rameau ${ }^{2}$. Gramn avait envoyé à Telemann une longrue lettre, où il dépeçait les récitatifs de C'astor

1. Inmburgische Berichte von gelehrten Suchen, 1737.

2. Habliec par M. Nax Schueider. 
et Pollux. Il en blâmait lo manque de naturel, les intonations fausses, l'arioso introduit mal à propos dans le récitatif, les changements de mesure sans raison, qui, dit-il, " causent des difficultés au chanteur et à l'accompagnateur : donc ils ne sont pas naturels. Et je tiens pour une règle capitale qu'on ne doit recourir à aucune difficulté antinaturelle, sans une raison importante. "-Bref, il déclare que "le Récitatif-Singen (le chant du récitatif) francais lui fait l'effet d'un hurlement de chien', que nulle part si ce n'est seulement en France le récitatif français ne plait, comme il en a fait l'expérience, toute sa vie "; et il daube sur Rameau. "Rameau, que les Parisiens appellent le grand Rameau, l'honneur de la France... Il doit avoir fini par y croire lui-mème : car, à ce que raconte Hasse, il dit qu'il ne peut rien écrire de mauvais.... Je voudrais bien eavoir où l'on trouve sa science rhétorique, philosophique et mathématique: dans la mélodie ou dans la polyphonie?... Je confesse que je n'ai guère ou point étudié les mathématiques, je n'en ai pas eu l'occasion dans ma jeunesse; mais mon expérience m'a montré que les compositeurs mathématiciens ne font rien qui vaille. Témoin, Euler, qui écrivait des morceaux faux... »

\section{Telemann répond ${ }^{2}$ :}

a Hautement noblement né, hautement honorable Monsieur et très digne ami,... nous allons donc nous mesurer! Vous prétendez que le récitatif des V'elches ${ }^{3}$ est plus raisonnable que celui des Français. Je dis qu'ils ne valent rien, ni l'un ni l'autre, en tant que nous y cherchons une

1. -... Le chant français n'est qu'un aboiement continuel, insupportable à toute oreille non prévenue " (J.-J. Rousseau, Lettre sur la musique françuise).

2. 15 décembre $1751 .-3$. C'est-ì-dire des Italiens. 
ressemblance avec la parole; et si vous y tenez, je veux bien souscrire pacifiquement le mandat qu'à l'avenir tous les peuples devront réciter à la facon italienne... Mais quant aux exemples musicaux dont vous me faites part, vous vous étes complètement fourvoyé. Car la plupart des passages de Rameau, que vous critiquez, témoignent d'une pénétration non petite dans l'art du discours. 》

Là-dessus, il reprend le passage de Rameau, cité par Graun ${ }^{1}$ :

Télaïre (à Pollux).

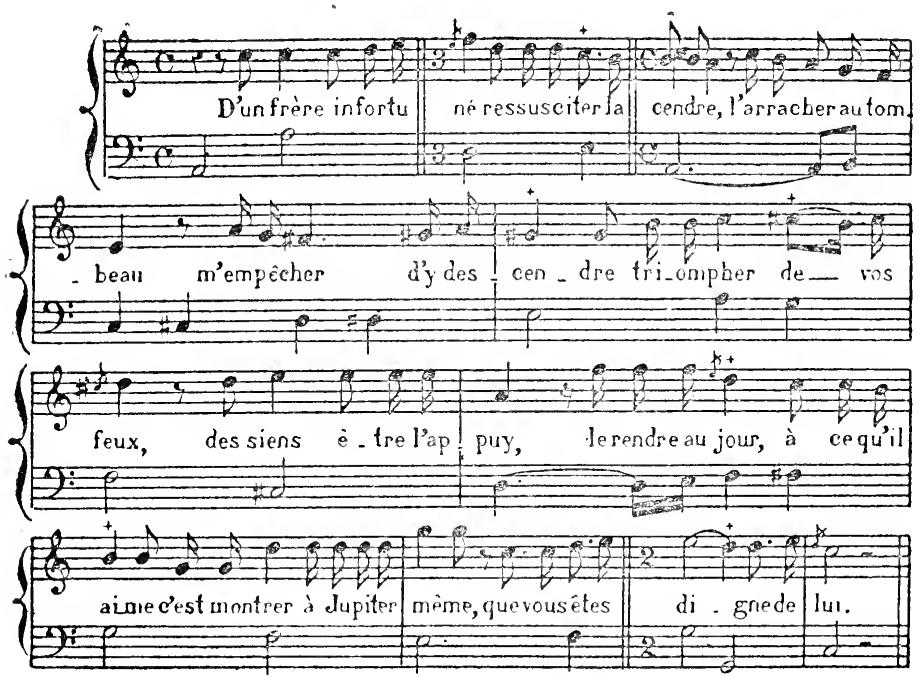

a Dans cet exemple, dit-il, la passion dominante est impérieuse, ce qui ressort des mots : a Digne de Jupiter même ». Le composteur a non seulement exprimé cette

1. Castor et Pollux, acte II, scène $\mathbf{5}$. 
passion, mais rendu aussi les sentiments accessoires, en passant. Le mot : “ Infortunè 》 est rendu tendrement.

- Ressusciter », par un trille qui roule. "L'arracher au tombeau 》: pompeux. " I'cmpêsher 》: un retard. a Triomphe 》: hautain. "A ce qu'il aime » : tendre.

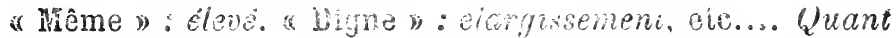
ì la basse, snus êire fade, ello ne sarirail être antre qu'elle n'esi. - Comment se comporte maintenant " notre Isalien »? - (L' "Italien "était Graur, qui arait prétendu corriger et refaire le passage de liameau; et voici quelle était sa rersion :)
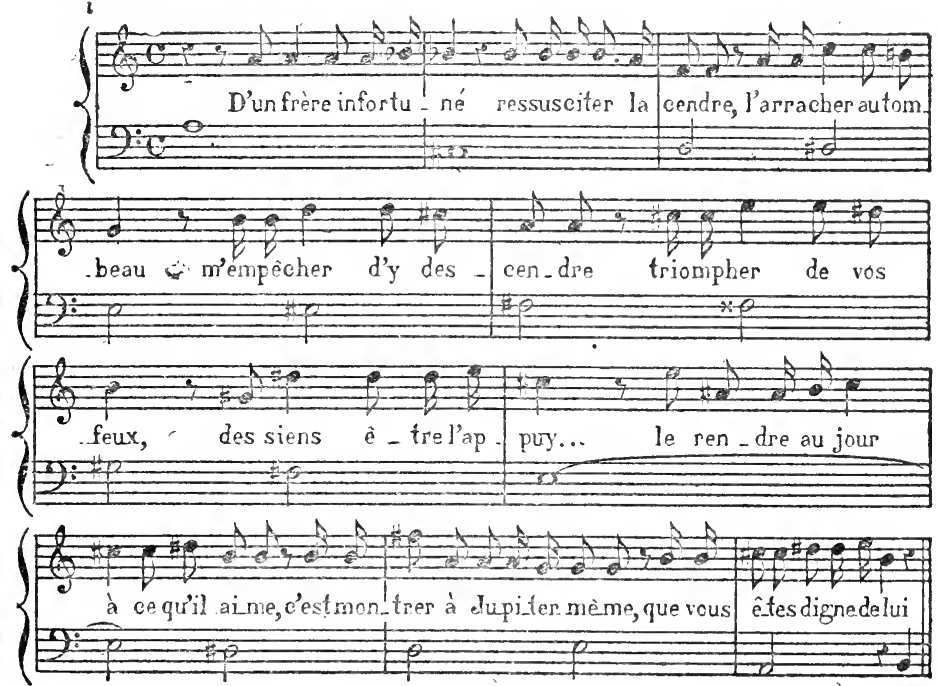

Telemann, malignement, s'amuse à la passer au crible.

"L'harmonie, dit-il, est jusqu'à la moitie. trisle et angre; les mots, malgré leur diversité, sont rendus de la même facon, qui est fatigante pour l'oreille.... Il y $a, \dot{a}$ 
la seconde mesure, une paise qui interrompl le sens; a la sej,tiène, une faute de prosodie: " rendre au jour", en quatre syliabes... ». - Suivent des observations tris justes sur la façon dont un Français "récite » uno question, tout autrement qu'un Italien, - sur la prononciation de divers mots français, que Graun a mal saisie, - sur les « mots privilégiés », qui doivent avoir des vocalises, en français : "Triompher, voler, chanter, rire, gloire, victoire ". (Telemann a ici un petit sourire ironique). - "Quant aux changements de mesure, ils n'offrent aucune difficulté à un Français. Tout cela court, tout cela mousse et pétille comme un vin de Champagne.... Les récitatifs français, dites-vous, ne plaisent en aucune partie du monde. Je n'en sais rien, parce que les livres d'histoire n'en disent rien.... Mais ce que je sais, c'est que jai connu des Allemands, des Anglais, des Russes, des Polonais, et mème une paire de Juifs, qui me chantaient par cœur des scènes entières d'Atys, de Bellérophon, etc. J'imagine que c'éiait parce que cela leur plai tit. En revanche, je n'ai pas vu un seul homme qui miait dit des Velches autre chose que ceci: C'est beau, c'est excelleni, c'est incomparable, mais je n'ai rien pu en retenir... »-Il ajoute que si lui, pour son compte, il écrit en général ses récitatifs « $\dot{a}$ la facon velche, c'est pour suivre le courant", mais qu'il a composé des cycles entiers de musique religieuse et des Passions dans le style français. Enfin, il termino par une profession de foi en faveur des audaces harmoniques, s'appuyant sur l'exemple des Français qui les applaudissent.

Graun, ur peu piqué, riposte'. Il prétend que ย. 14 jaavier 1752 , 
Telemann a mis quelque malice à défendre le récitatif de Rameau.... "Car, dit-il, vous lui prétez une inlention bien frivole, en voulant que l'expression soit sacrtlich (tendre) pour le mot: Infortuné. Je crois que si le mot était : Bienheureux, l'expression serait aussi bonne.... Exprimer la résurrection par un « trille roulant» m'est quelque chose de tout à fait nouveau... Dans toutes les Résurrections dont il est question dans les Écritures, on ne voit nulle part que quelque chose ait été a roule ".... Vous trouvez magnifique l'expression musicale pour : l'arracher au tombeau. Si la phrase disait: mettre dans lo tombeau, ce serait encore mieux.... Vous trouvez du tendre à ce qu'il aime. Ce serait à ce qu'il hait que cela conviendrait aussi bien. Quant à la prétendue sublimité du mot : même, je me représente un plaintif hurlement français, parce qu'il faut dire deu.x syllabes sur un son élevé, ce qui est toujours aigre, même avec le meilleur chanteur.... 》

\section{Et, après avoir noté certaines fautes de Rameau :}

- Mon cler, il me semble que vous étes un peu trop partial pour cette nation; autrement, vous ne laisseriez pas si facilement passer de telles fautes capitales, ni cette fausse rhetorique dont est pleine la musique de a l'honneur de la France ».

Puis, passant aux critiques adressées contre lui :

"Quant ̀̀ « notro Italien ", mon cher, en bon Allemand que je suis, comme vous, je cherche à exprimer le débit général du discours, et jabandonne l'expression des mots isolés, quand elle ne se présente pas d'une manière naturelle... Je préfère $m^{\prime}$ en tenir $\dot{a}$ la routine. qui est sage. La gradation crescendo du récitatif musi- 
cal me semble une imitation vraie de celui qui parle, et qui èlève la voix en parlant. »)

Il n'accorde pas sans peine qu'il s'est trompé dans le compte des syllabes du vers français, et il a cette curieuse excuse :

a Les comédiens francais récilent leur poésie, comme si c'était de la prose, et sans tenir un compte exact des syllabes ${ }^{1}$. )

Nous n'avons pas la réponse de Telemann; mais une lettre de Graun, du 15 mai 17306 , nous montre que, quatre ans après. ils discutaient encore sur le récitatif de Rameau, et que ni l'un ni l'autre ne démordait de son opinion.

Cette joute d'esthétique entre deux des plus célèbres musiciens allemands du xvin ${ }^{\mathrm{e}}$ siècle, dénote chez tous les deux une connaissance attentive de la musique et de la langue française. Telemann s'y montre - co qu'il fut toute sa vie - le champion de l'art français en Allemagne. Le mot dont il se sert pour caractériser "la musique francaise, subtile imilatrice de la nature", convient aussi à désigner sa propre musique. Il a contribué à faire passer les qualités d'intelligence et de précision expressive de notre art dans la musique allemande, qui, sans cela, eût couru le risque, avec des maîtres comme Graun, de s'affadir dans un idéal de beauté vague et abstraite.

En même temps, il y importait les qualités de verve

1. L'observation de Graun s'appliquait à l'école de Baron, qui rompait la mesure des vers, au point qu'on ne pouvait distinguer si c'était des vers ou de la prose; - et encore plus, à la Dumesnil, alors célèbre, qui récitait les tirades poétiques avec une volubilité, dont les puristes étaient scandalisés 
prime-sauiière, d'expression nette, vive, alerte, de la musique polonaise et de la nouvelle musique italienne. Ce n'étaił point superflu : la puissante musique allemande sentait un peu le renfermé. On risquait de ne plus respirer, sans les grands courants d'air que les Telemann firent entrer par toutes les portes ouvertes de France, de Pologne, d'Italie, - en attendant que Jean Stamitz ouvrit la principale peut-être, la porte de Bohème. Si l'on veut comprendre l'extraordinaire flambée musicale qui illumina l'Allemagne du temps de Haydn, de Mozart et de Beethoven, il faut connaitre ceux qui ont préparé ce beau bùcher, il faut voir le feu s'allumer. Sans quoi, les grands classiques paraîtraient un miracle, alors qu'ils sont au contraire la conclusion logique de tout un siècle de génie.

\section{$*$}

Je vars montrer quelques-uns des chemins que Telemann a frayés à la musique allemande.

Au théâtre d'abord, même les plus injustes à son égard ont reconnu ses dons comiques. Il semble avoir été l'initiateur principal de l'opéra-comique allemand. Sans doute, on trouve des touches comiques çà et là chez Keiser : c'était une habitude du théâtre de Hambourg.qu'un clown, un valet bouffon, figurât dans toutes les pièces, même dans les tragédies musicales; on prêtait à ce personnage des lieder bouffes, d'un accompagnement très simple - (souvent à l'unisson) ou sans accompagnement. Hændel lui-même obéit à cette tradition, dans son Almira, jouée à Hambourg. On parle aussi d'un Singspiel de Keiser, remontant 
à 1710: Le bon vivant, ou la foire de Leipzig; et d'autres représentations du mème genre durent être données, à cette époque. Mais le style comique ne fut vraiment consacré dans la musique allemande que par les œuvres de Telemann; le seul opéra bouffe que nous ayons conservé de Keiser, Jodelet (1726), est postérieur à ceux do Telemann, et très certainement il s'en inspire. Telemann était d'humeur comique. Il commença par écrire, selon le goùt du temps, de petits lieder bouffes pour le clown de l'opéra ${ }^{1}$. Mais cela ne lui suffit point. Il avait ine tendance moqueuse, comme l'a noté M. Oitzenn, à montrer le côté comique d'une figure, ou d'une situation, dont le librettiste n'avait vu que le sérieux. Et il savait habilement dessiner des caractères comiques. Son premier opéra, joué à Hambourg: La patience de Socrate (Der geduldige Sokrates), 1721, offre d'excellontes scènes. Le sujet est l'histoire des malheurs de Socrate en ménage. Trouvant qu'il n'avait pas assez d'une mauraise femme, le librettiste lui en a généreusement uctroyé deux, qui se disputent, et que Socrate doit apaiser. Le duo des criailleuses, au second acte ${ }^{2}$, est amusant, et aurait encore du succès aujourd'hui.

Le courant bouffe se dessina surtout à partir de 1724 dans la musique de Hambourg. L'opéra ennuyait; on essaya d'importer en Allemagne les intermezzi comiques d'Italie, qui étaient dans toute leur nouveauté. On y mêlait des ballets comiques français. Au carnaval ae 1724, on donne à Hambourg des fragments de $l ' E u$ -

1. Ainsi, pour le personnage Turpino, dans Sieg der Schcenheit (1722), qui met en scène l'invasion des Vandales à Rome. - M. Ottzenn a publié un air bouffe de cet opéra, dans le Supplément à son étude : Telemann als Opernkomponist, 1902.

2. P. ร du Supplément de Ottzenn. 
rope galante de Campra, et de Pourceungnac, de Lully; Teleman nécrit des danses comiques ì la françaiso ${ }^{1}$. Et, l'ance suivante, il fait jouer un inlermezzo à l'italienne, Pimpinone oder die ungleiche Heirat (Pimpinone, ou le Mariage mal assorti), dont le sujet est exactement lo mène que celui de la Serva padrona, qui fut écrito quatre ans plus tard. Le siyle mnsical est, aussi, proche parent de celui de Pergolèse. Quel est lo modèle commun? Súrement un Italien, peut-être Leonardo Vinci, dont les premiers opéras bouffes datent de 17:0. En tout cas, volia un exemple curieux de la rapidité arec laquelle les sujets et les styles se transmetlaient, d'un bout de l'Europe à l'autre, et de l'adresse de 'Telemann à s'assimiler le génie étranger.

Le texte allemand de cette Serva padrona avant la lettre était de Pretorius. Deux personnages: Pimpinone et Vespetta. Trois scènes. - Pas de prélude orchestral. Au lever du rideau, Vespetta chante un excellent petit air, où elle énumère ses qualités commo femme de chambre ${ }^{2}$. La musique, pleine d'esprit, est d'un pur caractère napolitain, pergolésien, avant Pergolèse. Elle en a la viracité nerveuse, les petits gestes saccadés, les brusques arrêts et les soubresauts, les réponses gouailleuses de l'orchestre qui souligne, ou contredit la liste des vertus de Vespetta:

"Son da bene, son sincera, non ambisco, non pretendo...."

Paraît Pimpinone. Vespetta, dans un air allemand, commence à enjôler le vieux; au milieu de son chant, trois brefs a parte expriment son contentement. Un duo, où les deux personnages utilisent le même motif,

1. Une * Chaconne comique "et un " Niais *, dans son Damon de $\mathbf{1 7 2 4 .}$ Voir p. 41 de l'ouvrage de Oltzenn.

2. P. 31 du Supplément de Ottzenn. 
termine la première scène, ou le premier intermezzo. Dans le second, Vespetta demande pardon pour une faute insignifiante, et elle s'y prend de telle façon qu'elle reçoit des éloges. Elle fait tant que Pimpinone lai propose de devenir Pimpinona. Elle se fait beancoup prier. Dans le troisième intermezzo, elle est devenue padrona. Prrgolèse n'a pas été jusque-là : en quoi il a montré son tact; car l'histoire devient moins plaisante. Mais il fallait des coups de bâton, pour contenter le public de Hambourg. Donc Vespetta gouverne, et elle ne laisse plus la moindre liberté à Pimpinone, qu'on voit seul et se lamentant. Il se joue à lui-même une conversation de sa femme avec une commère, - (il imite les deux voix) - puis une discussion entre lui et sa femme, où il n'a pas le dernier mot. Vespetta paraît. Nouvelle discussion. Dans un duo final, Pimpinone, rossé, pleurniche, tandis que Vespetta rit aux éclats ${ }^{1}$. C'est un des premiers exemples de duo, où les deux caractères soient tracés d'une façon individuelle, et comique par leur opposition même. Hændel, tout grand musicien de thêâtre qu'il fût, n'a jamais tenté véritablement cet art nouveau.

Evidemment. le style comique de Telemann est encore trop italien; il fau !ra l'assimiler davantage à la pensée, à la parole germanique, le combiner avec cette forme de petits lieder, d'une bonhomie bouffonne, que Telemann emploie aussi à l'occasion. Mais, enfin, le premier pas est fait. Et ce style alerte et pétillant de Vinci ou de Pergolèse ne sera plus oublié par l'art allemand; il fouettera de sa verve la gaieté trop gourmée des compatriotes du grand J.-S. Bach. Non sculement. il

\section{P. 35 du Supplément de Oltzenn.}


contribuera à la formation du Singspiel allemand, mais de la nouvelle symphonie de Mannheim et de Vienne; il l'éclairera de son rire.

Je passe sur les autres intermezai comiques de Telemann : la Capricciosa, les Amours de Vespetta (seconde partie de Pimpinone), etc. Je note seulement, au passage, un Don Quichotte (1733) qui a de joyeux airs et des caractères bien tracés ${ }^{1}$.

Mais ce n'est là qu'une des faces du talent de Telemann, au théâtre; on a trop oublié l'autre masque, le tragique. Même le seul historien qui ait abordé l'étude de ses opéras, M. Curt Ottzenn, n'y insiste pas assez. Quand sa fièrre d'écrire lui permet de réfléchir à ce qu'il fait, Telemann est capable de tout, mêmo d'être profond. Ses opéras n'ofirent pas seulement de beaux airs sérieux, mais - ce qui est plus rare - de beaux chœurs. Celui qui représente, au troisième acte de Solirates $(1721)^{2}$, une fète d'Adonis, est d'un style étonnamment moderne ${ }^{3}$. L'orchestre comprend trois clarini sordinati (trompettes graves roilées), deux hantbois, qui font entendre en notes longues une mélodie plaintive, deux violons, une viole, et la basse, senza cembalo. La sonorité en est fort belle. “ Telemann a obtenu vaiment la fusion des divers groupes sonores », que l'on ne cherchait guère alors. Le morceau est d'une émotion sereine, qui a déjà la pureté néo-antique de

1. Voir, p. 4 it de Ottzenn, le premier air de Don Quichotte, paisible et entêté, bon toqué, avec les fanfares de violons qui célèrent à l'avance les exploils du héros. - Le puème est de Seliebler, qui fut plus tard un des libreltistes de J.-A. Hiller, le grand auteur de Singsinele allemands.

2. uter aussi des quinteites dans Solrates: (les disciples et Aristo. phane, - ou les disciples et le valet Pitho).

3. P. 7-10 du Supplémen'l de Ottzenn.

R. Foldad - Voyge musical. 
Gluck. Ce pourrait être un chour d'Alcest", et l'harmonie en est expressive.

On trouve aussi chez Telemann une note romantique, une poésie de la nalure, qui n’est pas inconnue à Handel, mais qui est peut-être plus raffinée chez Telemann, - quand il veut bien s'appliquer, - car sa sensibilitó est plus moderne. Ainsi, l'air de rossignol, chanté par Mirtilla, dans Damon (172\%)', tranche, parmi les innombrables airs de rossignol de ce temps, par la subtilité de son impressionnisme.

\section{$*^{*} *$}

Les opéras de Telemann ne suffisent pas à le juger. Ceux qui nous ont été conservés, et qui sont au nombre de huit, - plus la Serenata : Don Quichott der Löwenritter (Don Quichotte, le chevalier aux lions), - ont tous été écrits à Hambourg, dans une période restreinte, de 1721 à $1729^{2}$. Dans le demi-siècle qui a suivi, Telemann s'est beaucoup développé; et on ne sera juste pour lui que si on l'apprécie d'après les œuvres de la seconde moitié de sa vie, ou même de la fin : car là seulement, il donne toute sa mesure.

A défaut d'opéras, nous avons, pour cette période, des oratorios et des cantates dramatiques. Ceux qui ont été publiés par M. Max Schneider, dans les Denkmaeler der Tonkunst, - le Jour du Jugement (Der Tag des Gerichts) et Ino - sont presque aussi intéressants à étudier, pour l'histoire du drame musical, que des opéras de Rameau et de Gluck.

1. P. 27-28 du Supplément de Ottzenn. Il y aurait lieu de lire aussi la Miriways de 1728.

2. Sauf le Don Quichott, qui est de 1735. 
Le poime du Jour du Jugement ${ }^{1}$, — « ein Singgeticht woll starlier Bewegungen 》) (un libretto plein do force et d'action), - était d'un ancien élève de Telemann au Gymnasium de Hambourg, le pasteur Ahler. Libre pasteur, nullement piétiste. Au début de son curre, les croyants attendent l'arrivée du Christ; l'incroyant se moque d'eux, en bon philosophe du xvire siècle, au nom de la science et de la raison. Après une première méditation, un peu faible et abstraite, commence le cataclysme. Les vagues se soulèvent, les éclairs luisent, les mondes vacillent et tombent, l'ange parait, la trompette sonne. Voici le Christ. Il appelle à lui les croyants, dont le chœur entonne ses louanges; et il rejette dans l'abìme les pécheurs, qui hurlent. La quatrième partie décrit la joie des bienheureux. - De la seconde à la quatrième partie, l'œuvre forme un crescendo puissant; et l'on peut dire que la troisième et la quatrième parties ne sont qu'un tout, fortement lié, sans interruption. «Depuis la seconde Méditation, il n'y a plus une pause entre les morceaux, la musique coule, d'un flot, jusqu'à la fin. Même les airs da capo, souvent employés au début, disparaissent, ou ne sont plus employés que d'une façon très sobre, aux instants où le drame ne s'y oppose point ${ }^{2}$. "Récitatifs, airs, chorals et chœurs se fondent, entrent les uns dans les autres ${ }^{3}$, se font valoir par contraste, doublant ainsi leur effet dramatique 4 . Telemann s'en est donné à cœur joie, avec un sujet qui

1. La première exécution eut lieu le 17 mars 1762 .

2. Nax Schneider.

3. Voir le chant de Jésus qui s'enchaine au chant des croyants.

4. Ainsi, le chœur dramatique : Ach Hülfe, que fait ressortir le voisinage d'un choral grégorien, calme et monotone. 
lui fournissait l'occasion d'aussi riches peintures : les crépitements et les vagues tumultueuses des violons, dans le chœur qui ouvre la seconde partie : Es rauscht, so rasseln stark rollende Wragen, avec sa fin dramatique, presque beethovenienne; le récit des prodiges, avantcoureurs de la fin du monde, les flammes qui jaillissent de la terre, le flot impétueux des nuées, l'harmonie des sphères qui se rompt, la lune qui sort de sa route, l'océan qui se soulève; enfin, la trompette du Jugement. Le plus saisissant de tous les chœurs est celui des pécheurs précipités en enfer, avec ses syncopes d'effroi et le grondement de l'orchestre ${ }^{1}$ - - Les jolis airs ne manquent pas, surtout dans la dernière partie ${ }^{2}$. Mais ils sont moins originaux que les récitatifs accompagnés, avec les peintures de l'orchestre. C'est le style de Hændel ou de J.-S. Bach, dégagé de la rigueur de l'écriture contrapontique. L'art mélodique nouveau s'y mêle parfois à une sévérité de forme, qui était déjà archaïque, pour Telemann ${ }^{3}$. Là, n'est pas l'importance de l'œuvre, mais dans les scènes descriptives et les chœurs dramatiques.

La cantate Ino va bien plus loin encore dans la voie du drame musical. Le poème est un chef-d'œuvre, de Ramler, qui contribua à la résurrection du lied allemand. Il fut publié en 1763 . Plusieurs compositeurs le mirent en musique : entre autres, Joh. ChristophFriedrich Bach de Bückeburg, Kirnberger, l'abbé Vogler. Ce serait encore un beau sujet de cantate pour

1. P. 77, de l'édition des Denkmæler.

2. Par exemple, l'air avec gamba: Ein ew'ger Palm (p. 92); - l'air avec deux violons : Heil! wenn um des Erwürgten (p. 96); - ou l'air avec grosie oboe e fagotto: Ich bin erwacht (p. 103)).

3. Voir les deux airs du Christ (p. 73 et 82 ), qui sont beaux et ont de la dignité, sans profondeur intime. 
un musicien d'aujourd'hui. - On connait la légende d'Ino, fille de Cadmus et d'Harmonia, sœur de Sémélé, et nourrice de Dionysos. Elle épouse le héros Athamas. Athamas, que Junon rend fou, tue l'un de ses fils, et veut tuer l'autre. Ino s'enfuit, avec l'enfant, et toujours poursuivie, elle sejette dans la mer, qui lui fait accueil; elle y devient Leucothea, la blanche, pareille à l'écume des vagues. - Le poème de Ramler met en scène la seule Ino, du commencement à la fin : c'est un rôle écrasant, car il y faut dépenser une passion continuelle. Au début, elle arrive, en courant, sur les rochers au-dessus de la mer; elle n'a plus la force de fuir, elle invoque les dieux. Elle aperçoit $A$ thamas, elle entend ses cris, elle se jette dans les flots. Une douce et calme symphonie l'y reçoit. Ino exprime son émerveillement; mais son enfant s'est échappé de ses bras; elle le croit perdu, l'appelle, et demande à mourir. Elle voit le chœur des Tritons et des Néréides qui le porte; elle décrit son voyage fantastique au fond de la mer; les coraux et les perles s'attachent à sa chevelure; les Tritons dansent autour d'elle, ils la saluent déesse, sous le nom de Leucothea. Soudain, Ino voit les dieux marins qui se retournent et qui courent en levant les bras : c'est Neptune qui arrive sur son char, le trident d'or à la main, avec ses chevaux qui s'ébrouent. Et un chant de gloire au Dieu termine la cantate.

Ces magnifiques visions helléniques prêtaient à l'imagination d'un musicien poète et peintre. La musique de Telemann est digne du poème. Il est prodigieux qu'un homme de plus de quatre-vingts ans ait écrit une œuvre aussi fraîche et aussi passionnée. Elle appartient nettement à la catégorie des drames musicaux. Si Gluck a très probablement exercé son 
influence sur l'Ino de Telemann ${ }^{1}$, il se pourrait que l'Ino, à son tour, lui eùt beaucoup appris. Bien des pages rivalisent avec les plus célèbres récitatifs dramatiques d'Alceste ou d'Iphigénic en Aulide. Bès les premières mesures, on est jeté en pleine action. Une énergie grandiose, un peu lourde, cornme celle de Gluck, anime le premier air ${ }^{2}$. L'orchestre qui décrit l'épouvante d'Ino, l'arrivée d'Athamas, Ino qui se jette dans la mer, est d'un pittoresque étonnant, pour l'époque. On croit voir, à la fin, les flots qui s'ouvrent, on suit le corps d'Ino disparaissant au fond, et la mer qui se referme. La symphonie sereine, qui peint le calme royaume des eaux, a une beauté Hrendelienne. Mais rien, dans cette cantate, ni, je crois, dans l'œuvre entier de Telemann, ne surpasse la scène du désespoir d'Ino, quand elle croit avoir perdu son fils ${ }^{3}$. Ces pages sont dignes de Beethoven, avec quelques touches berliozéennes dans l'accompagnement orchestral. L'émotion est d'une intensité et d'une liberté uniques. L'homme capable d'écrire une telle page était un grand musicien et méritait sa gloire, et ne mérite pas son oubli d'aujourd'hui.

Le reste de l'œuvre n'a plus rien qui atteigne à celte hauteur, quoique les beautés ne manquent point, et que, comme dans le Jour du Jugement, elles se fassent valoir les unes les autres, soit par leur enchaînement ${ }^{4}$, soit par leurs contrastes. Les gémissements passionnés d'Ino sont suivis d'un air en $9 / 8$,

1. L'Orfeo de Vienne est de 176', la première Alceste de 1769.

2. Surtout la seconde partie de l'air, p. 129 des Dentimæler.

3. P. 138-140.

4. Tous les morceaux forment une chaine qui se tient, du cummencement s̀ la fin. 
qui peint la belle ronde des Néréides autour de l'enfant. Puis, c'est le royage d̀ travers les eaux, les varues légères qui portent "les divins royageurs », de petites danses en "style galant ", qui font un court repos, au milieu du chant, - un air délicieux arec deux flùtes et violons con sordini : Meint ihr mich, un peu dans le style vocal et instrumental de Irasse. Un récitatif instrumental éroque arec puissance l'apparition de Neptune. Enfin, l'œuvre a pour conclusion un air de bravoure, qui anncnce le style Rossiniste germanisé, tel qu'on le trouve, dans les vingt premières années du xix sièele, chez Weber, el mème un peu chez Beethoven. - Dans tout le cours de cetto ceurre, il n'y a pas une interuption de musique, pas un recitativo secco. Tout est d'une seule coulée et suit le mouvemert du poème. Deux seuls airs da capo, au débutet à la fin.

Quand on lit de tels ouvrages, on est confus d'avoir si longtemps ignoré Telemann, et en mème temps on lui en veut de n'avoir pas fait d'un tel talent l'usage qu'il aurait pu, - qu'il aurait dù. On s'indigne de trouver des platitudes et des niaiseries à côté de parfaites beautés. Si Telemann avait été plus soucieux do son génie, s'il n'avait pas tant écrit, tant accepté de tâches, son nom aurait peut-ètre laissé dans l'histoire un écho plus profond que celui de Gluck; en tout cas, il eùt été associé à sa gloire. Mais c'est ici qu'on voit la justice morale de certains arrêts de l'histoire : il ne suffit pas d'avoir du talent en art, il ne suffit mème pas d'y joindre de l'application - (qui travailla plus que Telemann?) - il faut le caractère. Gluck, avec beau-

\section{P. 152 .}


coup moins de musique que dix autres compositeurs allemands du xvir siecle, - que Ilasse, que Graun, que 'Telemann, - a réalisé l'ceurre, dont les autres avaient amassé les matériaux - (et il n'en utilisa mème point la dixième partie!) - C'est qu'il exerça une discipline souveraine sur son art et sur son génie. Il fut un homme. Les autres n'ont été que des musiciens. - Et, en musique même. cela n'est pas assez.

\section{NOTE ANNEXE}

Il y aurait lieu d'étudior aussi le rôle de Telemann dans l'histoire de la musique instrumentale. - Il fut un des champions en Allemagne de l'ouverture française. - (On sait que l'on désigne sous ce nom la symphonic Lullyste, à trois parties : $1^{\circ}$ lentement, $2^{\circ}$ vitement, $3 \circ$ lentement, le vilement ayant un caractère librement fugué, et le lentement du début se reproduisant en général, à la fin.) - L'ouverture francaise s'était introduite en Allemagne, dès 1679 avec Stefiani, et 1680 avec Cousser; elle eut son apogée, précisément à l'époque de Telemann, pendant les vingt premières années du $x^{\prime}{ }^{\prime} I^{\mathrm{e}}$ siècle. On a vu que Telemann avait cultivé celte forme instrumentale, avec prédilection, vers 170'-170弓, quand il apprit à connaître, chez le comte de Promnitz, à Sorau, les œuvres de Lully et de Campra. Il écrivit alors, en deux ans, 200 ouvertures /rançaises. Il emploie encore cette forme pour certains de ses opéras de Hambourg ${ }^{1}$.

Cela ne l'empêche point d'user à l'occasion de l'ouverture italienne. - $\left(1^{\circ}\right.$ rapide, $2^{\circ}$ lent, $3^{\circ}$ rapide. $)$ - Il la nommait : concerto, parce qu'il y employait un violon principal concertant. Nous en avons un assez joli exemple dans l'ouverture de Damon $(1724)^{2}$, dont le style est analogue à celui des

1. L'ouverture, assez médiocre, de Sokrates (1721), est de ce type.

2. P. 18 et suiv. du Supplément de Ottzenn. 
concerti grossi de Hændel, qui sont de 1733-1739. On remarquera que la troisième partie (vivace $3 / 3$ ) est un da capo, dont la partie du milieu est en mineur.

Telemann écrivit également, pour ses opéras, des pièces instrumentales où l'on sent l'influence française, - surtout dans les danses ${ }^{1}$, parfois chantées.

Parmi les autres formes orchestrales qu'il pratiqua, la principale est le trio instrumental, la Trio-Sonate, comme l'appellent les Allemands ${ }^{2}$. Elle a tenu une très grande place dans la musique, depuis le milieu du xvir siecle jusqu'au milieu du $\mathrm{Xvill}^{\circ}$, et elle a beaucoup contribué au développement de la forme sonate. Telemann s'y adonna surtout à Eisenach, en 1708; et il dit que rien de ce qu'il écrivait n'était autant apprécié que ces œuvres. - " Je faisais en sorte, dit-il, que la seconde partie semblâtêtre la première, et que la basse fùt une mélodie naturelle, formant arec les autres une harmonie appropriée, qui avançait, à chaque note, de telle façon que cela semblât ne pouvoir être autrement. 0 n voulut me persuader que j'avais montré là le meilleur de mes forces. ") - M. Hugo Riemann a publié un de ces trios, dans sa collection du Collegium Musicum. Ce trio, en mi $b$ majeur, extrait de la Tafelmusik de Telemann, est en quatre morceaux : $1^{\circ}$ affeltuoso; $2^{\circ}$ vivace $3 / 8 ; 3^{\circ}$ grave; $4^{\circ}$ allegro $2 / 4$. Le second et le quatrième morceaux sont en deux parties avec reprise. Le premier et le deuxième morceaux ont une tendance à s'enchaîner, à la façon du grave et du fugué de l'ouverture française. La forme est encore celle de la sonate à un seul thème, auprès duquel commence faiblement à poindre un dessin secondaire. On est encore tout près de l'instant où le type sonate se dégage de la suite; mais les thèmes ont déjà un caractère moderne; plusieurs, surtout celui du grave, sont nettement italiens, - on peut dire : pergolésiens. Par sa tendance à l'expression indivi-

1. On en trouvera un certain nombre dans le recueil de M. Ottzenn : Sarabande et Gigue (p 29), Gavotte (p. 30), "le Niais " (p. 41), Bourrée, Chaconne, Passacaille, etc.

2. Il s'agit du trio à cordes, avec basse continue, c'est-à-dire, en somme, à quatre parties. 
duelle, dans la musique instrumentale, Telemann a exercé wne action sur Joh. Friedrich Fasch, de Zerbst; mais ici, le disciple a surpassé de beaucoup le maître. Fasch, sur qui H. Hugo Riemann a eu le grand mérite de ramener l'attenŁion, dans ces dernières anilées, a été un des maîtres les plus puissants de la Trio-Sonute, et un des initiateurs du style symphonique moderne. On voit que dans toutes les provinces de la musique : théâtre, église, ou musique instrumentale, Telemann est à l'origine des grands courants modernes. 


\section{VI}

\section{METASTAEE PRECURSEUR DE GLUCK}

La question du drame lyrıque n’a laissé indifférent aucun des grands musiciens et poètes-musiciens du $x_{\text {vinl }}$ siècle. Tous ont travaillé à le perfectionner, ou à le fonder sur des bases nouvelles. Ce serait une injustice d'attribuer au seul Gluck la réforme de l'Opéra. Hændel, Hasse, Vinci, Rameau, Telemann, Graun, Jommelli, et bien d'autres s'en préoccupèrent. Métastase lui-même, qu'on représente souvent comme le principal obstacle à l'établissement du drame lyrique moderne, parce qu'il fut en opposition avec Gluck, n'eut pas beaucoup moins que Gluck, (bien que d'une autre façon), le souci de faire entrer dans l'opéra toute la vérité psychologique et dramatique, qui était compatible avec la beauté de l'expression.

Il n'est peut-être pas inutile de rappeler comment se forma le talent de ce poète, le plus musical qui fùt jamais - " cet homme, ose dire Burney, dont les écrits ont probablement contribuè à la perfection de la mélodie vocale et de la musique en général, plus que les efforts réunis de tous les grands compositeurs de l'Europe ».

Dès ses débuts d'enfant prodige, l'étude de la musiquo 
lui avait donné l'idée de la réforme poétique qui devait l'illustrer. Les hasards de sa vie sentimentale, savamment dirigée, n'avaient pas peu servi à son perfectionnement poético-musical. Ce fut une chanteuse qui eut le mèrite de le découvrir. M. E. Celani a conté cette histoire dans un article intitulé : Il primo amore di P. Metastasio ${ }^{1}$.

Métastase avait d'abord aimé la fille du compositeur Francesco Gasparini, élère de Corelli et de Pasquini, l'homme qui possédait le mieux la science du bel canto, et qui forma les chanteurs les plus renommés, le maitre de la Faustina et de Benedetto Marcello. Ils se connurent à Rome en 1718-19. Gasparini voulait marier Métastase avec sa fille Rosalia, que Métastase a chantée sous le nom de Nice; et M. Celani a retrouvé le projet de contrat de mariage, qui fut dressé en avril 1719. Mais un obstacle imprévu surgit. Métastase partit pour Naples en mai 1719, et Rosalia épousa un autre.

A Naples, Métastase rencontra la femme qui devait avoir l'influence décisive sur sa carrière artistique : la Romanina (Narianna Benti), chanteuse célèbre, femme d'un certain Bulgarelli. Métastase était alors clerc d'avocat, chez un patron qui haïssait les vers : ce qui ne l'empêchait pas de composer des poésies, cantates et sérénades, qui paraissaient sous un autre nom. En 1721, il écrivit, pour un anniversaire de naissance impériale, une cantate : Gli orti Esperidi, qui fut mise en musique par Porpora; la Romanina, de passage à Naples, y chanta le rôle de Vénus. Le succès fut grand; la Romanina voulut connaître le jeune poète, et s'éprit de lui. Elle avait trente-cinq ans. Il en avait vingt-trois.

\section{Rivista Musicale Italiana, 1904.}


Elle n'était pas belle', elle arait les traits forts, assez masculins, mais une grande bonté sensuelle et beaucoup d’intelligence. Elle réuñissait chez elle, à Naples, l'élite des artistes : Hasse, Léo, Vinci, Palma, Scarlatti Porpora, Pergolesi, Farinelli. Métastase achera dans ce cercle sa culture poética-musicale, grâce aux conversa. tions de ces hommes, à l'instruction qu'il reçut de Porpora, et surtout aux conseils, aux intuitions et à l'expérience artistiques de la Romanina. Pour elle, il écrivit son premier mélodrame la Didone abbandonata (1721), qui marque une date dans l'histoire de l'opéra d'Italie, par son émotion et son charme raciniens. La Romanina fut l'interprète triomphante de ses premiers poèmes, entre autres de Siroe, que presque tous les grands compositeurs d'Europe devaient traduire en musique.

Après 1727, ils allèrent à Rome. Ils y menaient ung singulière vie de famille, à trois : Métastase, la Romanina, et le mari Bulgarelli. La Romanina méprisait son mari, et aimait jalousement Métastase d'un amour passionné. La vieille histoire, tant de fois répétée, eut son dénouement inévitable. Métastase partit. En 1730, il fut appelé à Vienne, comme " poeta Cesareo ». Il quitta Rome, laissant tout pouroir à sa "cara Marianna", pour administrer, aliéner, vendre, changer, convertir ses biens et ses rentes, sans aucun compte à lui rendre. Ia Romanina ne put supporter ce départ; trois mois après, elle se mit en route pour Vienne. Elle ne put dépasser Venise. Un contemporain ${ }^{2}$ écrit : «On raconte que la Didone abbandonata est en grande partie l'histoire de Métastase et de la Romanina. Métastase crai-

1. On trouvera dans l'article de Celani la reproduction de deux petit portraits, un peu caricaturesques (p. 250 et 252 ).

2. Lessing, bibliothécaire de Wolfenbüttel (voir Celani). 
gnait qu'elle ne lui causât des ennuis à Vienne, et que sa réputation nen souffrît. Il obtint un ordre de cour qui interdit à la liomanina d'entrer dans les domaines impériaux. La Romanina devint furieuse; et, dans son emportement, elle tenta de se tuer, en se frappant à la poitrine arec un canif. La blessure ne fut pas mortelle; mais elle mourut peu après, de douleur et de désespoir. »

Quelques lettres d'elle à l'abbé Riva, qui servait d'intermédiaire, montrent la passion de la malheureuso femme. Voici quelques lignes, particulièrement touchantes, écrites à Venise, le 12 août 1730 , sans doute après sa tentative de suicide, et quand elle avait promis J'être sage :

" Puisque vous conservez tant d'amitie pour l'Ami, gardez-le moi, soutenez-le, faites qu'il soit le plus heureux que vous pourrez, et croyes que je n'ai pas d'autre pensée au monde; et si, parfois je me désole, c'est parce que je connais trop son mérite, et que d'être forcée de vivre séparée de lui est la plus grande douleur que je puisse sentir. Mais je suis si résolue à ne pas démériter de son estime que je souffrirai patiemment la tyrannie de qui permet une telle cruauté : je vous assure que tout ce qu'il me sera rermis de faire pour plaire à mon très cher ami et pour le conserver, je le ferai; je ferai le possible pour me conserver en bonne santé, dans l'unique pensée de ne pas l'affliger.... )

Elle traîna sa misérable vie encore quatre ans. Métastase répondait avec une tranquille politesse à ses lettres passionnées. Les reproches de la Romanina lui semblaient « réguliers et inévitables, comme la fièvro quarte ». - Elle mourut, le 26 février 1734, à Rome, âgée de quarante huit ans, faisant à Métastoso le 
suprême afiront d'amour de le nommer son légataire unirersel. - "Et cela, disait-elle, je le fais non seulement en témoignage de ma reconnaissance pour ses conseils et pour son aide dans mes malheurs et ma longne maladie, mais encore afin qu'il puisse plus commodément se donner à ces études qui lui ont acquis tant de gloire. " - Métastase, rongissant de cette générosité, renonça à l'héritage en faveur do Bulgarelli, et il eut des remords amers, en pensant à la " povera e generosa Marianna .... "Je n'espère plus pouvoir mien consoler; et je crois que le reste de ma vie sera insipide et douloureuse. ") (13 mars 1734.)

Telle fut cette histoire d'amour, qui se trouve liée aux destinées de la musique, puisque c'est à l'influence de cette femme que Métastase a dû d'être le Racine de l'Opéra italien. L'écho de la voix de la Romanina résonne encore dans ses vers " si fuides et si harmonieux qu'il semble, disait Andrès, qu'on ne puisse les live qu'en chantant ».

Ce caractère de chant noté en paroles avait frappé les contemporains. Marmontel remarquait que « Métasiase avait disposé les phrases, les repos, les nombres, et toutes les parties de ses airs, comme s'il les eût chantés luinême ».

Il les chantait, en effet. Quand il composait ses drames, il était au cembalo; et souvent il écrivit la musique de ses poésies. On se sourient de Lully, se chantant au clavecin les poésies de Quinault, et les remaniant. Ici, les rôles sont intervertis. C'est le Quinault italien rui compose la pósic au clavecin, et déjà 
trace les linéaments de l'air qui doit la revêtir. - Dans une lettre du 15 avril 17300 , Métastase, envoyant à la princesse de Belmonte la musique de Caffarello sur sa poésie : „artenza di Nice, ajoute : "Caffarello a connu les défauts de ma musique (della mia musica) ), - (co qui laisse donc entendre qu'il en avait écrit une); - « il a eu compassion des paroles et les a revétues d'une meilleure étoffe $e^{1}$ ). - Dans une autre lettre de la même année (21 février 1750) à la même princesse, il disait :

"Votre Excellence sait que je ne puis rien écrire qui ait à être chanté, sans que j’en imagine (bien ou mal) la musique. La poésie que je vous envoie a été écrite sur la musique qui l'accompagne. C'est une musique à la vérité très simple; mais si on veut la chanter avec la tendre expression que j"y suppose, on y trouvera tout ce qu'il faut pour seconder les paroles. Et tout ce qu'on y ajoutera de plus recherché pourra bien procurer au musicien plus d'applaudissements, mais fera certainement moins de plaisir aux cœurs aimants ${ }^{2}$.

Jamais Métastase ne donnait ses compositions à un ami, sans y joindre la musique. On n'a donc pas le droit de juger des vers, à part, dépouillés de la mélodie qu'il entendait, dont il avait, comme dit Marmontel, “ le pressentiment ${ }^{3}$ ». - La musique lui semblait d'autant plus indispensable à la poésie qu'il vivait dans

1 Leltres inédites, publiées dans la Nuova Antologia vol. 77, et citées par Jole-Hlaria Baroni, dans son étude sur la Lirica musicale di Metastasio (Rivista musicale italiana, 1903).

2. lbid.

3. "Un talent sans lequel il est impossible à un poète de bien écrire une aria, c'est le pressentiment du chant, e'est-à-dire $\dot{v}_{1}$ caracière que l'air doit avoir, de l'étendue qu'il demande et du mouvement qui lui est propre (Marmontel). 
un pays allemand, où sa langue italienne n'avait tout son pouvoir que lorsque le charme de la musique la faisait pénétrer dans l'âme étrangère. Il écrivâit en 1760, au comte Florio : «Depuis les premières années que je me suis transplanté dans cette terre, je me suis convaincu que notre poésie n'y prend racine qu'autant que la musique et la représentation s'y ajoutent ».

Ainsi, sa poésie était faite pour la musique et pour la représentation théàtrale. On imagine combien elle dut séduire tous les musiciens italiens et italianisants $\mathrm{du}$ siècle. Suivant le mot de Marmontel, « tous les musiciens se sont donnés à lui ${ }^{1}$ ». D'abord, ils furent captivés par l'harmonie de ses vers. Puis, ils trouvèrent en lui un guide très doux, très poli ${ }^{2}$, mais très ferme. Hasse se mit sous sa tutelle. Jommelli disait qu'il avait plus appris de Métastase que de Durante, Leo, Feo, et du père Martini, c'est-à-dire de tous ses maîtres. Non seulement ses vers, auxquels il ne permettait pas qu'on fît de changements, se prêtaient merveilleusement à la mélodie, l’inspiraient, l'appelaient, pour ainsi dire; mais très souvent, ils suggéraient au musicien le motif de l'air ${ }^{3}$.

1. M. Francesco Piovano, quı prépare une bibliographie Métastasienne, évalue à 1200 le nombre de partitions composées sur des textes de Métastase (Revue I. M. G., oct.-déc. 1906).

2. Burney a tracé un portrait charmant de Métastase, qu'il vit à Vieune. Il avait, dit-il, une conversation pure, vive, aisée. Il était gai, aimable, plein de charme, extrêmement poli. Il ne disputait jamais par politesse et par indolence. Jamais il ne répliquait à une proposition erronée. Il n'aimait pas la discussion. "Il avait ce calme, celle douce harmonie, qu'on retrouve dans ses écrits, où la raison fait tout, jamais le délire, même dans les passions."

3. Burney raconte une conversation entre un visiteur anglais et Métastase. L'Anglais demande si llétastase n'a jamais mis un de ses opéras en musique. Nétąstase repond que non, mais qu'il lui est arrivé de donner au musicien les motifs de ses airs.

R. Roliamd. - Voyago musical. 
Jole-Maria Baroni, dans une étude sur la Lirica musicale di Metastasio ${ }^{1}$, a fait une brève analyse des divers genres poético-musicaux qu'il traita : Canzonette, Cantate, Arie. Je me borne à indiquer ici les réformes musicales que Métastase fut amené à accomplir.

Il eut le mérite de restaurer les chœurs dans l'opéra italien. En cela, il s'appuya sur les traditions musicales, qui s'étaient conservées à Vienne. Tandis que les chœurs étaient tombés en désuétude dans les opéras d'Italie, les maîtres viennois Joh.-Jos. Fux et Carlo Agostino Badia en avaient obstinément conservé l'emploi. Métastase tira partı de cette survivance; et il traita les chœurs avec un art inconnu jusqu'à lui. Il eut soin de ne les introduire qu'au moment de l'action où ils étaient naturels et nécessaires. Et l'on sení qu'en les écrivant, il prit souvent modèle sur la simplicité solennelle des tragédies antiques ${ }^{2}$. C'est dans le même esprit que les compositeurs, amis de Métastase et soumis à son influence, comme Hasse, les ont traités en musique. Qui prendra connaissance du chœur magnifique des prêtres, dans l'Olimpiade de Hasse (1756), y admirera, avec surprise, le plein épanouissement du style néo-antique, simple, tragique et religieux, dont on est trop enclin à attribuer le monopole, ou l'invention, à Gluck.

Mais c'est dans la scène récitative que Métastase et ses musiciens accomplirent les principales réformes.

L'opéra italien d'alors était un assemblage mal équilibré de recitativo secco et d'airs. Le recitativo secco

1. Rivista musicale Italiana, 1905.

2. Ainsi, dans l'Olimpiade, la Clemenza di Tito, A lillo in Sciro, c'est-àdire dans sers couvres de la maturité. 
était une psalmodie monotone et très rapide, s'écartant peu du parlar ordinaire, et déroulant son inteminable fibereau sur l'accomparnement du clavecin solo, sontena de quelques basses. Le musicien ne s'en souciait guère, réservant ses soins pour l'Aria, où sa virtuosité et celle de l'interprète se donnaient libre champ. Au contraire, le poète restait attaché au recitativo. qui permettait d'entendre assez nettement ses rers. Cette cote mal taille ne satisfaisait personne. Le poète et le musicien étaient tour à tour sacrifiés; presque jamais, ils n'associaient vraiment leurs efforts. - Cependant, depuis la seconde moitié du xvil siècle, s'était glissce dans l'opéra une forme intermédiaire, qui devait peu à peu prendre la première place, qui l'a prise (dirai-je : malheureusement!) dans le drame lyrique moderne : - cétait le récitatif accompagné par l'orchestre, le recittivo stromentale, ou, d'un nom plus courant et plus bref, l'Accompagnato. Lully en avait fait un bel usage, dans ses derniers opéras ${ }^{1}$. Mais, dans l'opéra italien, l'Accompagnato ne s'installa, d'une façon régulière, qu'à partir de IIændel ${ }^{2}$ et de Leonardo Vinci (1690-1732). Ce dernier, que le président do Brosses appelait le Lully italien, eut déjà l'idée d'employer l'A ccompagnato, au faite de l'action dramatique, pour peindre les passions portées au paroxysme. Toutefois, çavaient été plutôt chez lui des intuitions de génie, dont il ne s'était pas préoccupé de cueillir les fruits.

Le mérite d'avoir compris l'importance de cette invention et de l'avoir utilisée, d'une façon logique et

\footnotetext{
1. Triomple de l'Amour (1680), Persée (1682), Phatéton (1683).

2. Giulio Cesare (1724), Tamerlonn (1724), Admeto (1727).
} 
raisonnée, semble revenir à IIasse, sous l'influence de Métastase, ainsi que l'a montré $\mathbf{H}$. IJermann Ibert ${ }^{1}$. A partir de la Cleofide de $1731^{2}$, dont le second acte so termine par une grande scène récitative accompagnée, très hardie, Hasse emploie les Accompagnati pour les fins d'actes et les sommets de l'action : visions, apparitions, lamenti, invocations, tumulte de l'âme. Dans la C'emenza di Tito de 1738, M. Abert note six Accompagnati, dont cinq sont réservés aux deux héros principaux et peignent leurs déchirements intérieurs; le sixième, qui appartient à un personnage secondaire, est la description de l'incendie du Capitole. Deux de ces grands récitatifs d'orchestre ne sont suivis d'aucun air. - Dans la Didone abbandonata de 1743 , on remarquera tout particulièrement le dénouement tragique, qui contredit (entre tant d'autres exemples ${ }^{3}$ ) la légende erronée affirmant que tous les opéras avant Gluck étaient obligés par la mode à un dénouement heureux. Tout le drame se ramasse en cette scène finale, sobre, violente et tendue.

Quelle part avait Métastase à la pratique de cette architecture poético-musicale, qui réserve les récitatifs d'orchestre aux grands moments de l'action? On le verra par une lettre mémorable, qu'il écrivit à Hasse, le 20 octobre 1749 , à propos de son Attilio Regolo, et qu'il est bon de rappeler aux lecteurs français ". Jamais poète ne surveilla de si près le travail du musicien et

1. Nicollo Iommelli als Opernkomponist, 1908, Halle.

2. Jouée à Dresde, en présence de J.-S. Bach.

3. Voyez le Tumerlano de Handel et le Piramo e Tisbe de Hasse.

4. Celte lettre, qui fait partie des Opere postume del sig. Ab. Pietro Metaslasio (1793, Vienne, t. I), a été reproduite par M. Carl Mennicke, daus son ouvrage : Hasse und die Brüder Graun als Symphoniker, 19u6, Leipzig. 
ne détermina, d'arance, avec plus de précision, la forme musicale qui convenait à chaque scène.

Après un assez long préambule, d'une courtoisie exquise, où Métastase s'excuse de donner des conseils à Hasse, il commence par expliquer les caractères de sa pièce: - Régulus, le héros romain. supérieur aux passions, égal et serein.... "Il ne ine plairait pas, dit-il, que son chant et la musique qui laccompayne fussent jamais précipités, sinnn en deux ou trois endronts de l'cuvre... » - le consul Manlius, grand homme, trop sensible à l'émulation; - Amilcar, Africain qui ne comprend rien aux maximes romaines d'honnêteté et de justice, mais qui finit par envier ceux qui y croient; - Barcé, belle et ardente Africaine, de tempérament amoureux, uniquement occupée d'Amilcar... etc. " Telles sont, en général, les physionomies que je me suis proposé de retracer. Mais vous savez que le pinceau ne suit pas toujours le dessin de l'esprit. C'est à vous, non moins excellent artiste que parfait ami, de vêtir avec une telle maitrise mes personnages que, sinon par les traits du visage, du moins par leur parure et leur halillement, ils aient une individualité marquée. 》

Puis, après avoir mis en lumière l'importance des récitatifs « animés par les instruments », c'est-à-dire des Accompagnati, il indique où et comment il faut en user, dans son drame.

a Dans le premier acte, je trouve deux endroits, où les instruments peuvent m'aider. Le premier est la harangue d'Attilia à Manlio, dans la seconde scène, depuis le vers :

"A che vengo! Ah sino a quando...

( A près les paroles a che vengo, les instruments doivent commencer à se faire entendre, et, tantôt se taisant, 
tantôt accompagnant, tantót rinforzando, donner de la chaleur à un disconis dija passionné par lui-nême. Il me plairait qu'ils n'abandonnassent pas Attilia, avant le vers:

(c La barbara or qual è? Cartago, o Roma?

" Je crois de plus qu'il convient de se garder de la faute de faire attendre le chanteur plus que la basse seulo ne l'exige. Toute la chaleur du discours se refroidirait; et les instruments, au lieu d'animer, énerveraient le récitatif qui serait comme un tableau coupé en morceaux et relégué dans l'ombre : auquel cas, mieux vaudrait qu'il n'y en eît pas. 》

Même recommandation pour la septième scène do l'acte I : " J'insiste de nouveau pour que l'acteur ne soit pas obligé d'altendre la musique, et que ne se refroidisse pas ainsi la chaleur dramatique: je désire la voir grandir, de scène en scène. )

\section{Un peu plus loin, après le vers de Manlio : T'accheta : si viene...}

« Une brève symphonie me paraît nécessaire, pour donner le temps au consul et aux sénateurs d'aller s'asscoir, et pour que Régulus puisse ienir sans se presser, et s'arréter pour réfléchir. Le caractère de cetle symphonie doit être majestueux, lent, et, si possible, elle doit s'interrompre, pour exprimer l'état d'esprit de Régulus, réféchissant qu'il retourne esclave là oit naguère il s'est assis consul. Il me plairait que, dans une de ces interruptions de la symphonie, Amilcar dit les deux vers:

"Rogolo, a che t'arresti? è forse nuovo

\section{Per te questo soggiorno?}


et que la symphonie ne conclût pas avant la réponse de Régulus :

(Penso qual ne partii, qual vi ritorno.")

$\mathrm{Au}$ second acte, il faut deux récitatifs instrumentaux. Dans une de ces scènes, «Régulus doit rester assis, jusqu'aux mots :

" Ah no. De'vili questo è il linguaggio.

"Il dira le reste, debout... Si, par suite de la disposition de la scène, Régulus ne pouvait s'asseoir tout de suite, il devrait s'acheminer lentement vers son siège, en s'arrêtant parfois et paraissant plongé dans une grave méditation; il serait alors nécessaire que l'orchestre le prévint et le secondât, jusqu'à ce qu'il s'assît. Toutes ses paroles : réflexions, doutes, hésilations, donneront lieu $\dot{a}$ quelques mesures instrumentales, aux modulations imprévues. Aussitòt qu'il se lève, la musique doit exprimer la résolution et l'énergie. Et toujour's éviter de faire longueur.... »

Pour le troisième acte, « il me plairait qu'on n'usdt point des instruments dans les récitatifs, avant la dernière scène, - bien qu'ils puissent ètre employés à propos dans deux aulres scènes; - mais il me semble qu'il faut ménager un pareil effet $)$.

Cette dernière scène est précédée d'un tumulte violent du peuple, qui crie :

\section{Resti, Regolo, resti....}

"Cette clameur doit être lìès bruyante, d'abord parce que la vérité le veul ainsi, et de plus afin de faire valoir le silence qu'impose ensuite au per!ple tumultueux la seule présence de Régulus.... Les instruments doivent 
se taire, quand parlent les autres personnages; au contraire, ils accompagnent constamment Régulus, dans cette scène; les modulations et les mouvements varient, non pas d'après les simples paroles, comme font les autres écrivains de musique (scrittori di musica), mais d'après l'émotion intérieuro, comme font les grands musiciens, vos pairs. Car, vous le savez aussi bien que moi, les mémes paroles peuvent, suivant les circonstances, exprimer (ou cacher) la joie, ou la douleur, ou la colère, ou la pitié. Je suis bien convaincu qu'un artiste comme vous saura traiter un si grand nombre de récitatifs instrumentaux, sans fatigner les auditeurs : d'abord, purce que vous éviterez soigneusement de faire longueur, ainsi que je vous l'ai recommandé avec insistance; - et surtout, parce que vous possédez, à la perfection l'art de varier et de faire alterner les piani, les forti, les rinforzi, les enchainements staccati ou congiunti, les retards, les pauses, les arpèges, les tremolos, et pardessus tout ces modulations inattendues, dont vous seul savez les ressources cachées.... )

"Vous croyez que j"ai finide vous ennuyer? Pas encore.... Je souhaiterais que le chœur final fît de ceux qui, grâce à vous, ont donné au public le désir, inconnu jusqu'alors, de les écouter. Je voudrais que vous fissiez sentir que ce chœur n'est pas un accessoire, mais une partie très nécessaire de la tragédie et de la catastrophe qui la termine.... )

Et Métastase ne met fin à ses minutieuses recommandations que parce qu'il est fatigué, dit-il, nullement parce qu'il a tout dit. Nul doute que des conversations ultérieures n'aient commenté et complété cette lettre. 


\section{$* * *$}

Résumons ces conseils. On notera :

$1^{\circ}$ La suprématie de la poésie sur la musique. "Les traits du visage ", c'est la poésie. "Les parures et habillements », c'est la musique. Gluck ne s'exprimera pas très différemment.

$2^{\circ}$ L'importance donnée au drame, les conseils d'homme du métier, pour ne pas laisser languir le débit de l'acteur, pour qu'il n'y ait pas de trous dans le dialogue. C'est la condamnation de l'air inutile. La musique est subordonnée à l'effet scénique.

$3^{\circ}$ Le caractère psychologique attribué à l'orchestre. ( La symphonie qui exprime les réflexions, les doutes, les troubles de Régulus. "Le pouvoir reconnu à la bonne musique de traduire non seulement les paroles, mais l'âme cachée qui sent parfois tout autrement qu'elle ne s'exprime, - en un mot, la tragédie intérieure.

Tout cela, je le répète, est conforme à la pensée de Gluck. Pourquoi donc représente-t-on toujours Métastase et ses musiciens comme opposés à la réforme de Gluck? Cette lettre est de 1749, à une date où Gluck n'avait encore aucun pressentiment de sa réforme ${ }^{1}$. On voit ici que tous les artistes, dans tous les camps, étaient agités des mêmes préoccupations, travaillaient à la même œuvre. Seulement, la formule adop-

1. Gluck avait débuté en 1742 ; il revenait d'Angleterre, en 1746; il n'avait pas encore écrit, en 1749 - je ne dis pas l'épitre dédicatoire d'Alceste, qui est de vingt ans plus tard (1769) - mais même ses opéras italiens, réellement signiflcatifs : Ezio est de 1750 , et la Clemenza di Tito, de 1752. 
tée n'était pas la mème chez tous. Nétastase, amoureux du beau chant, et l'un des derniers en Europo qui en eussent conservé l'exacte tradition ${ }^{1}$, ne voulait pas le sacrifer. Et quel musicien lui en ferait un reproche? Il voulait que la voix - poésie et musique - fút toujours la figure principale du tableau; il se défiait du développement excessif de l'orchestre de son temps; il le trouvait d'aulant plus dangereux qu'il en sentait la force et prétendait la tenir en bride, au service de son idéal de tragédie musicale, harmonieusement proportionnée ${ }^{2}$. Il faut dire les choses comme elles sont : avec Gluck, le drame a gagné; nullement la poésie. Vous ne trouverez plus chez lui, ni chez Jommelli la déclamation racinienne, qui s'était encore adoucie et raffinée, au cours du xirn siècle, mais une diction lourde, appuyée, étalée, criée : il le fallait bien, pour dominer le tumulte de l'orchestre! Comparez une scène de l'Armide de Gluck à la scène correspondante, dans l'A rmide de Lully ${ }^{3}$ : dans ces deux tragédies lyriques, quelle différence de déclamation! Colle de Gluck est plus lente, répétée; l'orchestre bruit et gronde; la voix est celle d'un masque tragique de théâtre grec : elle hurle. Chez Lully, et bien plus encore chez les collaborateurs musicaux de Métastase, la voix était celle d'un grand acteur du temps; elle obéissait à certaines conventions de bon

1. Burney entendit, à Vienne, une excellente chanteuse, Mlle Yartinetz, ¿̀ gui Métistase avait ensei rné le chnnt. Il ajoute que Métastase éiait un des derniers qui connussent la tradition du beau vieux chant italien, de l'école de Pislocchi ei de Bernacchi. Ajoutons : de Francesco Gasparini.

2. “ La esatta proporzione dello stile drammatico proprio dell' Opera in musica n, comme dit Arteaga, qui fait de cette qqualité la caractéristique de Métasiase, celle qui le rend supérieur à tous les autres artistes.

3. Soit la scène où Armide fait appel à la Haine. 
goût, de modération et de naturel, au sens où l'entendait la société d'alors : - (car le naturel varie, suivant l'époque; et chaque société, chaque âge lui fixe des limites diférentes). - Le malentendu entre les deux écoles portait donc beaucoup moins sur le fond que sur la manière. Tout le monde s'accordait à rouloir que l'opéra fùt une tragédie en musique. Mais l'on n'était pas d'accord sur ce que devait être la tragédie. D'un côté, les Raciniens; de l'autre, les romantiques avant la lettre.

Ajoutez que le principal, en art, ce ne sont pas les théories, c'est l'homme qui les applique. Gluck voulait la réforme du drame musical. Hétastase la roulait aussi. Et aussi, à Berlin, Algarolti, Graun, Frédéric II luimême. Nais il y a la façon de vouloir, il y a le tempérament. Celui de Gluck était d'un révolutionnaire, intelligent, audacieux, qui savait, au besoin, être brutal, qui se moquait du qu'en dira-t-on et bousculait les conventions. Celui de Métastase était d'un homme du monde, qui respectait les usages établis. Il farcissait de froides sentences et de comparaisons précieuses ses libretti d'opéras; et, pour les justifier, il s'appuyait sur l'exemple des Grees et des Romains; il disait à Calsabigi que de tels moyens \& avaient toujours fait le principal attrait de l'éloquence profane et sacrée ${ }^{1}$ ».

Les critiques de son temps les justifiaient aussi, par l'exemple des anciens et des classiques français. Ils ne se disaient pas que, pour juger si une chose est bonne, il ne faut pas se demander si elle a été bonne et vivante autrefois, mais si elle l'est aujourd'hui. - Voilà le vice radical de l'art d'un Métastase. Il est plein de

1. "Han fatto sempre una gran parte finora della sacra e della profana eluquenza. 
goût et d'intelligence, parfaitement équilibré, mais érudit et mondain; il manque d'audace, il manque de sève.

N’importe! S’il était condamné à périr, il portait en lui beaucoup d'idées de l'avenir. Et qui sait si sa pire malchance n'a pas été l'échec de Jommelli, qui, de tous les musiciens soumis à son influence, fut le plus audacieux et marcha le plus loin sur les voies que Métastase avait ouvertes? Jommelli, que l'on a parfois nommé le Gluck italien, marque le suprême effort de l'ltalie pour conserver sa primauté dans l'opéra. Il voulut accomplir la réforme de la tragédie musicale, sans rompre avec la tradition italienne, mais en la revivifiant avec des éléments nouveaux et surtout avec la puissance dramatique de l'orchestre. Il ne fut pas soutenu dans son pays; et en Allemagne il était un étranger, comme Métastase. Ils furent vaincus; et leur défaite fut celle de l'Italie. Le Gluck italien ne fit pas école. Ce fut le Gluck allemand qui assura la victoire, non seulement à une forme d'art, mais à une race. 


\section{VII}

VOYAGE MUSICALA TRAVERS L'EUROPE DU XVIII" SIECLE

\section{I}

I T A L E

L'Italie fut, pendant tout le xviI ${ }^{e}$ siècle (comme au siècle précédent), la terre de la musique. Ses musiciens exerçaientsur l'Europe entière une supériorité analogue à celle des " philosophes 》 et des écrivains français. Elle était le grand marché de chanteurs, d'instrumentistes, de virtuoses, de compositeurs et d'opéras. Elle les exportait par centaines en Angleterre, en Allemagne, en Espagne. Elle en faisait elle-même une consommation prodigieuse : car elle était insatiable de musique, et il lui fallait du nouveau, du nouveau, toujours du nouveau. Les maîtres les plus célèbres d'Allemagne : Hændel, Hasse, Gluck, Mozart, venaient se mettre à son école; et certains d'entre eux en sortaient plus intransigeants dans leur italianisme que les I aliens. Les mélomanes anglais envahissaient l'Italie; on les royait chemincr de ville en ville, à la suite des 
chanteurs el des troupes d'opéra, passant le carnaval à Naples, la Semaine Sainte a Hone, l'Ascension a Vunine, les mois d'élé à Paduve el à Vicence, l'automne a Wilan, lhiver ì Mlorence : pendant des années, sans se lass r, ils accomplissaient le mome tour. Cependant, ils n'avaient guere besoin de se déranger pour entendre des opéras italiens : car ils avaient l'Italie à Londres. L'Angleterre était si bien conquise par le goût italien, depuis le commencement du siècle, que l'historien Burney faisait cette étrange réllexion, - qui, dans sa bouche, ćtait un éloge pour son pays :

Les jeunes compositeurs anglais, sans avoir été en Italic, tombent moins souvent dans le grenre anglais que les jeunes compositeurs français, qui ont passé des années en Italie, lie retombent, en dépit de tout, dans le genre français.

En d'autres terines, il se félicite que les musiciens anglais réussissent mieux à se dénationaliser que les Français. Ils le devaient aux excellents théatres italiens d'opéra et d'opera buffa qui existaient à Londres et qui avaient eu à leur tête des maitres tels que Hændel, Puononcini, Porpora et Galuppi. Burney en concluait, dans son engouement pour l'Italie, que « l'Angleterre était par conséquent une école plus propre que la France à former un jeune compositeur ».

L'observation est, à l'insu de Burney, assez flatteuse pour la France, qui fut, en eflet, de toutes les nations d'alors celle qui opposa la résistance la plus opiniâtre à l'influence italienne. Cette influence ne s'en exerça pas moins sur la soci té et los artistes de Paris; et l'italianisme, qui trouva un vigoureux appui chez les " philosophes » de l'Encyclopédie - Diderot, Grimm, surtout Rousseau, - souleva de réritables guerres 
musicales, et finit par aroir, en partie, gain de canse : car, dans la seconde moilié du siecle, on peut dire que la musique française est une proie que se partagent, comme une lerre conquise, trois grands artistes étrangers : un Italien, Piccinni, - un Allemand italianisé, Gluck, - et un Belge italianisé, Grétry.

Les autres nations n'avaient pas attendu silongitemps pour succomber. L'Espagne était, pour la musique, une colonie italienne depuis que s'y était établie, en 1703, une compagnie italienne d'opéra, et surtout après l'arrivée, en 1737, du fameux virtuose Farinelli, loutpuissant auprès de Philippe $\mathrm{V}$, dont il calmait, avec son chant, les accès de manie. Les meilleurs compositeurs espagnols, revêtus de noms italiens, deviennent, comme Terradellas, maitres de chapelle à Rome, ou comme Arossa (Abos), professeurs dans les conserratoires de Naples, à moins que, comme Martini (Warlin $y$ Soler), ils n'aillent porter l'italianisme dans les autres pays d'Europe.

Il n'était pas jusqu'aux contrées du Nord que n'atteignît l'invasion italienne; et l'on royait s'établir en Russie Galuppi, Sarti, Paisiello, Cimarosa, qui y implantaient des écoles, des conservatoires, des théàtres d'opéra.

On comprend qu'un pays qui arait ce rayonnement d'art dans toute l'Europe fùt considéró par elle comme une Terre Sainte de la musique. Aussi l'Italie fut-elle, au xrni siècle, un lieu de pèlerinage pour les musiciens de toutes nations. Beaucoup d'entre eux ont noté leurs impressions; et certaines de ces relations de voyages, signées de noms tels que ceux de Montesquieu, le prósident de Brosses, Pierre-Jean Grosley de Troyes, le sarant Lalande, Gothe, le poete espagnol Don 
Leandro de Moratin, abondent en observations spirituelles et profondes. Le plus curieux de ces ouvrages est peut-être celui de l'Anglais Charles Burney, qui, avec une patience inlassable, traversa l'Europe à petites journées, pour réunir les matériaux nécessaires à sa grande Histoire de la Musique. Très italianisant de goùt, mais ouvert et impartial, il eut la bonne fortune de connaitre personnellement les principaux musiciens de son temps : en Italie, Jommelli, Galuppi, Piccinni, le père Martini, Sammartini; - en Allemagne, Gluck, Hasse, Kirnberger, Philippe-Emmanuel Bach;en France, Grétry, Rousseau et les philosophes. Et certains des portraits qu'il en a tracés sont les plus vivants qui nous restent de ces hommes.

$J_{\theta}$ vais tâcher de refaire, à la suite de Burney et de tant d'illustres voyageurs, le pèlerinage d'Italie, vers le milieu du xvin ${ }^{\mathrm{e}}$ siècle ${ }^{1}$.

1. Montesquieu voyagea en Italie de 1728 à 1729 (Voyages, Bordeaux, 1894); le président de Brosses, de 1739 à 1740 (Lettres familières écrites d'Italie); Grosley, en 1758 (Observations sur l'Italie); Lalande, en 1763̈-66 (Voyage en Italie, 8 vol. in-12, Venise, 1769); Gœthe, en 1786-87 (Italienische Reise); Moratin, de 1793 à 1796 (Obras postumas, Madrid, 1867).

Le grand voyage de Burney date de 1770-72, et a été raconté par lui dans ses deux ouvrages : The present state of music in France and Italy (1771), et The present state of music in Germany, the Netherlands and United Provinces (1773), traduits presque aussitot en français.

Il $\mathrm{y}$ a lieu de consulter aussi les lettres de Mozart, qui fit trois voyages en Italie (1769-71, 1771, 1772-73), les Mémoires de Grétry, qui resta huit ans à Fiome, de 1759 à 1767, l'autobiographie de Karl Ditters von Dittersdorf, qui accompagna Gluck en Italie, - sans parler des nombreuses études sur les inusiciens allemands qui voyagèrent en Italie, comme Rust, Jean-Chrétien Bach, etc.

Un intéressant travail de M. Giuseppe Roberti : La musica in Italia nel secolo xvin secondo le impressioni di viaggiatori stranieri (Rivista musicale italiana, 1001) m'a été un guide précieux. 


\section{$\stackrel{* *}{*}$}

A peine entrés en Italie, les étrangers élaient saisis par la passion musicale qui dérorait la nation tout entière. Cette passion n'était pas moindre dans le peuple que dans l'élite.

Les violons, les instruments, le chant nous arrêtent dans les rues, - écrit l'abbé Coyer, en 1763. - On entend sur les places publiques un cordonnier, un forgeron, un menuisier chanter une aria à plusieurs parties arec une justesse, un goût, qu'ils doivent à la nature et à l'habitude d'entendre des harmonistes que l'art a formés.

A Florence et à Gènes, les marchands et les artisans se réunissaient, les dimanches et fêtes, en plusieurs compagnies de Laudisti ou chanteurs de psaumes. Ils se promenaient ensemble dans la campagne et chantaient des musiques à trois parties.

A Venise, « si deux personnes se promènent ensemble, se tenant sous le bras, il semble, dit Burney, qu'elles ne causent qu'en chantant. Toutes les chansons y sont chantées en duo. " - Sur la place SaintMarc, souvent, écrit Grosley, « un homme de la lie du peuple, un cordonnier, un forgeron, avec les habits de son métier, commence un air : d'autres gens de sa sorte, se joignant à lui, chantent cet air à plusieurs parties arec une justesse, une précision et un goût, qu'à peine rencontre-t-on parmi le plus beau monde de nos pays septentrionaux $»$.

Depuis le $\mathrm{xv}^{\circ}$ siècle, des représentations populaires en musique avaient lieu, tous les ans, dans la campagne toscane; et le génie populaire de Naples et de la Calabre s'exprimait par des chants qui ne laissaient pas

R. Rolland. - Voyage musical. 
indifférents les musiciens : Piccinni et Paisiello en surent tirer parti.

Ilais l'admirable, c'était surtout l'ardente joie que ce peuple témoignait en écoutant la musique.

"Quand les Italiens admirent, ils semblent mourir d'un plaisir trop grand pour leurs sens ", écrit Burney. A un concert symphonique, donné en plein air, à Rome, en 1758, l'abbé Morellet dit que le peuple « se pâmait. On entendait gémir : O benedeito, o che gusto, piacer di morir! ( 0 bénédiction! quelle jouissance! plaisir à en mourir!) 》- Un peu plus tard, en 1781, l'Anglais Hoore, assistant ì un spectacle musical, à liome, note que « le public se ienait, les mains jointes, les yeux demi-fermés, retenant son souffle. Une jeune fille se met à crier, du milieu du parterre : O Dio! dove sono? Il piacere mi fa morire! " (O Lieu! où est-ce que je suis? Je meurs de plaisir!) Certarnes représentations étaient interrompues par les sanglots de l'auditoire.

La musique tenait tant de place en Italie que le mélomane Burney lui-même voyait dans la passion qu'elle excitait un danger pour la nation. "A en juger par la quantité d'établissements de musique et de représentations publiques, on pourrait accuser l'Italie de cultiver la musique avec excès. "

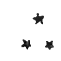

La supériorité musicale de l'Italie ne tenait pas seulement à son goût naturel pour la musique, mais à l'excellence de l'instruction musicale dans toute la péninsule.

Le foyer le plus brillant de cette culture artistique 
était Naples. C'était l'opinion courante, au temps de Burney, que plus on descendait vers le sud, plus le goùt musical s'affinait. "L'Italie, dit Grosley, peut être comparée à un diapason, dont Naples tient l'octave. " Le président de Brosses, l'abbé Coyer, surtout Lalande, expriment le neême avis. " La musique - écrit Lalande - est le triomphe des Napolitains. Il semble que, dans ce pays-là, les cordes du tympan soient plus tendres, plus harmoniques, plus sonores que dans le reste de l'Europe; la nation même est toute chantante; le geste, l'inflexion de la voix, la prosodie des syllabes, la conversation, tout y marque et y respire la musique; aussi Naples est-elle la source principale de la musique. »

Burney réagit contre cette opinion, qui n'était plus tout à fait vraie de son temps, et qui arait dû toujours être un peu exagérée. « On accorde aux Napolitains, dit-il, plus de confiance dans l'art qu'ils n'en méritent aujourd'hui, malgré les titres qu'ils ont dù aroir à cette célébrité dans les temps passés. „ Et il revendique la première place pour Venise. Sans trancher cette question de prééminence entre les deux villes, on peut dire que Venise et Naples étaient, au xvin ${ }^{e}$ siècle, les grands séminaires de musique vocale, non seulement d'Italie, mais d'Europe. Chacune d'elles était le siège d'une école illustre d'opéra : celle de Venise, la première en date, issue de Monteverdi, comptait des noms tels que ceux de Cavalli et de Legrenzi, au xviI ${ }^{e}$ siècle, de Marcello et de Galuppi, au xviII ${ }^{e}$; celle de Naples, un peu plus tard venue, à la fin du xvir siècle, avec Francesco Provenzale, avait établi, au $\mathrm{xviII}^{\circ}$, sa suprématie incontestée dans la musique dramatique, avec 'l'innombrable école d'Alessandro 
Scarlatti et celle de Pergolèse. Venise ef Naples avaient aussi les conservatoires les plus réputés d'Italie.

A côté de ces deux métropoles de l'opéra, la Lombardie était un centre de musique instrumentale. Bologne était célèbre par ses théoriciens; et Rome jouait dans l'ensemble de cette organisation artistique son rôle de capitale, moins par la supériorité de sa production personnelle que par le jugement souverain qu'elle s'attribuait sur les œuvres d'art. « Rome - dit Burney - est le poste d'honneur pour les compositeurs, les Romains étant regardés comme les juges les plus sévères de la musique en Italie. On estime qu'un artiste qui a du succès à Rome n'a rien à craindre de la sévérité des critiques dans les autres villes. 》)

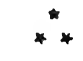

La première impression produite par la musique napolitaine sur les voyageurs étrangers était plutôt une surprise qu'un plaisir. Ceux qui étaient plus sincères, ou plus fins connaisseurs, en éprouvaient même une déception, d'abord. Ils trouvaient, comme Burney, des exécutions peu soignées, où la mesure et la justesse péchaient également, des voix rauques, une brutalité naturelle, quelque chose de déréglé, a un goût - à ce que dit Grosley - pour le capriccioso et le stravagante $)$. Les relations du xviI $^{\mathrm{e}}$ et $\mathrm{du} \mathrm{xviI}^{\circ}$ siècle sont là-dessus d'accord. Voici ce que note, en 1632, un voyageur français, J.-J, Bouchard ${ }^{1}$ :

1. Un Parisien à Rome et à Naples en 1632, d'après un manuscrit inédit de J.-J. Bouchard, - par Lucien Marcheix. - Paris, Leroux. 
Le musique napolitaine est surtout frappante par ses mouvements bizarres et allègres. Sa manière de chanter, tout à fait différente de celle de Pome, est éclatante et comme dure: non pas trop gaie à la vérité. mais fantasque et écervelée, plaisant seulement par son mouvement prompt, étourdi et bizarré; c'est un mélange d'air français et d'air sicilien ${ }^{1}$, au reste extraragantissime pour ce qui est de la suite et uniformité qu'elle ne garde aucunement, courant, puis s'arrêtant tout court, sautant de bas en haut et de haut en bas, jetant arec effort toute la roix, puis tout à coup la resserrant; et c'est proprement dans ces alternatives de haut et de bas, de piano et de forte, que se reconnaît le chant napolitain.

\section{Et Burney, en 1770, écrit :}

Le chant napolitain dans les rues est heaucoup moing agréable, quoique plus original qu'ailleurs. C'est une singulière espèce de musique, aussi sauvage dans sa modulation, et aussi différente de celle de tout le reste de l'Europe que la musique écossaise... Le chant artistique a une force, un feu qu'on ne rencontre peut-être pas dans le monde entier, et qui compense le manque de goût et de délicatesse. Cette manière d'exécuter est si ardente qu'elle tient de la frénésie. C'est cette impétuosité de génie qui fait qu'il est ordinaire de voir un compositeur napolitain, en partant d'un mourement doux et sobre, mettre l'orchestre en feu avant qu'il soit fini.... Les Napolitains, comme les chevaux de race, sont impatients du frein. Dans leurs conservatoires, on arrive difficilement à obtenir le pathétique et le gracieux; et, en général, les compositeurs de l'école de Naples recherchent moins que ceux des autres parties de l'Italieles grâces délicates et étudiées....

Mais si les caractères du chant napolitain étaient demeurés à peu près les mêmes, $d u x x_{I I}{ }^{e}$ au XviII ${ }^{e}$ siècle,

1. C'est-à-dire, suivantıBouchard, de style galant et de style dronatique. 
sa valeur avait bien changé. Au temps de Bouchard, la musique napolitaine était en retard sur le reste de l'Italie. Au temps de Burney, les compositeurs de Naples étaient renommés, non seulement pour leur génie naturel, mais pour leur science. Et c'est ici que l'on voit ce que peuvent des institutions artistiques, non pas sans doute pour transformer une race, mais pour lui faire produire ce qu'elle avait en réserve et qui, sans elles, n'eût probablement jamais levé du sol.

Ces institutions étaient, pour Naples, ses fameux conservatoires pour l'éducation musicale des enfants pauvres. Idée admirable, que nos démocraties modernes n'ont pas eue, ni reprise.

Ces conservatoires, ou Collegii di musica, étaient au nombre de quatre principaux ${ }^{1}$ :

$1^{\circ}$ Le Collège des pauvres de Jésus-Christ (Collegio de' poveri di Gesù Cristo), fondé en 1589, par un Calabrais du tiers ordre de saint François, Marcello Fossataro di Nicotera, qui y recueillit les pauvres petits, mourant de faim et de froid. On y admettait les enfants de toutes nations, de sept à onze ans. Ils étaient une centaine. Ils portaient la soutane rouge et la simarre bleu de ciel. De ce collège, - c'est tout dire, - est sorti Pergolèse.

2. Le Collège de San Onofrio a Capuana, fondé vers 1600, par les confrères de San Onofrio pour les orphelins du pays de Capoue. Le nombre des écoliers variait de quatre-vingt-dix à cent cinquante. Ils portaient la soutane blanche et la simarre grise.

1. Voir la préface du marquis de Villarosa à ses Memorie dei compositori di musica del regno di Napoli (Naples, 18\%0). 
3o Le Collège de Santa Maria di Loreto, fondé en 1337, par un protonotaire apostolique de nation espagnole, Giovanni di Tappia, " pour y recueillir les fils des citoyens les plus paurres, et les élever dans la religion et les beaux-arts $»$. Ce très grand collège compta d'abord jusqu'a huit cents enfants, garçons et filles. Puis, vers le milieu du xvme siècle, on cessa d'y recevoir des filles, et on commença à y enseimner exclusivement la musique. Quand Burney le visita, il y avait là deux cents enfants. Ils portaient la soutane et la simarre blanches.

$4^{\circ}$ Le Collège de la Pietà de' T'urchini, fondé à la fin du $\mathrm{xvI}^{\mathrm{e}}$ siècle par une confrérie, qui recueillait les paurres enfants du quartier. Le nombre des élèves était, au milieu du xvir ${ }^{\mathrm{e}}$ siècle, d'une centaine. Ils portaient la soutane et la simarre bleues. Les plus illustres compositeurs napolitains professèrent dans ce college. Francesco Provenzale en fut un des premiers maîtres.

Chacun de ces conservatoires avait deux maîtres principaux : l'un pour corriger les compositions, l'autre pour professer le chant. Il y avait, de plus, des maîtres assistants (maestri scolari), pour chaque instrument. Les enfants restaient, en général, huit ans. $\mathrm{Si}$, après quelques années d'école, ils ne montraient pas de dispositions suffisantes, ils étaient renroyés. Un certain nombre étaient reçus comme pensionnaires payants. On retenait les meilleurs élèves, après leur temps d'études, pour professer à leur tour.

Burney fait une description pittoresque d'une visite au Collègè de San Onofrio :

Qur le palier du premier étage, une clarinette s'escrimait. Sur le palier du second, un cor beuglait. Dans 
une chambre commune, sept ou huit clavecins, un nombre encore plus grand de violons et des voix exécutaient, chacun un morceau différent, tandis que d'autres élères écrivaient. Les lits servaient de tables aux clavecins. Dans une seconde chambre, les violoncelles étaient réunis. Dans une troisième, les flûtes et les hautbois. Les clarinettes et les cors n'araient de place que sur l'escalier. Dans le haut de la maison, et tout à fait à part des autres enfants, seize jeunes castrats avaient des appartements plus chauds, à cause de la délicatesse de leur voix. Tous ces petits musiciens travaillaient sans relâche, du lever (deux heures avant le jour, en hiver) jusqu'au coucher (vers huit heures du soir); il n'avaient qu'une heure et demie de repos, pour le dìner, et quelques jours de vacances, à l'automne.

Ces conservatoires, qui furent pour toute l'Europe une mine de chanteurs et de compositeurs d'opéra, étaient déjà vers leur déclin au temps de Burney. Leur période la plus brillante semble avoir été dans le premier tiers du siècle, du vivant de Alessandro Scarlatti.

Il se trouvait, à Naples, des entrepreneurs de musique étrangers, dont le seul emploi était de recruter des musiciens et des sopranistes, pour leurs gouvernements. Tel, un certain M. Gilbert, que Lalande rencontre, et qui opérait pour le compte de la France.

On y recrutait aussi des compositeurs. Les deux plus célèbres compositeurs napolitains au milieu du

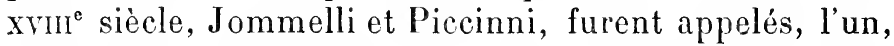
Jommelli, en Allemagne, où il resta quinze ans à Stuttgart; - l'autre, Piccinni, à Paris, où on l'opposa à Gluck. Il y mourut, après avoir été professeur à l'Ecolo 
royale de chant et déclamation, et inspecteur du Conservatoire de Paris. Ces deux hommes formaient un parfait contraste. Piccinni, petit, maigre, pâle, lo visage fatigué, très poli, doux et vif à la fois, avec un extérieur plutôt grave, et un cœur affectueux, impressionnable à l'excès, était surtout inimitable dans la comédie musicale; et c'est un malheur pour lui que ses petits opéras-comiques en dialecte napolitain n'aient pu être transplantés en dehors de son pays, où ils faisaient fureur; mais, comme disait l'abbé Galiani, « il était bien impossible que ce genre passât en France, puisqu'il n'allait même pas jusqu'à Rome. Il fallait être Napolitain pour se rendre compte du chef-d'œuvre de perfection auquel Piccinni avait poussé l'opéra-comique à Naples. » - Jommelli, au contraire, était plus goûté à l'étranger qu'à Naples. Les Napolitains lui gardaient rancune de s'être trop germanisé à Stuttgart. Physiquement, il ressemblait à un musicien allemand. "C'était un homme extrêmement gros de corps; sa figure - dit Burney - m'a rappelé celle de Hændel. Mais il est beaucoup plus poli et plus doux dans ses manières. " Ce sérieux artiste, noble, ému, un peu lourd, avait rapporté d'Allemagne un goût pour une harmonie et une orchestration compactes; il n'avait pas peu contribué à la révolution qui s'accomplissait de son temps dans l'opéra napolitain, où l'orchestre commençait à faire rage, au détriment des chanteurs qui étaient forcés de crier. « De la musique, - écrit Burney, tout le clair-obscur est perdu; les demi-teintes et le fond disparaissent; on n'entend que les parties bruyantes. 》 


\section{$* *$}

Venise se distinguait de Naples par la délicatesse de son goût. Aux conservatoires de Naples elle opposait ses fameux conservatoires de femmes : la Pietà, les Mendicanti, les Incuralili et l'Ospedaletto di S. Giovanni e Paolo.

C'étaient des hôpitaux d'enfants trouvés, sous la protection des principales familles aristocratiques de la ville. On y gardait les jeunes filles jusqu'à leur mariage, en leur donnant une instruction musicale accomplie. « La musique - dit Grosley - y étaitla partie principale d'une éducation qui paraissait plus propre à former des Laïs et des Aspasies que des religieuses ou des mères de famille. "Il ne faudrait pourtant pas croire que toutes fussent musiciennes. Il n'y en avait guère que soixante-dix sur mille, à la Pietà; qquarante à cinquante, dans chacun des autres hôpitaux. Mais on ne négligeait rien pour y attirer des musiciennes; et, souvent, on y admettait des enfan!s. sans qu'ils fussent orphelins, quand ils avaient une belle voix. On en amenait de tout le Veneto, de Padoue, de Vérone, de Brescia, de Ferrare. Les maîtres étaient : à la Pietà, Furlanetto; aux Mendicanti, Bertoni; à l'Ospedaletto, Sacchini ; aux Incurabili, Galuppi, qui succédait à Hasse. La rivalité qui existait entre ces compositeurs illustres excitait l'émulation des élèves. Chaque conservatoire avait cinq ou six maitres assistants pour le chantet les instruments; les plus àgées parmi les jeunes filles instruisaient à leur tour les plus jeunes. Les élèves apprenaient non seulement à chanter, mais à jouer de tous les instruments : du violon, du clavecin, voire du cor ou de la 
contrebasse. Burney dit qu'elles savaient, d'ordinaire, jouer de plusieurs instruments et qu'elles passaient de l'un à l'autre avec aisance. Ces orchestres de femmes donnaient des concerts publics, tous les samedis et dimanches soir. C'était un des principaux attraits de Venise; et aucun des voyageurs f́traigers qui visitèrent la ville n'a manqué de nous décrire ces concerts, aussi plaisants à regarder qu'à entendre. "Pien de plus charmant à voir - dit le président de Brosses - qu'une jeune et jolie religieuse en habit blanc, arec un bouquet de grenades sur l'oreille, conduire l'orchestre et battre la mesure avec toute la griàce et toute la précision imaginable. ) Il ajoute que " pour la grande exécution et pour être chef de meute à la tête d'un orchestre, la fille de Venise ne le cède à personne ». Certaines de ces musiciennes étaient célèbres dans toute l'Italie; et Venise se partageait en des camps ennemis pour soutenir telle ou telle chanteuse.

Mais les récits un peu fantaisistes des galants voyageurs risqueraient de tromper sur le sérieux de l'éducation musicale qu'on donnait dans ces conservatoires. Burney, qui les visita avec soin, admire leur science. Le meilleur était celui des Incurabili, que dirigeait Galuppi. Galupni avait alors soixante-dix ans; mais il était encore vif, alerte, et brùlait de plus de feu à mesure qu'il avançait en âge. Il était très mince, avec une petite figure pleine d'intelligence. Sa conversation pétillait d'esprit. Il avait des manières distinguées et du goùt pour tous les arts : il possédait de beaux tableaux de Véronèse. Son caractère n'était pas moins estimé que ses talents; il avait une nombreuse famille, et vivait de la façon la plus rangée. Comme compositeur, il fut un dés dernicrs représentants de l'ancienne 
tradition vénitienne, un de ces génies brillants et prime-sautiers, où s'alliaient avec un éclat séduisant la fantaisie, le naturel et la science. Vrai Italien, et d'esprit classique, il définissait la bonne musique, dans ses conversations avec Burney, par « la beauté, la clarté et la bonne modulation ». Extrêmement occupé à Venise, où il cumulait les fonctions de premier maitre de chapelle de Saint-Marc et des Incurabili, d'organiste dans des maisons aristocratiques, et de compositeur d'opéra, il ne négligeait aucun de ses devoirs, et son conservatoire était un modèle de bonne tenue. "L'orchestre - dit Burney - était soumis à la plus exacte discipline. Aucun des exécutants ne paraissait curieux de briller; tous restaient dans cette espèce de subordination qu'on exige dans un serviteur à l'égard de son maître. " Les artistes faisaient preuve d'une grande virtuosité; mais leur goût était toujours pur, et l'on retrouvait l'art de Galuppi dans les moindres cadences de ses élèves. Il les exerçait dans tous les genres, sérieux ou profanes; et les concerts qu'il dirigeait se prêtaient aux combinaisons instrumentales et vocales les plus variées. Il n'était point rare, à Venise, d'employer dans une église deux orchestres, deux orgues, deux chœurs en écho; et Burney entendit, à Saint-Marc, sous la direction de Galuppi, une messe à six orchestres : deux grands orchestres dans les galeries des deux orgues principales, et quatre orchestres moindres, distribués, deux par deux, entre les bascôtés, chaque groupe étant soutenu par deux petites orgues. C'était là une tradition vénitienne : elle datait des Gabrieli, au xvi siècle.

En dehors des conservatoires et des églises, on donnait do nombreux concerts ou " académies 》 dans 
les maisons particulières. La noblesse y prenait part. De nobles dames jouaient du clavecin, exécutaient des concertos. On organisait parfois des festivals en l'honneur d'un musicien : Burney assista à un concert Harcello. Ces soirées musicales se prolongeaient fort avant dans la nuit. Dans un même soir, Burney note quatre concerts de conservatoires et plusieurs a académies » privées.

Les concerts ne faisaient point tort aux théâtres qui étaient, à Venise comme à Naples, le meilleur titre de gloire musicale. Longtemps ils avaient été les premiers d'Italie. Au carnaval de 1769 , sept théâtres d'opéra furent ouverts à la fois : trois d'opera seria, et quatre d'opera buffa, sans parler de quatre théâtres de comédie: tout était plein, chaque soir.

Un dernier trait montre la libéralité et l'esprit vraiment démocratique qui animait ces villes italiennes. Les gondoliers avaient leur entrée, gratis, au théâtre; et, “ lorsqu'une loge, appartenant à une famille noble, n'était point occupée, le directeur de l'opéra permettait aux gondoliers de s'y installer ». Burney voit là, assez justement, une des raisons de « la manière distinguée avec laquelle les gens du peuple chantent à Venise, par comparaison avec les gens de même classe ailleurs ». Nulle part, la musique n'était meilleure en Italie et plus répandue parmi le peuple.

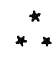

Autour de ces deux capitales de l'opéra, Venise avec ses sept théâtres, Naples avec ses quatre ou cinq, dont le San Carlo, un des plus grands de l'Europe, 
avait un orchestre de quatre-ringts musiciens ${ }^{1}$, l'opéra florissait dans toutes les villes d'Italie, - à liome, avec ses tléatres fameux : l'Argentina, l'Alibeíi, le Capranica; - à Milan et à Turin, dont les théàtres de musiqua jouaient tous les jours, pendant la saison, sauf le vendredi, et où l'on représentait d'immenses actions, des batailles de cavalerie ${ }^{2}$; à Parme, ò s'élevait le théàre Farnèse, le plus fastueux de l'lalie; - à Plaisance, à Reggio, à Pise, à Lucques, qui, d'après Lalande, “ possédait l'orchestre le plus pariait »; - dans icuie la Toscane, dans tout le Veneto, à Vicence, à Vérone, qui, écrit Edmund Rolfe, a était folle d'opéra ${ }^{3}$ ». - C'était la grande passion italienne. L'abbé Coyer, en 1763, se trouve à Naples, au temps d'une famine : la fureur des spectacles n'en est pas diminuée.

Entrons à l'un de ces opéras. Le spectacle commence en général à huit heures, et se termine vers minuit et demi ${ }^{4}$. Le prix des places au parterre est d'un « paule » (six pence anglais, ou douze sols) ${ }^{5}$, à moins que l'entrée ne soit gratuite, comme c'est souvent le cas, à Venise ou à Naples. Le public est bruyant et inattentif à la pièce : il semble que le plaisir véritable du théutre, l'émotion dramatique, compte pour très peu de

1. Marquis d'Orbessan, Voyage d'Italie, en 17\%0-30. (Mélanges historiques et critiquts, Toulouse, 1768.)

2. Edmund Rolfe, en 1761 : Continental Dairy, publıé par E. Neville Rolfe (Naples, 1897).

3. Sans parler des moindres villes, où l'on trouvait toujours de bons orchestres et de bonnes troupes. (Voir les lettres de Nozart.)

4. Lalande. (Voyage de 176̆̃ à Parme.)

5. Burney. - Les théâtres d'opéra italiens étaient, en général, donnéz à entreprise à une société de grands seigneurs, qui souscrivaient chacun pour une loge, et louaient le reste à l'année, en réservant seulement le parterre et le paradis (ainsi, à Milan et à Turia). 
chose. Il cause sans se grinor pendant une partie du spectacle. On se fait des visites d'une loge à l'autre. A Milan, " chaque loge mène à un appartement complet, ayant chambre à feu et toutes les convenances possibles, soit pour préparer des rafraîchissements, soit pour jouer aux cartes. Au quatrième étage, un jeu de pharaon reste ouvert, de chaque côté de la salle, pendant tout le temps que dure l'opéra ${ }^{1}$. " - “A Bologne, les dames se mettent fort à l'aise; elles causent, ou, pour mieux dire, crient pendant la pièce, d'une loge à celle qui est vis-àvis, se lèvent en pied, battent des mains, en criant : bravo! Pour les hommes, ils sont plus modérés : quand un acte est fini, et qu'il leur a plu, ils se contentent de hurler jusqu'à ce qu'on le recommence ${ }^{2}$. " - A Milan, ( ce n'est point assez que chacun y fasse la conversation, en criant du plus haut de sa tête, et qu'on applaudisse avec de grands hurlements, non les chants, mais les chanteurs dès qu'ils paraissent, et tout le temps qu'ils chantent. Messieurs du parterio ont en outre de longs bâtons, dont ils frappent tant qu'ils peuvent sur les bancs, par forme d'admiration. Ils ont des correspondants dans les cinquièmes loges qui, à ce signal, lancent à millions des feuilles contenant un sonetto imprimé à la louange de la signora ou du virtuoso qui vient de chanter. Chacun s'élance à mi-corps des loges pour en attraper. Le parterre bondit, et la scène finit par un : “Ah! "général, comme au feu de la SaintJean ${ }^{3}$. 》)

Cette description, un peu chargée, n'est pourtant pas si loin encore de certaines représentations italiennes d'aujourd'hui. Un spectateur français ou alle-

\section{Burney. - 2. Lettręs du président de Brosses (1739). - 3. Ibud.}


mand, assistant à de telles scènes, sera enclin à douter de la sincérité de l'émotion que ce public italien prétend goùter à l'opéra : il pensera que le plaisir du théâtre n'est, pour ees gens, que le plaisir de se trouver ensemble. - Il n'en est rien. Tout ce bruit s'apaise subitement, à quelques pages de l'œurre. «On n’écoute ou ne s'extasie qu'à l'ariette, — dit l'abbé Coyer. - Je ine trompe : on prête aussi son attention aux récitatifs obligés, plus touchants que les ariettes. „Dans ces instants, " quelque légères que soient les nuances, aucune n'échappe aux oreilles italiennes; elles les saisissent, elles les sentent, elles les savourent avec un plaisir qui est comme l'avant-goùt des joies du paradis ».

Ne disons pas qu'il s'agit là de morceaux de concert, qui valent uniquement par leur beauté de forme. Ce sont, dans la plupart des cas, des pages expressives, parfois très dramatiques. Le président de Brosses reproche aux Français de se prononcer sur la musique italienne, avant de l'avoir entendue en Italie. "Il faut être parfaitement au fait de la langue, et entrer dans le sentiment des paroles. A Paris, nous entendons de jolis menuets italiens ou de grands airs chargés de roulades; et nous prétendons que la musique italienne, d'ailleurs mélodieuse, ne sait que badiner sur des syllabes, et qu'elle manque de l'expression qui caractérise le sentiment.... ) Rien de plus faux : elle excelle, au contraire, à traduire les sentiments, selon le génie de la langue; et les passages les plus goùtés en Italie sont les plus simples et les plus émouvants, " les airs passionnés, tendres, touchants, propres à l'expression théâtrale et à faire valoir le jeu de l'acteur », tels qu'on en trouve chez Scarlatti, Vinci et Pergolèse. Ce sont naturellement aussi ceux qu'il est le plus difficile 
d'exporter au dehors, " puisque le mérite de ces lambeaux de tragédies consiste dans la justesse de l'expression », que l'on ne peut sentir sans connaître la langue.

Ainsi, nous trouvons chez le public italien du $x_{\text {viII }}{ }^{\circ}$ siècle une extrème indifférence à l'action dramatique, à la pièce : on en viendra, dans cette superbe insouciance du sujet, à jouer le deuxième acte, ou le troisième, d'un opéra, avant le premier, quand il plait à quelque personnage qui ne peut passer toute la soirée au théâtre. Don Leandro de Moratin, le poète espagnol, voit, dans un opéra, mourir Didon sur son bùcher; puis, à l'acte suivant, Didon ressuscite, et elle accueille Enée... Mais ce mème public, qui dédaigne le drame, se passionne avec fureur pour telle page dramatique, séparée de l'action.

C'est qu'il est avant tout lyrique, mais d'un lyrisme qui n'a rien d'abstrait, qui s'applique à des passions précises, à des cas particuliers. L'Italien ramène tout à lui. Ce n'est pas l'action, ni les personnages qui l'intéressent. Ce sont les passions : il les épouse tout entières; il les prend toutes pour son propre compte. De là cette exaltation frénétique où le jette par instants le spectacle d'opéra. Chez aucun autre peuple, l'amour de l'opéra n’a ce caractère passionné, parce que chez nul autre, il n'a ce caractère personnel et égoïste. L'Italıen ne vient pas à l'Opéra pour voir les héros d'opéra, mais pour se voir, pour s'entendre, pour caresser, pour attiser ses passions. Tout le reste lui est indifférent.

Grande force pour l'art, qui se sent réchauffé par ces cœurs enflammés! Hais aussi, grand danger. Tout ce qui n'est pas, en art, astreint à l'imitation ou au contrôle de la nature, tout ce qui ne dépend que de l'inspi-

R. Rolland. - Voyage musical. 
ration ou de l'exaltation intérieure, tout ce qui suppose, en somme, le génie ou la passion, est instable, par essence, le génie, la passion étant toujours exceptionnels, même chez l'homme de grénie, même chez l'homme passionné. Une telle flamme est sujette à des éclipses momentanées, ou à des disparitions totales; et si, dans ces sommeils de l'esprit, le talent laborieux et scrupuleux, l'observation et la raison ne prennent pas la place du génie, c'est le néant complet. On ne peut que trop vérilier cette remarque chez les Italiens de tous les temps : leurs artistes, même médiocres, ont souvent plus de génie que beaucoup d'artistes du Nord, célèbres et bien doués; mais ce génie se gaspille en des riens, s'endort, ou vugabonde; et quand il n'est plus dans la maison, il n'y a plus personne...

Le salut pour la musique italienne du xvm siècle eût été dans un genre qu'elle venait de créer: l'opera buffa, l'intermezzo, qui, à son point de départ, chez Vinci et chez Pergolèse, repose sur l'observation humoristique de la nature italienne. Les Italiens, qui sont de grands railleurs, ont laissé là des chefs-d'œuvre inimitables. Le président de Brosses avait raison de se passionner pour ces petites comédies. "Moins le genre est grave, dit-il, et mieux la musique italienne y réussit; car elle respire la gaieté et elle est dans son élément. " Et il écrit, au sortir de la Serva padrona: “Il n'est pas vrai qu'on puisse mourir de rire; car à coup sùr j'en serais mort, malgré la douleur que je ressentais de ce que l'épanouissement de ma rate m'empêchait de sentir, autant que je l'aurais voulu, la musique céleste de cette farce ».

Mais, comme il arrive toujours, les gens de goût, les musiciens, n'estimaient pas tout à fait ces œuvres à 
leur valeur; ils les considéraient commo des divertissements sans importance, et ils eussent rougi de les mettre au mème rang que les tragédies musicales. Constamment, dans l'histoire, cette inintelligente hiérarchie des genres a fait priser davantage des œurres médiocres, d'un genre noble, que d'excellentes œurres d'un genre moins relevé. Au temps du président de Brosses, « les précieux et précieuses d'Italie affectaient de dédaigner les opéras bouffes et raillaient " l'affolement de de Brosses pour ces farces $)$. Aussi ces excellentes petites pièces furent-elles bientôt négligées; et des abus aussi grands que dans l'opéra s'introduisirent dans l'Intermezan : même invraisemblance, et même insouciance de l'action. Burney est forcé de dire que, « si l'on ôte la musique de l'opéra-comique français, c'est encore une jolio comédie, tandis que sans musique l'opéra-comique italien est insupportable ». A la fin du siècle, Moratin gémit sur l'absurdité du genre. C'était pourtant l'époque de Cimarosa, de Paisiello, de Guglielmi, d'Andreozzi, de Fioravanti, et de bien d'autres. Que n'eussent pas fait ces petits maîtres, avec plus de discipline et des poètes plus scrupuleux!

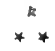

A Venise, on l'a vu, la passion pour l'opéra s'unissait à un goùt très vif - que Naples n'avait pas à ce point - pour la musique instrumentale. 11 en avait toujours été ainsi depuis la Renaissance; et déjà, au commencement du $\mathrm{XVII}^{\ominus}$ siècle, co trait distinguait do l'opéra napolitain, florentin ou romain, l'opéra du Vénitien Montevererdi. 
D'une façon générale, on peut dire que le Nord de l'Italie - le Veneto, la Lombardie, le Piémont - était au xviI $^{\mathrm{e}}$ siècle une terre d'élection pour la musique instrumentale.

C'était le pays des grands instrumentistes, surtout des violonistes. L'art du violon était proprementitalien. Doués d'un sens naturel de l'harmonie des lignes, amoureux du beau dessin mélodique, créateurs de la monodie dramatique, les Italiens devaient exceller dans la musique pour violon. a Personne, comme eux, dit M. Pirro ", - ne savait écrire en Europe avec la clarté et l'expression qu'il réclame. \Corelli et Vivaldi furent des modèles pour les maîtres allemands. L'âge d'or de la musique italienne de violon est entre 1720 et 1750 , avec Locatelli, Tartini, Vivaldi et FrancescoMaria Veracini. Grands compositeurs et virtuoses, ces maîtres se distinguaient par la sévérité du goût.

Le plus fameux était Tartini de Padoue. « Padoue, dit Burney, est non moins illustre parce que Tartini y vécut et mourut que par la naissance de Tite-Live. » On allait visiter sa maison, et, plus tard, son tombeau, " avec la ferveur des pèlerins de la Mecque ». Aussi célèbre comme compositeur et comme théoricien que comme virtuose, et un des créateurs de la science de l'harmonie moderne, Tartini était une des autorités musicales de son siècle. Aucun virtuose italien ne so croyait consacré avant d'avoir reçu son approbation. De tous les musiciens de son pays, il avait le goût le plus grave et l'intelligence la plus ouverte aux mérites artistiques de toutes les nations. \& Il est poli, complaisant, sans orgueil et sans fantaisie, - dit le président

1. Pirro, L'Orgue de Bach (Paris, Fischbacher, 1805). 
de Brosses; - il raisonne comme un ange et sans partialité sur les différents mérites des musiques française et italienne. Je fus au moins aussi satisfait de sa conversation que de son jeu. 》 - «Ce jeu n'avait que peu de brillant » : ce virtuose avait horreur de la virtuosité vide. Quand les violonistes italiens venaient lui faire entendre leurs tours d'adresse, “ il écoutait froidement, puis disait : "Cela est brillant, cela est vif, cela est très fort, mais - ajoutait-il, en portant la main à son cœur - cela ne m'a rien dit là ${ }^{1} »$. Son style était « d'une extrême netteté de sons, dont on ne perdait jamais le plus petit », et d'un pathétique concentré. Jusqu'à sa mort, Tartini fit modestement partie de l'orchestre du Santo de Padoue.

Auprès de ce grand nom, d'autres ont gardé jusqu'à nous une légitime renommée. A Venise, était Vivaldi, que le président de Brosses connut aussi, et qui devint promptement un de ses plus intimes amis, - «pour me vendre, dit-il, ses concertos bien cher.... C'est un vecchio, qui a une furie de composition prodigieuse. Je l'ai ouï se faire fort de composer un concerto, avec toutes ses parties, plus promptement qu'un copiste ne le pourrait copier. 》Il n'était déjà plus très estimé dans son pays, " où tout était de mode, où l'on entendait ses ouvrages depuis trop longtemps, et où la musique de l'année précédente n'était plus de recette ". Une compensation lui était réservée : celle d'être un modèle pour Jean-Sébastien Bach.

Les autres violonistes du même temps : Nardini, le meilleur élève de Tartini, Veracini, compositeur profond, en qui l'on a pu voir un précurseur de Beethoven,

\section{Grosley}


Nazzari, Pugnani, avaient les mêmes qualités sobres et exprasives, fuyant l'efiet, plutut qu'ils ne le cherchaient. Bumey écrit de Narduni \& qu'il doit plaire, plus qu'il ne surprend "; et le président de Brosses dit de Veracini que " son jeu était justo, noble, savant et précis, mais aesez dénué de grâce ».

L'art du clavecin avait compté des maîtres, tels que Domenico Zipoli, contemporain et émule de Kiændel, et Domenico Scarlatti, génial précursetir, qui ourrit à l'art deg voies nourelles où le suivit Philippe-Emmanuel Bach. Il était encore illustré par Galuppi. Mais la décadence s'y faisait déjà sentir, au temps de Burney. a A dire rai, - écrit-il, - je n'ai rencontré ni grand joueur de clavecin, ni compositeur original pour eet instrument dans toute l'Ktalie. La raison en est qu'on n'en fait usage ici que pour accompagnor la roix. Lt, à présont, il est si négligé, tant par les facteurs que par les joneurs, qu'il est difficile de dire lesquels sont les plus mavais, ou des instruments, ou de ceux qui en jouent. " - L'art de l'orgue s'était mieux conservé, depuis le vieux Frescobaldi. Mais, malgré les apprécialions élogieuses que Grosley et Burney ont faites des organistes italiens, on peut accepter comme vrai le jugement de Rust, disant que « les Italiens semblaient regarder comme impossible de produire un grand plaisir, en jouant sur des instruments à clavier ». On reconnait la leur génic expressif gui trouvat dans la roix et le violon ses instruments de prédilection ${ }^{1}$.

1. Les instruments à vent étaient assez négligés. Alessandro Scarlatti, qui se prêta malaisément ì l'entrevas in lie Hasse sullicitisit, en 1725, pour le celèbre flutiste Quantz, lui dil : Mon fils, vous con-

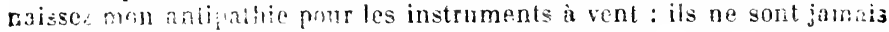

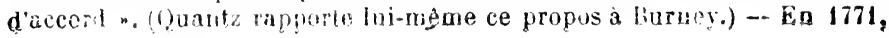


Nais ce qui avait plus d'importance que les grands virlurses, si nombreux dans l'Italie du Nord, c'était le goùi général pour la musique symphonique. Les orchestres lombards et piémontais étaient fameux. Lo plus renommé était celui de Turin, où jouaiznt Pugnani, Veracini, Somis, les Besozzi. Il y avait "symphonie " à la chapelle royale, chaque matin, de onze heures à midi : l'orchestre du roi était divisé en trois groupes, qui se répartissaient entre trois galeries assez éloignées. Ils s'entendaient si bien qu'ils n'avaient pas besoin qu'on battit la mesure. Cet usage, constant en Italie, a naturellement frappé les voyageurs étrangers. "Le compositeur - dit Grosley - n'est occupé qu'à exciter du geste ou de la voix, comme un général d'armée l'est de ceux qui vont à la charge. Toute cette musique, malgré la variété et la complication de ses parties, s'exécute sans battement de mesure. „Et cela prouve, sans doute, que la variété et la complication de cette musique n'étaient pas encore bien grandes, pour qu'elle pût s'accommoder d'une telle liberté; mais c'est aussi l'indice de l'expérience et de l'esprit musical des orchestres italiens ${ }^{1}$. Il suffit de penser à ceux de la France d'alors, qui ne jouaient pas de musique plus difficile, et qui avaient pourtant besoin d'être conduits à grands coups de bâton... et de talon. - "Ces gens-ci, - écrit le président de Brosses - ont tout autrement que nous

Mozart constate que, pour la grande fète de San Petronio à Bologne, on a été obligé de faire venir des trompettes de Lucques, et qu'elles étaient détestables. - On ne trouvait guère de bons instruments à vent qu'à Venise et dans le Nord de l'Italie. A Turin étaient les deux frères Besozzi, hautboïste et bassoniste, connus dans toute l'Europe.

1. Il semble que ceite habitude se soit perdue, à la fln du siècle. Gœthe se plaint, à Vicence, en 1786, a du maudit battement de mesure par le muestro, usage que je croyais réservé à la France . 
de justesse et de précision. Leurs orchestres ont un grand sentiment des gradations et du claip-obscur. Cent instruments à cordes et à vent savent les accompagner sans couvrir les voix ${ }^{1}$. 》

A Milan surtout, la musique symphonique était en honneur. On pourrait presque dire qu'elle y a été fondée: car c'est là que vivait un des deux ou trois hommes qui peuvent prétendre à la gloire d'avoir créé la symphonie, au sens moderne du mot, - et, je crois, celui des trois qui a les titres les plus sérieux à cette gloire ${ }^{2}$ : G.-B. Sammartini, précurseur et modèle de Haydn. Il était maître de chapelle de presque la moitié des églises de llilan, et il composa pour elles d'innombrables morceaux symphoniques. Burney, qui le connut et entendit plusieurs concerts donnés sous sa direction, dit que " ses symphonies étaient pleines d'un esprit et d'un feu qui lui étaient propres. Les parties instrumentales étaient bien écrites; il ne laissait pas un seul instrument longtemps oisif, et les violons surtout n'avaient pas le temps de se reposer ». Burney lui faisait le reproche, plus tard adressé à Mozart, que sa musique avait « trop de notes et trop d'allegros. Il semblait absolument courir au galop. L'impétuosité de son génie le poussait en avant dans une suite de mouvements rapides, ce qui, à la longue, fatigue et l'orchestre et les auditeurs. ") Burney admire pourtant aussi « la beauté vraiment divine » de certains de ses adagios.

Les Milanais montraient beaucoup de goût pour

1. Il n'en était plus tout à fait ainsi au temps de Burney, oû l'orchestre tendait à dominer les voix.

2. Les deux autres sont Gossec, pour la France, et Stamitz, pour l'Allemagne. 
cette inusique symphonique. Milan arait de nombreux concerts, non seulement publics, mais particuliers, où des amateurs formaient de petits orchestres: on y jouait des symphonies de Sammartini et de Jean-Chrétien Bach, le plus jeune fils de Jean-Sébastien. Il arrivait mème que la représentation d'opéra fût remplacée par un concert. Et, jusque dans l'opéra, cette prédilection pour la musique instrumentale faisait - au scandale des vieux amateurs du chant italien - que l'orchestre était trop nourri, trop fort; les accompagnements compliqués avaient tendance à cacher la mélodie et à couvrir la voix.

\section{$* *$}

Ainsi, la musique instrumentale avait pour foyers principaux Turin et Milan; la musique vocale, Venise et Naples.

Bologne était la tête de l'art italien, le cerveau qui raisonne et dirige, la ville des théoriciens et des académies. Là était la principale autorité musicale de l'Italio au xvine siècle, - autorité reconnue à la fois par les Italiens, par les maitres de toute l'Europe, par Gluck, par Jean-Chrétien Bach, par Mozart : - le Père Martini. Ce religieux franciscain, maitre de chapelle de l'église de cet ordre à Bologne, était un compositeur savant et aimable, d'une grâce un peu rococo, un historien érudit, un maître du contre-point, et un collectionneur passionné, qui centralisait chez lui, dans sa bibliothèque de dix-sept mille volumes, la science musicale de l'époque. Il en faisait généreusement part à tous ceux qui s'adressaient à lui : car il était plein de bonté; il avait une de ces âmes pures et 
sereines, comme on en trouve chez les anciens artistes italiens. Aussi était-il très aimé, et l'on avait constamment reccurs à ses lumières, soit qu'on lui écrivît, soit qu'on vint le voir à Bologne. Burney parle de lui avec affection :

Il est avancé en âge, et d'une mauvaise santé. Il a une toux inquiétante, les jambes enflées et l'air tout malade... On ne saurait, en lisant ses livres, se former uno idce du caractère de ce bon et digne homme. Ce caractère est fel qu'il inspire non seulement le respect, mais la tendresse. Il allie à la pureté de sa vie et à ln simplicité de ses mœurs, de la gaicté. de la douceur et de la philanthropic. Je n'ai jamais aimé personne davantage, après une connaissance aussi légère. J'avais aussi peu de réserve avec lui au bout de quelques heures, que j'aurais fait arec un vieil ami ou un frère chéri.

Bologne possédait aussi la principale académie musicale d'Italie : la Société philharmonique, fondée en 1666, où les maîtres italiens et étrangers tenaient à honneur d'être reçus. Le petit Mozart y fut admis après un concours, où la légende ne dit pas qu'il fut secrètement aidé par le bon Père Martini. Il en fut de même pour Grétry, qui ne cache point le fait dans ses Mémoires. La Société philharmonique discutait les questions de théorie et de science musicale; et elle donnait, tous les ans, un festival; on y exécutait les œuvres nouvelles des compositeurs bolonais. Cette fête, d'un caractère solennel, avait lieu à l'église de San Giovanni in Monte, où était alors exposée la Sainte Cécile de Raphaël. L'orchestre et les chœurs comptaient une centaine de musiciens; chaque compositeur dirigeait ses œuvres Tous les critiques musicaux d'Italie assistaient à cette épreuve, où se décidaient les réputations, pour la musique d’écrliso 
et la musique instrumentals. Purney so rencontra à l'unis de ces fètes avec Léopold llozart " et son fils, lo petit Allemand, dont les talents prématurés et presquo surnaturels nous étonnaient à Lontres, - dit-il, - il y a quelques années, lorsqu'il était à peine sorti de l'enfance ». a Ce jeune homme, - ajoute-t-il plus loin, - qui a surpris l'Europe par son exécution et scs connaissances précoces. est encore un maitre très habile sur son instrument ${ }^{1}$ ».

\section{$* *$}

Enfin, Rome exerçait une dictature sur toute la musique italienne.

Rome avait la spécialité de sa musique religrieuse, de sa chapelle Sixtine, d'ailleurs en décadence, par suite de la concurrence que lui faisaient les théâtres, qui par leurs traitements considérables, attiraient les meillein's artistes ${ }^{2}$. Rome arait ses grandes collections de musique

1. Burney est des plus dédaigneux pour la scur de Mfozart, Marianne: "La jeune personne paralt ètre arrivée à son plus haut degré, qui u’est pas merveilleux; et, si j'en peux juger par la musique dorchestre de sa compositiou que j'ii entendue, c'est du fruit prématuré plus extraordinaire qu'il n'est excellent."

2. "Cumme les sujets d'un mérite distingué qui appartiennent à la chapelle Sixtine y trouvent peu d'enconragement, la musique commence à être moins bonne et à se perdre sensiblement... Il doit en résuller pru à peu la perte de ces beaux établissements, celle de l'ancienne musique, aussi bien que de l'élėante simplicité qui fait la réputation de refte chapelle. " (Burney.) - Déjà, un ami de Burney, qui avait passé vinget ans à liome, lavait prévenu que la chapelle du pape n'avait plus la même supériorité qu'autrefois. Autrefois, les musiciens attachés au service du pape étaient les mieux payés. Maintrnant "leur traitement est resté le inème. Cependaut la vie est devenue plus chère. II en résulte que les musiciens ont été obligés, pour vivre, de reunır une autre profession à ceile de chanter, qui se perd, landis que l'exécution musicale des théâtres se perfectionne, chaqque jour : 
ancienne. liome avait ses sept ou huit théâtres illustres, entre autres l'Argentina et l'Aliberti pour l'opera seria, et le Capranica pour l'opera buffa.

Rome arait surtout, par l'attraction que sa gloire, ses souvenirs, son charme éternel, ont toujours rayonnée sur les esprits d'élite, une société d'une rare compétence musicale, un public vraiment souverain, qui savait sa valeur, peut-être avec excès, et prononçait ses jugements sans appel.

Il y a à Rome - écrit Grétry - nombre d'amateurs, de vieux abbés, qui, par leurs sages critiques, retiennent le jeune compositeur qui se laisse emporter hors des limites raisonnables de son art. Aussi, lorsqu'un compositeur a réussi à Naples, à Venise, même à Bologne, on se dit : "Il faut le voir à Rome! »

Les représentations d'opéras nouveaux à Rome étaient pour les auteurs la plus redoutable des épreuves; on y édictait des sentences qu'on prétendait définitives; et les juges y apportaient la passion du tempérament italien. Dès le début de la soirée, la bataille s'engageait. Si la musique était condamnée, on savait faire la distinction entre le compositeur et les chanteurs : on sifflait le maestro, et on acclamait les artistes. Ou bien, c'était les chanteurs qu'on sifflait, et on portait en triomphe, sur la scène, le compositeur.

Les Romains - dit Grétry - ont l'habitude de crier, au théâtre, pendant un morceau de musique où l'orchestre domine : Brava la viola, brava il fagotto, brava l'oboè! Si c'est un chant mélodieux et poétique qui les flatte, ils s'adressent à l'auteur, ou ils soupirent et pleurent; mais ils ont aussi la terrible manie de crier, tour à tour : Bravo Sacchini, bravo Cimarosa, brawn Paisiello! aux représentations 
de l'opéra d'un autre auteur : supplice bien propre à réprimer le crime de plagiat.

Avec quelle brutalité s'exerçait parfois cette justice populaire, nous le savons par l'histoire du paure Pergolèse, quî reçut, dit on, à la première de son Olimpiade, au milieu des huées, une orange en pleine figure. Et ce fait montro assez que le public romain n'était pas infaillible. Mais il prétendait l'être. Fidèle à ses traditions, il s'arrogeait sur la musique un empıre :

Tu regere imperio populos, Romane, memento...

Personne ne s'en étonnait : on lui reconnaissait ce droit : - "Rome, capitale du monde », écrivait dans une de ses lettres, en 1770, « Amadeo Mozart D.

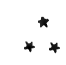

Tel était, dans ses grandes lignes, l'édifice de la musique italienne au xvile siècle. On voit quelle richesse et quelle vie. Le plus grand danger pour cet art - celui auquel il succomba - était son exubérance même. Il n'avait pas le temps de se recueillir, de méditer sur son passé. Il était dévoré par sa fureur de nouveauté ${ }^{1}$.

1. Je parle du goût public. Lc culte du passé se maintenait chez une petite élite. En outre du Père Martini et de sa bibliothèque de dix-sept mille volumes, l'Italie ne manquait pas de collectionneurs, comme le professeur Campioni, à Florence, qui rassemblait les madrigaux du $\mathbf{x v i}^{\circ}$ et du $\mathbf{x v I I}^{\circ}$ siècle; le chanteur Mazzanti, à Kome, qui réunissait tout ce qui avait trait à Palestrina; l'abbé Orsini et le chevalier Santarelli, à Rome, qui recueillaient tous les documents relatifs à l'opéra et à l'oratorio anciens. (Burney.) - Le style ancien s'était aussi maintenu, en partie, dans la musique d'église. Burney note souvent, à Milan, Brescia, Vicence, Florence, etc., qu'elle était " dans le vieux style, pleine de fugues ..

Sans doute, on exécutait dans les églises italiennes beaucoup de 
"Vous me faites mention de Carissimi, - écrit le présilent de Brosses. - Pour Dieu! gardez-vous d'en parler ici, sous peine d'èlre regardé comme un chapeau pointu : il y'a longrtemps que ceux qui lui ont succédé sont passés de mode!"

Le même, entendant à Fraples, arec ravissement, un célèbre chanteur, le Senesino, "s'aperçut avec étonnement - dit-il - que les grens du pays n'en étaient gruère satisfails. Ils se plaignaient qu'il chantait d'un stile antico. C'est qu'il faut vous dire que le groût de la musique change ici au moins tous les dix ans. D

Burney est plus affirmatif encore :

En Italie, on traite un opéra déjà entendu comme l'almanach de l'année écoulée... C'est une rage de nouveauté; et elle a été cause quelquefois des révolutions qu'on remarque dans la musique d Italie; elle donne naissance souvent à d'étranges concetti. Elle conduit les compositeurs à chercher, à tout prix, du nouveau. La simplicité des maìtres anciens ne plaît plus au public. Elle ne flatte plus assez les goûts

musique mondaine, comme celle que décrit le chevalier Goudar, dans un amusant récit (l'Espion chinois, 17̈63̈):

* J'allai dernièrement, à Bologne, à ce qu'on appelle ici une grand'messe en musique. En entrant dans l'église, je crus d'abord ètre à l'Opéra. Entrées, symplıonies, menuets, rigaudons, airs à voix seule, duos, chceurs, accompagnements de tanbours, trompettes, timbales, cors de chasse, hautbois, violons, lifres, flageolets, en un mot, tout ce qui sert à former l'harmonie d'un spectacle se trouvait employé à celuici. C'ètait un chef-d'œuvre d'impiété. Quand le compositeur aurait fait une messe pour la déesse de la volupté, il n'aurait pu employer des sons plus tendres, ni des modulations plus lascives. "

Mais Burney assure que " ce n'était que les jours de fète qu'on pouvait entendre celte espèce de musique moderne dans les églises. Les jours ordinaires, daus les églises cathédrales, elle était dans un style grave et ancien; et dans les églises de paroisse, c'était purement du plainchant, quelyuefois avec l'orgue, mais plus souvent sans oryue. •

Malgré tout, dans un siècle et un pays aussi peu religieux que le xvin' siècle italien, la musique d'église ne pouvait être un contrepoids suffisant à la musique profane, qu'emportait la fièvre de la nouveauté. 
usés de ces cnifinís gâtés, qui n'ont pius de jouissances que dans l'élonnement ${ }^{1}$.

Cette inconstance du goùt, cette trépidation perpétuelle, étaient cause que l'on n'imprimait pour ainsi dire plus de musique en Italie.

Les compositions musicales durent si peu, et la faveur des noureautés est si grande que pour quelques copies qu'on voudrait avoir, ce n'est pas la peine de faire la dépense de la gravure ou de l'impression... Aussi l'art de graver la musique paraît entièrement perdu. On ne trouve rien dans toute l'Italie qui ressemble à un magasin de musique?.

Burney en vient même à entrevoir, au milieu de cette splendeur artistique qui lui est chère, la disparition prochaine et totale de la musique italienne. Il croit, à la vérité, que l'énorme force qui s'y dépense se transformera, qu'elle créera d'autres arts :

La langue et le génie des Italiens sont si riches et si fertiles que, lorsqu'ils seront ennuyés de la musique, - ce qui arrivera sans doute très prochainement, par l'excès même de la jouissance, - la même fureur qu'ils ont pour ìa nouveauté, qui les a fait passer avec tant de rapidité d'un style de composition à un antre. et qui les fait changer souvent d'un bon à un plus mauvais, les forcera à chercher l'amusement d'vin théâtre sans musique ${ }^{3}$.

La prédiction de Burney ne s'est qu'en partie réalisée. L'Italie a tenté, depuis, non sans éclat, de se constituer “ un théâtre sans musique ». Elle a surtout dépensé lo meilleur de ses forces, en dehors du théâtre et de la musique, dans ses luttes politiques, dans l'admirable

1. Burney parie surtout ici des Napolitains.

2. Burney : Venise.

3. Burney : Bologne. 
épopée de son Risorgimento, où tout ce qu'il y eut de grand et de généreux dans la nation s'est dépensé et souvent sacrifié avec enivrement. Mais Burney a bien vu la loi, secrète de cette musique italienno, le principe de sa vie, de sa grandeur, et de sa mort : l'îtalie da xvine siècle est toute au moment présent, il n'y a plus pour elle ni passé, ni avenir. Nulle réserve. Elle so brûle.

Quelle différence entre cette Italie prodigue et la sage économie de la France et de l'Allemagrne du même temps, - celle-ci amassant, amassant en silence des greniers pleins de science, de poésie, de génie artistique, celle-là mettant de côté lentement, patiemment, parcimonieusement, son avoir musical, comme le paysan français qui empile ses écus dans le fameux bas de laine! - Aussi se trouveront-elles jeunes, vigoureuses, et comme neuves, quand l'Italie sera épuisée par sa dépense extravagante de forces.

La blame qui voudra! Si les vertus d'économie domestique sont dignes de toute estime, toutes mes sympathies vont à l'art qui se donne sans compter. C'est le charme de cette musique italienne du xvin' siècle, qu'elle se dépense à pleines mains, sans souci de l'avonir. Que la beauté ne soit pas durable, il n'imporie. Ce qu'il faut, c'est qu'elle ait été la plus bello possible. Du rayonnement passager des beaux siècles disparus, il reste pour toujours dans le cœur une joie et une lumièro. 


\section{II}

A L L EMA G N

Malgré un siècle et demi de grands musiciens, l'Allemagne, vers 17 ŏ 0 , était bien loin encore de tenir dans l'opinion musicale de l'Europe la place qu'elle occupe aujourd'hui. A la vérité, on n'était plus au temps où un chroniqueur romain disait des pensionnaires du Collège germanique, à Rome :

$\mathrm{Si}$, par hasard, ces pensionnaires se trouvaient dans le cas de faire de la musique en public, il est certain que ce serait une musique tudesque, bonne à exciter le rire et à mettre l'auditoire en joie. ${ }^{1}$

Le temps était même passé - mais pas très éloigné - où Lecerf de la Viéville mentionnait négligemment les Allemands, « dont la réputation n'est pas grande en musique ${ }^{2}$ », et où l'abbé de Châteauneuf félicitait un joueur de tympanon allemand, d'autant plus, disait-il, “ qu'il venait d'un pays peu sujet à produire des hommes de feu et de génie ${ }^{3}$ ».

1. Chronique du Père Castorio (1630), citée par Henri Quittard, dans sa préface aux Histoires Sacrées de Carissimi, publiées par la Scholu Cantorum.

2. Lecerf de la Viéville, Comparaison de la musique française et de la musique italienne (1705).

3. Abbé de Châteauneuf, Dialogue sur la musique des anciens (1705).

R. Rolland. - Vojage musical. 
En 17.̈.冂. l'Nllomane arait eu Ilandel et Jean Sébastien bach. Elle aval tiuck et Philippe-Emmanuel Bach. Et pourtant elle subissait encore le jougécrasant de l'Italie. Bien que certains de ses musiciens, qui prenaient cumsience de leur force, supportassent impatiemmont cette domination, ils netant pas assez unis four en venis a bout. Trop grands etarnt les dons de séduction de leurs rivaux, trop parfat l'art italien, quel qu'en fùt le ride de peinsée. Il fassil ressortir crùment les macherips. les lowrdeurs, les fautes de goùt. qui ne manquent proint cinz las malres allemants, et rendent souvent rebutante la lecture des arlistes de second ordre.

Le voyageur anghis Burney, qui. dans ses notes sur l'Allemirgne ${ }^{1}$, finit par rendre un très bel honmagre à la grandeur de l'art germanique, n'en est pas moins choqué, à chaque pras, par la grossièreté des exécutions musicales; il grince des dents aux instruments mal accordés, aux orgues fausses, aux roix qui crient.

On ne retrouve pas - dit-il - chez les musiciens allemands qui courent les rues. cette dilicatesse d'oreille que j'avais rencontrée daus la mène classe du peuple en Italie ${ }^{2}$.

Dans les écoles de Gaxe et d'Autriche, « le jeu des écoliers est en général dur et grossier ».

A Leipzig, le chant n'esî “ qu'un éclat désagréable, un glapissement en prenant les tons élevés, une espèce de cri frappé, au lieu d'émettre la voix et de filer ou d'euller le sons.

A Berlin. l'école instrumentale « ne fait presque point d'usagre des forte et des piano. Charjue exécutant ne

1. Charles Burney, The present state of music in Germany, the Netherlands, and United Provinces (1773), - traduction frauçaise du mêmo temps.

?, Beney : Vienue. 
rivalise aver son voisin que pour jouer plus fort que lui. Lè but principal du musicien de Berlin paraît ètre de se faire entendre... ¿. sucune nuance... Nulle attention à la nature çe la voix des instruments, qui n'ont qu'un certain degré de force en chantant, et au delà duquel ce n'est plus que du bruit. »

A salzbourg, la musinue tres nombreuse du prince archevèue "se lait remarquer surtout par son inélégance et par son bruit ». Hozart en parle avec dégoût: ( C'est une des grandes raisons pour lesquelles Salzbourg m'est odieux : cet orchestre de la cour est si grossier, si débraillé, et si débauché! Un honnête homme, qui a de bonnes manières, ne peut pas vivre avec ces gens-là ${ }^{1}$ ! »

Mème à Mannheim, qui possédait l'orchestre le plus parfait d'Allemagne, les instruments à vent - les bassons, les hautbois, - manquaient de justesse.

Quant à l'orgue, c'était une souffrance d'en entendre jouer en Allemagne. A Berlin, " les orgues sont grandes, grossières, chargées de registres, bruyantes et fausses ». A Vienne, dans la cathédrale, « les orgues sont horriblement discordes ». Même à Leipzig, dans la ville sacrée de l'orgue, la ville du grand Jean-Sébastien Bach, “ malgré toutes mes recherches, - dit Burney, - je n'entendis bien jouer de l'orgue nulle part ».

Bien plus, il semble qu'à l'exception de quelques cours princières - « ou les arts, écrit Burney, rendaient le pouvoir moins insupportable, et où la diversion de la pensée étail peut-être aussi nécessaire que celle de l'action », - il semble que le goût pour la

1. Lettre de Mozart à son père, du 9 juillet 1778. - Le meilleur musicien de Salzbourg, un homme presque de génie, Michel Haydn, venait jouer de l'orgue, quand il était abomiuablement ivae. 
musique ne soit pas, à beaucoup près, aussi ardent et aussi universel en Allemagne qu'en Italie.

Pendant les premières semaines de son voyage, Burney est déçu :

En voyageant sur les bords du Rhin, de Cologne à Coblentz, je fus singulièrement étonné de ne pas trouver trace de cette passion pour la musique, dont on dit que les Allemands sont possédés, particulièrement le long du Rhin ${ }^{2}$. A Coblentz, quoique ce fùt un dimanche, et que les rues fussent remplies par la foule du peuple, je n'entendis pas une seule voix, ni un instrument, comme c'est l'usage dans la plupart des autres pays catholiques romains.

Hambourg, naguère célèbre par son opéra, le premier et le plus glorieux d'Allemagne, est devenue une Béotie musicale. Philippe-Emmanuel Bach s'y trouve perdu. Quand Burney vient le voir, Philippe-Emma. nuel lui dit: « Vous êtes venu ici cinquante ans trop tard $)$.

Et, d'un ton gouailleur, qui dissimule un peu d'amertume et de honte, il ajoute :

Adieu la musique! Les Hambourgeois sont de bonnes gens, et je jouis ici d'une tranquillité et d'une indépendance que je n'aurais pas dans une cour. Depuis l'âge de cinquante ans, j'ai quitté toute ambition. J'ai dit: ("Mangeons, buvons : demain nous dormirons "). Et me voilà réconcilié arec ma position, sauf lorsque je rencontre des gens de goût et d'esprit qui peuvent apprécier une meilleure musique que celle que nous faisons ici : alors, je rougis pour moi même et pour mes bons amis les Hambourgeois.

1. Burney passa à Bonn, peu de temps après la naissance de Beethoven. 
Burney en vient à croire que ce n'est pas à la nature, mais a l'étude que les Allemands doivent les connaissances qu'ils ont de la musique ${ }^{1}$.

Peu à peu, il changera d'opinion, en découvrant la richesse cachée, l’originalité, la vie puissante de l'art allemand. Il sentira la supériorité de la musique instrumentale allemande. Il trouvera même plaisir au chant allemand, et il le préférera à tout autre, l'italien excepté. - Mais ses premières impressions font assez comprendre que l'élite, les princes et les amateurs allemands de ce temps aient, aux dépens de leurs compatriotes, favorisé les Italiens, avec une exagération que l'italianisant Burney lui-même reconnaît.

La musique italienne avait, au cœur de l'Allemagne, plusieurs foyers. C'étaient, au $\mathrm{xvII}^{\mathrm{e}}$ siècle, Munich, Dresde et Vienne. Les plus grands maîtres italiens :

1. Burney : Dresde.

Remarquer, à cette époque, la grossièreté des spectacles populaires en Allemagne, même à Vienne, où Burney relève des programmes d'amusements barbares comme ceux-ci :

" $1^{\circ}$ Combat de chiens dogues et d'un taureau sauvage de Hongrie, au milieu du feu, c'est-à-dire, ayant du feu atlaché sous la queue, des pétards aux oreilles et aux cornes; $-2^{\circ}$ Combat d'un cochon sauvage et de dogues; $-3^{\circ}$ Combat d'un grand ours et de dogues; $-4^{\circ}$ Combat d'un loup sauvage et de chiens courants; $-5^{\wedge}$ Combat d'un taureau sauvage de Hongrie et de chiens sauvages et affamés; $-6^{\circ}$ Combat d'un ours et de chiens de chasse; $-7^{\circ}$ Combat d'un sanglier sauvage et de dogues défendus par une armure de fer; $-8^{\circ}$ Combat d'un tigre et de dogues; - etc, ; $-11^{\circ}$ Combat d'un ours furieux, n'ayant pas mangé depuis huit jours, et d'un jeune taureau sauvage, qu'il mangera vivant sur la place, - ou aide par un loup."

beux ou trois mille personnes, parmi lesquelles des femmes de qualité, assistaient à ces combats, qui se donnaient fréquemment dans un amphithéâtre de Vienne. - Tels étaient les spectacles qui charmaient les yeux des auditeurs de Haydn et de Mozart. 
Cavalli, Cesti, Draghi, Bontempi, Bemabei, Torri, Pallavicino, Caldara, Porpora, Vivaldi, Tornli, Veracini, y avaient séjourné et résgné. 1)resde surtout avait eu une "oraison d'italianisme éclatante, dans la première moitié du xvin siècle, au temps où Lotti, Porpora, et Hasse, le plus italianisé des Allemands, dirigeaient l'Opéra.

Mais, en 1760, Dresde fut sauvagement dévastée par Frédéric II, qui s'appliqua à effacer pour toujours sa splendeur. Il fit détruire méthodiquement par son artillerie, pendant le siège de la ville, tous les monuments, églises, palais, statues et jardins. Quand Burney y passa, elle n'était qu'un amas de décombres. La Saxe était ruinée, et ne joua plus, de longtemps, aucun rôle dans l'histoire musicale. "Le théâtre était fermé, par raison d'économie. "La troupe d'instrumentistes, fameuse en Europe, était dispersée dans les villes étrangères. " La misère était générale. Les artistes qui n’avaient pas été congédiés étaient à peine payés. La plus grande partie de la noblesse et de la bourgeoisie était si pauvre qu'elle n'avait pas de quoi faire apprendre la musique à ses enfants... Sauf un misérable 0 péra-Comique, il n'y avait à Dresde d'autre spectacle que celui de la misère'. » - Mème ruine à Leipzig.

Les citadelles de l'italianisme, dans la seconde moitié du siècle, étaient Vienne, Munich, et les villes des bords du Rhin.

A Bonn, au moment du voyage de Burney, la troupe des musiciens de l'électeur de Cologne était presque

1. Burney ajoute qu'on ne voyait pas un bateau sur l'Elbe, et que, depuis trois ans, on ne donnait pas d'avoine aux chevaux, ni de poudre aux soldats, pour leur coiffure. 
toute composée d'Italiens, sous la direction du maîtro do chapelle Lucchese, compositeurbien connu en Toscano.

A Coblentz, où l'on jouait souvent des opéras italiens. lo maitre de chapelle élait Sales. de Brescia.

Darmstadt avait áté naguère illustrée par le séjour de Vivaldi, violoniste de la Cour.

Mannheim et Schwetzingen, résidence d'été do l'électeur Palatin, avaient des théâtres d'opéra italien. Celui de Mannheim pouvait contenir cinq mille personnes; la mise en scène en était somptueuse, la figuration plus nombreuse qu’a l'Opéra de Paris et de Londres. La prenque totalité des acteurs étaient Italiens. Des deux maîtres de chapelle. l'un, Toschi, était Italien, l'autre, Christian Cannabich, avait été envoyé en Italie, aux frais de l'électeur, pour étudier sous Jommelli.

A Stuttgart et à Ludwigsburg, où le duc de Wurtemberg était en lutte avec ses sujets, à cause de sa passion extravagante pour la musique ${ }^{1}$, Jommelli resía quinze ans maître de chapelle et directeur de l'Opéra italien ${ }^{2}$. Le théâtre était immense; il pouvait, en s'ouvrant par derrière, former à volonté un amphithéâtre en plein air, « qu’on laissait quelquefois remplir par la multitude, exprès pour produire des effets de perspective $»$. Tous les chanteurs d'opéra bouffe étaient Italiens. L'orchestre comptait de nombreux Italiens, en particulier des violonistes célèbres : Nardini, Baglioni,

1. Les Wurtembergeois avaient réclamé à la Diète de l'Empire contre la prodigalité de leur souverain : ils l'accusaient de ruiner le pays par la musique. On comparait sa mélomanie à celle de Néron. Dans sa folie d'italianisme, le duc se faisait fahriquer des castrats à Sluttgart par deux chirurziens de Bologne. - Burney parle avec une piiié inéprisante de ce prince. "dont la moitié des sujels se compose de musiciens de théâtre, de violons et de soldats, et l'autre moilié do gueux et do misera'lt's".

2. Un autre ílalien, Boroni, lui succèda. 
Lolli, Ferrari. «Jommelli - écrit Léopold Mozart se donne toutes les peines du monde pour fermer aux Allemands l'accès de cette cour... En plus de son traitement de quatre mille florins, de l'entretien de quatre chevaux, de l'éclairage et du chauffage, il possède une maison à Stuttgart et une autre à Ludwigsburg.... Joignez à cela qu'il a sur ses musiciens un pouvoir illimité.... Et voulez-vous une preuve du degré de partialité pour les gens de sa nation? Sachez que lui et ses compatriotes, dont sa maison est toujours remplie, ont été jusqu'à déclarer, à propos de notre Wolfgang ${ }^{1}$, que c'était chose incroyable qu'un enfant de naissance allemande pût avoir tant de verve et de feu ${ }^{2}$ ! »

Augsbourg, qui n'avait cessé d'être en relations régulières avec Venise et la haute Italie, Augsbourg, où l'italianisme avait pénétré dans l'architecture et les arts du dessin, au temps de la Renaissance, et qui fut la patrie de Hans Burgkmair et des Holbein, était aussi le berceau des Mozart. Léopold Mozart s'était, il est vrai, établi à Salzbourg; mais en 1763, il fit un voyage à Augsbourg, avec son petit garçon âgé de sept ans; et Teodor de Wyzewa a montré que c'est là que, selon toutes probabilités, Mozart « commença à s'initier à la grande et libre beauté italienne ${ }^{3}$ ».

Munich était presque une ville italienne. Elle avait

\section{Le petit Mozart.}

2. 11 juillet 1763. Lettre de Leopold Mozart aux Haguenauer, de Salzbourg, publiée par Nissen, reproduite par Teodor de Wyzewa.

3. Un éditeur de musique, J.-J. Lotti, faisait alors, à Augsbourg, de nombreuses publications italiennes; et Wyzewa remarque que l'une d'elles, les Trente arias pour orgue et clavecin de Gius. Antonio Paganelli, de Padoue (1756), a de très grands rapports avec la première sonate, que le petit Mozart quelques semaines après son passage à Augsbourg, écrivit, le 14 octobre 1763, à Bruxelles. (T. de Wyzewa, Les premiers voyages de Mozart. - Revue des Deux Mondes, $1^{\text {er }}$ novembre 1904). 
des thèâtres d'opéra-comique italiens, des concerts italiens, les plus célèbres chanteurs et virtuoses italiens. La sœur do l'électeur de Bavière, l'électrice douairière de Saxe, était élève de Porpora et avait composé des opéras italiens, paroles et musique. L'électeur était luimème un virtuose excellent et un assez bon compositeur.

A peine entré en Autriche, Burney note « la mélodie corrompue, factice, italianisée, que l'on entend dans les villes de cet immense empire ».

Salzbourg, dont Teodor de Wyzewa a décrit la vie musicale dans de charmantes pages consacrées à la Jeunesse de Mozart, était à demi italienne en musique, comme en architecture. Vers 1700, un méchant auteur d'opéras bouffes, Fischietti, de Naples, y était maitre de chapelle.

Mais la métropole allemande de l'italianisme était Vienne. Là trônait le monarque de l’opéra, l'opéra fait homme : Métastase. Père d'une lignée innombrable de poèmes d'opéra, dont chacun fut mis en musique, non pas une fois, mais deux, mais trois, mais dix, et par tous les compositeurs illustres du siècle, Métastase était regardé par tous les artistes d'Europe comme un génie unique. « ll a - dit Burney - tout le pathétique, l'âme et la perfection de Racine, avec plus d'originalité. „Il était la première autorité du monde, pour le théâtre musical. " Ce grand poète, - dit encore Burney, - dont les écrits avaient peutêtre plus contribué à la perfection de la mélodie vocale, et par conséquent de la musique en général, que les efforts réunis de tous les compositeurs de l'Europe », laissait entendre qu'il donnait quelquefois aux musiciens le motif ou le sujet de leurs airs; et il 
s'arrogeait sur eux une suprématie protectrice. Rien ne montre mieux l'italianisation de l'Allemigne que ce fait : le représentant le plus glorieux de l'opéra italien prenant pour résidence, non pas liome ou Venise, mais Vienne, où il avait sa cour. Poète lauréat de l'Empereur, il dédaignait d'apprendre la languo du pays où il virait; il n'en. savait que trois ou quatre mots : juste ce qu'il fallait, comme il disait, « pour se sauver la vie ", c'est-à-dire pour se faire comprendro de ses domestiques. Adulé par l'Allemagne, il ne lui cachait pas son dédain.

Son bras droit à Vienne, son principal traducteur en musique, ćtait le compositeur Hasse, le plus italianisé des musiciens allemands ${ }^{1}$. Adopté par l'ltalie, baptisé par elle il Sassone (le Saxon), élève de Scarlatti et do Porpora, Uasse avait pris une sorte de chauvinismo italien qui surpassait celui des Italiens eux-mêmes. I! no voulait entendre parler d'aucune autre musique, et il faillit assommer le président de Brosses. quand celui-ci, à home, essaya de lui vanter la supériorité du Français Lalande, dans la musique d'égrlise.

Je vis - écrit le président de Brosses - mon homme prêt à suffoquer de colère contre Lalande et ses fauteurs. II tenait déjà du chromatique; et si Faustine, sa femme ${ }^{2}$, ne s'était mise entre nous deux, il m'allait harper avec une double croche et m'accabler de diésis.

On peut dire que l'Allemand Hasse était, vers le

1. Johann-Adolph Hasse, né en 1699 à Bergedorf, près de Hambourg, mort en 1782 a Venise. Il ful te plas grand malle de lippera de Dresde, qu’il réorganisa et dirigea, de 1731 à 1763 . Il écrivii plus de celst operist.

2. Hasse avait épousé la plus faneuse chantease italienne du lemps la Taustina (Bordoni). 
milieu du siècle, le compositeur italien le plus goùté, dans l'opera seria, en Allemagne, en Angleterre, et en Italie même. Il avait mis en musique tous les libretti d'opéra de Métastase, à l'exception d'un seul, - quelques-uns trois ou quatre fois, - tous au moins deux fois. Et, bien que l'on ne pût certes pas dire que Métastase travaillàt lentement ${ }^{1}$, Irasse ne trouvait point qu'il écrivît assez vite; et, pour passer le temps, il avait aussi composé la musique de divers opéras d'Apostolo Zeno. Le nombre de ses œuvres était si grand qu'il avouait « qu'il pourrait bien ne pas les reconnaitre, si on les lui montrait »; il avait plus de plaisir, disait-il, à créer qu'à conserver ce qu'il avait écrit; et il se comparait à « ces animaux féconds, dont la race est détruite en naissant, ou abandonnée au hasard ${ }^{2}$ ».

1. Nétastase se vantait d'aroir écrit son meilleur drame : Hypermnestre, en neuf jours. Achille à Scyros avait été écrit, mis en musique, monté et joué en dix-huit jours.

2. Burney fait un beau portrait de ce grand compositeur, dont la gloire, au $\mathbf{x}$ vin $^{\circ}$ siècle, domirsa de beaucoup celle de Jean-Sébastien Bach. Il était partout regardé " comme le compositeur, pour la musique vocale, le plus près de la nature, le plus élegant et le plus judicieux, et aussi le plus fécond des auteurs vivants.. - - Il était haut de taille et fort. Sa figure avait dû ètre belle et bien dessinée. II semblait plus vieux que Faustina, petite, brune, spirituelle et vive, quoiqu'il fùt de dix ans moins âgé. It avait beaucoup de douceur et de bonté dans ses manières. Il était communicatif, plein de raison, également détaché d'orgueil et de préjugé; il ne disait de mal de personne; au contraire, il rendait justice aux talents de plusieurs de ses rivaux. Il respectait infiniment Philippe-Emmanuel Bach, ne parlait qu'avec respect de Hændel; mais il disait qu'il avait mis trop d'ambition à déployer son talent, à travailler ses parties et ses sujets, et qu'il s'était montré trop amoureux du bruit. Faustina ajoutait que son chant était sonvent rudte. Par-dessus tout, il admirait le vieux Keiser, " un des plus grands musiciens que le monde eût jamais possédés ", et Alessandro Scarlatti, * le plus grand harmoniste de l'Italie, e'est-à-dire du monde entier *. En revanche, il, trouvait Durante * dur et baroque, grossier et saurage n. Quend Burney vit Hasse, tous ses livres, ses mauuscrits et 
Cet illustro représentant de l'opéra italien en Allemagne commençait, il est vrai, à être discuté. Vers 1760 , se formait à Vienne, en face de Métastase et de Hasse, un autre parti très ardent. Mais quels en étaient les chefs? Raniero da Calsabigi, de Livourne, encore un Italien, - le poète d'Orphée et d'Alceste; et Gluck, - non moins italianisé que Hasse, élève de Sammartini à Milan, auteur d'une quarantaine d'ouvrages dramatiques italiens, et qui, toute sa vie, prétendit écrire des opéras italiens ${ }^{1}$. - Tels étaient les deux camps : entre eux, il ne s'agissait pas d'un débat sur la supériorité de l'opéra italien : elle n'était contestée ni par l'un ni par l'autre; il ne s'agissait que d'introduire, ou non, dans l'opéra, des réformes néces-

ses biens avaient èté brûlés en 1760 dans le bombardement de Dresde par le roi de Prusse, au moment oủ le compositeur allait faire graver aux frais du roi de Pologne l'édition de ses œuvres complètes. Mais ce désastre n'avait pas altéré sa sérénité. "Il est si doux et d'un accueil si facile que je me sentis aussi à mon aise avec lui, au bout d'un quart d'heure, que si je l'eusse connu depuis vingt ans. "Burney, qui « devait à ses ouvrages une grande partie des plaisirs que lui avait donnés la musique, depuis l'enfance ", le compare à Raphaël, et rapproche son rival Gluck de Michel-Ange. - Il n'est guère, en effet, de plus beau dessin mélodique que celui de Hasse; et seul, Mozart peut lui être éçalé en cela. L'oubli de cet artiste admirable est une des pires injustices de l'histoire; et nous tâcherons, quelque jour, de la réparer.

1. Le portrait de Gluck par Burney est un des meilleurs que nous ayons de ce grand homme.

Burney lui fut présenté par l'ambassadeur extraordinaire d'Angleterre, lord Stormont, - ce qui n'était pas superllu, car "Gluck était d'un caractère aussi sauvage que Handel, dont on sait que tout le monde avait peur.... Il vivait avec sa femme et une jeune nièce, musicienne remarquable. Il était bien logé et bien meullé.... Il était marqué horriblement de la petite vérole. Il était laid de figure et dans le regard. " Mais Burney eut la chance de le trouver a d'une bonne humeur inaccoutumée.... Gluck chanta. Quoiqu'il eût peu de voix, il faisait grand effet. Il joignait à la richesse d'accompagnement, de l'énergie, de la véhémence dans la manière de faire marcher l'allegro, et une expression judicieuse dans les mouvements lents; enfin, il savait 
saires. «L'école de Hasse et de Métastase - dit Burney - regardait toute innovation comme de la charlatanerie et restait attachée à l'ancienne forme du drame musical, où le poète et le musicien exigeaient une égale attention de la part des spectateurs, - le poète dans le récitatif et la narration, - le compositeur, dans les airs, dans les duos et dans les chœurs.

L'école de Gluck et de Calsabigi s'attachait davantage aux effets scéniques, à la convenance des caractères, à la simplicité de la diction et de l'exécution musicale, plus qu'à ce qu'ils appelaient des descriptions fleuries, des comparaisons superflues, une morale froide et sentencieuse, avec d'ennuyeuses symphonies et de longs développements musicaux. " - Voilà toute la diffé-

si bien dissimuler ce qui manquait à sa voix, qu'on oubliait qu'il n'en avail pas. Il chanta presque tout Alceste, plusieurs morceaux de Páris et Hélène, et quelques airs de l'Iphigénie de Racine, qu'il venait de finir.... Il exécutait tout, de lête, sans avoir une seule note écrite, avec une facilité prodigieuse. Il se levait fort tard. Il avait l'habitude d'écrire toute la nuit et se reposait le matin. "

Burney le retrouva à un diner chez lord Stormont, où il l'avait comme voisin de table. Gluck, rendu expansif par les rasades, confia qu'il venait de recevoir de l'électeur palatin un tonneau d'excellent vin, en remerciement d'un de ses opéras-comiques: le prince avait été ravi d'apprendre que la musique était a d'un honnête Allemand, qui aimait le bon vieux vin". - Il se vantait volontiers de la façon dont il dirigeait un orchestre, " où il était aussi redoutable que Handel. Il disait qu'il n'avait jamais trouvé de rebelles, quoiqu'il obligeàt les musiciens à abandonner pour l'opéra toute autre occupation, et qu'il leur fit répéter souvent une partie de ses œuvres, vingt et trente fois. " - Il parla à Burney de son séjour en Angleterre, "à laquelle il attribuait entièrement l'étude qu'il avait faite de la nature pour ses compositions dramatiques ". Il y était à l'époque de la gloire de Hændel : il n'y avait pas de place pour lui, et le peuple était fort excité contre les étrangers. On eut peine à faire jouer la Caduta de' Giganti de Gluck, qui échoua. Gluck fut frappé de voir "que le naturel et la simplicité agissaient le plus fortement sur les spectateurs, et il s'attacha, depuis, à ne s'en départir jamais. On peut remarquer - ajoute Burney - que la plupart des airs d'Orphée sont aussi simples et aussi naturels que des ballades anglaises. 
rence : au fun 1 . c'était une question d'âge, non de race ou de style. Ilasse et Hélastase étaient vieux : ils so plaignaient qu'il n'y eût plus de bonne musique, depuis le temps où ils avaient été jeunes. Mais ni Gluck ni Calsabigi n'avaient, plus qu'eux, la pensée de détrôner la musique italienne et de la remplacer par une autre. Dans sa préface de Pìris et IIélène, écrite en 1770, après Alceste, Gluck parle uniquement de a détruire les abus qui se sont introduits dans l'opéra italien et qui le déshonorent $)$.

Entre ces deux coteries italianisantes, ne différant l'une de l'autre que par une simple nuance, la société de Vienne se partageait. La famille impériale tout entière était musicienne. Les quatre archiduchesses jouaient et chantaient dans les opéras de Métastase, mis en musique alternativement par Hasse et par Gluck. L’impératrice chantait et avait même joué jadis sur le théâtre de la cour. Salieri venait d'être nommé compositeur de la chambre et directeur du Théâtre Italien; et il resta chef d'orchestre de la cour jusqu'en 1824, faisant obstacle aux maîtres allemands, en particulier à Mozart.

Vienne resta donc, jusqu'au $\mathrm{x}^{\circ} \mathrm{x}^{\ominus}$ siècle, un centre d'art italien en Allemagne. Au temps de Beethoven et de Weber, le Tancrède de Rossini suffit à ruiner l'édifice, péniblement élevé, de la musique allemande; et l'on sait avec quelle injuste violence Wagner a parlé de cette ville infidèle, selon lui, à l'esprit germanique : « Vienne, n'est-ce point tout dire? Toute trace du protestantisme allemand effacée; même l'accent national perdu, italianisé ${ }^{1} \ldots$...

1. Richard Wagner, Beethoven, 1 S70. 


\section{$* *$}

En face de l'Allemagne du Sud et de l'ancienne capitale du Saint-Empire liomain, se dresse déja la nouvelle capitale du futur empire d'Allemagne : Berlin.

"La musique de ce pays - dit Burney - est plus véritablement allemande que celle de toute autre partie de l'empire. "Frédéric Il avait pris à cœur de la germaniser; il ne permettait pas qu'on exéculât dans ses Etals d'autres opéras que ceux de son favori Graun, du Saxon Agricola, et quelques-uns, en petit nombre, de Hasse. Hais admirons la difficulté qu'avait le goût allemand à se faire libre : ces opéras étaient des opéras italiens; et lo roi ne pouvait même pas imaginer qu'il y eût quelque bon sens à chanter dans une autre langue que l'italienne:

«Une chanteuse allemande! - disait-il. - J'aurais autant de plaisir à entendre le hennissement de mon cheval'! »

Et qui étaient ces compositeurs allemands, dont il s'était constitué le protecteur exclusif et intolérant, au point que Burney pouvait écrire : "Les noms de Graun et de Quantz sont sacrés à Berlin, et plus respectés que ceux de Luther et de Calvin. Il y a bien des schismes; mais les hérétiques doivent se taire. Car, dans ce pays de tolérance universelle en matière de religion, quiconque oserait professer d'autres dogmes

1. Frédèric II avait, de plus, une antipathie violente contre la musique religieuse. * Il suffisait - raconte Agricola à Burney - qu'un compositeur eût écrit une antienne ou un oratorio pour que le roi regardât son goût comme usé et tlétri, et pour qu'il dit do ses autres productions : - Oh! cela sent l'église 
musicaux que ceux de Graun et de Quantz serait bien assuré d'être persécuté.... »

Jos.-Joachim Quantz, compositeur et musicien ordinaire de la chambre du roi, et son maître pour la flùte, " avait le goût que l'on avait il y a quarante ans », entendez le goût italien. Il avait voyagé longuement en Italie. Il s'était lié avec Vivaldi, Gasparini, Alessandro Scarlatti, Lotti: et pour lui, l'âge d'or de la musique était le temps de ces ancêtres. Comme dit Burney, " il avait été avancé et libéral..., il y avait quelque vingt ans ".

$1 l$ en était à peu près de même de Graun. CharlesHenri Graun fut, avec Hasse, le plus glorieux nom de la musique en Allemagne, au temps de Bach et de Hændel ${ }^{1}$. Marpurg le nomme " le plus bel ornement de la muse allemande, le maitre de la douce mélodie..., tendre, doux, compalissant, élevé, pompeux et terrible tour à tour. Tous les traits de sa plume furent également parfaits. Son génie fut inépuisable. Jamais homme n'a été plus généralement regretté par toute une nation, depuis le roi jusqu'au dernier de ses sujets. "

Graun - dit plus sobrement Burney - fut, il y a trente ans, d'une élégante simplicité, ayant été le premier parmi

1. Charles-Henri Graun, né en 1701 à Wahrenbrick, en Saxe, mort en 1759, était entré au service de Frédéric II en 1735. Il fut l'organisateur de l'opéra de Berlin, pour lequel il écrivit vingt-sept œuvres. Frédéric II fut, plusieurs fois, son collaborateur; il lui fournit les libretti des Fratelli Nemici, d'après Racine (1756), de Merope, d'après Voltaire (1756), de Coriolano (1749), de Silla (1753), et de Montezuma (1755). Cette dernière cuvre, - opéra anticlérical, - où Frédéric II voulut montrer, comme il l'écrit à Algarotti, que clopéra même peut servir à réformer les mœurs et à détruire les superstitions $\bullet,-$ vient d'être rééditée par M. Albert Mayer-Reinach, dans la cullection des Denkmiler deutscher T'onkunst (Leipzig, Breilkopf, 1904). 
les Allemands qui ait laissé là la fugue et toutes ces inventions travaillées.

Médiocre éloge pour nous, qui nous sommes repris depuis d'un amour singulier pour " toutes ces inventions travaillées! "Mais, pour un italianisant, c'était le meilleur compliment. En fait, Graun s'était appliqué à acclimater à Berlin le style de l'opéra italien, et particulièrement de Lionardo Vinci, ce compositeur de génie, qui porte un nom doublement illustre. C'est dire qu'il arait lo goùt de la génération italienne comprise entre Alessandro Scarlatti et Pergolèse. Lui aussi, comme Quantz, datait de 17:0.

En patronnant Graun et Quantz, Frédéric II n'était donc rien de plus qu'un conservateur italianisant, qui prétendait défendre contre la mode du jour « les productions d'un temps qu'on regardait comme le siècle d'Auguste en musique: celui des Scarlatti, des Vinci, des Leo, des Porpora, aussi bien que des plus grands chanteurs, et depuis qui la musique, pensait-il, avait dégénéré ». Ce n'était pas la peine de prétendre représenter l'art germanique, en face de Vienne dénationalisée. Frédéric II n'eùt pas été si loin de s'entendre, au fond, avec la coterie la plus italianisante de Vienne:

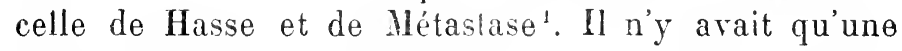
différence entre son goùt et celui de cette coterie : c'était que ses favoris ne valaient pas Hasse et Métastase. « En admettant - dit Burney - que l'époque d'art que préfère le roi soit la meilleure, il n'en a pas choisi les meilleurs représentants. "

1. Il laissait jouer à Berlin des opéras de Ilasse, mais il était ennemi déclaré de Cluck; il critiqua âprement son Alceste, - ainsi que firent Agricola, Kirnbermer, Forkel, et tout son reggiment de théoricieus prussiens qui emloitèrent le pas derriere lui.

R. Rolland. - Voyage musical. 
Je me trompe : il y avait encore une différence. A Vienne, quelle que fût l'exigence de la mode musicale, on avait toujours été libre en musique; le pouvoir, très peu libéral en toute autre matière, laissait aux artistes et aux dilettantes la liberté du goût. A Berlin, il fallait obéir. Nul autre goût permis que celui du roi. On ne saurait imaginer à quel point s'exerçait sur la musique la tyrannie tatillonne de Frédéric II. C'était le même esprit despotique qui régnait dans toute l'organisation de la Prusse ${ }^{1}$. Une surveillance inquisitoriale et menaçante pesait sur la musique, - car le roi était musicien : flùtiste, virtuose, compositeur, - nul ne l'ignore. Il donnait à Sans-Souci, chaque soir, entre cinq et six heures, un concert de flûte. La cour était invitée, par ordre, et écoutait religieusement les trois ou quatre concertos " longs et difficiles 》, qu'il plaisait au roi de lui faire entendre. Il n'était pas près d'en manquer: Quantz en avait composé trois cents, expressément pour cet usage; défense lui était faite d'en rien publier; nul autre ne devait les jouer. Burney observe avec douceur que a ces concertos avaient été composés sans doute en un temps où on tenait mieux sa respiration : car dans quelques-u as des

1. Il faut voir comment un étranger, mème très recommandé, était reçu dans la capitale prussienne. On lira, dans Burney, le récit de son arrivée à Berlin : malgré son passeport et une première visite de douane aux frontières de la Prusse, il est conduit, comme un prisonniır, à la douane de Berlin, et laissé deux heures, grelottant, dans la cour, sous la pluie, tandis qu'on examine jusqu'au moindre de ses effets. - Cela ne ressemble guère à la douane autrichienne, oủ le petit Mozart, âgé de sept ans, désarme les douaniers, en leur jouant un mennet sur son petit violon. - Mais le plus incroyable est la visite de Burney à Potsdam. A l'entrée principale, puis à chaque porte du palais, on lui fait subir un interrogatoire, qui est bien, dit-1l, " la chose la pluscurieuse qui me soit arrivée dans mes voyages. Il ne pourrait s ilre plus rigonreux à la poterne d'une ville assiégée. • 
passages difficiles, ainsi que sur les points d'orgue. Sa Mapesté duit obligre. contre la règle. de ropmondre

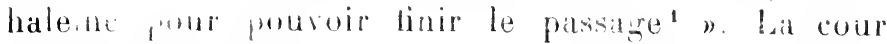
écoutait, résignée; et il lui était interdit de donner le moindre signe d'approbation : (on ne prévoyait pas l'éventualité contraire). Seul. le gigantesque M. Quantz, bien digne par sa taille de figurer dans les régriments du roi de Prusse ${ }^{2}$, "avait le privilège de crier bravo à son écolier royal, apres chaque solo, ou quand le concerto était fini $\gg$.

Mais sans nous attarder à ces faits connus, il faut voir comment le royal flùtiste prétendait gouverner, à coups de férule, la musique entière et, en particulier, l'Opéra de Berlin.

Certes il avait bien fait les choses. Depuis la mort de Frédéric I ${ }^{\text {er }}$ (1713) jusqu'en 1742, Berlin n'avait pas eu d'Opéra ${ }^{3}$. Aussitòt après son arènement, Frédéric II fit construire un des plus grands théâtres d'opéra qui existassent, avec l'inscription : Federicus Rex Apollini et Musis. Il réunit un orchestre d'une cinquantaine de mue: riens, engagea des chanteurs italiens et des danseurs trançais; et il mit son amour-propre à avoir une

1. Burney lui reconnaît d'ailleurs " une grande précision, une embouchure nette et égáie, un dolnté brillant, un goùt pur et simple, beilucoup de proprelé dans l'exécution, une perfection égale dans tous ses morceaux. Ses cadences sont bonnes, mais trop longues et trop étudiées. "

2. " La flgure de ce vieux musicien était d'une grandeur peu commune.

The son of Hercules ne justly seems

By his broadonitde rs, an 1 gantic limbs.

- Il parait être e vrai fils d'Hercule, par ses larges épaules et ses mercbres gizantesques. "

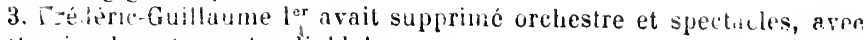
celte simple note : Au diable!. 
troupe, qu'on disait à Berlin la meilleure de l'Europe. Le roi faisait toute la dépense de l'Opéra; et l'entrée en était gratuite, à condition qu'on fût habillé décemment : ce qui permettait, en somme, de n'admettre aucun élément populaire, même au parterre ${ }^{1}$.

Mais si les traitements des artistes étaient royalement payés, j’imagrine qu'ils les gagnaient bien. Iceur situation n'était jas de tout repos.

Le roi - dit Burney - se tenait constamment derrière le maitre de chapelle, ayant les yeux sur la partition qu'il suivait, en sorte qu'on pouvait dire avec vérité qu'il tenait le rôle de directeur génèral... Dans la salle de l'Opéra, comme au camp, il était rigide obscrvateur de la discipline. Attentif à l'orchestre et à la scène, il remarquait la plus petite négligence dans la musique ou dans les évolutions, et en réprimandait celui qui l'avait commise. Et si quelqu'un de la troupe italienne osait s'écarter de la discipline, en ajoutant ou en retranchant à son rôle, ou en altérant le moindre passage, de suite il lui était ordonné, de par le Roi, de s'attacher strictement à l'exécution des notes ecrites par le compositeur, sous peine de punition corporelle.

Ce trait nous donne la mesure de la liberté musicale dont on jouissait à Berlin. Un pseudo-classicisme italien régnait d'une façon tyrannique, et n'admettait ni changements, ni progrès. Burney en est scandalisé :

Aussi - dit-il - la musique est stationnaire dans ce pays, et elle le sera tant que Sa Majesté ne laissera pas plus de liberté aux artistes dans l'art qu'il n'en accorde dans les matières civiles du gouvernement, voulant être en même

1. A Nannheim et à Schwetzingen, tous les sujets de l'Electeur palatin élaient admis à l'Opéra et même aux concerts de l'Électeur : ce qui, d'après Burney, n’avait pas dû peu servir "à former le jugement et à élablir le goût décidé pour la musique qu'on retrouve dans tout lélectorat. 
temps le monarque des vies, forlunes et affaires de ses sujets, et le régulateur de leurs moindres plaisirs.

Ajoutez que Berlin était surtout une ville de professeurs et de théoriciens musicaux, qui ne se permettaient point sans doute de discuter les goûts du roi, - car ils étaient tous plus ou moins officiels, comme le principal d'entre eux, Narpurg, directeur de la loterie royale et conseiller au ninistère de la guerre. - Mais ils prenaient leur revanche de cette contrainte, en se disputant âprement; et ces discutailleries ne rendaient pas la vie musicale plus aimable et plus libre.

Les disputes musicales, - écrit Burney, - ont lieu à Berlin avec plus de chaleur et d'animosité que partout ailleurs. En effet, comme il y a plus de théoriciens dans cette ville que de praticiens, il y a aussi plus de critiques, ce qui n'est pas fait - ajoute-t-il non sans impertinence - pour épurer le goût, ni pour nourrir l'imagination des artistes.

Les esprits un peu libres n'y pouraient tenir; et si Philippe-Emmanuel Bach y resta, de 1740 à 1767, ce fut bien contre son gré. Le pauvre diable ne pouvait quitter Berlin (on ne le lui permettait pas); il y souffrit dans son goût et dans son amour-propre. Il avait une situation et des appointements inférieurs; il devait, journellement, accompagner le roi-flûtiste sur son clavecin; et on lui préférait Graun et Quantz, « dont le style était absolument opposé à celui qu'il voulait établir ». C'est ce qui explique la joie qu'il eut à se trouver plus tard dans la bonne ville de Hambourg, dénuée d’intérêt musical et de goùt, mais hospitalière, accueillante et libre. Tout vaut mieux pour un artiste - mime l'ignorance - que le despotisme du goût. 
Tel semhlait donc, au premier regard, l'état musical des grandes ville's allemandes. L'opéra italien y était maître absolu; et Burney pouvait terminer ses notes sur l'Allemagne parces mot3 :

En résumé, le stylle mélodique des Allemands a autant de rapports avec le style mílodique des Italiens que le goût de la plupart des compositeurs el des artistes de ces deux pays offre d'analogies. La cause en est dans les relations existant entre l'Empire et ses grandes possessions d'au delà des Alpes, et dans les théàtres d'opéra italien quil y a presque toujours eu à Vienne, Munich, Dresde, Berlin, Mannheim, Brunswick, Stuttgart, Cassel, etc.

Mais quoi! l'Allemagne ne venait-elle pas de produire le génie le plus allemand, l'œuvre immense et profonde de Jean-Sébastien Bach? D'où vient que son nom tient si peu de place dans les notes de Burney et dans ce tableau de l'Allemagne?

Bel exemple de la diversité des jugements émis sur un génie par ses contemporains et par la postérité ! A deux siècles de distance, il nous semble impossible que Jean-Sébastien Bach n'ait pas dominé tout l'art de son siècle. A la rigueur, nous pouvons admettre qu'un grand homme reste totalement inconnu, si les circonstances de sa vie font qu'il reste isolé, sans pouvoir éditer ses ceuvres et se faire entendre du public. Mais nous avons peine à croire qu'il puisse êlre connu, et non reconnu, qu'on ait de lui une opinion moyenne et seulement bienveillante, qu'on ne sache pas faire la distinction entre lui et les artistes de second ordre qui l'entourent. C'est pourtant ce qui se passe sans cesso. 
Shakespeare ne fut jamais complètement ignoré ou méconnu. M. Jusserand a montré ${ }^{1}$ que Louis XIV l'avait dans sa bibliothèque, et qu'on le lisait en France au xvIl $^{\mathrm{e}}$ siécle. Le public de son temps l'appréciait, mais pas plus que beaucoup d'autres dramaturges, et moins que certains autres. Addison, qui le connaissait, oubliait, en 1694, de le nommer dans son T'ableau des meilleurs poètes anglais.

Il en était à peu près de même de Jean-Sébastien Bach. Il avait une solide réputation parmi les musiciens de son temps; mais cette célébrité ne sortait pas d'un cercle restreint. Sa vie à Leipzig était pénible, gênée, médiocre, en butte aux tracasseries de la Thomasschule, dont le conseil ne regretta pas sa mort, ne la mentionna même pas dans le discours annuel d'ourerture, pas plus que ne le firentles journaux de Leipzig, et refusa la petite pension accoutumée à la veuve de Bach, qui mourut indigente en 1760. Heureusement, Jean-Sébastien avait formé beaucoup de savants élèves, sans parler de ses fils, qui conservèrent le souvenir pieux de son enseignement. Mais comment était-il connu, vingt ans après sa mort? Comme un grand organiste et un savant professeur. Burney pense à lui, quand il passe à Leipzig : mais c'est pour citer le jugement de Quantz, disant de Bach « que cet habile artiste avait porté le talent de jouer de l'orgue au plus haut degré de perfection $\triangleright$. Il ajoute :

Uutre d'excellents ouvrages et en grand nombre qu'il a écrits pour l'église, cet auteur a donné un livre de préludes et de fugues pour lorgue, sur deux, trois ou quatre motifs différents, in modo recto el contrario, et dans chacun des

\section{Shaliesstèure et l'Ancièn Régime.}


vingt-quatre modes. Tous les organistes existants aujourd'hui en Allemagne sont formés à son école, comme la plupart des clarecinistes et des pianistes le sont à celle de son fils, l'admirable Charles-'hilippe-Emmanuel Bach, si connu depuis longtemps.

On remarquera la place de l'épithète : « admirablo ». “ L'admirable » Bach, en 1770, c'est Philippe-Emmanuel Bach. Il est le grand homme de la famille. Et Burney s'extasie sur la façon dont « ce sublime musicien ») a pu se former ${ }^{1}$.

1. En dépit de l'impertinence qu'il y a à l'opposer et à le préférer à son père, Philippe-Enimanuel Bach n'en est pas moins un musicien de génie, à qui n'a manqué qu'un caractère, ou du moins une volonté à la hauteur de l'iuspiration musicale. Nais une sorte de torpeur découragée paralysait des forces admirables; et c'est un spectacle attristant de voir en lui, par instants, comme l'àme d'un Beethoven qui se débat dans les liens dune vie médiocre, lance des éclairs de géuie, et retombe dans l'apathie.

Le portrait qu'en a tracé Burney est le meilleur qu'on ait fait. Je ne puis m'empècher d'en citer un fragment.

Philippe-Emmanuel avait invité Burney à diner chez lui. On fit monter Burney "dans un salon de musique, grand, élégamment orné de tahleaux, de dessins, de portraits gravés de plus de cent cinquante musiciens célèbres, dont plusieurs Anglais, et des portraits à l'huile de son père et de son grand'père. Philippe-Emmanuel s'assit à son clavecin de Silbermann. Il joua trois ou quatre morceaux très difficiles, avec toute la délicatesse, la précision et le feu qui le distinguaient si justement chez ses compatriotes. Dans les mouremenis pathétiques et tendres, il semblait tirer de son instrument des cris de douleur et de plainte, comme lui seul pouvait faire. Le diner fut élégant, bon, joyeux. Il y avait là trois ou quatre amis bien élevés, et la famille de PhilippeEmmanuel : Mme Bach, son fils ainé, étudiant en droit (le cadet faisait de la peinture) et sa fille. Après diner, Philippe-Emmanuel joua encore, presque sans interruption, jusqu'à onze heures du soir. Il s'anima, au point de paraitre inspiré. Il avait les yeux fixes, la lèvre inférieure pendante, et tout son corps était trempé de sueur. Il dit que s'il avait souvent l'occasion de forcer ainsi son travail, il redeviendrait jeune. 11 a cinquante-neuf ans. Il est plutot de petite stature, il a les cheveux et les yeux noirs, le teint brun; il est plein de feu, et a beaucoup de dispotions à la gaieté et à la vivacité. "

Burney était convaincu que Philippe-Emmanuel n'était pas seulement un des plus grands compositeurs pour clavecin, mais * le meilleur et lo 
Comment forma-t-il son style? Il est difficile de le dire. Il ne l'avait ni hérité ni pris de son père, qui avait été son seul maitre : car ce respectable musicien, que personne n'a égalé pour la science et pour l'invention, pensait qu il était nécessaire de ramasser sous ses deux mains toute l'harmonie qu'on pouvait saisir; et, sans doute, dans son système, il sacrifiait la mélodie et l'expression.

Rien de plus caractéristique que la promptitude avec laquelle les fils de Jean-Sébastien — qui d'ailleurs le vénéraient - renièrent son goût et ses principes. Philippe-Enmanuel parle avec ironie de la science musicale, en particulier des canons, "qui sont toujours secs et prétentieux ». Il regarde "comme un manque de génie de s'abandonner à ces études tristes et insignifiantes ${ }^{1}$ ». Il demande à Burney s'il a trouvé quelque grand contrepointiste en Italie. Burney répond que non.

Ma foi, - dit Philippe-Emmanuel, - quand vous en auriez trouvé, ce ne serait pas là une fameuse trouvaille : car, lorsqu'on sait le contrepoint, il y a d'autres choses nécessaires encore pour faire un bon compositeur.

Burney abonde dans son sens, et tous deux conviennent que « la musique ne doit pas être une grande

plus habile artiste pour l'expression.... Il avait tous les styles, mais il se renfermait surtout dans celui du sentiment. Il était savant, et l'était plus que son père, toutes les fois qu'il le voulait, et surtout dans la variété de ses modulations. "Burney le rapprochait de Domenico Scarlätli : "Tous deux, fils de célébres compositeurs, osèrent essayer des voies nouvelles. Ce n'est qu'à présent que l'oreille s'habitue à Domenico Scirlatti. Philippe-Emmanuel parait avoir également devancé son siècle.... Son style est si peu ordinaire qu'il faut un peu d'habitude pour le goùter. "Et Burney reconnaissait, assez justement, dans son inspiration, "les effusions d'un génie cultivé ".

1. Ce jugement acquiert un sens particulier quand on voit, un peu plus loin, que "Jean-Sebastien lui avait fait passer impitoyablement les premières années de sa vie "sur des travaux de ce genre. 
réunion où tout le monde parie à la fois, en sorte qu'il n'y a plus de conversation, rien que des criailleries, des inconvenances, et du bruit. Un homme sage doit attendre dans la conversation le moment pour placer son mot à propos. " - C'est l'école de la mélodie claire, à l'italienne, qui condamne la vieille polyphonie allemande. L’italianisme a pénétré la famille Bach.

Jean-Sébastien lui-mème n'était peut-être pas resté indifférent au charme de l'opéra italien. D'après son historien Forkel, il goùtait Caldara, llasse, Graun. Il était ami de Hasse et de la Faustina; il allait souvent, de Leipzig, à Dresde, avec son fils aîné, pour entendro l'opéra italien. Il s'excusait du plaisir qu'il prenait à ees petites escapades en se raillant lui-même : « Friedmann, - disait-il, - n'irons nous pas entendre encore les jolies chansonnettes de Dresde? „ - Est-il si difficile de reconnaitre dans telles de ses pages un ressouvenir des « jolies chansonnettes »? Et qui sait si, dans d'autres conditions de sa vie, ayant un théâtre à sa disposition, "il n'eût pas cédé au courant, comme les autres?

Ses fils n'y résistèrent pas. L'italianisme les conquit si bien qu'un d'eux devint, - pour un temps, - Italien tout à fait, sous le nom de Giovanni Bacchi. Je veux parler de Jean-Chrétien Bach, le cadet de la famille. Il avait quinze ans à la mort du père, et en avait reçu une solide instruction musicale; il montrait des dispositions pour l'orgue et le clavier. Après la mort de Jean-Sébastien, il alla auprès de son frère Philippe-Emmanuel, à Berlin. Il y trouva l'opéra italianisé des Graun et des Hasse. L'impression qu'il en reçut fut si forte qu'il partit pour l'Italie. Il vint à Bologne, et, là, ce fils de Bach se mit sous la discipline du Père 
Martini ${ }^{1}$. Pendant huit ans, il ne cessa point de se refaire avec Martini une éducation et une âme italiennes. Entre temps, il allait à Naples et y devenait un champion de l'école d'opéra napolitaine; il faisait jouer une suite d'opéras italiens sur des poèmes de llétastase: Catone in Utica (1761), Alessandro nelle Indie (1762), qui eurent grand succès. Burney disait que « ses airs étaient dans le meilleur goùt napolitain ». - Ce n'est pas tout : après avoir abjuré le goût musical de son père, il abjurait sa foi; le fils du grand Bach se faisait catholique. Il devenait organiste du Duomo de Milan, sous un nom italien ${ }^{2}$. Il est difficile de citer un exemple plus catégorique de la conquète de l'esprit germanique par l'Italie.

Et il ne s'agit pas d'hommes médiocres, qui n'ont d'autres titres à notre attention que d'être les fils d'un grand homme. Les fils de Jean-Sébastien sont euxmêmes de grands artistes, qui n'ont pas été placés par l'histoire à leur véritable rang. Comme la plupart des musiciens de cette période de transition, ils ont été trop sacrifiés à ceux qui les ont précédés et suivis. Philippe-Emmanuel, très en avance sur son temps et fort mal compris, sauf d'un petit nombre, a pu êtro justement désigné par M. Vincent d'Indy, comme un des précurseurs directs de Beethoven. Jean Chrétien est à peine moins important : ce n'est pas Beethoven, c'est Mozart qui procède de lui $\boldsymbol{\varepsilon}^{\text {. }}$

1. Trente et une lettres de Jean-Chrétien Bach au père Martini nous renselgnent sur cette éducalion.

2 Voir Max Schwarlz, Johann-Christian Bach, 1901.

3. Wax Schwarz montre l'influence direcle de Jean-Chrétien sur la mu-ique de clavier. dopéra, et surtout sur les premières symphones de Nozart. Mozart parle souvent de Jean-Chrétien daus ses leltres. Il dit qu' "il l'aime de tout son coeur ", qu' " il a une proforide estime 
Un autre musicien remarquable, qui, plus encore que Philippe-Emmanuel, fut le précurseur - on pourrait presque dire : le modèle - de Beethoven, dans ses grandes sonates et ses grandes variations, FriedrichWilhelm Rust, ami de Gœthe, directeur de la musique du prince Léopold III de Anhalt, à Dessau, fut pris comme les autres par le charme italien ${ }^{1}$. Il fit le voyage d'Italie, y resta deux ans, pratiqua assidûment les théâtres d'opéra, se lia avec les principaux maîtres, avec Martini, Nardini, Pugnani, Farinelli, surtout avec Tartini, dont il apprit beaucoup; - et ce séjour eut une action décisive sur sa formation artistique. Trente ans plus tard, en 1792, il retraçait encore ses souvenirs de voyage dans une de ses sonates, la Sonata italiana.

Si les chefs de la musique allemande - les Bach, les Rust, les Gluck, les Graun, les Hasse - subissent à un tel point l'influence de l'art italien', comment la musique allemande résistera-t-elle à l'esprit étranger? Où sera le salut pour son génie?

pour lui ". Certains airs de Jean-Chrétien le hantaient. Il travaillait à rivaliser avec lui, à écrire de nouvelles mélodies sur les mêmes paroles.

1. Voir Wilhelm Hosäus : Friedr. Wilh. Rust. (1882). - Rust avait été élève du fils ainé de Jean-Sébastien : Wilhelm-Friedmann, qui avait le mieux conservé la tradition du père. Il prit aussi des leçons de Philippe-Emmanuel. Son importance artistique n'a èté que depuis peu révélée, grâce à la publication par un de ses descendants de quelques-unes de ses curres.

2. Je ne parle pas des jeunes maîtres de l'époque suivante, - de Ilaydn, élève de Porpora, et imitateur génial de Sammartini, - de Mozart, qui, dans la première partie de sa vie, fut un pur Italien, dont les premiers opéras furent joués et acclamés en Italie. Hasse, ennemi de Gluck, parce qu'il ne le trourait pas assez fidèle à la vraie tradition italienne, aimait, au contraire, et admirait Mozart, eu qui il voyait son continuateur, plus heureux, ou plus grand. 


\section{$* *$}

D’abord, il était inévitable que la masse des petits artistes, la plèbe musicale de l'Allemagne, ceux qui n'avaient pas les moyens d'aller en Italie et de s'italianiser, souffrissent de leur situation humiliée et de la préférence donnée aux Italiens. Burney, forcé de convenir qu'on récompense les Italiens en Allemagne beaucoup mieux, souvent, que des artistes du pays qui leur sont supérieurs, ajoute que, pour cette raison, a on ne doit pas trop en vouloir aux Allemands de s'attacher à rabaisser le mérite de grands maîtres italiens, et de les traiter avec une sévérité et un mépris qui ne sont dus qu'à l'ignorance grossière et à la stupidité ». - « Tous sont jaloux des Italiens », dit-il ailleurs. Sans doute cette observation vier.t à la fin d'une phrase où Burney remarque que les Allemands se dévorent aussi entre eux. Chaque ville est divisée en fractions jalouses. “ Chacun est jaloux de l'autre, et tous sont jaloux des Italiens. " Ce manque d'union devait être aussi funeste aux Allemands en art qu'en politique; il les rendit d'autant plus incapables de se défendre contre l'invasion étrangère que leurs chefs, les Gluck et les Mozart, semblaient avoir passé à l'ennemi.

Mais le goût populaire restait à peu près étranger à l'italianisme. Les catalogues des foires de Francfort et de Leipzig, au XviII ${ }^{e}$ siècle, en fournissent la preuve ${ }^{1}$. Dans ces grands marchés de l'Europe, où la musique tenait une place importante, l'opéra italien ne figure

1. Ces catalogues des foires de Francfort et de Leipzig, de 1561 à 1759, ont été publiés par le docteur Albert Göhler : V'erzeichniss der in den Frankfurter und Lcipziger Messliatalogen der Jahre 156\% bis 1759 
pour ainsi dire pas ${ }^{1}$. Ce qui abonde, c'est la musique religieuse allemande : cantiques luthériens, concerts sacrés, Passions, - et surtout les recueils de Lieder et de Liedlein, éternel et inviolable refuge de la pensée allemande.

D'autre part, il est remarquable que ce ne soient plus - à quelques exceptions près - des Italiens, mais des Allemands, qui représentent l'opéra et l'art italien en Europe, vers le milieu du xvin e siècle. C'est Gluck, à Vienne; c'est Jean-Chrétien Bach, à Londres; c'est Graun, à Berlin; c'est liasse, en Italie même. Comment un esprit nouveau ne se fùt-il pas glissé dans cet italianisme germanisé? Chez ces maîtres allemands, conscients de leur supériorité, se développait peu à peu le désir, avoué ou non, de vaincre l'Italie avec ses propres armes. On est frappé de l'orgueil germanique que l'on sent grandir chez Gluck et chez Mozart. Et ces géniaux Italianisants sont des premiers à s'essayer dans le Lied allemand ${ }^{2}$.

Au théâtre même, voici que la langue allemande reprend sa place ${ }^{3}$. Burney, qui, après avoir remarqué les qualités musicales de cette langue, s'était d'abord étonné que l'on n'en fît pas plus d'emploi au

angezeigten Musikalien, angefertigt und mit Vorschlagen zur Förderung der musikalischen Bücherbeschreibung begleitet, von $D^{r}$ Albert Göhler (Leipzig, Kahnt, 1902, in- $8^{\circ}$ ). - Voir, à ce sujet, un intéressant article de Michel Brenet, dans la Tribune de Saint-Gervais (mai-juin 1904).

$\because$ Pas plus d'ailleurs que la musique rançaise, ni que l'œurre de Jean-Sébastien Bach.

2. Gluck, dès 1770 , sur des odes de Klopstock.

3. L'Opéra de Hambourg, à la fin du $\mathbf{x v i}^{\circ}$ siècle, avait joué des opéras en langue allemande. Nais, dès les premières années du xvir ${ }^{\bullet}$, Keiser et Hændel avaient donné l'exemple de mêler, dans les mèmes opéras, les paroles italiennes avec les paroles allemandes; et bientót l'italien avait tout envahi. 
théâtre, dut bientùt constater que les pièces musicales en langue allemande commençaient à se répandre en Saxe et dans le nord de l'Empire. Depuis le milieu du sic̀cle, le poète Christian Félix Weisse et les musiciens Standfuss et Johann-Adam Hiller composaient à Leipzig, à l'imitation des opérettes anglaises et des opéras-comiques de Favart, des opérettes allemandes (Singspiele), dont le premier exemple fut, en 1752, le Diable est lâché, on les Commères métamorphosées (Der Teufel ist los, oder die verwandelten Weiber'1), bientôt suivi d'une quantité d'œuvrettes analogues. " La musique - dit Burney - en était si naturelle et si agréable que les airs favoris, comme ceux du docteur Arne, en Angleterre, étaient chantés par toutes les classes du peuple, et certains dans les rues. " Hiller prêtait aux gens du peuple, dans ses pièces, de simples Lieder; et ces Lieder devinrent aussi populaires en Allemagne que les « vaudevilles " en France. "Aujourd'hui - écrit Burney - le goût pour les burlette (les farces) est si général et si prononcé qu'on peut craindre, avec les personnes sages, qu'il ne détruise celui pour la bonne musique, et surtout pour celle d'un genre plus relevé. » Bien loin de le détruire, ces Lieder populaires furent une des sources du nouvel opéra allemand.

1. Musique de Standíuss et Hiller. La mème pièce avait été donnée, sans succès, à Berlin, en 1743 , d'après une pièce anglaise de Coffey, avec les mélodies anglaises originiles. - Der Teufel ist los eut une seconde partie, qui, jouée en 1759, sous le titre de : Der luslige Schuster (Le joyeux Savetier), fut très populaire. Ces Singspiele firent fureur en Allemagne, pendant une vinglaine d'années : on peut dire qu'il-furent l'opéra de la petite bourgeoisie allemande. - Il est a noter que le principal élève de Hiller fut Christian-Guttlob Neefe, maltre de Beethoven. 
Mais le fait capital, qui devait être le salut de la musique allemande, ce fut, à ce moment, le développement soudain de la musique instrumentale. A l'instant où l'Allemagne semblait renier, avec la polyphonie vocale et les ressources infinies du style contrepointique, le vieux style allemand, sa personnalité même, - à l'instant où elle semblait renencer à exprimer son âme complexe t raisonneuse, pour épouser le style de la pensée latine, elle eut l'heureuse fortune de trouver dans la floraison subite de la musique instrumentale l'équivalent, et au delà, de ce qu'elle avait perdu.

Il peut paraître étrange de parler d'heureuse fortune, à propos d'un événement auquel l'intelligence et la volonté eurent évidemment une grande part. Pourtant on doit tenir compte ici, comme toujours en histoire, du hasard, du concours des circonstances, qui tantôt favorise, tantôt contrarie l'évolution d'un peuple. Sans doute, les peuples les plus vigoureux finissent toujours par violenter la chance et la mettre avec eux. Mais cette chance existe, et l'on ne saurait la nier.

On le voit bien ici. Les Allemands n'étaient pas seuls à perfectionner les ressources de l'instrumentation. Les mêmes tendances se manifestaient en France et en Italie. Les conservatoires de Venise cultivaient avec succès la musique instrumentale; les virtuoses italiens étaient partout célèbres; et la symphonio naissait à Milan. Mais la musique symphonique s'accordait mal avec le génie ilalien, essentiellement mélo- 
dique, clair, net et linéaire. Ou, du moins, pour changer ce génie et l'accommoder aux conditions nouvelles, il eùt fallu faire un effort dont l'art italien, surmené, épuisé, ndolent, n'était plus capable. C'était une révolution à accomplir en Italie. En Allemagne, c'était une évolution. Aussi les progrès de l'orchestre assurèrent la victoire de l'Allemagne, tandis qu'ils contribuaient à la décadence de l'art italien. Burney se plaint de ce que les orchestres des Opéras d'Italie soient devenus trop nombreux, et que leur bruit force les chanteurs à de véritables « braillements ». « De la musique tout le clair obscur est perdu; les demiteintes et le fond disparaissent : on n'entend que les parties bruyantes, qui étaient destinées à faire repoussoir au reste. "Ainsi, les voix italiennes se gâtent, et l'Italie perd le privilège du bel canto dont elle était si fière, et à juste titre. Sacrifice inutile : car, en renonçant à ses qualités propres et inimitables, elle ne peut acquérir des qualités et un style qui lui sont étrangers ${ }^{~}$.

Au contraire, les Allemands sont à l'aise dans la symphonie naissante. Le goùt naturel de la musique instrumentale, la nécessité, pour nombre de petites cours allemandes, de s'en tenir à cette musique, par suite d'une application rigoureuse des principes de l'Eglise réformée, qui leur interdisaient d'avoir un théàtre d'opéra, l'instinct sociable qui poussait les musiciens allemands à se réunir en petites sociétés, en petits "Collèges ", pour jouer ensemble, au lieu de pratiquer l'individualisme des virtuoses italiens, -

1. Hasse et Métastase, derniers représentants de la pure tradition italienne, avaient senti le danger. Nétastase, dans ses conversations avec Burney, se plaint fort des progrès de la musique instrumentale dans l'opéra.

R. ROLLAid. - Vojage inusical. 
tout, jasca'à la moliocrité rrlative du chant allemant, davit contribuer au développement uaversel en Allemagno de la musique instrumentale. Nulle part en Europe, il n'y avait plus d'écoles où on l'enseignait, et plus de bons orchestres.

Une institution musicale des plus curieuses, en Allemagne, était celle des ( Paurres Écoliers », qui correspondait (avec moins de générosité) aux Conservatoires d'enfants paurres, à Naples. Ces écoliers, dont Burney rencontra des bandes dans les rues de Trancfort, de Munich, de Dresde et de Berlin, avaient dans chaque ville de l'Empire « une école confiée aux jésuites, où on leur enseignait à jouer des instruments ef à chanter ». L'école de Munich comprenait quatre-vingts enfants, de onze ou douze ans. Avant d'y être admis, ils devaient déjà savoir jouer d'un instrument, ou avoir des dispositions marquées pour la musique. On les gardait jusqu'à vingt ans. Ils étaient logés, nourris, instruits, mais non pas habillés. Il fallait qu'ils gagnassent en partie leur vie, en chantant ou jouant dans les rues. C'était pour eux une obligation absolue, " afin qu'ils fissent connaître leurs progrès au public qui les entretenait ». - A Dresde, la ville était divisée par quartiers; et les Pauvres Écoliers, partagés en troupes de seize, dix-sept ou dixhuit, devaient chanter, tour à tour, devant les portes des maisons de chaque quartier. Ils formaient de petits chœurs et de petits orchestres - violons, violoncelles, hautbois, cors et bassons. - Les familles riches s'abonnaient, pour qu'ils vinssent jouer devant leurs portes, une fois ou deux par semaine. On les utilisait même pour des fêtes particulières ou pour les enterrements. Enfin, ils devaient participer aux céré- 
monies religieuses du dimanche. Le métier était rude, - surtout l'obligation de chanter dans les rues, l'hiver, par un temps rigoureux. - De ces Paures Écoliers on faisait plus tard des maîtres d'école dans les paroisses, à condition qu'ils sussent assez bien le latin, le grec et l'orgue. Les plus distingués étaient envoyés à des universités, comme celles de Leipzig et de Wittenberg, où l'on entretenait plus de trois cents étudiants paurres. Ils pouraient s'y adonner à la musique ou aux sciences,

Quelques cours princières avaient d'autres établissements musicaux pour les enfants paurres. Le duc de Wurtemberg arait installé à Ludwigsbourg et à « Solitude », dans un de ses palais d'été, deux conservatoires pour l'éducation de deux cents garçons et de cent jeunes filles pauvres. "Un de ses amusements favoris était d'assister à leurs leçons. "

En dehors de ces écoles d'enfants pauvres, les écoles communales faisaient une place considérable à la musique, et principalement à la musique instrumentale. Telle était la règle en Autriche, en Saxe, en Moravie, et surtout en Bohême. Burney constate que chaque village de Bohême avait une école publique, où l'on enseignait la musique aux enfants, en même temps que la lecture et l'écriture. Il en visita quelques-unes. A Czaslau, près de Collin, il trouva « une classe pleine de petits enfants des deux sexes, occupés à lire, écrire, jouer du violon, du hautbois, du basson et d'autres instruments. L'organiste de l'église, qui improvisait d'une façon magnifique sur un méchant petit orgue, tenait dans une petite chambre quatre clavecins, sur lesquels de petits élèves s'exerçaient. D A Budin, à Lobeschutz, plus de cent enfants des deux 
sexes apprenaient la musique, et étaient chanteurs ou instirumentistes à l'église.

Malheureusement, les talents qui sortaient de là étaient étouffés par la misère. "La plupart de ces enfants étaient destinés aux bas emplois de la servitude ou de la domesticité; et la musique restait pour eux une simple récréation privée, ce qui est peut-être, après tout, - dit philosophiquement Burney, -- le meilleur emploi et le plus honorable auquel on puisse appliquer la musique. "Les autres passaient au service des grands seigneurs, qui, avec ces domestiques, formaient des orchestres et donnaient des concerts. La noblesse de Bohême avait le tort de trop se détacher de son peuple si intéressant, et elle vivait la plus grande partie de l’année à Vienne. “Si les Bohémiens - dit Burney - avaient les avantages dont jouissent les Italiens, ils les surpasseraient. Ils sont la race la plus musicale, peut-être, de toute l'Europe. „ Ils excellaient surtout sur les instruments à vent : - les bois, du côté de la Saxe; les cuirres, du côté de la Moravie. - C'est de ces écoles de Bohême que sortit le réformateur de la musique instrumentale, le créateur de la symphonie allemande, Stamitz, né à Teuchenbrod, fils du chantre de l'église. C'est dans ces mêmes écoles que Gluck reçut sa première éducation musicale. C'est à Lukavec, près de Pilsen, que Haydn, directeur de la musique de la chapelle privée du comte Morzin, écrivit sa première symphonie, en 1759. Enfin, le plus grand violoniste allemand, Franz Benda, le seul qui osât, à Berlin, avec Philippe-Emmanuel Bach, avoir un style à lui, indépendant de Graun et des italianisants, était aussi de Bolıême.

Grâce à ces écoles et à ces dispositions naturelles, la 
musique instrumpitale était partout cultivée en Allemagne, même à Vienne et à Munich, métropoles par excellence de l'opéra italien. Ne parlons pas des virtuoses princiers : du roi flùtiste de Berlin, du violoncelliste qui était empereur d'Autriche, des princes violonistes, électeur de Barière, ou archevêque-prince de Salzbourg, des princes pianistes, duc de Wurtemberg, ou électeur de Saxe, celui-ci, d'ailleurs, « si timide en société - dit Burney - que l'électrice, sa femme, ellemême ne l'avait presque jamais entendu!... ) N'insistons pas non plus sur l'effroyable consommation de concertos que faisaient les dilettantes allemands : une moyenne de trois ou quatre concertos par concert, à Berlin; - à Dresde, jusqu'à cinq ou six, dans une même soirée!... Mais la symphonie naissante poussait de toutes parts. Vienne avait une floraison de symphonistes : on vantait, parmi eux, le naturel de Hoffman ${ }^{1}$, la fantaisie de Vanhall, Ditters, Huber, Gasman et le jeune Haydn, qui venait de débuter. Cette musique trouvait à Vienne un public enthousiaste. - Teodor de Wyzewa a décrit les musiques de cour et de table de l'archevêque de Salzbourg : trois maîtres de concert étaient chargés alternativement d'en préparer les programmes et d'en diriger les exécutions. L'œuvre de Léopold Mozart montre quelle quantité de musique instrumentale réclamait la vie quotidienne de ces petites cours allemandes. - Joignez-y les concerts particuliers et les sérénades données dans les rues, sur la commande des riches bourgeois.

1. Autant d'art que vous voudrez, disait Hoffman à ses compatriotes, pourvu qu'il soit toujours uni à la nature; et, même dans le mariage entre l'art et la nature, il faut toujours que la dame porte les culottes. "(Burney.) 
Le foyer de la musique instrumentale en Allemagne était alors Mannheim - ou, pendant les mois d'été, Schwetzingen, à trois lieues de Mannheim. Schwetzingen, qui n'était qu'un village, paraissait n'être habité, dit Burney, que par une colonie de musiciens. "Ici, c'était un joueur de violon qui s'exerçait; dans la maison voisine, un joueur de flûte; là, un hautbois, un basson, une clarinette, un violoncelle, ou un concert de plusieurs instruments réunis. La musique semblait l'objet principal de la vie. " L'orchestre de Mannheim «contenait à lui seul plus de virtuoses et plus de compositeurs distingués qu'aucun autre peut-être en Europe : c'était une armée de généraux ».

Cette troupe d'élite, qui fit aussi l'admiration de Léopold Mozart et de son fils, donnait des concerts célèbres. Ce fut là que Stamitz, premier Concertmeister et directeur de la musique de chambre du prince, depuis $\mathbf{1 7 4 5}$, fit les premiers essais de symphonie allemande.

C'est ici, - dit Burney, - que, pour la première fois, Stamitz osa franchir les bornes des ouvertures ordinaires d'opéra, qui n'avaient servi jusqu'alors au théâtre que comme une espèce de héraut de cour pour réveiller l'attention et imposer le silence... Cet homme de feu et de géníe a créé le style de la symphonie moderne, grâce aux grands effets de clair et d'ombre, dont il l'enrichit. Alors on essaya tous les divers effets que pouvait produire une réunion de timbres et de sons; alors se forma dans l'orchestre la science pratique du crescendo et du diminuendo; et le piano, qu'on n'avait employé jusque-là que comme synonyme d'écho, devint, ainsi que le furte, une riche source de couleurs qui eurent leur gamme de nuances en musique, comme le rouge et le bleu en peinture.

Ce n'est pas ici le lieu d'insister sur ce fait; il suffit de signaler en passant l'originalité et la hardiesso 
féconde des essais de ce charmant Stamitz, si peu et si mal connu aujourd'hui, bien qu'il ait èté regardé de son temps « comme un autre Shakespeare qui traversa dit Burney - toutes les difficultés et poussa l'art plus loin qu'on n'avait jamais fait avant lui : un génie tout invention, tout feu, toul contraste dans les mouvements vifs, arec une mélodie tenłre, gracieuse, séduisante, des accompagnements simples et riches et partout des effets sublimes produits par l'enthousiasme, mais un style pas toujours assez châtié ${ }^{1}$ ').

\section{$\stackrel{*}{* *}$}

On voit que, malgré l'italianisme. le génie allemand avait su se réserver des provinces indépendantes, où il pouvait grandir à l'abri, jusqu'au jour où, conscient de sa force, il livrerait bataille au génie étranger et s'affranchirait du joug. Il n'en est pas moins vrai que, vers le milieu du xvir ${ }^{\mathrm{e}}$ siècle. l'opéra italien était maitre de l'Allemagne et que les chefs de l'art allemanı, ceux mêmes qui devaient plus tard se faire ses premiers émancipateurs, étaient tous, sans exception, profondément italianisés. Et si splendide quait été l'évolution de la musique allemande chez Haydn, Mozart, Beethoven et leurs successeurs, il est permis de croire qu'elle ne fut pas le développement normal

1. Mentionnons enfin une forme de la musique insirumentale. où les Allemauds étaient passés matres, et dont ils imposèrent le modele à l'Europe : la musifue mi itaire. En France, dans la secunde moitié du siècle. la " musique des marche- ei les musciens mèmes de beaucoup de garnisons etaient lllemands " au lémbiguagra de Burney Une des ineilleures mu-igues militaires étant celle de parmistad. com-

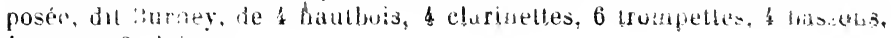
4. cors elt 6 ditiruas. 
de cette musique, tel qu'il aurait été si l'art allemand s'était formé avec ses seules ressources, et en tirant tout de son propre fonds.

Du triomphe écrasant de l'opéra italien sur l'Allemagne du xvine siècle est restée, pour des siècles, la marque ineffaçable de la pensée et du style italiens jusque sur les maîtres les plus allemands de notre temps. On n'aurait point de peine à montrer de combien d'italianismes est pleine l'œuvre de Wagner, et combien la langue mélodique et expressive de Richard Strauss est foncièrement italienne. Une victoire comme celle de l'Italie alı xvin ${ }^{\mathrm{e}}$ siècle laisse une trace éternelle dans l'histoire des peuples qui l'ont subie. 


\section{TABLE DES MATIÈRES}

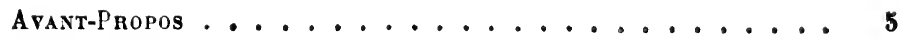

I. - Le Roman Cominue d'un musicion, au xvin' siècle. . . 7

II. - La vie musicale d'un amateur anglais, au temps de Charles II, d'après le Journal de Pepys. . . . . . . . 27

IIl. - Portrait de Hændel . . . . . . . . . . . . . . 54

IV. - Les origines du "style classique , dans la musique du XVIII ${ }^{\circ}$ siècle .............. 77

V. - L'autobiographie d'un illustre oublié : Telemann, rival heureux de J.-S. Bach . . . . . . . . . 10

VI. - Nétastase, précurseur de Gluck. . . . . . . . 153

VII. - Voyage musical à travers l'Europe du xviı' ${ }^{\mathrm{e}}$ siècle. . . 171

I. Italie . . . . . . . . . . 171

II. Allemagne. . . . . . . . . . . 207

12150. - Coulommiers. - Imp. PAUL BRODARD. - 3-28. 


1 


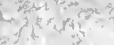




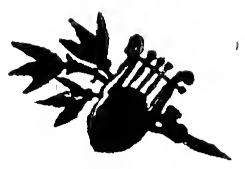

$12 \mathrm{fr}$. 




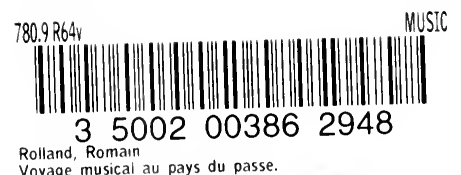

Voyage musical au pays du passe.

ML BGO . FEA

Rollarid, Fumats, 1SEG-
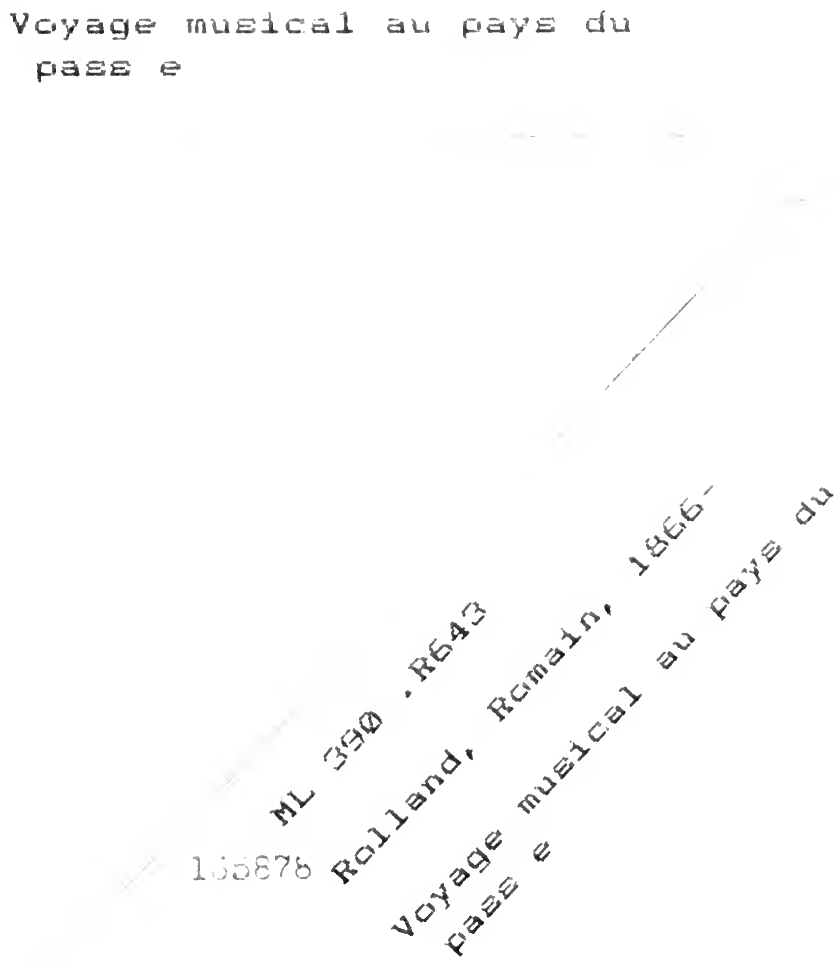
